6.

\title{
Deep-sea Fishes of the Bermuda Oceanographic Expeditions. Family Melanostomiatidae. ${ }^{1}$
}

\author{
William Beebe \& Jocelyn Crane \\ Department of Tropical Research, New York Zoological Society.
}

(Text-figures 1-77).

CONTENTS.

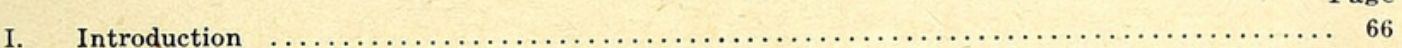

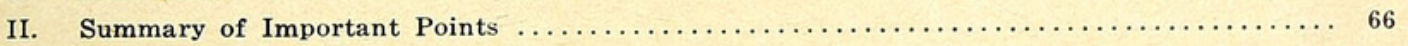

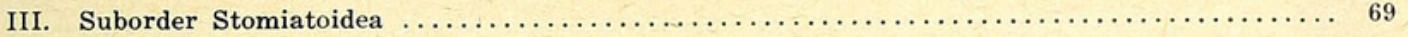

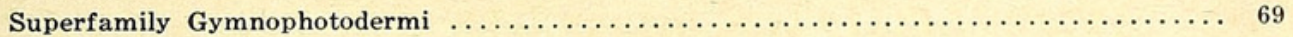

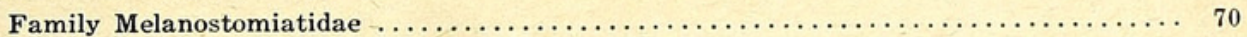

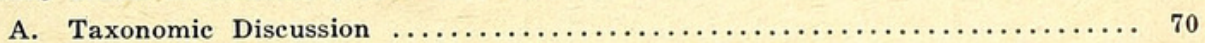

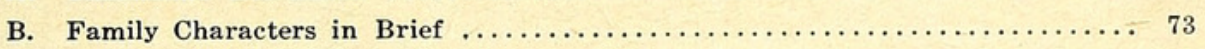

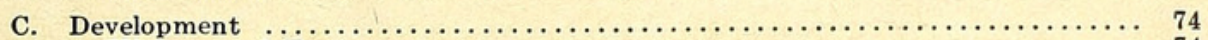

History and Taxonomy $\ldots \ldots \ldots, \ldots \ldots \ldots, \ldots \ldots \ldots, \ldots \ldots \ldots, 74$

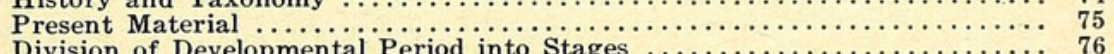

Division of Developmental Perod into Stages $\ldots \ldots \ldots \ldots \ldots \ldots \ldots \ldots \ldots \ldots \ldots 76$

Diagnostic Cha Melanostomiatid Larvae $\ldots \ldots \ldots \ldots \ldots \ldots \ldots . \ldots \ldots$

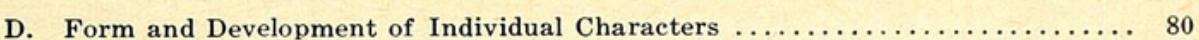

1. Color and Luminescence $\ldots \ldots \ldots \ldots, \ldots, \ldots, \ldots, \ldots, \ldots, \ldots, \ldots, \ldots$

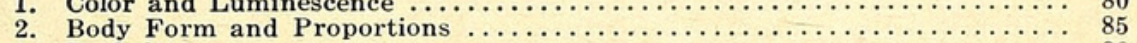

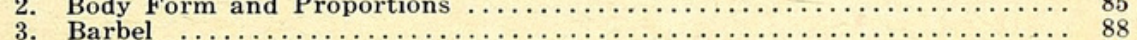

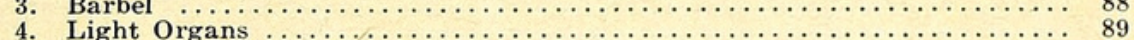

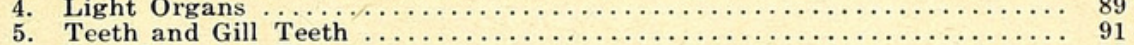

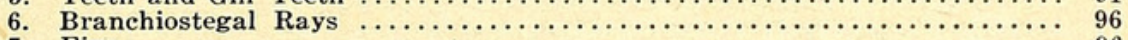

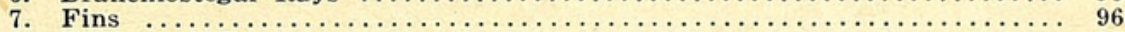

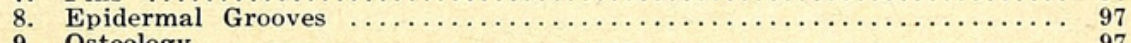

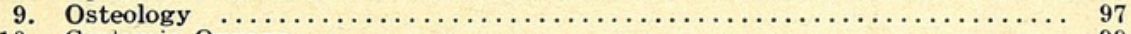

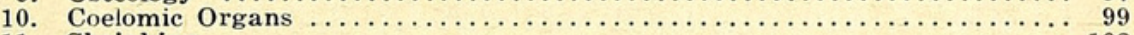

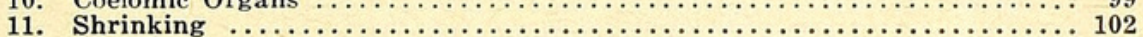

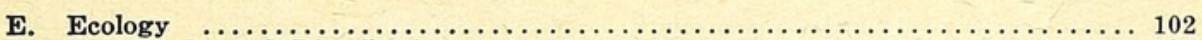

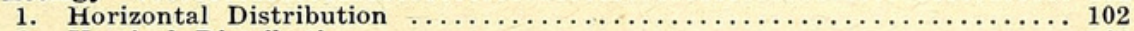

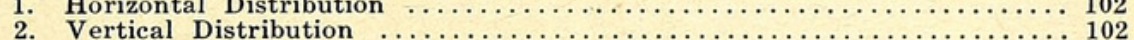

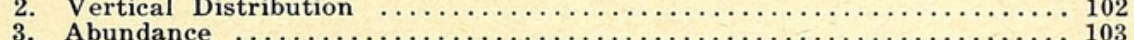

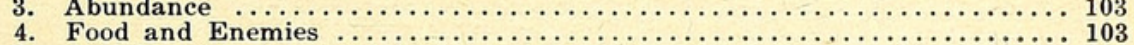

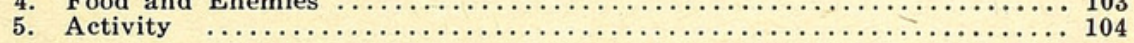

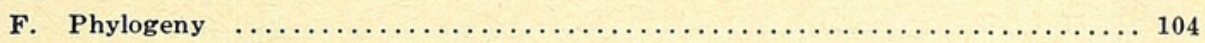

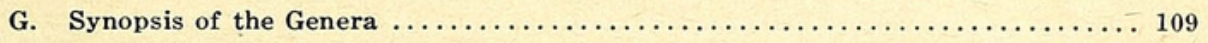

H. Report on the Collection of the Bermuda Oceanographic Expeditions, including Revisions of Genera and Species $\ldots \ldots \ldots \ldots \ldots \ldots \ldots \ldots \ldots \ldots \ldots \ldots \ldots \ldots \ldots, 111$

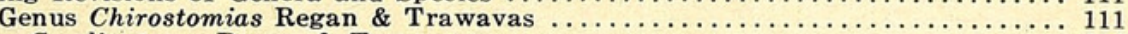

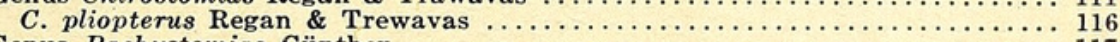
Genus Pachystomias Günther $\ldots \ldots \ldots \ldots \ldots \ldots \ldots \ldots \ldots \ldots \ldots \ldots \ldots \ldots \ldots \ldots \ldots \ldots \ldots \ldots \ldots \ldots$
$P$. atlanticus Regan \& Trewavas $\ldots \ldots \ldots \ldots \ldots \ldots \ldots$

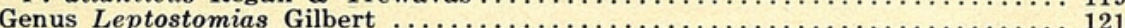

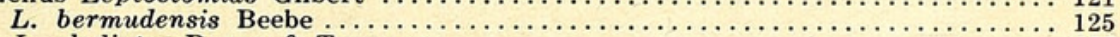

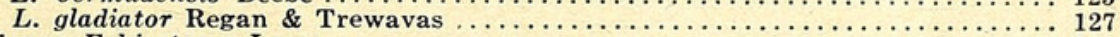

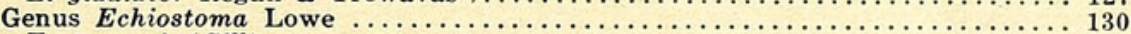

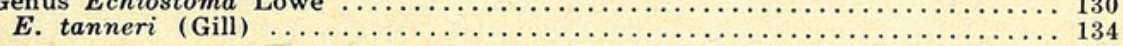

1 Contribution No. 580, Department of Tropical Research, New York Zoological Society. Contribution, Bermuda Biological Station for Research, Inc. 


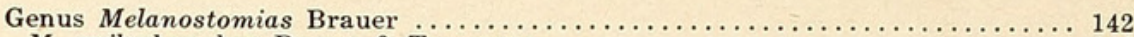

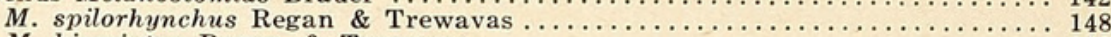

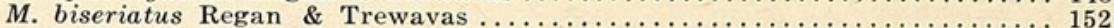

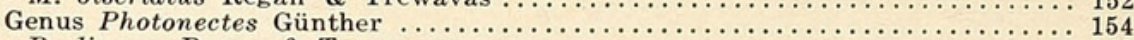

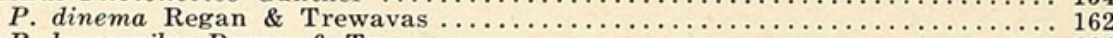

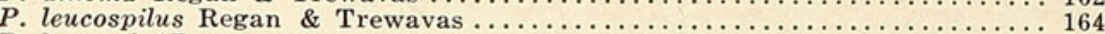

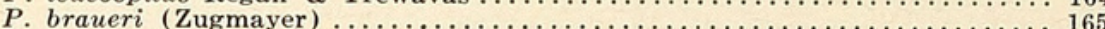

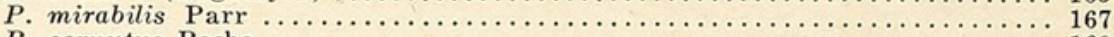

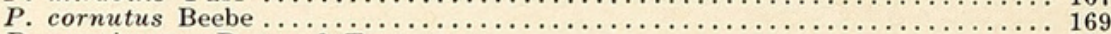

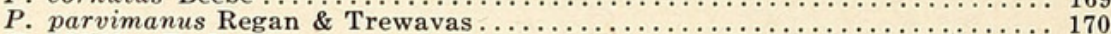

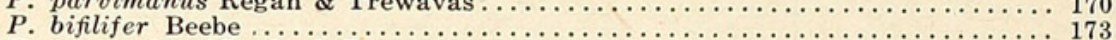

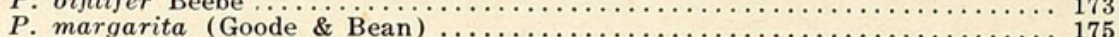

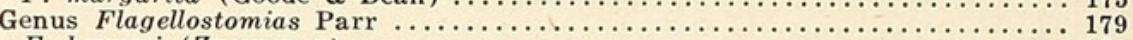

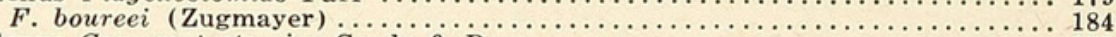

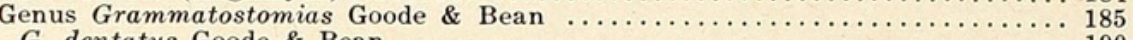

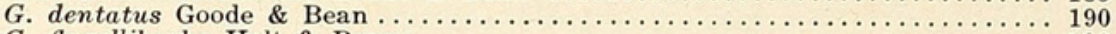

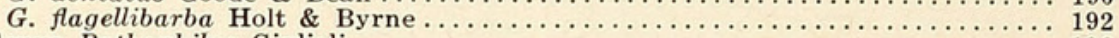

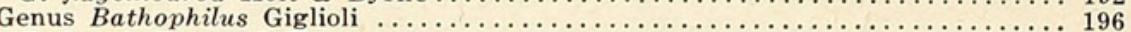

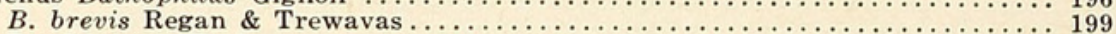

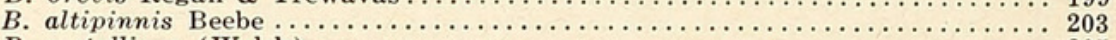

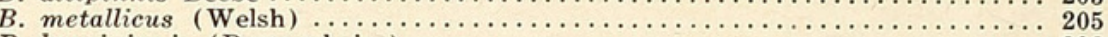

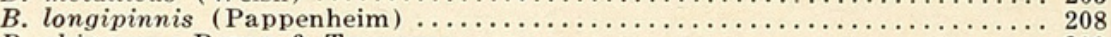

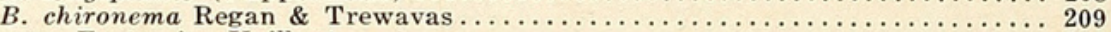

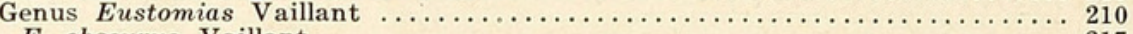

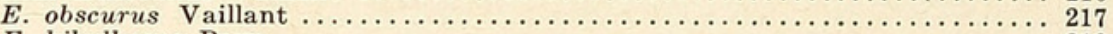

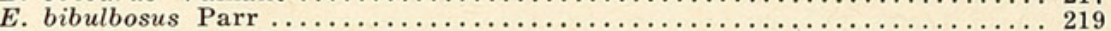

E. simplex Regan \& Trewavas . . . . . . .

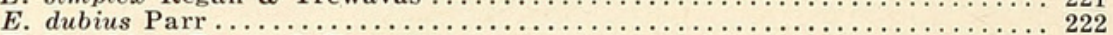

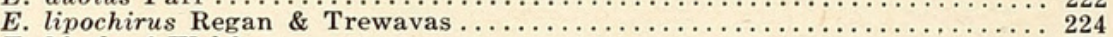

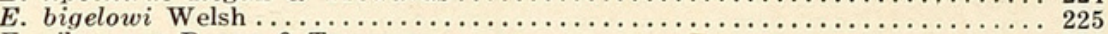

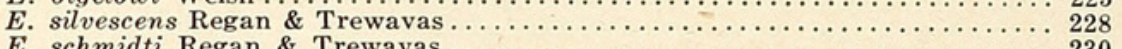

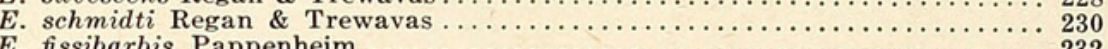

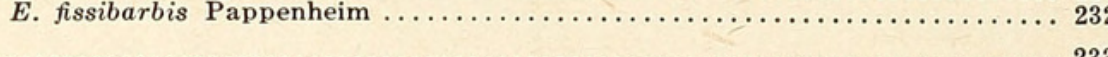

IV. Bibliography

\section{INTRODUCTION.}

For detailed data in regard to nets, locality, dates, etc., concerning the capture of the deep-sea fishes treated in this monograph, refer to Zoologica, Vol. XIII, Nos. 1, 2 and 3 and Vol. XX, No. 1, pp. 1-2. For physical data, methods of measurement and general definitions of growth stages, see Zoologica, Vol. XVI, No. 1. For the related family Idiacanthidae, see Zoologica, Vol. XX, No. 4.

The majority of the drawings in the present paper are the work of Harriet Bennett; Figs. 8 and 12 are by George Swanson. For the dyeing and clearing of many specimens and for the tail drawings in Text-fig. 9 we are indebted to Gloria Hollister.

We wish to express our appreciation to the following persons for their generous cooperation in lending specimens and enabling us to examine and sex type material deposited in various museums: Dr. J. R. Norman of the British Museum; Dr. A. Vedel Tåning of the Carlsberg Foundation's Marine Biological Laboratories, Copenhagen; Dr. Clinton V. MacCoy of the Boston Society of Natural History; Dr. A. E. Parr of the Peabody Museum; Dr. William C. Schroeder of the Museum of Comparative Zoology, and Dr. Leonard P. Schultz of the U. S. National Museum.

\section{SUMMARY OF IMPORTANT POINTS.}

MATERIAL. The Bermuda collection of Melanostomiatidae, taken in a cylinder of water 8 miles in diameter and a mile deep, consists of 250 specimens belonging to 10 genera and 32 species. Previously known melanostomiatids number about 1,450 specimens belonging to 16 genera and, at a generous estimate, slightly less than 100 valid species. The advantages, therefore, of continued, concentrated collecting in a single, definite area of ocean are again evident, since from the Bermuda 8 -mile circle have come more than $62 \%$ of all known genera and at least a third of the species taken in all seas.

In addition to the study of our own collection, we have examined (a) examples of all genera except Opostomias and Pareustomias, (b) all of the 
melanostomiatids deposited on this side of the Atlantic and (c) a number of specimens on loan from abroad.

TAXоNomy. 1. The sub-division of the Stomiatoidea into Gymnophotodermi, Lepidophotodermi and Heterophotodermi, suggested by Parr in 1927, is adopted, except that the three groups are given the status of superfamilies instead of suborders.

2. Parr's family Melanostomiatidae, exclusive of the malacosteids, is maintained, the family Stomiatidae being limited to Stomias, Macrostomias and Stomioides.

3. The following genera are synonymized: 1895.

Lamprotoxus Holt \& Byrne, $1913=$ Grammatostomias Goode \& Bean,

Haplostomias Regan \& Trewavas, $1930=$ Melanostomias Brauer, 1902.

Stomiatella Roule \& Angel, 1930 (part.) = Bathophilus Giglioli, 1884, and ? Flagellostomias Parr, 1927.

Parastomias Roule \& Angel, 1931 = Eustomias Vaillant, 1888.

Microdontostomias Fowler, $1934=$ Stomias Cuvier, 1817 (Family Stomiatidae). atidae).

Pseudeustomias Fowler, 1934 = Stomias Cuvier, 1817 (Family Stomi-

Photonectops Chapman, $1939=$ Tactostoma Bolin, 1939.

4. The following species are synonymized:

Chirostomias lucidimanus Beebe, $1932=C$. pliopterus Regan \& Trewavas, 1930. 1911).

Leptostomias problematicus $($ Parr, 1927) $=$ L. gladiator (Zugmayer,

Leptostomias ramosus Regan \& Trewavas, $1930=$ L. gladiator .

Echiostoma ctenobarba Parr, $1927=E$. tanneri Gill, 1883. 1843

Echiostoma guentheri Regan \& Trewavas, $1930=E$. barbatum Lowe,

Echiostoma calliobarba Parr, $1934=$ E. tanneri Gill, 1883.

Echiostoma ctenobarba ramifera Parr, $1934=$ E. tanneri Gill, 1883.

Melanostomias bulbosus Beebe, $1933=M$. spilorhynchus Regan \& Trewavas, 1930.

Melanostomias heteropogon Regan \& Trewavas, $1930=$ ? M. valdiviae Brauer, 1902.

Melanostomias melanocaulus Regan \& Trewavas, $1930=$ ? M. valdiviae Brauer, 1902.

Melanostomias albibarba Regan \& Trewavas, $1930=$ M. melanops Brauer, 1902.

Melanostomias stewarti Fowler, $1934=$ M. valdiviae Brauer, 1902.

Melanostomias vierecki Fowler, $1934=M$. valdiviae Brauer, 1902.

1895).

Photonectes richardi (Zugmayer, 1913) $=P$. margarita (Goode \& Bean, 1895). 1895).

Photonectes flagellatus Parr, $1927=P$. margarita (Goode \& Bean,

Photonectes intermedius Parr, $1927=P$. margarita $\quad$ (Goode \& Bean, 1913).

Photonectes ovibarba Regan \& Trewavas, $1930=$ P. braueri (Zugmayer,

Photonectes caerulescens Regan \& Trewavas, $1930=P$. achirus Regan

\& Trewavas, 1930.

Photonectes monodactylus Regan \& Trewavas, $1930=P$. margarita (Goode \& Bean, 1895).

Lamprotoxus phanobrochus Regan \& Trewavas, $1930=$ Grammatostomias flagellibarba Holt \& Byrne, 1910.

Lamprotoxus paucifilis Regan \& Trewavas, $1930=$ Grammatostomias flagellibarba Holt \& Byrne, 1910. 
Lamprotoxus angulifer Beebe, $1932=$ Grammatostomias dentatus Goode \& Bean, 1895. 1923).

Bathophilus alberti (Roule \& Angel, 1931) $=$ B. metallicus (Welsh,

Eustomias bibulbosus arborifer Parr, $1927=E$. bibulbosus Parr, 1927. 1927.

Eustomias bituberatus Regan \& Trewavas, $1930=$ ?E. micraster Parr,

Eustomias schiffi Beebe, $1932=$ E. dubius Parr, 1927.

Eustomias bigelowi paucifilis Parr, $1927=E$. bigelowi Welsh, 1923.

Eustomias bigelowi parvibulbus Parr, $1927=E$. bigelowi Welsh, 1923.

Eustomias dendriticus Regan \& Trewavas, $1930=? E$. fissibarbis Pappenheim, 1914. 1927.

Eustomias frondosus Regan \& Trewavas, $1930=E$. binghami Parr, 1930.

Eustomias satterleei Beebe, $1933=E$. silvescens Regan \& Trewavas, 1923.

Eustomias triramis Regan \& Trewavas, $1930=$ ?E. bigelowi Welsh,

Other species, especially in the genera Leptostomias and Eustomias, will doubtless prove also to be synonymous.

COLOR AND LUMINESCENCE. Color notes and sketches were made from more than 100 freshly caught specimens belonging to 28 species; 10 individuals, representing 5 species, were living and their luminescence and behavior noted. This work was supplemented by observations made from the Bathysphere. Up to the present, only eight specimens in the entire family had been studied when freshly caught or recently preserved.

SEXUAL DIMORPHISM. In the majority of genera the postorbital light organ is almost or completely atrophied in adult females. Striking sexual differences are found in the barbels of Eustomias; similar differences are suspected in other genera. The importance of sexing type specimens in this family is obvious.

DEVELOPMENT. Larvae and post-larvae of the following species have been identified for the first time: Flagellostomias boureei, Leptostomias gladiator, Melanostomias spilorhynchus, Melanostomias biseriatus, Photonectes parvimanus, Grammatostomias flagellibarba, Bathophilus brevis, Bathophilus metallicus, Bathophilus near longipinnis, Bathophilus sp., Eustomias bibulbosus, Eustomias dubius, Eustomias spp. In addition, our collection includes adolescents of most other species taken by the Bermuda Expeditions. This material has been sufficient for the tabulations of family and generic juvenile characters.

A number of recorded species prove synonymous with others due to their being based on juvenile characters, such as partly developed barbels. Dissection alone can determine whether or not a specimen is wholly adult, with well developed gonads, fully pigmented stomach of relative length typical of the genus, and hour-glass-shaped centra.

SPECIAL CharaCteristics. In the comparison of the form and development of various parts of the body in the different genera, certain structures have proved to be of unexpected phylogenetic or taxonomic importance. Among the most interesting are the form and distribution of gill-teeth in adults, the presence of spiny gill-rakers in larvae and post-larvae, the variation of larval pigment patterns and the development of the eye. Probable relationships of the genera to each other and to adjacent families are discussed.

Vertical Distribution. As with most families of Bermuda deep-sea fish, the depths at which these fish are taken are greater than the average in other areas, practically none except very young melanostomiatids having been taken above 500 fathoms, although they were seen above this level from the Bathysphere. 


\section{SUBORDER STOMIATOIDEA.}

Characteristics: Oceanic isospondyls differing from the Clupeoidea and Salmonoidea in the presence of photophores, which are arranged typically in a double series along the abdomen and in a single series above the anal fin.

Discussion: It should now be generally agreed that the suborder Stomiatoidea be divided into eight families, namely, the Gonostomatidae, Sternoptychidae, Chauliodontidae, Stomiatidae, Astronesthidae, Melanostomiatidae, Malacosteidae and Idiacanthidae.

In 1927 (p. 1) and 1930 (p. 136), Parr proposed separating the smoothskinned members of the old family Stomiatidae (including the malacosteids) from the scaly Stomias and placing the former in a family of their own, Melanostomiatidae. This new family he grouped with the other smoothskinned stomiatoids, the Astronesthidae and Idiacanthidae, in a new suborder, Gymnophotodermi. A second suborder, Lepidophotodermi, was proposed to include the Stomiatidae proper (Stomias and Macrostomias) and, provisionally the Chauliodontidae. A third suborder, Heterophotodermi, was suggested to embrace the Gonostomatidae and Sternoptychidae.

Regan and Trewavas, on the other hand, in the Dana "Fishes of the Families Stomiatidae and Malacosteidae" (1930) employed the old classification, including Stomias (as an aberrant genus), Idiacanthus, and all the smooth-skinned fishes with posterior vertical fins and complete floors to their mouths in the single family Stomiatidae. The malacosteids were treated as a separate family.

From our own studies we draw the following conclusions:

1. Parr's three suborders, the Gymnophotodermi, Lepidophotodermi and Heterophotodermi, are valid and useful subdivisions of the stomiatoid isospondyls. However, since the apparently quite natural group of Stomiatoidea as defined on the preceding page is generally regarded as a suborder of the order Isospondyli, we propose that each of Parr's three divisions be given the rank of superfamily instead of suborder.

2. Parr's family Melanostomiatidae (excluding Malacosteus, Aristostomias and Photostomias), should unquestionably be maintained.

3 . The three genera just mentioned, along with the more recent genus Ultimostomias described by Beebe in 1933, should form the family Malacosteidae, as suggested by Regan and Trewavas (1930).

4. The family Idiacanthidae should be maintained, due chiefly to its exceptional life-history (Beebe, 1934.1).

5. The family Stomiatidae should be limited to Stomias, Macrostomias, and Stomioides Parr, 1933.

\section{SUPERFAMILY GYMNOPHOTODERMI.}

Characteristics: Naked Stomiatoidea with black skin, large mouths, barbel (except in Malacosteus), postorbital luminous organ present at least in males, serial photophores developed on branchiostegal membranes and isthmus as well as in the usual lateral and ventral rows on each side (vestigial in Malacosteus and Bathophilus brevis); these organs lacking lumen or duct; smaller organs usually scattered on skin. Parietals small and well separated or absent; orbitosphenoid absent; opisthotic absent; entopterygoid membranous or very thinly ossified; preoperculum slender; vertebral centra thin cylinders of bone enclosing notochord; parapophyses and at least anterior neural arches not ankylosed with centra; parapophyses with pleural ribs; epipleurals present or absent; epineurals present. Long caecal stomach present, giving off a short arm anteriorly which opens into the usually straight intestine. 
Key to the families:

A. Dorsal fin not confined to caudal peduncle.

B. Dorsal fin short, ending before anal origin.... Astronesthidae. BB. Dorsal fin very long, extending almost to caudal base Idiacanthidae.

AA. Dorsal fin confined to caudal peduncle.

C. Lower jaw and hyoid arch joined by a membrane, forming a floor to the mouth........................................ Melanostomiatidae.

CC. Lower jaw and hyoid arch not joined by a membrane, the symphysis and hyoid being connected only by a muscular cord

Malacosteidae.

\section{Family Melanostomiatidae.}

\section{A. Taxonomic Discussion.}

Thirty-two generic names have been proposed for fishes referred to this family, or to naked fishes of the old family Stomiatidae. Of these we recognize 16 as valid. In chronological order, the 32 names, along with their present standing and the type species, are as follows:

1. Echiostoma Lowe, 1843. Valid. Type: E. barbatum Lowe, 1843.

2. Opostomias Günther, 1878. Valid. Type: O. micripnus Günther, 1878. 1878.

3. Pachystomias Günther, 1878. Valid. Type: P. microdon Günther,

4. Lucifer Doderlein, 1882 . = Photonectes. Name given by Günther, 1887, because Lucifer preoccupied. Type: Lucifer albipinnis Doderlein, 1882.

5. Hyperchoristius Gill, 1883. = Echiostoma. Synonymized by Parr, 1927. Type: H. tanneri Gill, 1883.

6. Bathophilus Giglioli, 1884. Valid. Type: B. nigerrimus Giglioli, 1884. 1882).

7. Photonectes Günther, 1887. Valid. Type: P. albipinnis (Doderlein,

8. Eustomias Vaillant, 1888. Valid. Type: E. obscurus Vaillant, 1888.

9. Grammatostomias Goode \& Bean, 1895. Valid. Type: G. dentatus Goode \& Bean, 1895.

10. Dactylostomias Garman, 1899. = Bathophilus. Synonymized by Parr, 1927. Type: B. filifer Garman, 1899. 1902.

11. Melanostomias Brauer, 1902. Valid. Type: $M$. valdiviae Brauer, 1905.

12. Leptostomias Gilbert, 1905. Valid. Type: L. macronema Gilbert,

13. Neostomias Gilchrist, 1908. = Eustomias. Synonymized by Parr, 1927. Type: E. filiferum Gilchrist, 1908.

14. Nematostomias Zugmayer, 1911. = Leptostomias. Synonymized by Parr, 1927. Type: N. gladiator Zugmayer, 1911.

15. Trichostomias Zugmayer, 1911. = Bathophilus. Synonymized by Parr, 1927. Type: T. vaillanti Zugmayer, 1911.

16. Gnathostomias Pappenheim, 1911. = Bathophilus. Synonymized by Parr, 1927. Type: G. longifilis Pappenheim, 1911.

17. Lamprotoxus Holt \& Byrne, 1913. = Grammatostomias. Synonymized in present paper; see below. Type: L. flagellibarba (Holt \& Byrne, 1910).

18. Flagellostomias Parr, 1927. Valid. Type: F. tyrannus Parr, 1927. = F. boureei (Zugmayer, 1911). 
19. Chirostomias Regan \& Trewavas, 1930. Valid. Type: C. pliopterus Regan \& Trewavas, 1930.

20. Trigonolampa Regan \& Trewavas, 1930. Valid. Type: T. miriceps Regan \& Trewavas, 1930.

21. Thysanactis Regan \& Trewavas, 1930. Valid. Type: T. dentex Regan \& Trewavas, 1930.

22. Haplostomias Regan \& Trewavas, 1930. = Melanostomias. Synonymized in present paper; see below. Type: H. tentaculatus Regan \& Trewavas, 1930. 1930.

23. Odontostomias Norman, 1930. Valid. Type: O. micropogon Norman,

24. Stomiatella Roule \& Angel, 1930 (part.). = Bathophilus (larva) and Flagellostomias (larva). Synonymized in present paper (pp. 74, 75).

25. Stylophthalmella Roule \& Angel, 1930 (part.). = Eustomias (larva). Synonymized in present paper (p. 75).

26. Pareustomias Bailly, 1930. Probably valid, although apparently very close to Eustomias. Type: P. chabanaudi Bailly, 1930.

27. Parastomias Roule \& Angel, 1931. = Eustomias. Synonymized in present paper. Type. P. tetranema (Zugmayer, 1911).

28. Elapterostomias Fowler, 1934. = Borostomias, family Astronesthidae. Synonymized by Myers, 1935 (in footnote, p. 2).

29. Microdontostomias Fowler, 1934. = Stomias, family Stomiatidae. Synonymized in present paper; see below.

30. Pseudeustomias Fowler, 1934. = Stomias, family Stomiatidae. Synonymized in present paper; see below.

31. Tactostoma Bolin, 1939. Valid. Type: T. macropus Bolin, 1939.

32. Photonectops Chapman, 1939. = Tactostoma Bolin, 1939, the latter genus having priority by a few weeks. Type: P. multipunctata Chapman, 1939 , probably synonymous with $T$. macropus.

The systematic position of the six-foot fish Bathysphaera Beebe, 1932, described from a specimen observed from the Bathysphere off Bermuda, is of course still uncertain, since no specimen has yet been taken. That it is a stomiatoid, near the Melanostomiatidae, seems certain, but in all probability it does not belong in this family, and is therefore omitted from systematic treatment in the present paper. For reference, however, we include herewith a copy of the type description:

"On the twentieth dive in the Bathysphere, at a depth of 2100 feet, we saw two large, elongate, barracuda-shaped fish, which twice passed within eight feet of the windows, once partly through the beam of our electric light. These were at least six feet in length.

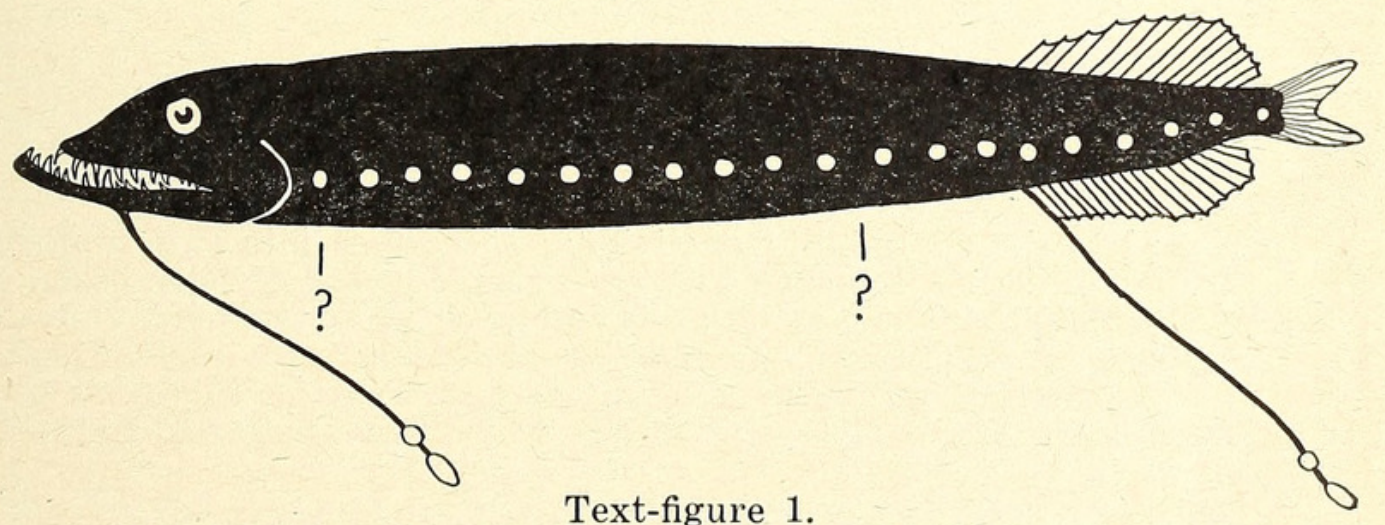

Bathysphaera intacta. Actual length about 6 feet. Numbers of photophores and finrays approximate. 
"No direct lights were visible on the head, yet the rather large eye and the faint outline were distinct. There was a single row of strong, pale blue lights along the side, large and not far from twenty in number. The mouth, with strongly undershot jaw, and numerous fangs was illumined either by mucous or indirect internal lights along the branchiostegals.

"The fish reminded me in general of barracudas, with deeper jaws open all the time. Posteriorly placed vertical fins were seen when they passed through the electric beam. There were two ventral tentacles, each tipped with a pair of separate, luminous bodies, the superior reddish, the lower one blue. These twitched and jerked along beneath the fish, one undoubtedly arising from a mental base, the other so far back that its origin must have been at the anal fin. Neither the stem of the tentacles nor paired fins were distinguishable.

"I assume from the position of the vertical fins and the general facies, that the position of the fish must be somewhere near the Melanostomiatidae, but the single line of large, lateral photophores and the two ventral tentacles set it apart from any known species or genus.

"The depth was 2100 feet, the date September 22nd, 1932, the position $32^{\circ} 17^{\prime}$ No. Lat., $64^{\circ} 36^{\prime}$ West Long., 5 miles southeast of Nonsuch Island, Bermuda.

"Relying on this recognizable diagnosis I propose for it the name of Bathysphaera intacta, the Untouchable Bathysphere Fish." (Beebe, 1932.2 pp. 175-177).

We have compared specimens of Lamprotoxus with the type of Grammatostomias dentatus at the United States National Museum, and found the two genera to be unquestionably synonymous. For a detailed discussion, see p. 185 .

Through the kindness of Dr. Norman, we have been able to examine a specimen of Haplostomias Regan \& Trewavas from the British Museum. In view of the very slight differences between this genus and Melanostomias, compared with the large differences between these genera and their nearest relatives, we have little hesitation in synonymizing these two groups. (See p. 143.)

At the United States National Museum we have also examined the type specimens of Microdontostomias and Pseudeustomias. In his descriptions (1934) Fowler does not mention that both of these fish have the hexagonal scales of Stomias. They are, in fact, both clearly members of that genus. Microdontostomias orientalis, the type and unique species, is close to or identical with Stomias nebulosus Alcock. It is likely that a third barbel filament, which would make the synonymy certain, has been broken off. Similarly, Pseudeustomias myersi, the type and unique specimen, belongs unquestionably in the elongatus-valdiviae-affinis group of the genus Stomias (see Parr, 1934). The barbel bulb, instead of terminating in a single filament, as is stated in the description, ends in three of about equal length, as is usual in the genus. The figures (Fowler, loc. cit. figs. 21 and 22) of both the proposed genera are inexact in regard to the general appearance of the fish, since both specimens have the pronounced slenderness and strongly curved jaws characteristic of Stomias.

In regard to the advisability of dividing Eustomias into two or more genera, we agree with Regan and Trewavas that cleancut divisions cannot be made; also the groups of species are so much closer to one another than they are to other genera that any division seems wholly inadvisable. Therefore, we do not accept the proposal of Roule and Angel (1931) that the name Parastomias be given to the species which have branched barbels. (See p. 210.)

In addition to the 10 genera of Melanostomiatidae taken by the Bermuda Expeditions, we have examined specimens of Trigonolampa, Odontostomias, Thysanactis, Haplostomias (which we synonymize with Melanosto- 
mias) and Tactostoma (the type of Photonectops; examination superficial). This leaves Opostomias and Pareustomias as the only valid genera which we have not examined; both are known from unique types.

A key to the genera of Melanostomiatidae as now understood will be found on page 109 .

\section{B. Family Characters in Brief.}

Gymnophotodermi, usually elongate and little compressed, with very short caudal peduncle, to which the vertical fins are entirely confined; lower jaw and hyoid arch joined by a membrane, forming a floor to the mouth; teeth in jaws highly developed, often depressible; premaxillary almost always with a small, anterior ascending process; maxillary usually much longer than premaxillary, forming posterior part of upper margin of mouth, and usually furnished with normal, erect teeth anteriorly and oblique denticles posteriorly; vomer with or without teeth; palatine usually toothed; gill-arch teeth usually present, often in pairs or groups; a series of teeth, usually strong, on third and fourth pharyngobranchials (= upper pharyngeals); branchiostegals 8 to 22 ; pectorals well developed, reduced or absent; pelvics typically of seven rays, their insertion usually at or behind middle of body, rarely in front of it; caudal fin very short, forked, the ventral lobe the longer; adipose fin absent except in Chirostomias; no pseudobranchiae; special grooves for barbel and pectoral fins often present.

Skeleton moderately well developed, the jaws always more strongly ossified than any other portion of the body. Mesethmoid with or without lateral process; frontals united by suture; parietals present or absent; hyomandibular and quadrate forming with the jaw an angle of 45 degrees or less; one supramaxillary; opercular apparatus weak, reduced or rudimentary; hyoid and branchial apparatus well developed; pectoral girdle moderately or feebly developed; post-temporal present or absent; upper and lower coracoids always present, mesocoracoid sometimes absent, all 3 elements often reduced; actinosts often reduced; caudal fin alone strongly supported; vertebrae moderately numerous, 35 to 82 , an average number being around 60 ; anterior vertebrae usually more or less modified, permitting free movement of head.

Usually two pyloric caeca; gonads dorsal.

Sexual dimorphism usually apparent in development of postorbital photophore, sometimes in form of barbel.

Size: The largest known melanostomiatid is the unique specimen of Opostomias, measuring $380 \mathrm{~mm}$. in length. The size records in the remaining genera are as follows: Echiostoma, $355 \mathrm{~mm}$., (375 mm. when fresh); Photonectes, $340 \mathrm{~mm}$.; Odontostomias, $290 \mathrm{~mm}$.; Tactostoma, $280 \mathrm{~mm}$.; Leptostomias, $270 \mathrm{~mm}$. (285 mm. when fresh); Melanostomias, $242 \mathrm{~mm}$.; Trigonolampa, $223 \mathrm{~mm}$.; Flagellostomias, $222 \mathrm{~mm}$.; Grammatostomias, $206 \mathrm{~mm}$; Chirostomias, $205 \mathrm{~mm}$.; Eustomias, $204 \mathrm{~mm}$.; Pachystomias, $165 \mathrm{~mm}$.; Bathophilus, $140 \mathrm{~mm}$; Thysanactis $139 \mathrm{~mm}$.; Pareustomias, $62 \mathrm{~mm}$.

The specimens listed above of Echiostoma, Leptostomias, Melanostomias, Grammatostomias and Chirostomias were taken by the Bermuda Expeditions.

In Leptostomias, Flagellostomias and Thysanactis, at least, and doubtless in other genera as well, no fully adult specimens have been taken. Judging from this fact and from the number of melanostomiatids more than a foot long which were seen from the Bathysphere, it is probable that larger specimens of these swiftly swimming fishes escape the net. The largest Echiostoma, Photonectes and Melanostomias, however, were definitely in breeding condition, while others near the lengths given in the above paragraph had well developed gonads.

Larva, as far as known, moderately elongate, translucent, with the 
posterior, unpaired fins of the adult; no yolk sac but a gut hanging below myomeral body and extending as a free tube beyond the anal fin; pigment spots usually present in a longitudinal series just below the dorsal mid-line, sometimes in additional rows above and/or below the lateral mid-line; temporary, small teeth present in jaws, and temporary gill-rakers, often bristling with minute spines, usually present; larval pectoral pad with raylets always present, even when pectoral is much reduced or absent in adult.

The family characters given above will be discussed in detail, after a general account of development.

\section{Development.}

History AND TAXoNomy: Thanks to Lo Bianco, Jespersen \& Tåning, Ege, Sanzo, Regan \& Trewavas, Roule \& Angel, and Beebe, developmental stages of a number of representative stomiatoids have been recognized and described. In some cases, complete series have been obtained; in others, only one or two stages, known from single specimens, have so far been identified. Exclusive of the Melanostomiatidae, the stomiatoid genera of which one or more juvenile stages have been identified include the following: the gonostomids Gonostoma, Cyclothone, Maurolicus, Ichthyococcus and Vinciguerria; the sternoptychids Argyropelecus and Sternoptyx; Stomias; Chauliodus; one or two astronesthids; a questionable Malacosteus; and Idiacanthus. Representative references are included in the bibliography.

Sanzo's (1931) account of Chauliodus is especially complete, since he succeeded in raising a larva from the last three days in the egg through the thirteenth day after hatching, at which stage it was apparent that the little fish was identical with a free-swimming larva taken at the surface. The latter specimen, in turn, unquestionably formed a link with older Chauliodus in which generic characters were well established. Sanzo's evidence for the continuity of the series is convincing, and of great interest to us in our study of the Melanostomiatidae, since Chauliodus is the most closely related genus of which the egg and pre-larva have been identified.

On the other hand, very little previous work has been done on the larvae of the Melanostomiatidae. In 1914 Sanzo (pp. 1-12) described the first known larval melanostomiatid, Bathophilus nigerrimus.

In 1930 Regan and Trewavas (p. 73) stated that Regan's larva described in 1916 (p. 136) as Stylophthalmus macrenteron was in all probability a larval Eustomias. They described briefly a number of similar young Eustomias from the Dana collection, including some metamorphosing and juvenile forms which could be subgenerically and sometimes specifically identified. Parr, in 1927, described as new species two immature Eustomias (adolescents) and Regan and Trewavas in the same Dana collection found a number of specimens belonging to other genera which could be specifically identified, or described, although they had juvenile characters remaining. It may also be remarked here that a majority of the Dana melanostomiatids, as well as those of other collections including our own, are immaturethat is, in the transitional adolescent stage, in which most or all of the external characteristics of adults are present, but with immaturity apparent internally. These advanced specimens, however, obviously shed little light on the characteristics of early stages in the family.

In 1930 Roule and Angel described and figured a number of stomiatoid larvae under the general names of Stomiatella and Stylophthalmella, suggesting, where possible, their systematic positions. Thanks to our additional material, we are able to contribute further suggestions in regard to the identity of these larvae.

Stomiatella A Roule \& Angel (1930, p. 14; pl. I, fig. 6): We agree with the authors and with Sanzo $(1930$, p. 89), that this larva should be referred to Bathophilus. We do not, however, agree with Sanzo that it is 
B. nigerrimus, providing that the pelvic fin is shown correctly in the figure, since it is much too far forward and too high. Comparison with Sanzo's own figures of $B$. nigerrimus larvae (1931, pl. vii, figs. 7,8 ) will show the difference. If the fin of Roule and Angel's specimen is accurately shown, it is very likely that this fish is B. brevis Regan \& Trewavas, 1930 .

Stomiatella D Roule \& Angel (1930, p. 17; pl. I, figs. 10, 11): Roule and Angel suggest that both these larvae may be young Malacosteus niger Ayres. We agree that the specimen shown in their Fig. 11 should in all probability be referred to this species. We are certain, however, that their Fig. 10 represents a quite different form and belongs to some genus of Melanostomiatidae. Myomere counts are not given, but from the number shown in the figure (about 70 to the end of the anal), the distribution of the pigment, and the general facies, it appears very likely that the specimen should be referred to Flagellostomias or a closely related genus (cf. our Text-fig. 47).

Stylophthalmella B Roule \& Angel (1930, p. 52; pl. III, figs. 62, 63) : This larva almost certainly belongs to the genus Eustomias.

Stylophthalmella D Roule \& Angel (1930, p. 53; pl. III, figs. 66, 67, $68)$ : This larva remains a puzzle, and should be remembered by subsequent workers on the Melanostomiatidae and Malacosteidae, since in all probability it belongs to one or the other of those families.

The other Stylophthalmella larvae, as has already been pointed out (Beebe, 1934, p. 155) include argentinids (bathylagids), but no Idiacanthus. Stylophthalmella C (loc. cit., p. 52, pl. III, figs. 64, 65) may be Chauliodus (cf. Sanzo, 1931, p. 82, pl. VI).

The most recent study of melanostomiatid larvae is by Sanzo who redescribes and figures early stages of Bathophilus nigerrimus, the only species of the family known to occur in the Mediterranean (1931, p. 89; pl. VII).

In the summary, up to the present time the only larvae and postlarvae of the Melanostomiatidae (as defined in the present paper) have been Bathophilus nigerrimus, B. brevis?, Flagellostomias? and Eustomias ssp.

Present Material: To this list we add the following forms, of which larvae, post-larvae or both have been taken by the Bermuda Oceanographic Expeditions :

Flagellostomias boureei: larvae and post-larvae.

Leptostomias gladiator: larvae and post-larvae.

Melanostomias spilorhynchus: larva and post-larva.

Photonectes parvimanus: larva and post-larva.

Grammatostomias flagellibarba: post-larva.

Bathophilus brevis: post-larva.

Bathophilus, near longipinnis: larva.

Bathophilus metallicus: post-larva.

Bathophilus sp.: larva.

Eustomias bibulbosus: post-larva.

Eustomias dubius: post-larva.

Eustomias (Nominostomias) spp.: post-larvae.

Eustomias (Dinematochirus) spp.: post-larvae.

Eustomias spp.: larvae.

Only three of the ten genera of Melanostomiatidae taken by the Bermuda Expeditions are not represented in the collection by either larvae or post-larvae, namely, Chirostomias, Pachystomias and Echiostoma. We have, however, adolescent specimens of Chirostomias and young transitional adolescent specimens of every genus. Thanks to borrowed specimens, we have found under the skin remains of larval pigment spots in the genera Odontostomias and Echiostoma which will aid in the identification of the larvae of these genera in the future. (Text-fig. 2). 
Division of Developmental Period into Growth Stages: The growth stages of Stomiatoidea in general and Melanostomiatidae in particular fall easily into our accepted classification of larvae, post-larvae, adolescents and adults (see Beebe, 1933.3, p. 7; 1934.1, p. 158 ff.; Beebe \& Crane, 1936 , p. $80 ; 1937$, p. 357$)$.

In addition, the prelarval stage is more clearly defined in the Stomiatoidea than in the other groups we have previously studied, although no pre-larval melanostomiatids have been found in our collection. Roule \& Angel $(1930$, p. 6) define the stage succinctly as the one immediately following hatching, often characterized by temporary traits which rapidly disappear. Their conception of larvae, post-larvae (hemi-larves), and adolescents (alevins), drawn from the work of their predecessors as well as from their own experience, corresponds well with our own, which will be redefined relative to the Stomiatoidea in succeeding pages. It seems that at last the unfortunate confusion in the nomenclature of the growth stages of fishes, and the definition of the boundaries of these stages, is becoming a thing of the past.

In spite of the number of stomiatoid young which have been previously described, there has been as yet no effort to characterize the larvae of the group as a whole, and this we propose to do, showing at the same time likenesses and differences of the young of the superfamily Gymnophotodermi, including the family Melanostomiatidae, to those of other stomiatoids. In this study of the young the importance of the recognition of the group Gymnophotodermi has become especially apparent.

Diagnostic Characteristics of Stomiatoid Growth Stages: From a study of the published records discussed above and from our own material we find that the known early stages of all Stomiatoidea have in common the following characters: (1) transparency, or at least, translucence when freshly caught; (2) a somewhat compressed but non-leptocephalic body; (3) moderate to extreme slenderness; (4) well-developed finfolds; (5) a lack of pigment except for a few evanescent spots which, varying with the group are of great taxonomic importance; (6) with few exceptions, a large number of myomeres; (7) the early disappearance of the yolk sac, during the pre-larval stage; (8) the occurrence of a period, usually absent in the pre-larva and confined wholly to the larva, when the eyes are elongate and rotated more or less forward. This combination of characters does not seem to occur in the development of any other group of fishes.

The diagnostic characteristics of the various growth stages of Stomiatoidea in general and of Gymnophotodermi and Melanostomiatidae in particular are as follows:

\section{Pre-larva.}

Stomiatoid Characters: Yolk sac present throughout most of stage; special pre-larval pigment often present; teeth lacking; eye round; pectoral pad present; dorsal, anal and pelvic completely lacking.

Gymnophotodermid Characters: (Not known).

\section{LARVA.}

Stomiatoid Characters: True yolk sac absent, but intestine not yet enclosed by myomeres; typical larval pigment spots usually present; temporary larval teeth usually present; eye small, elongate, rotated forward; dorsal and ana! appearing; pelvic rudiment usually appearing toward end of stage. A period of growth.

Gymnophotodermid Characters (Present in known larvae of Astronesthidae, Melanostomiatidae, Malacosteidae and Idiacanthidae): End of gut prolonged beyond anal origin, sometimes more than a third the total length 
of the body; pigment in longitudinal series of spots, along full length of body, rarely absent; head strongly inclined; barbel absent; rudiments of photophores appearing at end of stage; temporary, small teeth present in jaws; temporary gill-rakers present or absent; these teeth and gill-rakers both reach their maximum development late in the stage; larval pectoral pad with a continuous frill of undifferentiated rays always well developed, even when pectoral is much reduced or absent in adult; dorsal and anal clearly visible in their normal positions, although some of the rays are often not developed (especially the anterior anal rays in fishes where this fin originates before the dorsal; and the anterior dorsal rays of Idiacanthus); finfolds usually very high in early part of stage, but dwindling as post-larval stage is reached; stomach absent.

The larvae of the family Melanostomiatidae may be distinguished from those of other gymnophotodermids by use of the following key:

A. Dorsal fin ending before anal origin ........................Astronesthidae.

AA. Dorsal and anal opposed, confined to caudal peduncle.

B. Eyes stalked; larval gill-rakers absent............... Idiacanthidae.

BB. Eyes not stalked; larval gill-rakers present.

C. Pigment sparse or absent.

Malacosteidae.

CC. Pigment spots almost always present in longitudinal series immediately below dorsal mid-line and sometimes in additional row or rows below the lateral mid-line Melanostomiatidae.

It will be observed that the distinction between malacosteid and melanostomiatid larvae is not satisfactory; this is because, save for the specimen of Malacosteus? described by Roule and Angel (1930, pl. I, fig. 11) and for several transitional larvae and early post-larvae in the present collection of Photostomias and Aristostomias (an account of which will be published at a future date), the young of the family are unknown.

\section{Post-larva.}

Stomiatoid Characters: Intestine partly enclosed by myomeres; larval pigment spots remaining; general body pigment appearing; light organs appearing; eye once more becoming round, directed laterally; all fins present, but rays not completely differentiated, nor full relative length attained; traces of finfolds remaining. A period of metamorphosis, often accompanied by shrinking in length.

Gymnophotodermid Characters: End of gut protruding only as a papilla; larval pigment spots remaining under the developing, lightly pigmented epidermis, sometimes more distinct and numerous than in larvae; depth greatest toward middle of length instead of at shoulder; barbel a stump; serial photophores well developed; larval teeth absent, but larval gill-rakers remaining throughout all or most of stage; permanent teeth and gill-arch teeth not yet apparent, or very rudimentary; caudal fin relatively larger than in larva or adult; stomach a papilla on wall of intestine.

Thanks to the presence of photophores and relatively well-developed fins in this and succeeding stages, melanostomiatid larvae can be easily distinguished from those of related families and referred to their proper genus.

\section{Adolescent.}

Stomiatoid Characters: Intestine completely enclosed in body cavity; larval pigment spots disappear during this stage; pigment, light organs, proportions and internal organs all gradually approaching adult conditions; fin rays fully developed, except, sometimes, in the case of highly specialized 


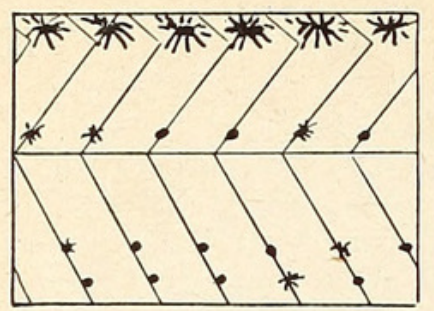

A

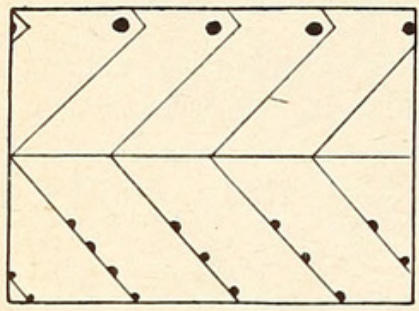

D

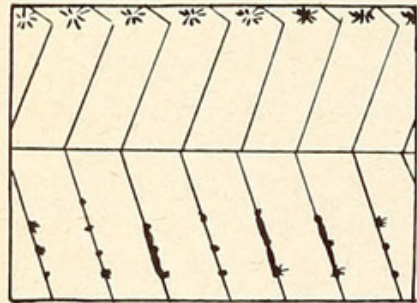

G

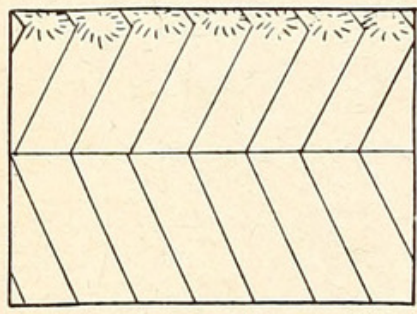

J

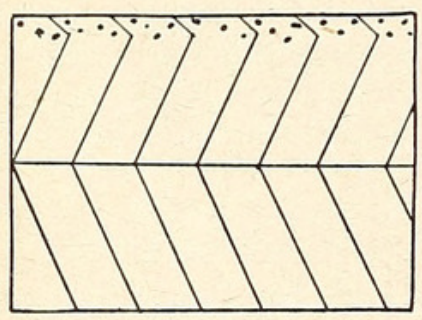

$M$

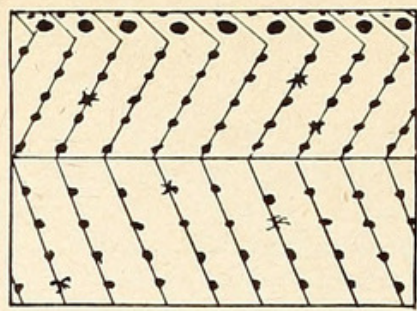

B

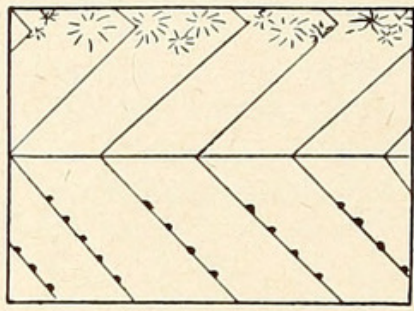

E

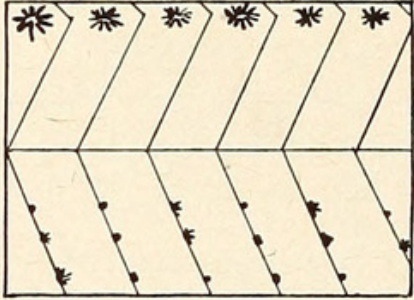

$\mathrm{H}$

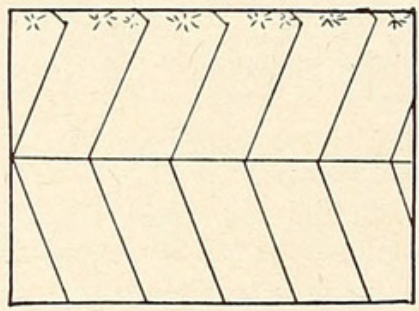

K

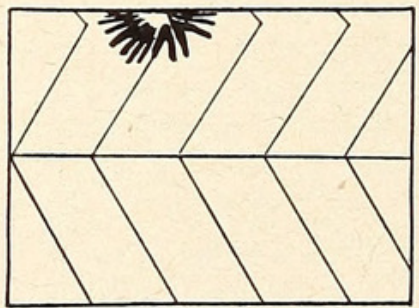

M

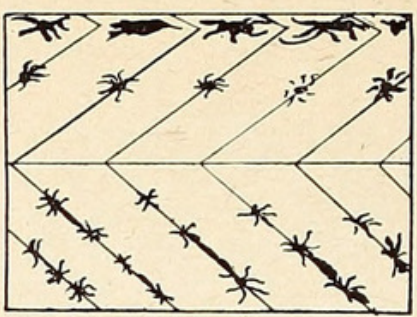

C

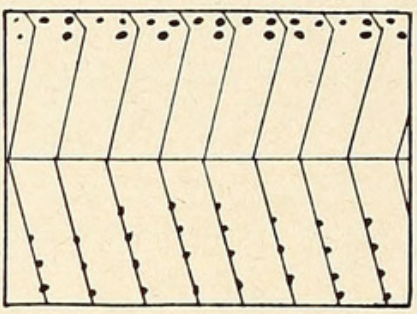

$F$
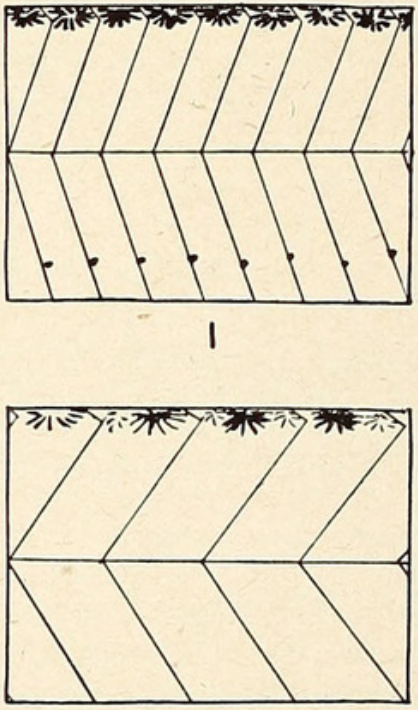

L

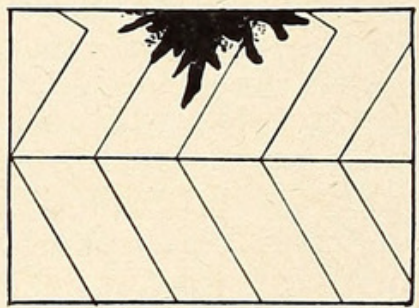

0

Text-figure 2.

Pigment patterns of young Melanostomiatidae. Each diagram represents a typical series of myomeres from near the middle of the body, the upper and lower boundaries being, respectively, the dorsal mid-line and the upper level of the lateral serial photophores, A, Leptostomias gladiator, larva, standard length $14 \mathrm{~mm}$.: B, same, post-larva, standard length $42 \mathrm{~mm}$.; C, Odontostomias micropogon, transitional adolescent, standard length $42 \mathrm{~mm}$. (pattern subdermal); D, Melanostomias micropogon, transitional adolescent, standard length $42 \mathrm{~mm}$. (pattern subdermal); D, Melanostomias
spilorhynchus, post-larva, standard length $24 \mathrm{~mm}$; , Photonectes parvimanus, larva, standard length $26 \mathrm{~mm}$.; F, same, post-larva, standard length $25 \mathrm{~mm}$; G, Photonectes braueri, late adolescent, standard length $25 \mathrm{~mm}$. (pattern subdermal) ; H, Echiostoma tanneri, adolescent, standard length $25 \mathrm{~mm}$. (pattern subdermal); I, Flagellostomias boureei, post-larva, standard length $34 \mathrm{~mm}$.; J, Grammatostomias flagellibarba, adolescent, standard length $30 \mathrm{~mm}$.; K, Bathophilus sp., larva, standard length $7 \mathrm{~mm}$.; L, Bathophilus sp., near longipinnis, larva, standard length $11 \mathrm{~mm}$.; $\mathbf{M}$, Bathophilus metallicus, post-larva, standard length $29 \mathrm{~mm}$.; N, ?Eustomias sp., larva, standard length $12 \mathrm{~mm}$.; O, Eustomias sp., larva, standard length $13 \mathrm{~mm}$. C, G and J, from specimens in the Dana collection of the British Museum; remainder from present collection. 
fins, the details of which are gradually differentiated during this stage; caudal fin still relatively larger than in adult; finfold absent. The latter part of adolescence, which as in many fishes apparently lasts a long time, is conveniently referred to as "transitional adolescence"; it is characterized by the fish's being externally almost or completely adult in appearance, its immaturity being attested only by its size and undeveloped gonads, and by the incomplete development of any or all of the following characters: minute details of light organ and tooth development, skeleton (especially in form of vertebrae) and digestive organs. The entire period of adolescence is marked by growth.

Gymnophotodermid Characters: End of gut completely enclosed; subdermal larval pigment spots become reduced and vanish; barbel short and roughly formed; permanent teeth on both jaws and gill-arches growing slowly; stomach short, its pigment lacking or incomplete.

The transitional adolescent is especially well marked in this group, having completely developed external pigment, proportions and light organs, and the barbel more or less perfectly formed. This stage is sometimes reached when the fish is very small-at $18 \mathrm{~mm}$., for example, in certain species of Photonectes. Immaturity, however, in the form of slightly developed gonads; few maxillary teeth; short, partially pigmented stomach; and often a different barbel, is shown as usual. Sometimes, too, immaturity is shown in the slow development of the specialization of an organ, such as a luminous or elongate pectoral fin. These transitional adolescents form by far the greater part of our collection, and it would seem that these fish are designed to win through to the safety of an adult external appearance as soon as possible.

IDENTIFICATION of Melanostomiatid LARVAE: We have found the following characters to be of the most diagnostic value in the identification of melanostomiatid larvae:

1. Number of Myomeres: These are counted only to the end of the anal fin, since in most cases the few segments occurring behind this point are too ill-defined to count. - The myomere count thus gained is between one and four more than the vertebral count of the grown fish, and usually three to six more than the number of ventral serial photophores between pectoral origin and caudal base. Unlike the myomeres of some fish, such as nemichthyid eels, the full number found in the adult is present even in young larvae.

2. Myomeres from Nape to Pelvic Rudiment: The pelvic bud can often be detected by careful manipulation of lighting while it is still subdermal. The number of myomeres between the nape and this point, is of course, roughly equivalent to the number of vertebrae and to the future number of photophores in the P-V series; usually the count is two to four more than the photophore count.

3. Myomeres from Pelvic Rudiment to Anal Origin: The count will roughly equal the future number of photophores in the V-A series, minus, of course the number of organs in the series above the anal fin, and to the number of corresponding vertebrae.

4. Pigment: Although, next to myomere counts, the pigment pattern is the most persistent of larval characters, it must always be used only as a partial guide, since almost identical pigment patterns are sometimes found in closely related genera (e.g., Melanostomias, Echiostoma and Photonectes), while in others the arrangement of spots differs between species of the same genus (e.g., Eustomias) and in still other cases certain chromatophore rows are found in post-larvae which are absent in larvae of the same species (e.g., Leptostomias).

5. Larval Teeth: The larval teeth, since their appearance, growth and disappearance are all confined to this single growth stage, are not a good 
identification character. We can see apparent differences between genera, but the material at present is far too scanty to make up a table of frequencies.

6. Larval Gill-rakers: Their number and form are a useful secondary check in larvae of doubtful position.

7. Dorsal and Anal Fin Counts: Except in the youngest larvae, approximate counts can be made, which either fall within, or slightly below, the generic or specific limits.

8. Anal Origin with Reference to that of the Dorsal: This character is very useful; it must always be remembered in using it that in larvae the anal origin usually is slightly behind its position in the adult; that is, in genera where the anal originates well in front of the dorsal, it starts only barely in front in the larva; similarly, when the adult origin is immediately below the dorsal, in the larva it is usually under the second to fourth dorsal ray.

9. Length: Metamorphosis begins at slightly different lengths in different genera. In most melanostomiatids in which the young stages are known, the larval period ends when the fish is around $20 \mathrm{~mm}$. long, while post-larvae and adolescents (excluding transitional adolescents) measure between 20 and $30 \mathrm{~mm}$. In Flagellostomias, Leptostomias and Eustomias, however, post-larvae and adolescents measure between 30 and $50 \mathrm{~mm}$. or more.

Absolute specific identification always, of course, waits upon the study of intermediate forms, which retain characteristic larval pigmentation subdermally, along with recognizable adult characters. With the single exception of the youngest larva referred to Eustomias, we have series complete enough so that we are confident of generic identification in every case, and of specific in most of these.

Because of the evanescence of a number of characters - the change in pigment spots at different phases, of relative gut lengths and fin development, and the relatively few genera of which true larvae are knownwe cannot yet give an adequate key. The accompanying table, however, used in conjunction with Text-fig. 2 and the full-length figures of larvae scattered throughout the text, should form a basis for future work.

\section{Form and Development of Separate Characters.}

1. COLOR AND LUMINESCENCE: Up to the present time the colors of the light organs in living and freshly dead Melanostomiatidae have been almost completely unknown. Lowe in 1843 (p. 88), in describing Echiostoma barbatum, the first known melanostomiatid, remarked that the postorbital was rose-colored. Murray, writing pioneer notes on the Challenger Expedition, observed that in Opostomias "the end of the barbel, which was thickened, was flesh colour with a rose tint; there was also a rose tint on the dorsal and anal fins. The rest of the animal was of a dark colour with a perceptible slatecoloured tint. The phosphorescent spots along the belly and lateral line were red, as was also that below the eye." (Tizard, etc., 1885, p. 412). In regard to Pachystomias microdon, which was living, he wrote (ibid., p. 521), "It had one club-shaped spot of a rose colour directly below the eye, and another, about half the size, directly in front of this, of the same colour. ... The two rows of probably phosphorescent dots along the body were red surrounded by a circle of pale violet."

Only one of the Monaco melanostomiatids seems to have been described while still fairly fresh. Zugmayer $(1911.2$, p. 78$)$ reported in his description of Trichostomias vaillanti that the fish had the organs of the lateral series yellowish-white, and the suborbital (postorbital) pale red. The colored plates of the family in both the Monaco reports and in Brauer's Valdivia Tief-see Fische (1906) were obviously not made from field sketches, since in none do the organs have the brilliant colors which we have found, by repeated observations in Bermuda, to be characteristic of these fishes. 
TABLE I.

Characteristics of larvae and post-larvae in the Bermuda Collection².

\begin{tabular}{|c|c|c|c|c|c|c|c|c|c|}
\hline & 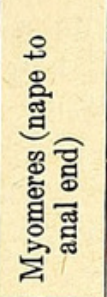 & 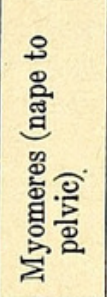 & 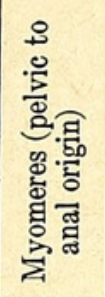 & 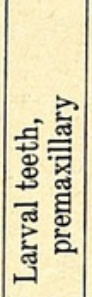 & 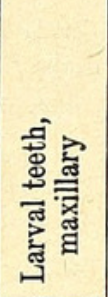 & 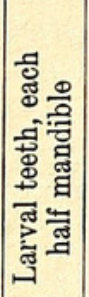 & $\begin{array}{c}\text { Larval gill-rakers } \\
\text { (Numbers refer to } \\
\text { arches) }\end{array}$ & 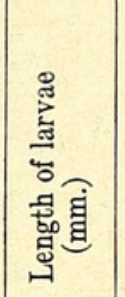 & 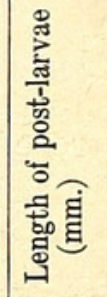 \\
\hline $\begin{array}{l}\text { Leptostomias } \\
\text { gladiator }\end{array}$ & $75-78$ & $43-44$ & $16-18$ & 7 & 18 & 12 & $\begin{array}{l}\text { Long on 1st, 2nd, 3rd. } \\
\text { Mounds on } 4 \text { th, 5th. }\end{array}$ & $12-30$ & $38-45$ \\
\hline $\begin{array}{l}\text { Melanostomias } \\
\text { spilorhynchus }\end{array}$ & $49-52$ & $29-30$ & $10-12$ & 7 & 15 & 7 & $\begin{array}{l}\text { Long on 1st, 2nd, 3rd. } \\
\text { Rudiments on } 4 \text { th, } 5 \text { th. }\end{array}$ & 17 & $21-32$ \\
\hline $\begin{array}{l}\text { Melanostomias } \\
\text { biseriatus }\end{array}$ & $55-56$ & $33-34$ & $10-12$ & - & - & - & $\begin{array}{l}\text { Long on 1st, 2nd, 3rd. } \\
\text { Rudiments on } 4 \text { th, } 5 \text { th. }\end{array}$ & - & 23,25 \\
\hline $\begin{array}{l}\text { Photonectes } \\
\quad \text { parvimanus }\end{array}$ & $64-67$ & $39-41$ & $12-13$ & 5 & 10 & 7 & $\begin{array}{l}\text { Long on 1st, } 2 \mathrm{nd}, 3 \mathrm{rd} \text {. } \\
\text { Mounds on } 4 \text { th, } 5 \text { th. }\end{array}$ & 14,26 & 25 \\
\hline $\begin{array}{l}\text { Flagellostomias } \\
\text { boureei }\end{array}$ & $67-68$ & $32-33$ & $14-16$ & 4 & 14 & 5 & $\begin{array}{l}\text { Long on 1st, 2nd, 3rd. } \\
\text { Mounds on 4th, } 5 \text { th. }\end{array}$ & $20-21$ & 34,39 \\
\hline $\begin{array}{l}\text { Grammatostomias } \\
\text { flagellibarba }\end{array}$ & 55 & - & - & - & - & - & $\begin{array}{l}\text { Short on 1st, 2nd. } \\
\text { Mounds on 3rd. } \\
\text { Absent on 4th, 5th. }\end{array}$ & - & 29 \\
\hline Bathophilus sp. & $45-46$ & 一 & - & - & 15 & 10 & None. & 7 & - \\
\hline $\begin{array}{l}\text { Bathophilus, near } \\
\text { longipinnis }\end{array}$ & $42-44$ & $19-21$ & $11-12$ & 5 & 12 & $6-7$ & $\begin{array}{l}\text { Short on 1st, 2nd, 3rd. } \\
\text { Mounds on 4th, 5th. }\end{array}$ & 11,12 & - \\
\hline $\begin{array}{l}\text { Bathophilus } \\
\text { metallicus }\end{array}$ & 45 & 19 & 17 & - & - & - & $\begin{array}{l}\text { Moderate on 1st, 2nd. } \\
\text { Absent on 3rd, 4th, } 5 \text { th. }\end{array}$ & - & 25,29 \\
\hline ? Eustomias sp. & 55 & - & - & 6 & $18-19$ & 9 & $\begin{array}{l}\text { Short on 1st, 2nd, 3rd. } \\
\text { Mounds on 4th. } \\
\text { Absent on 5th. }\end{array}$ & 12 & - \\
\hline Eustomias sp. & 77 & - & - & 8 & 10 & 10 & $\begin{array}{l}\text { Rudimentary mounds } \\
\text { on all } 5 .\end{array}$ & $13,151 / 2$ & - \\
\hline $\begin{array}{l}\text { Eustomias } \\
\text { bibulbosus }\end{array}$ & ca. 72 & 37 & 14 & - & - & - & $\begin{array}{l}\text { Moderate on 1st. } \\
\text { Short on 2nd. } \\
\text { Mounds on 3rd, 4th. } \\
\text { Absent on 5th. }\end{array}$ & - & 42,52 \\
\hline $\begin{array}{l}\text { Eustomias sp. } \\
\text { (Dinematochirus) }\end{array}$ & 78 & 32 & 14 & - & - & - & $\begin{array}{l}\text { Long on 1st. } \\
\text { Short on 2nd, 3rd. } \\
\text { Mounds on 4th. } \\
\text { Absent on 5th. }\end{array}$ & - & 43 \\
\hline
\end{tabular}

2 Fins and photophore counts of post-larvae, typical of species; diagrams of pigmentation in Text-fig. 2 ; typical teeth and gill-rakers in Text-figs. 5,7 ; full length drawings in Text-figs. 21, 30, 42, $47,57,58,61,66,67,68$. 
The first notes on the actual luminescence of a living melanostomiatid were taken on the Arcturus by Beebe in 1926. Of Echiostoma tanneri (then identified as $E$. barbatum) the following observations were made: "It was alive and stayed so for several hours while we got movies. The most noticeable character of this otherwise brownish-black fish was a wedge-or-pearshaped light organ of rich rose color below the eye. In the dark this gave forth a warm reddish glow. The lateral light organs were all tinged with rose." (Beebe, 1926, p. 422).

Finally, Borodin (1931, pp. 65 and 67) noted that the postorbital was red in Echiostoma, rose in Photonectes, while Bolin (1939, p. 41) describes this same organ as "pale luminous green" in Tactostoma.

This handful of observations apparently includes recently preserved as well as actually living fish, and all told represents only six out of the sixteen valid genera in the family. Except for the single Arcturus observation, the actual luminescence of the fish has never before been recorded.

The Bermuda observations which follow, while naturally incomplete, at least lay a sound foundation for future research, which will emphasize the functions of these organs. Our notes give hints of the relationship between the colors of the photophores in daylight and their luminescence in the dark, as well as of their respective uses, and on their appearance under natural conditions, as observed from the Bathysphere. The field notes and color sketches were all made while the fish were actually alive or else when they were freshly dead, still in water, and within two hours of the nets' having reached the surface. We have made these observations upon all 10 genera taken by the Expeditions and on 29 of the 32 species, or about one-third of the known forms. From one to more than a dozen individuals of each species were painted and described. In the case of the more common forms, such as Melanostomias spilorhynchus, the colors of the barbel and postorbital were so consistent and unvarying that after having made a number of sketches and notes, we simply checked the various organs mentally in order to devote more time to rarer forms taken in the same nets.

The colors usually faded with extreme rapidity, the organs often being almost or quite white after only a few minutes at the surface, so that the taking of notes was useless by the time they reached the laboratory. Occasionally, however, the serial organs retained traces of violet even after two years in alcohol, and the postorbitals of Echiostoma usually remained pink for several months.

Individuals of five of the species, Chirostomias pliopterus, Pachystomias atlanticus, Echiostoma tanneri, Photonectes margarita and Eustomias bibulbosus, were still alive when they reached the laboratory. In the case of Echiostoma, five specimens of both sexes came up alive, and two of them lived overnight. Thanks to these living examples, we could compare the colors in daylight with those soon after death. There was found to be no difference at all except, sometimes, in relative brilliancy, so that we may consider our notes on fresh fish very accurate. No dead fish, no matter how fresh, showed any luminescence in the dark-room. Since the functioning of the organs in the dark-room was exactly similar on a small scale to their functioning when seen from the Bathysphere, objections that our observations were made upon dying specimens are not as valid as they would be in the case of freshly caught shallow water fish, where the superficial coloration is known often to go through unusual or abnormal phases.

In the dark-room an ultra-violet lamp was sometimes used to help in the observation of luminescent areas.

A table, summarizing the observations on each species, will be found at the end of this section; detailed color descriptions are included under the headings of the various genera and species further on. We will now sum- 
marize what we have learned of the general body color, and of the colors, luminescence and uses of the barbel and light organs.

General Color: When alive or recently dead, these fishes appear velvety, jet black in the shade; in direct sunlight, however, the color is dark brown. The presence and arrangement of the evanescent pigment spots of the translucent larvae has already been discussed above. The pigment of the adult begins to appear at the end of the post-larval or beginning of the adolescent stage; by early transitional adolescence it is nearly or quite as well developed as in adults; advanced transitional adolescents are invariably as deeply pigmented as mature fish. Pigmented skin, forming on top of the larval spots, appears first along the sides, last around the snout and end of the caudal peduncle.

Iridescence has been observed in the following fishes: Chirostomias pliopterus, green bronze on shoulder; Bathophilus longipinnis and B. metallicus, head and body iridescent in both males and females. In the latter species this iridescence is often completely lacking; it is obviously very easily damaged, however, and we consider it a normal, rather than a variable characteristic. It appears in transitional adolescence.

The fins of melanostomiatids are usually translucent, or whitish, because of luminous mucous (of which more will be said later). Often, however, the skin of the body, as in certain species of Grammatostomias and Photonectes, extends almost to the tips of the dorsal and anal, and often all of the fins are tinged with pink because of the coursing blood.

Barbel: This highly specialized and variable structure cannot be listed definitely as either a luminous or a tactile organ; in all probability it is sometimes one, sometimes the other, sometimes both, and perhaps always connected with one or more senses of which we have no knowledge whatever.

The Bathysphere observations on this subject were necessarily disappointing. "In the great majority of cases, it was quite impossible to make accurate generic identifications. By the time I had satisfied myself that I was looking at a member of this family, the Bathysphere or fish would move. So I invariably lost the chance of seeing the barbel and its light. In Bathysphaera I thought, on the occasion of their first passing, that a parti-colored jelly or small fish was swimming beneath. Only on their return did I suddenly realize that the bobbing red and blue lights terminated a dangling, invisible barbel thread. One other time I thought I saw a long strand of tissue studded with minute lights, but I am not certain, and so far as identification by barbels is concerned, my dives were quite ineffective. This may indicate that barbels in general subserve a tactile rather than a luminescent function." (Beebe, 1934.2, Appendix G, p. 312.)

The old suggestion that barbels in this family sometimes serve as luminous lures is more plausible than ever after these Bathysphere observations. In other cases, however, it is possible that luminescence of the organ is a purely secondary matter, or an accidental byproduct, its primary function being sensory. We have also found that, at least in the genus Eustomias, barbels differ in both form and color in males and females of the same species (see p. 211). In regard to sexual differences in barbel color, Eustomias bigelowi had the bulb and bulblets bright yellow in the male and brilliant bluish-green in the female. Unfortunately, these fish were not taken alive, so that comparison of luminescence in the two sexes could not be made.

As might be expected, the genera Pachystomias, Grammatostomias and Bathophilus, which have in common long, filamentous, bulbless barbels practically lacking in pigment, save for a few rudimentary photophores, showed no color tints and gave out no luminescence. Genera with more elaborate barbels, on the other hand, usually had the bulbs and bulblets brightly colored, often combining two or more contrasting hues. The structures were always more or less translucent, and the colors consequently wonderfully clear. They ranged from gleaming white and silver (Chirostomias) through 
pinks, yellows, blues, greens and lavenders: only bright red was missing from the spectrum. In some, such as Echiostoma, the daylight tints were rather delicate, but in Eustomias and Photonectes they were often blazingly vivid, even in dead specimens. In the two last genera, the only ones with non-filamentous barbels on which we have observations on a number of species, we find that many colors are found in the same genus, although there is practically no variation (except sexual, as noted) within species.

One of the most interesting results of the dark-room studies is that barbel luminescence does not, in the two species observed, correspond to the color of the barbel in daylight. In Chirostomias the silver-white barbel bulb gave off a steady pink glow anteriorly and a white one posteriorly. In a male Eustomias bibulbosus the bulbs were bright pink, but gave a distinctly green light in three brilliant flashes. In Echiostoma, the barbel, though highly developed and colored in the young, was never observed to be luminous; similarly, there was no glow from that of Photonectes margarita. In Bathysphaera intacta, seen only from the Bathysphere, the proximal bulb glowed rosy red, the distal blue.

Postorbital Light Organ: The color of the postorbital in freshly caught specimens varies greatly, and includes all the colors of the spectrum as well as white and silver-white. The luminescence of these lights is known only for Echiostoma, the adults giving a rosy glow and a blue or white flash, while the young also gave a rosy glow (the anterior part of the organ being pink) but a distinctly green-white flash (the posterior portion being green). Silver or silver-white with opalescent reflections seems to be a generic character in the postorbital of Eustomias. Bathophilus, on the other hand, varies within the genus. Other multi-specific genera have not yet been sufficiently observed to draw any conclusions.

The postorbital is definitely under the control of the fish, can be rolled down out of sight, and made to glow steadily or emit sharp flashes of a different color, at least in Echiostoma. In the new Tactostoma Bolin, 1939, it apparently rotates forward, or forward and downward, instead of the usual downward. The following summary has been made of observations on this organ from the Bathysphere: "The cheek lights seemed under control, and were seen occasionally to blink. Their color, whenever a definite tint could be assigned, was yellow or red. Every time they were rolled up into sight, these organs illumined the fish's eye and most of its head. Why the creature is not momentarily blinded by the light is a question which has always puzzled me." (Beebe, 1934.2, Appendix G, p. 313.)

Serial Photophores: Throughout the superfamily Gymnophotodermi (Astronesthidae, Melanostomiatidae, Malacosteidae and Idiacanthidae) the color of the serial photophores in fresh specimens in all the observed genera save one is invariably purple or violet, sometimes verging on scarlet. The known exception is Bathophilus in which the organs in the two species observed were always golden yellow. This apparent color may have been due however to the inconspicuousness of the organs themselves in this genus and the relatively large size of the tinselly gilt reflectors. The latter characters are visible only in perfectly fresh specimens and consist apparently of small crescents or circles of specialized iridescent skin, always giving off bright golden reflections, which cap or completely surround the organs of the lateral series, the ventral or both. Their function is doubtless to magnify the light of the photophores, exactly as do tin reflectors placed behind the individual lights on a Christmas tree. Due to their evanescence, we have not been able to determine whether the crescentic caps above the organs in some species are the rule, or whether only the upper part of a complete gilt circle has survived capture.

The luminescence of serial photophores has been observed in the darkroom only in Echiostoma, in which case it was rosy to scarlet. They glowed steadily for a time, but were apparently under the control of the fish. From 
the Bathysphere the serial photophores appeared as follows: "The two rows of lateral serial organs were usually distinct, though not brilliant, and as far as I could tell glowed steadily. I cannot generalize on their tint, except that they often seemed faintly yellowish. It is interesting to note that on freshly caught dead specimens these organs are always clear violet or purple." (Beebe, 1934.2, Appendix G, p. 312.)

In fresh specimens of Malacosteus and Bathophilus brevis, the only stomiatoids in which regular serial organs are lacking, certain of the numerous tiny, non-serial photophores were distinctly larger, brighter, and more violet than their fellows, and in roughly linear formation in the region where serial organs are usually found. The differences were not, however, clear enough for counting of these larger organs.

Non-serial Photophores: Their color, in fresh specimens, ranges from red or pink, through violet to bluish, differing in tint considerably from that of the clear violet photophores, and fading much more quickly than the serial organs. From the Bathysphere their importance was apparent: "One unexpected observation was the brightness of the tiny-non-serial organs scattered in large numbers over the heads and bodies of these fish. In newly caught specimens these are very inconspicuous in comparison with the much larger serial organs, and usually show no vestige of color. Yet a number of times in the Bathysphere I noted Melanostomiatids with these tiny pinpricks of light glowing with considerable brilliancy." (Beebe, 1934.2, Appendix G, p. 312). In the laboratory dark-room the non-serial lights of Echiostoma glowed with a rosy light.

Other Luminous Areas: The luminous tissue in which pectoral fins are often more or less imbedded is usually creamy white in fresh specimens. The highly specialized luminous line or loop on the side of Grammatostomias is bluish to bright metallic green-violet in fresh specimens. Yellow, purple, pink and green snout and jaw spots have been observed in freshly dead Melanostomias, Photonectes and Bathophilus. The whitish longitudinal body bands of Echiostoma gave off a bluish-white luminescence under ultraviolet light. Some genera, such as Echiostoma and Melanostomias, also certainly have the bases of the teeth luminous, the material being deposited in the soft portion which permits bending of the fang. Also, luminous granules are frequently present on the dorsal and anal fins, being sometimes more easily seen in the adolescent than in the adult. We have never observed luminescence in this region, however, in the dark-room.

Bathysphere observations show that a luminous mucous, of which we see few traces in captured specimens, may be a general family attribute. "Another point I cannot explain is how I could see outline after outline of the fish when they were in absolutely black water, while their lights had very little reflecting power. Perhaps there was a general coating of luminous mucous, as trawled specimens frequently exude a whitish slime, or a loose epidermal membrane." (Beebe, 1934.2, Appendix G, p. 313).

The table on pp. 86-87 gives in summarized form all that we know at present of the color and luminescence of melanostomiatid light organs. In all cases, unless prefixed by the word "luminescence," colors refer to those found on freshly dead, apparently unfaded, specimens. Detailed color descriptions will be found in the discussions of the individual species.

2. BODY FORM AND PROPORTIONS: With the exception of the highly specialized Bathophilus brevis (depth in length $c a$. 2.5), all melanostomiatids are moderately to excessively elongate in form; some species of Leptostomias, for example, are of anguilliform slenderness, the depth being contained in the length up to 17 times. Adult melanostomiatids are deepest at the shoulder except in the more specialized Photonectes, in which the fish is deepest toward mid-body, as in juvenile forms. The head is usually small, there being a distinct correlation between large heads and deep bodies; the extremes of head lengths range from about 2.5 (for B. brevis) to 11 


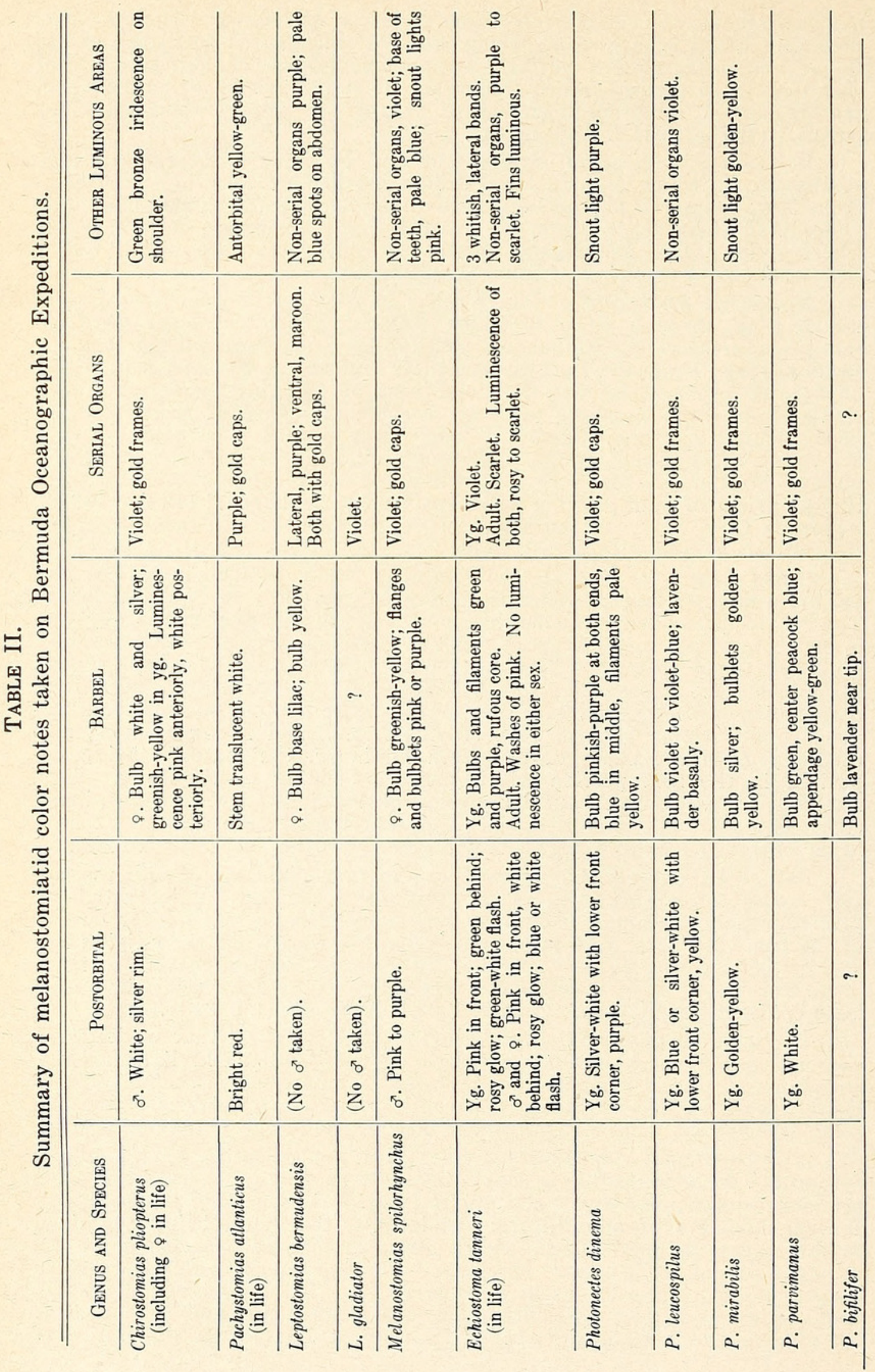




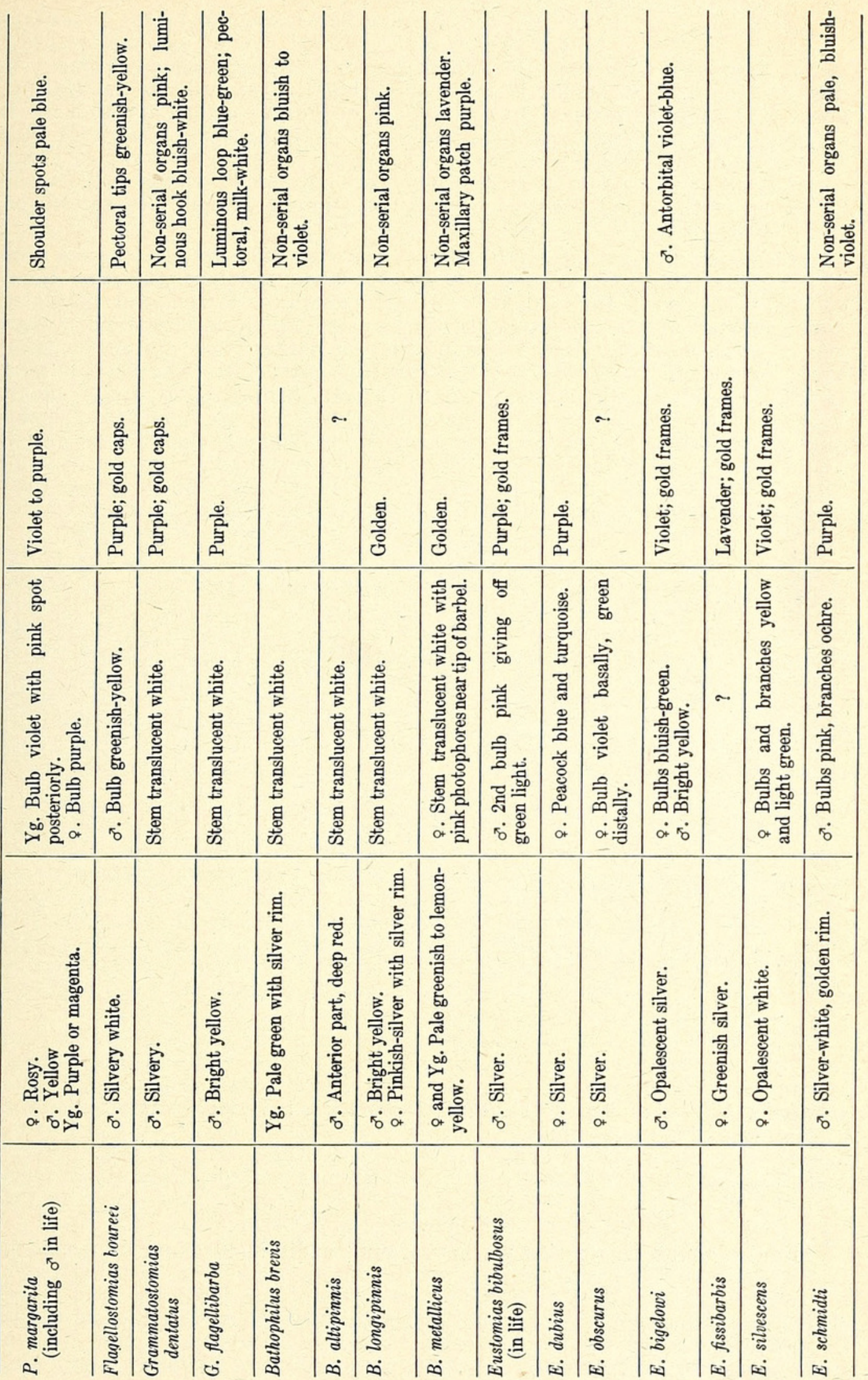



TABLE II.

Summary of melanostomiatid color notes taken on Bermuda Oceanographic Expeditions.

\begin{tabular}{|c|c|c|c|c|}
\hline GeNUS aNd SpeciEs & Postorbital & BARBEL & Serul Organs & OTHER LUMINous AREAS \\
\hline $\begin{array}{l}\text { Chirostomias pliopterus } \\
\text { (including } \odot \text { in life) }\end{array}$ & ๑. White; silver rim. & $\begin{array}{l}\text { ๑. Bulb white and silver; } \\
\text { greenish-yellow in yg. Lumines- } \\
\text { cence pink anteriorly, white pos- } \\
\text { teriorly. }\end{array}$ & Violet; gold frames. & $\begin{array}{l}\text { Green bronze iridescence on } \\
\text { shoulder. }\end{array}$ \\
\hline $\begin{array}{l}\text { Pachystomias atlanticus } \\
\text { (in life) }\end{array}$ & Bright red. & Stem translucent white. & Purple; gold caps. & Antorbital yellow-green. \\
\hline Leptostomias bermudensis & (No o taken). & ๑. Bulb base lilac; bulb yellow. & $\begin{array}{l}\text { Lateral, purple; ventral, maroon. } \\
\text { Both with gold caps. }\end{array}$ & $\begin{array}{l}\text { Non-serial organs purple; pale } \\
\text { blue spots on abdomen. }\end{array}$ \\
\hline L. gladiator & (No o taken). & $?$ & Violet. & \\
\hline Melanostomias spilorhynchus & o. Pink to purple. & $\begin{array}{l}\text { १. Bulb greenish-yellow; flanges } \\
\text { and bulblets pink or purple. }\end{array}$ & Violet; gold caps. & $\begin{array}{l}\text { Non-serial organs, violet; base of } \\
\text { teeth, pale blue; snout lights } \\
\text { pink. }\end{array}$ \\
\hline $\begin{array}{l}\text { Echiostoma tanneri } \\
\text { (in life) }\end{array}$ & $\begin{array}{l}\mathrm{Yg} \text {. Pink in front; green behind; } \\
\text { rosy glow; green-white flash. } \\
\sigma^{\prime} \text { and } 9 \text {. Pink in front, white } \\
\text { behind; rosy glow; blue or white } \\
\text { flash. }\end{array}$ & $\begin{array}{l}\text { Yg. Bulbs and filaments green } \\
\text { and purple, rufous core. } \\
\text { Adult. Washes of pink. No lumi- } \\
\text { nescence in either sex. }\end{array}$ & $\begin{array}{l}\text { Yg. Violet. } \\
\text { Adult. Scarlet. Luminescence of } \\
\text { both, rosy to scarlet. }\end{array}$ & $\begin{array}{l}3 \text { whitish, lateral bands. } \\
\text { Non-serial organs, purple to } \\
\text { searlet. Fins luminous. }\end{array}$ \\
\hline Photonectes dinema & $\begin{array}{l}\text { Yg. Silver-white with lower front } \\
\text { corner, purple. }\end{array}$ & $\begin{array}{l}\text { Bulb pinkish-purple at both ends, } \\
\text { blue in middle, filaments pale } \\
\text { yellow. }\end{array}$ & Violet; gold caps. & Snout light purple. \\
\hline P. leucospilus & $\begin{array}{l}\mathrm{Yg} \text {. Blue or silver-white with } \\
\text { lower front corner, yellow. }\end{array}$ & $\begin{array}{l}\text { Bulb violet to violet-blue; laven- } \\
\text { der basally. }\end{array}$ & Violet; gold frames. & Non-serial organs violet. \\
\hline P. mirabilis & Yg. Golden-yellow. & $\begin{array}{l}\text { Bulb silver; bulblets golden- } \\
\text { yellow. }\end{array}$ & Violet; gold frames. & Snout light golden-yellow. \\
\hline$P$. parvimanus & Yg. White. & $\begin{array}{l}\text { Bulb green, center peacock blue; } \\
\text { appendage yellow-green. }\end{array}$ & Violet; gold frames. & \\
\hline P. bifilifer & $?$ & Bulb lavender near tip. & $?$ & - \\
\hline
\end{tabular}

\begin{tabular}{|c|c|c|c|c|}
\hline $\begin{array}{l}\text { P. margarila } \\
\text { (including } \sigma^{*} \text { in life) }\end{array}$ & $\begin{array}{l}\text { ९. Rosy. } \\
\text { o. Yellow } \\
\text { Yg. Purple or magenta. }\end{array}$ & $\begin{array}{l}\text { Yg. Bulb violet with pink spot } \\
\text { posteriorly. } \\
\text { ९. Bulb purple. }\end{array}$ & Violet to purple. & Shoulder spots pale blue. \\
\hline Flagellostomias toureri & ๑. Silvery white. & ه. Bulb greenish-yellow. & Purple; gold caps. & Pectoral tips greenish-yellow. \\
\hline $\begin{array}{l}\text { Grammatostomias } \\
\text { dentatus }\end{array}$ & a. Silvery. & Stem translucent white. & Purple; gold caps. & $\begin{array}{l}\text { Non-serial organs pink; lumi- } \\
\text { nous hook bluish-white. }\end{array}$ \\
\hline G. flagellibarba & ๙. Bright yellow. & Stem translucent white. & Purple. & $\begin{array}{l}\text { Luminous loop blue-green; pec- } \\
\text { toral, milk-white. }\end{array}$ \\
\hline Bathophilus brevis & Yg. Pale green with silver rim. & Stem translucent white. & $\longrightarrow$ & $\begin{array}{l}\text { Non-serial organs bluish to } \\
\text { violet. }\end{array}$ \\
\hline B. altipinnis & o. Anterior part, deep red. & Stem translucent white. & $?$ & \\
\hline B. longipinnis & $\begin{array}{l}\text { 8. Bright yellow. } \\
\text { \&. Pinkish-silver with silver rim. }\end{array}$ & Stem translucent white. & Golden. & Non-serial organs pink. \\
\hline B. metallicus & $\begin{array}{l}Q \text { and } Y g . \text { Pale greenish to lemon- } \\
\text { yellow. }\end{array}$ & $\begin{array}{l}\text { Q. Stem translucent white with } \\
\text { pink photophores near tip of barbel. }\end{array}$ & Golden. & $\begin{array}{l}\text { Non-serial organs lavender. } \\
\text { Maxillary patch purple. }\end{array}$ \\
\hline $\begin{array}{l}\text { Eustomias bibulbosus } \\
\text { (in life) }\end{array}$ & o. Silver. & $\begin{array}{l}\text { o. 2nd bulb pink giving off } \\
\text { green light. }\end{array}$ & Purple; gold frames. & \\
\hline E. dubius & ๑. Silver. & จ. Peacock blue and turquoise. & Purple. & \\
\hline B. obscurus & ๑. Silver. & $\begin{array}{l}\text { 8. Bulb violet basally, green } \\
\text { distally. }\end{array}$ & ? & \\
\hline B. bigelowi & o. Opalescent silver. & $\begin{array}{l}\text { ๑. Bulbs bluish-green. } \\
\text { o. Bright yellow. }\end{array}$ & Violet; gold frames. & o. Antorbital violet-blue. \\
\hline E. fissibarbis & १. Greenish silver. & $?$ & Lavender; gold frames. & \\
\hline B. siliescens & १. Opalescent white. & $\begin{array}{l}\text { Bulbs and branches yellow } \\
\text { and light green. }\end{array}$ & Violet; gold frames. & \\
\hline B. schmidti & o. Silver-white, golden rim. & o. Bulbs pink, branches ochre. & Purple. & $\begin{array}{l}\text { Non-serial organs pale, bluish- } \\
\text { violet. }\end{array}$ \\
\hline
\end{tabular}


(Leptostomias) in the length, the average being about 6 to 8 . In Pachystomias the head is very broad as well as long. In all cases the eye is small, compared with those of fish in general, although as an organ it is well developed. The snout is noticeably short, excessively so in Melanostomias and related genera. In Eustomias and Pareustomias, and to a much lesser degree in Flagellostomias, the snout is protractile; traces of this tendency are also present in Grammatostomias. The thrust forward is accomplished by the dislocation of the upper jaw bones, which project the fleshy tip of the snout forward beyond the ethmoid region (see section on Osteology).

The body proportions of larval melanostomiatids are not greatly different from those of adults, if the finfolds and pendulous guts are disregarded. However, the trunk is usually slimmer (when the depth is measured exclusive of the coelomic organs), and the head and snout always longer throughout the larval and post-larval stages, the jaw angle being under or well in front of the eye instead of behind it. The deepest part of the body is toward the middle of the length, instead of at the shoulder. With the material at hand, we have not been able to deduce any satisfactory numerical ranges for these proportions in the various larvae which would be of help in identification. It may be remarked, however, that in Eustomias the snout (and with it the head) is relatively much longer than in other genera; the snout itself is more than half the length of the head, and of a flattened, duck-bill-like shape, very much as in Idiacanthus.

The elongate, forwardly rotated eye, which is confined to the larval stage of stomiatoids alone, is of especial interest. Apparently no larvae in other groups possess just this characteristic. The closest are certain young alepocephalids and myctophids, and in these forms the eyes are merely elliptical, and not at all turned toward the front. The vast majority of fishes pass through all phases of development with the round eye, often very large, which they have upon hatching. It seems likely that this transient, elongate eye of the stomiatoids is a phylogenetic character, reminiscent of ancestors which, like Ichthyococcus today-one of the least specialized of existing stomiatoids-had semi-telescopic eyes. Further evolution in that direction led to Argyropelecus.

3. BARBEL: This highly specialized organ is the most variable in the entire family. It ranges from simple forms similar to that of the astronesthids, with moderate stems and small, simple bulbs, to all extremes: to the attenuated, bulbless barbel of Grammatostomias flagellibarba, seven times as long as the fish; to the complex, tree-like organ characteristic of the eustomiad subgenus Dinematochirus; and, in the opposite direction, to the degenerate barbels of adult Echiostoma and Photonectes, and the almost atrophied organ of Tactostoma, which consists only of a minute black stem with the slightest of distal swellings.

Variability is great not only between genera, but, sometimes, between the species of one genus, as in Eustomias and Photonectes. In species having more or less complicated barbels, as in Flagellostomias boureei, Leptostomias gladiator and many forms of Eustomias, individual variation is the rule. Lack of adequate material to show specific ranges in this character has been another common cause for the erection of invalid species. Nevertheless, it is often true that closely related but valid species differ from each other solely in the form of the barbel; as such, this organ is the most useful single taxonomic character in the entire family.

In the genus Eustomias we have found a distinct sexual dimorphism in the shape of the barbel in most of the species which we have been able to study. In the subgenus Nominostomias the distal filaments tend to be branched in the females, but unbranched in the males. In the subgenus Dinematochirus the median posterior branch is short and tipped with a prominent bulb in the females, while in the males it is longer, with the 
bulb small or absent; the main barbel bulb is smaller in the female than in the male.

The probable functions of barbels have already been discussed under the heading "Color and Luminescence" (p. 83).

Completely absent in the larva, a stump in the post-larva, and roughly formed in the adolescent, the barbel is often not fully formed until the completely adult stage is reached. This has been found to be especially true of the genera Eustomias, Echiostoma and Photonectes. Because it usually appears fully pigmented and apparently completely defined in transitional adolescence, a number of species in various genera (notably the same ones mentioned above) have been described on the basis of this character, whereas it merely represents a different stage in the development of a previously known species. It is interesting that in Odonotostomias, Echiostoma and the majority, if not all, species of Photonectes, the barbel bulb is relatively larger in young specimens than in older; in Echiostoma, at least, the entire barbel is apparently actually shortened in the adult.

In general, the relative length of the barbel increases with that of the fish until the proportion characteristic of the species is attained, sometime during transitional adolescence. In a few species, however, the barbel is longer relative to the length in the transitional adolescent than in the adult; that is, it grows faster than the rest of the body.

4. Light ORgans: Antorbital: This small photophore, situated at the lower front corner of the eye, is of phylogenetic interest, since it is well developed and functional in all the lower stomiatoids, while in adult melanostomiatids it is almost or completely atrophied. In young melanostomiatids, however, it appears with the other photophores in the post-larval stage, quickly develops at least one luminous center and sometimes two, and for a while may even be functional. In adolescence, however, it ceases to grow, and usually atrophies during transitional adolescence. In Pachystomias however, it is well developed and brightly colored even in adult fish. Also, a transitional adolescent Eustomias bigelowi, had an antorbital with a luminous center tinted violet-blue. Subdermal traces of the organ are sometimes found in fully adult melanostomiatids.

Postorbital Organ: The postorbital, which is small or absent in gonostomids, sternoptychids, stomiatids and Chauliodus, is well or highly developed in male melanostomiatids and sometimes in females. Unlike the barbel, this organ does not vary greatly in structure throughout the family, althour $h$ there are large differences in its size and color, and in most genera it is reduced or entirely atrophied in the female. In general form it is a gigantic photophore, apparently always under the control of the fish, which nevertheless can also be rotated downward out of sight, so that the luminous face is replaced by the pigmented inner surface of the organ. The histology of the postorbital has been described by Brauer (1908, p. 87). In genera having very large postorbitals, such as Echiostoma, Photonectes and Grammatostomias, an overhanging "eye-brow" of skin protects the eye from receiving the full glare of the light; nevertheless, it is hard to understand how the fish can see when this organ is fully illumined.

Sexual dimorphism in the form of reduced or absent postorbital organs in females has previously been noted in the case of the malacosteid Photostomias (Regan \& Trewavas, 1930, p. 134), of the melanostomiatid Odontostomias (Norman, 1930, p. 309) and of Idiacanthus (Beebe, 1934.1). We have found that it is present in varying degrees in the majority of genera of Melanostomiatidae. We have not, however, been able to check it in every genus, nor in all the species, due both to a lack of material, since many species are known only by immature examples which cannot be sexed, and to the impossibility of our examining many type specimens which are deposited in European museums. However, the evidence so far obtained gives the following results: 


\begin{tabular}{|c|c|c|c|}
\hline Genus & $\begin{array}{l}\text { No. SPECIES } \\
\text { EXAMINED }\end{array}$ & MaLe Light & Female Light \\
\hline Chirostomias & 1 out of 1 & Moderate & Atrophied \\
\hline Trigonolampa & 1 out of 1 & Large & $?$ \\
\hline Pachystomias & $1 \mathrm{yg}$. out of 2 & $?$ & $?$ \\
\hline Thysanactis & 1 out of 1 & Moderate & $?$ \\
\hline Leptostomias & 3 out of $c a .9$ & Probably moderate & Atrophied \\
\hline Odontostomias & 1 out of 2 & Moderate & Atrophied \\
\hline Melanostomias & 3 out of $\mathrm{ca} .12$ & Large & Large \\
\hline Echiostoma & 1 out of 1 & Large & Large \\
\hline Photonectes & 3 out of ca. 15 & Large & Large \\
\hline Tactostoma & 1 (yg.) out of 1 & $?$ & $?$ \\
\hline Opostomias & .. & $?$ & $?$ \\
\hline Flagellostomias & 1 out of 1 & Moderate & Atrophied \\
\hline Grammatostomias & 2 out of 2 & Large & Almost atrophied \\
\hline Bathophilus & 4 out of 16 & Moderate & Small but functional \\
\hline Eustomias & 7 out of $<50$ & Moderate to large & Small or atrophied \\
\hline Pareustomias & & $?$ & $?$ \\
\hline
\end{tabular}

We surmise that Melanostomias, Echiostoma, Photonectes and possibly the closely related Tactostoma, will prove to be the only genera in which dimorphism in this organ is absent.

A preliminary survey of related families shows that similar postorbital sexual dimorphism is absent in at least two genera of Astronesthidae (Astronesthes and Neonesthes), present or absent in Malacosteidae, and present in Idiacanthidae.

The atrophying of the organ in the females is most interesting to trace through the developmental stages. The organ is always apparent, and even, possibly, functional in adolescence. In transitional adolescence, however, it ceases to grow with the fish, the protecting transparent skin becomes gradually pigmented, and the organ remains relaxed, rolled down almost out of sight. Finally, in adults in which it is completely atrophied, such as Chirostomias, the covering skin is indistinguishable from the surroundng epidermis, and dissection shows no trace of the organ except a cavity above the maxillary.

In the male, however, its growth like that of the serial organs is steady and fast. Colored (and presumably functional) postorbitals have been noted in early adolescence.

Serial Photophores: These organs are well developed and are ranged in regular rows except in Bathophilus, Tactostoma and some species of Photonectes, in which genera they are small and sunken (atrophied in B. brevis) ; notably in $B$. irregularis and $P$. margarita, those of the lateral series are placed high on the sides, out of alignment. Also, in Pachystomias, Pareustomias and Eustomias obscurus the photophores of the upper series are grouped, a similar condition being found in certain gonostomids, in Aristostomias and in Pareustomias.

The serial photophores appear almost simultaneously, with the lateral series a little in advance of the ventral, and the last A-C photophores a little behind the rest of the series, especially in the development of luminous centers. Unpigmented anlagen of the photophores are sometimes visible in advanced larvae. Pigmented frames appear in early post-larvae, with luminous centers following almost at once. Fully formed, violet photophores, presumably capable of giving off light, have been noted in advanced postlarvae.

Non-serial Photophores: The tiny organs scattered over the head and 
body of melanostomiatids vary greatly in number and prominence in the different genera. Sometimes they are located in definite patterns and sometimes no particular arrangement is discernible. Usually there are about three principal sizes of non-serial lights; the smallest of these are possibly not true photophores at all, but rather pores exuding luminous mucous. The number of lights on a good-sized melanostomiatid, such as a 12-inch Echiostoma, may total several thousand. They are sometimes found on the posterior side of the barbel and on the pectoral fins. Non-serial organs do not usually appear until adolescence, and are fully developed only in late transitional adolescence.

Other Luminous Areas: In most melanostomiatids, luminous tissue is not confined to barbels and typical photophores. Chirostomias, Trigonolampa, Flagellostomias and Grammatostomias all have large or small amounts of luminous tissue on the pectoral fins. Many species, chiefly of the genera Melanostomias, Echiostoma, Photonectes, Grammatostomias and Bathophilus, have characteristic spots, patches or bands of luminous tissue on the head and body. These areas usually appear in adolescence, but sometimes, as in the body bands of Echiostoma, they are apparent only in adults. It is likely that the exudation of luminous mucous is a family character.

5. TEETH AND GILl-TeEth: The dentition of the jaws is exceptionally well developed in the Melanostomiatidae. It and the Idiacanthidae are the only families in which depressible teeth are developed. Except in Chirostomias, Trigonolampa and Pachystomias, at least one or two, and sometimes all of the teeth in premaxillaries and mandibles are depressible, an attribute which is undoubtedly of great aid in swallowing large fish. Usually the general proportion and arrangement of fixed and depressible teeth serve as useful generic distinctions, the more specialized genera having the most depressible teeth; in Eustomias, however, a highly specialized genus, the species run the gamut from almost all fixed to all depressible; in this genus too, the number and size of the teeth are very variable. In Opostomias and Flagellostomias the largest fang in the mandible is not depressible and fits, respectively, into a hole in the premaxillary or into a groove in the same bone. In Echiostoma, Melanostomias and Photonectes the teeth are strongly barbed or bicuspid; the same character is found to a lesser extent in Flagellostomias and Grammatostomias. The unossified central portions of the tooth bases, which enable them to bend, are often filled with luminous matter (see Beebe, 1934, p. 199, fig. 67). The jaw teeth are in single rows except in Echiostoma and Tactostoma; sometimes, however, especially in Chirostomias, the row is irregular, outer teeth alternating with inner ones; in genera with some teeth depressible, the fixed teeth are usually external to the depressible ones. Vomerine teeth are altogether absent only in Grammatostomias, Bathophilus, Tactostoma, and most species of Eustomias. Palatine and basibranchial teeth vary greatly in development throughout the family. Replacement teeth frequently develop before the loss of the tooth to be superseded.

The gill-teeth have turned out unexpectedly to be a character of great importance. They are paired or in groups of threes or fours in about half the genera in the family, including both primitive and specialized forms; single in other genera and altogether absent in Bathophilus, Eustomias and, presumably, Pareustomias. Whether paired or unpaired, they are strongest, most numerous and present on the most arches in the most primitive genera (see p. $105 \mathrm{ff}$.). Although they are almost invariable in their number and position within the genus, they are not identical in any two genera; hence they form a valuable generic character. Although the teeth on the posterior arches are often small, are almost covered by skin in large specimens, it is easy to determine their presence even in uncleared specimens. Along with the palatines, basibranchials and pharyngobranchials, the gill-teeth, except where much reduced, must be of considerable importance in gripping prey. 


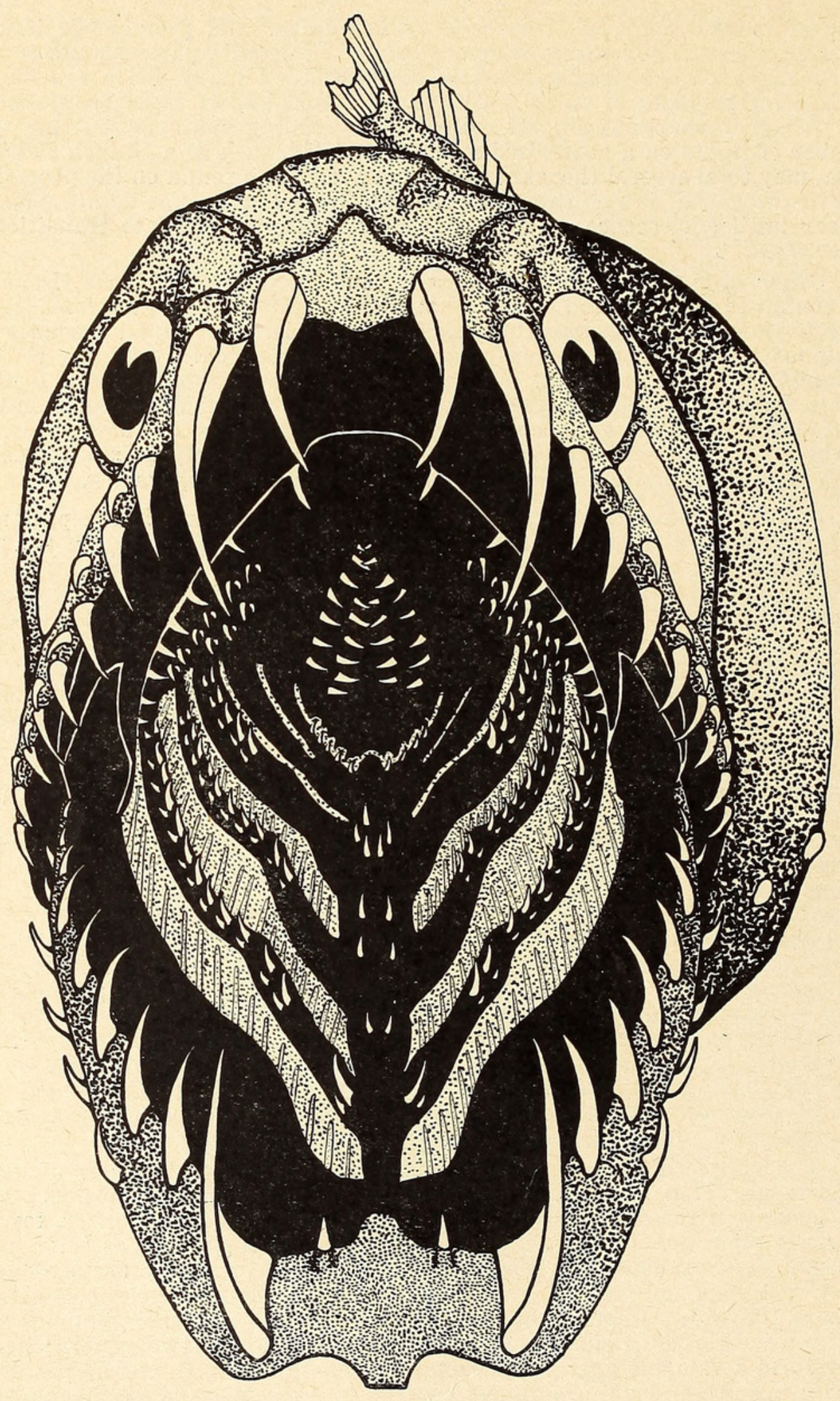

Text-figure 3.

Chirostomias pliopterus. Anterior view, showing abundance of teeth on floor and roof of mouth in a primitive genus. Standard length $205 \mathrm{~mm}$. 


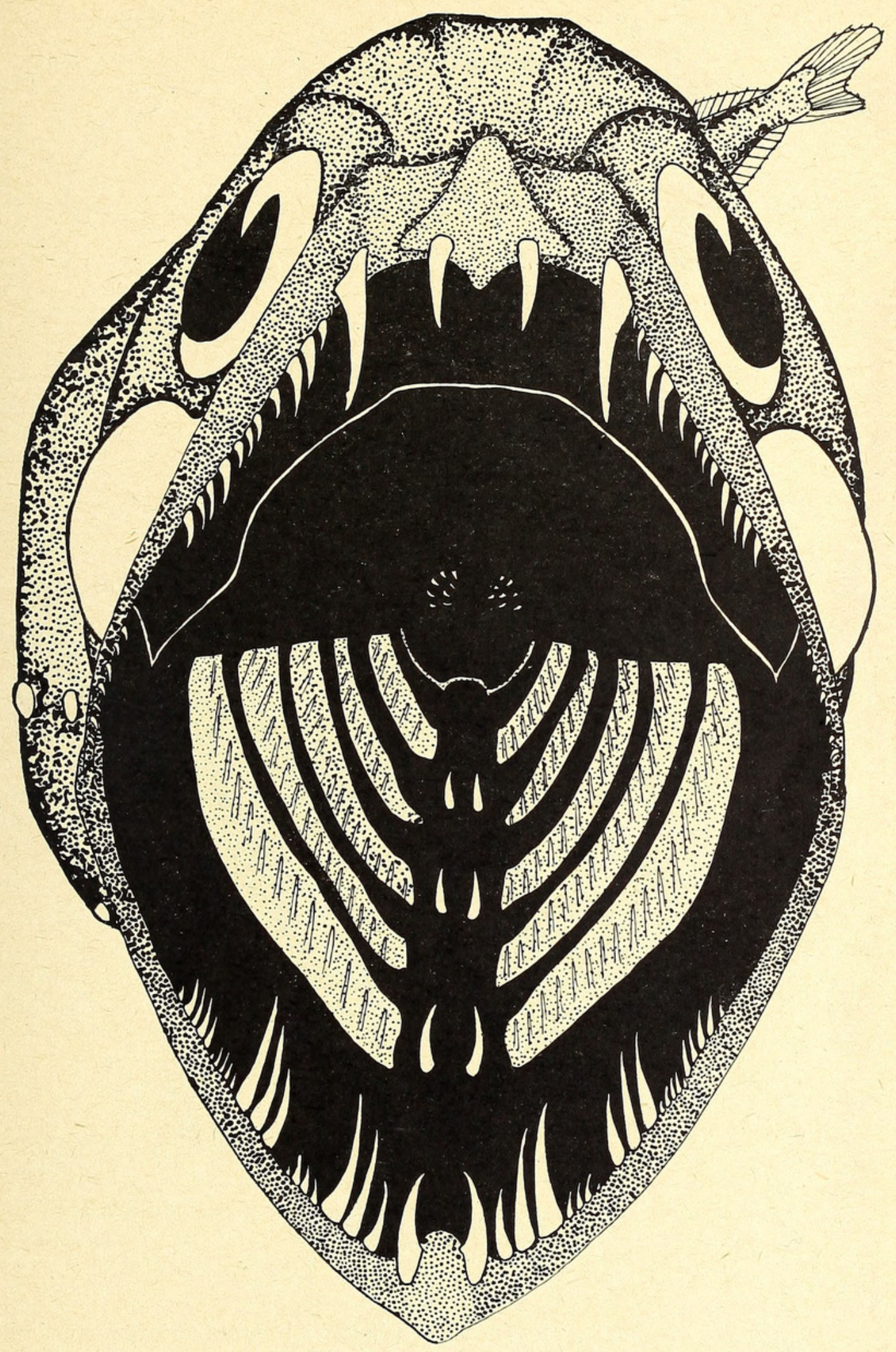

Text-figure 4.

Eustomias bigelowi. Anterior view, showing paucity of teeth on floor and roof of mouth in a highly specialized genus. Standard length $134 \mathrm{~mm}$. 

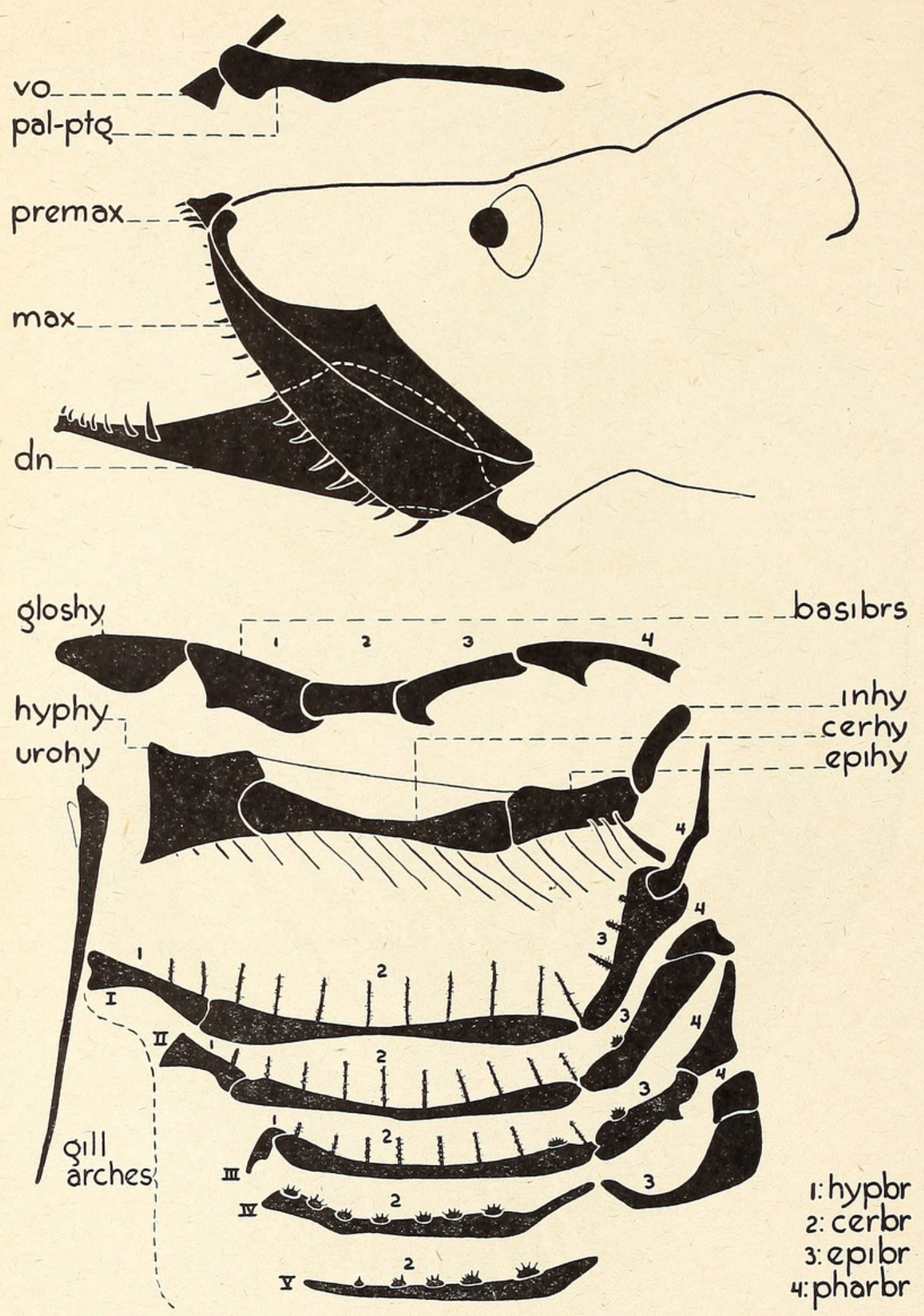

Text-figure 5 .

Leptostomias gladiator. Jaws, hyoid, and branchial arches of larva, standard length $23 \mathrm{~mm}$. The general proportions of the cartilaginous elements and the character of the jaw- and gill-teeth are typical of melanostomiatid larvae. Abbreviations as in Text-fig. 18 . 


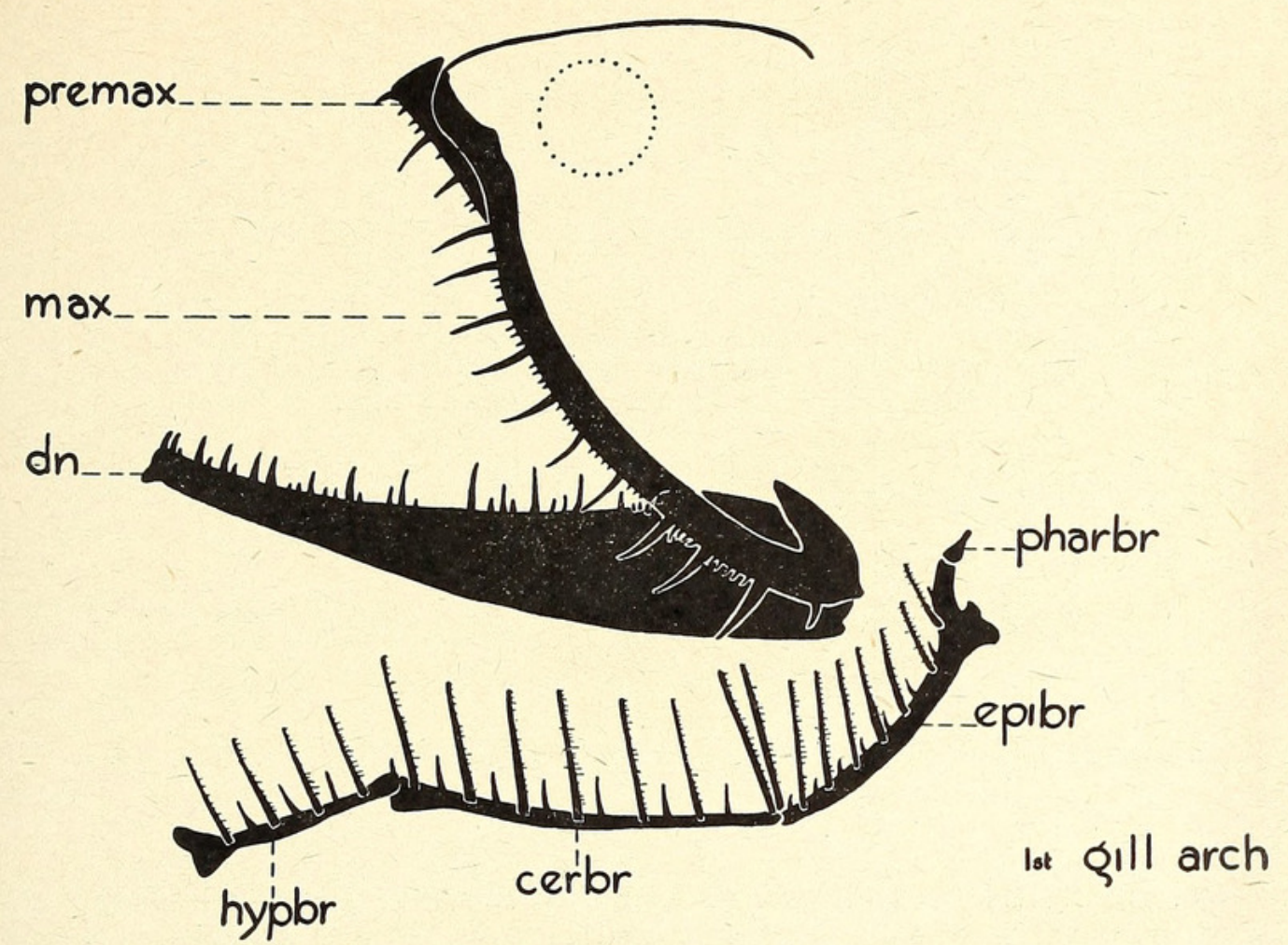

Text-figure 6.

Gonostoma elongatum. Jaws and first branchial arch, standard length 90 mm. For comparison with Text-fig. 5.

The temporary teeth of the larva present a problem of much interest. Doubtless they help the young fish in catching its minute planktonic food, but their resemblance to the permanent teeth of certain gonostomids is noteworthy (Text-figs. 5, 6). On the other hand, they have their counterpart in other larval fish, notably the enormous fangs of leptocephali.

The toothless post-larval stage, and the early periods of adolescence, when the permanent teeth are too few and too weak to be of any practical value, are, perhaps, accompanied by fasting on the past of the shrinking, metamorphosing young fish. In any case, these stages are probably of short duration. The growth of the permanent teeth is slow; maxillary teeth in particular often increase in number until very late in transitional adolescence.

Larval gill-rakers have apparently not been observed before in this family. They lag behind the larval teeth in development, appearing as mere stumps when the temporary teeth are already strong, and reaching their maximum development at the very end of the larval stage, when the teeth are already falling out, or even during the post-larval period, when the jaws are toothless. The rakers on the first arch usually are equal in number and position to the gill-teeth, found in the adult, each raker corresponding to a single tooth, pair or group, i.e., the rakers are never paired, as is so often the case with the gill-teeth of adults. Also, they can generally be found on all five arches, although in the form of low, spiny mounds on the last two. We have found well developed gill-rakers in the larvae of Eustomias and Bathophilus, genera in which they are entirely lacking in the adult. These larval gill-rakers at maximum development are long and strong, with spines at irregular intervals, exactly like the rakers found in some adult gonostomids, such as Photichthys and Gonostoma. They are doubtless of use in straining out microscopic organisms from the water. 


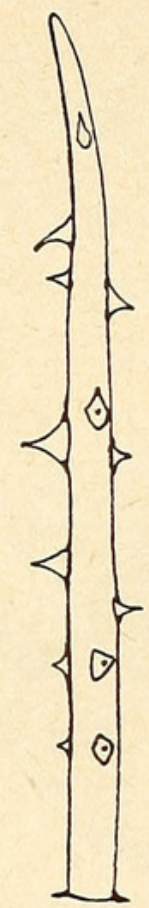

Text-figure 7 .

Leptostomias gladiator. Tooth from first branchial arch of larva, standard length $23 \mathrm{~mm}$.

6. BRANCHIOSTEGAL RAYS: As with the gill-teeth, the branchiostegal rays are in general most numerous and strongest in the less specialized genera. They are present on hypo-, cerato- and epihyals although often reduced on the first. They are of some use as a generic character, but, since the last three or four arise close together, and, moreover, tend to split and laminate, it is difficult to count them accurately except in cleared and stained specimens. Visible development begins in the post-larval period.

7. Fins: In the Melanostomiatidae the entire function of swimming and balancing must be relegated to the caudal peduncle and vertical fins, with balancing assistance from the pelvics, since pectorals are always modified beyond their usual function: they may be small (their usual condition) or absent, as in some Photonectes and Eustomias; imbedded in luminous tissue, as in Chirostomias, Grammatostomias, Trigonolampa, Thysanactus and Flagellostomias; or one or more rays may be long as in the tactile fins of certain bottom-dwelling fish, examples being Echiostoma and Bathophilus. The number of rays varies greatly often even in the same genus. The maximum is 47 , in Bathophilus nigerrimus; however, 2 to 10 rays are most commonly found. Rudimentary, subdermal rays are often present in cleared specimens. The pelvic is far less variable; in all genera except Echiostoma and some Eustomias, which have 8 rays, and Bathophilus, which numbers up to 26, the pelvic is 7-rayed. The posterior rays are sometimes very long, and all seem to be fully webbed in well-preserved specimens. The dorsal and anal, being almost continuous with the caudal, form a powerful swimming organ; sometimes, as in Chirostomias, Grammatostomias and some Photonectes, the rays are covered almost to their tips with the thick, black skin of the body. The caudal fin, like the peduncle, is very short, usually between oneeighteenth and one-twentieth the length of the fish. The lower lobe is always considerably longer than the upper. The dorsal finfold persists longer than the anal fold, remains of one or both being present throughout the postlarval stage. The genera which are known at the present time to have the largest larval finfolds are Flagellostomias and Bathophilus.

The typical larval pectoral fins are large, even when, as has been noted, the pectoral is much reduced or absent in the adult. When the fin is highly specialized, as in Grammatostomias, the full length of the ray or formation 
of the luminous material is not completed until transitional adolescence; when the fin is normal, as in Melanostomias, it is fully formed in the postlarval stage. Pelvic anlagen are often discernible in advanced larvae, but the rays are not differentiated before the post-larval stage; the fin does not reach its full length until adolescence or later. The majority of the rays of both dorsal and anal are distinguishable in the larvae. In Flagellostomias and Eustomias, in which the anal originates conspicuously in front of the dorsal, the anterior rays are the last to form. The caudal, even in late larvae, leaves the typical larval heterocercal form behind, goes through a homocercal stage, and immediately afterwards passes into the final phase, in which the lower lobe is longer than the upper. The entire fin, though small in the larva, is relatively much longer in the post-larva and adolescent than in the adult.

8. EPIDERMal GRooves: More or less well developed depressions are usually present along the isthmus to receive the barbel, or at least the basal part of its stem, when it is laid back. In long-barbeled forms, such as Bathophilus, a median groove runs to the anus and continues along one side of the anal fin. Similar grooves behind the pectoral insertion are the rule when the rays support luminous material, as in Chirostomias and Grammatostomias.

9. OSTEOLOGY: In the accompanying diagrams of osteology, we do not include, except for Bathophilus which will serve as an example, any dorsal views of skulls, since they have been figured already for most genera by Regan \& Trewavas (1930). The same is true of the vertebral column. We have verified their findings in so far as possible, although the boundaries of skull bones are difficult to determine in cleared and stained examples of this family, the majority of which are immature. Our only major difference is that we have found the post-temporal to be present in a number of genera in addition to Chirostomias and Trigonolampa (see below). The following remarks and comparisons are necessarily derived only from cleared specimens of genera in the present collection, combined with the observations of Regan \& Trewavas on apparently uncleared examples.

The skeleton of melanostomiatids is moderately well developed, but with apparently little calcium phosphate deposit and a great deal of calcium carbonate, judging from its usually feeble reaction to calcium phosphate stain.

In all general features the skeleton of Idiacanthus is typical also of that of the melanostomiatids, especially of the group including Melanostomias. We refer, therefore, to the detailed description of Idiacanthus already published in this series (Beebe, 1934). Due to the unsatisfactory reaction of most of the fish to alizarin stain, we can say little about relative degrees of ossification, both between genera at different growth stages and within the species. It is obvious, nevertheless, that as usual in deep-sea fish the jaws are the only really strongly ossified parts of the body, the gill-arches usually come next, then the tip of the caudal peduncle, while the skull proper, the rest of the vertebral column and the supports of the vertical fins are ossified very late, and then usually weakly. No ossification is ever found before transitional adolescence.

Head: The lack of parietals in most genera; the union of the frontals by suture; the mesethmoid usually with lateral expansions; the upward, median projection of the premaxillary in all except Leptostomias; the reduced, laminar mesopterygoid; and the weak opercular apparatus are the principal characteristics of this family. The skull, especially in Melanostomias and Photonectes, is very short in comparison with the length of the jaws. The hyoid and gill-arches in some genera, especially Eustomias and Photonectes, are also very short. The single supramaxillary (not differentiated from the maxillary in Text-fig. 11, varies in its boundaries and degree of attachment to the maxillary; the relative lengths of premaxillary 

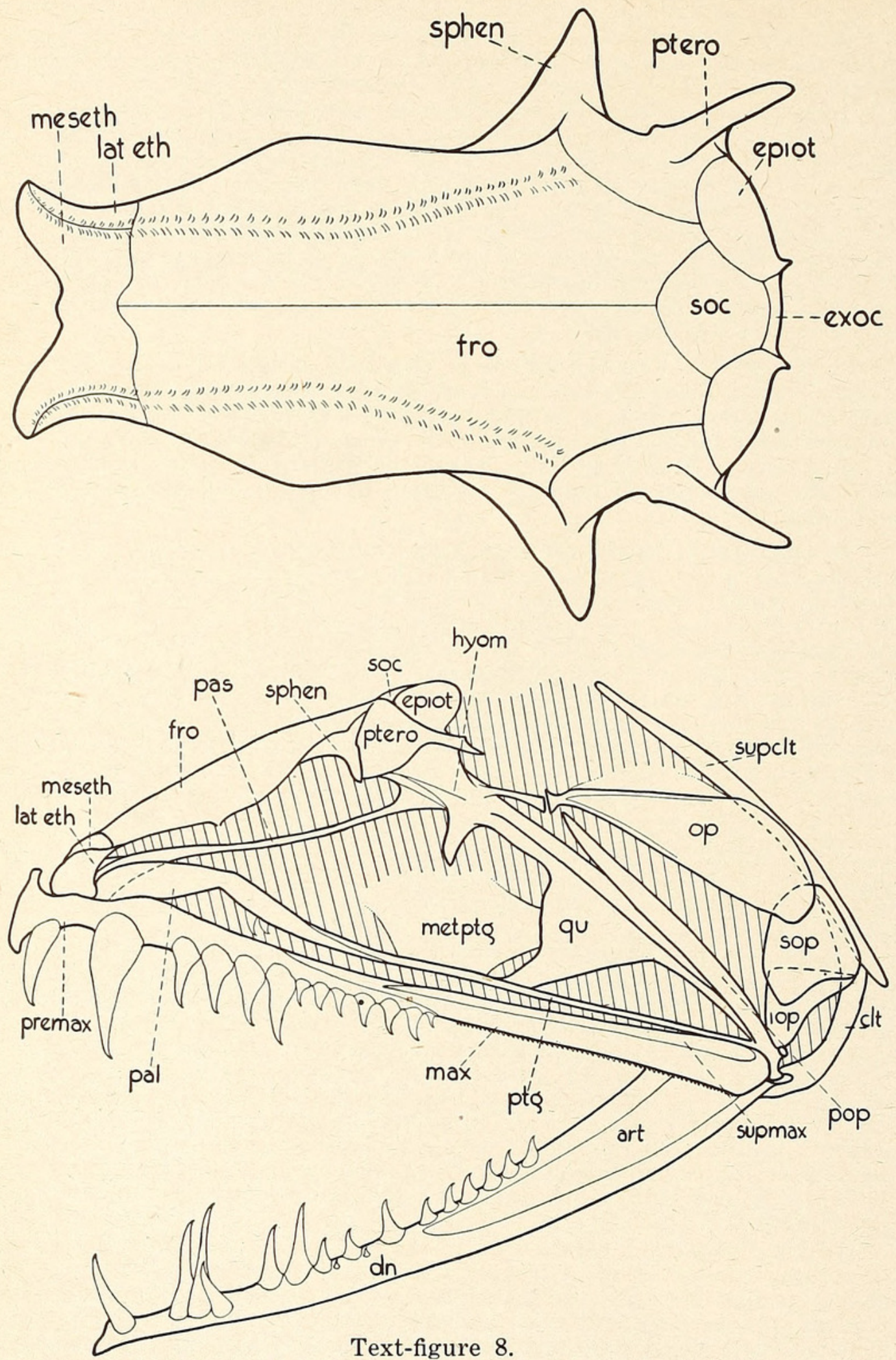

Bathophilus metallicus. Skull. Upper, dorsal view; lower, lateral view. Standard length $105 \mathrm{~mm}$ Boundaries of bones approximate. General facies typical of the Melanostomiatidae. art, articular; clt, cleithrum; dn, dentary ; epiot, epiotic ; exoc, exoccipital; fro, frontal; hyom, hyomandibular; iop, interopercle; lat eth, lateral ethmoid : $\max$, maxillary; meseth, mesethmoid; metptg, metopterygoid; op, opercle; pal, palatine; pas, parasphenoid; pop, preopercle; premax, premaxillary; ptero, pterotic; ptg, pterygoid; $q u$, quadrate; soc, supraoccipital; sop, subopercle; sphen, sphenotic; supclt, supracleithrum; supmax, supramaxillary. 
and maxillary bordering on the gape also vary; the premaxillary is shortest in Chirostomias, Leptostomias and Photonectes margarita, longest in Eustomias. In the latter genus, the palatine and ectopterygoid are loosely attached by ligaments to the mesethmoid and quadrate respectively, but firmly fastened to the upper jaw; this arrangement permits the forward projection of the jaw. There are 3 hypohyals.

Pectoral Girdle: According to Regan \& Trewavas (1930) post-temporals are present only in Chirostomias and Trigonolampa. We have found small ones, however, brightly stained, but not connected with the skull, in Flagellostomias, Leptostomias and Echiostoma. In addition vestigial slivers (sometimes absent on the opposite side of the same specimen) are occasionally found in Photonectes. The supra-cleithrum is reduced in Melanostomias and Photonectes and entirely absent in Eustomias. The mesocoracoid is usually present, but sometimes has the upper arm reduced, and is entirely absent in Eustomias and Photonectes. Upper and lower coracoids usually well developed, laminar. The actinosts tend to be reduced in number and of peculiar shapes and positions, corresponding to the various modifications of the pectorals. The rays themselves are laminate and strongly ossified basally in Grammatostomias, doubtless to support the weight of the luminous tissue.

Vertebral Column: Regan \& Trewavas have already described and figured the extraordinary modifications in the anterior part of the vertebral column in some of the melanostomiatids. Chirostomias and Trigonolampa alone are completely unmodified, with the first centrum fixed firmly to the skull. Most genera have the first one or two centra represented only by spinal nerves, there being a tough fibrous sheathing around the notochord. Leptostomias has similar modifications of seven vertebrae and Eustomias is the extreme with 9 or 10 specially adapted. The use of the modification in all, of course, is for the increase of the gape in grasping prey; the separation of the post-temporals from the skull and their atrophy are closely connected with this adaptation.

Posterior Part of Vertebral Column and Caudal Fin: The last 2 or 3 vertebrae before the urostyle are the first to be markedly modified, with prolonged neural and haemal arches reinforced with laminar expansions. There are 6 hypurals, 3 dorsal and 3 ventral to the median axis. Each gives rise to from 2 to 5 rays, the fifth and third hypurals being usually broadest, and supporting the most rays. This part of the vertebral column often becomes ossified before the rest. The sequence of raylets and rays, counting from the anterior dorsal raylet around to the corresponding ventral one, is as follows: 5 to $10+9$ to $11+9$ to $10+3$ to 5 ( $i$. e., 18 to 21 true rays).

10. CoElomic ORgans: The general plan of the body cavity of melanostomiatids is identical with that found in female Idiacanthus (Beebe, 1934.1, p. 218, fig. 75). The stomach varies from about $20 \%$ to $45 \%$ of the length of the fish, being shortest in Leptostomias, longest in Echiostoma. A straight intestine with two pyloric caeca is the rule, although in Chirostomias and Pachystomias the caeca are rudimentary, and in Opostomias, Flagellostomias, Thysanactis and Leptostomias an anterior pouch gives rise to a single caecum; in Odontostomias there is a second caecum in addition to the pouch structure.

The great posterior extension of the gut, free of the body during the larval stage, is apparently confined to and characteristic of all of the Gymnophotodermi. This phenomenon is probably a specialization connected with the lack of the yolk sac at this stage plus the absence of a stomach; therefore the gut is large in diameter and projects behind, so as to give additional absorptive surface. Sometimes it is more or less gathered in humps in the middle of its length, which accordingly presents still more digestive area. Subsequently, during the post-larval shrinking period, it is gradually absorbed.

The stomach is certainly never large enough to be used until the 

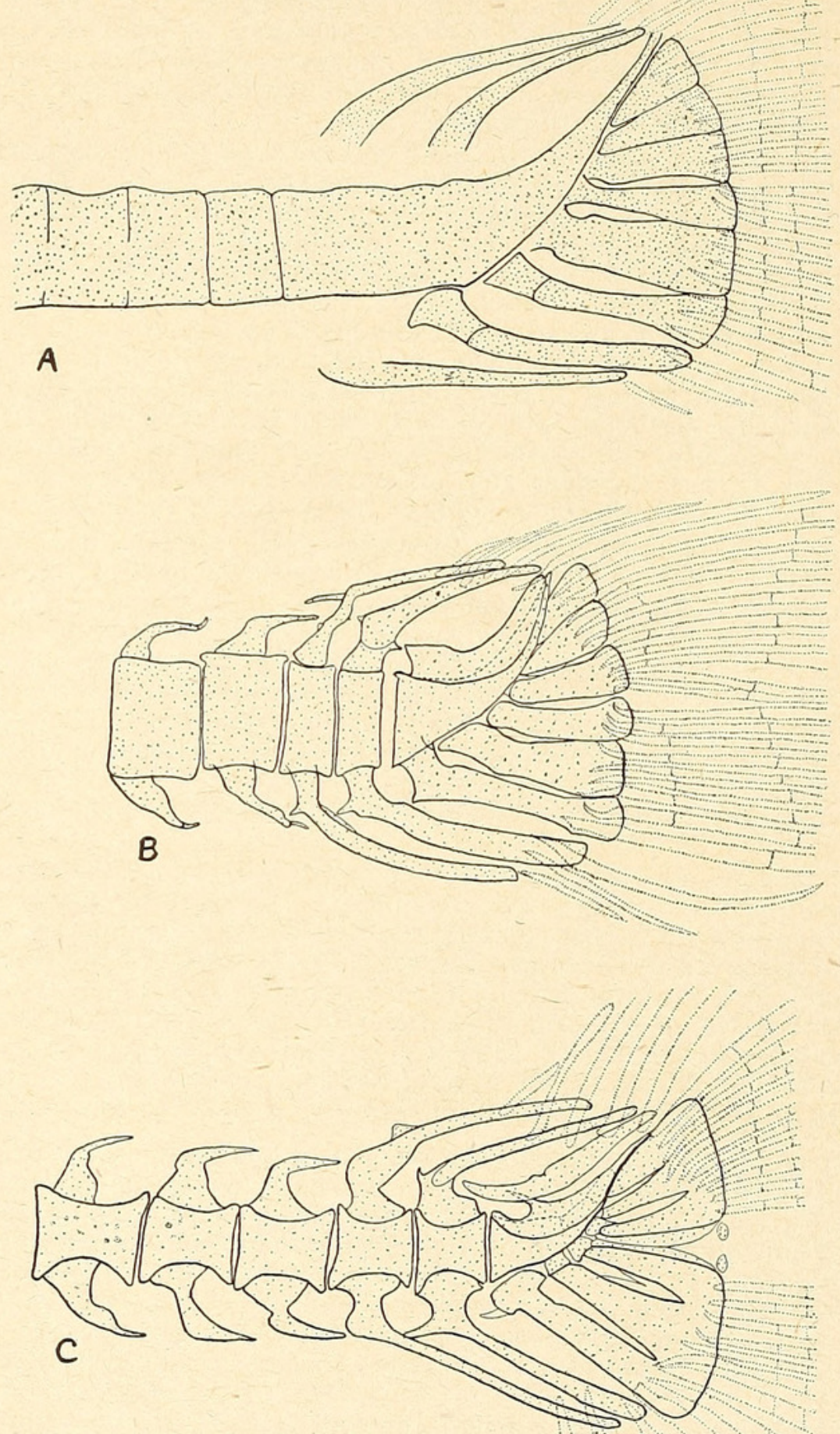

Text-figure 9.

Bathophilus metallicus. End of vertebral column in $\mathbf{A}$, post-larva, standard length $25 \mathrm{~mm}$.; B, adolescent, $30 \mathrm{~mm}$.; and C, transitional adolescent, $96 \mathrm{~mm}$. Principal characteristics typical of the Melanostomiatidae. 

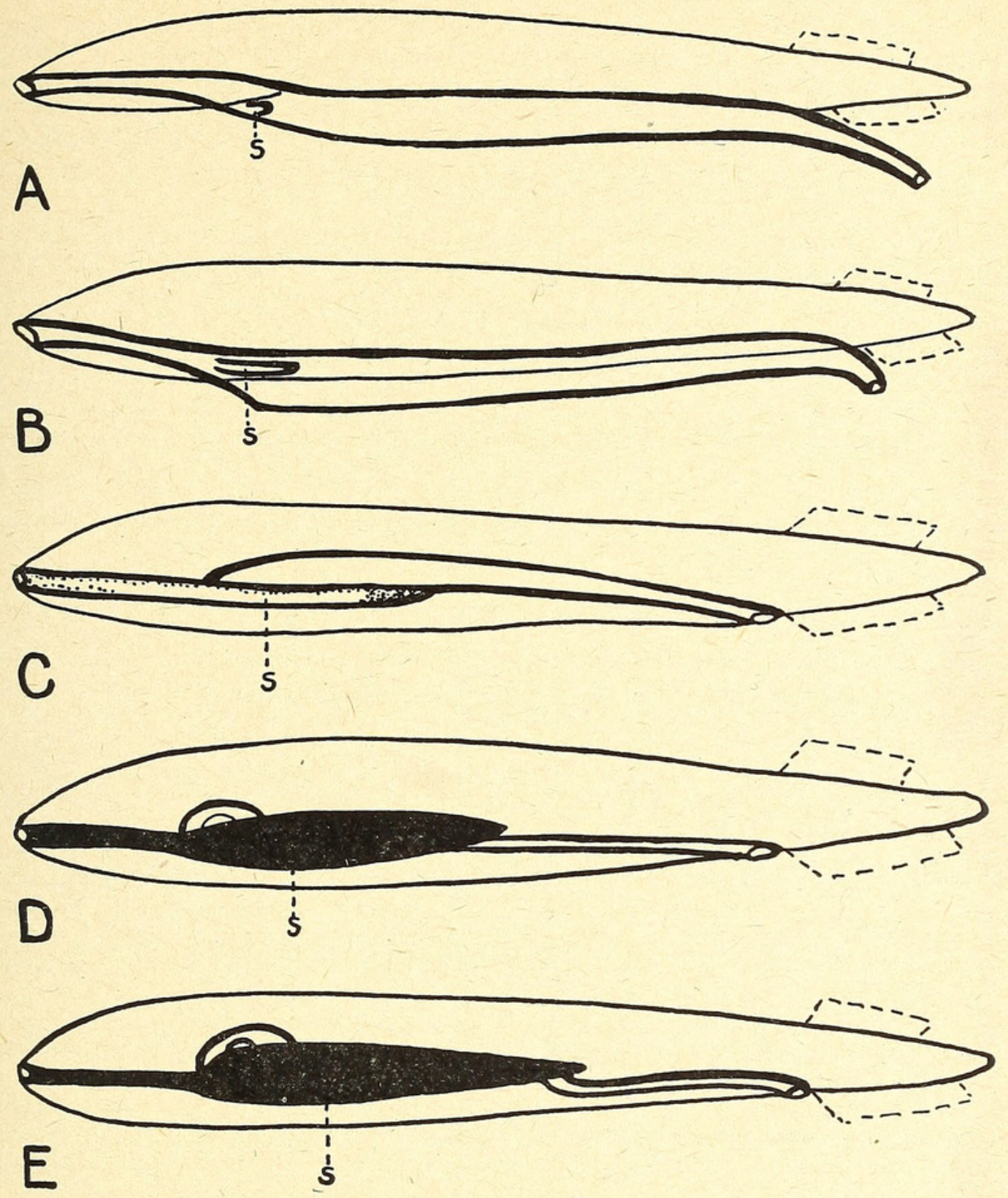

Text-figure 10.

Melanostomias spilorhynchus. Diagrams showing relative lengths of stomach and intestine, and position of anal fin, in respect to standard length. A, larva, standard length $17 \mathrm{~mm}$.; B, post-larva, $24 \mathrm{~mm}$.; C, adolescent, $31 \mathrm{~mm}$.; D, transitional adolescent, $35 \mathrm{~mm}$.; E, adult, $222 \mathrm{~mm}$. This series is typical of the Melanostomiatidae.

adolescent stage. It does not reach its full pigmentation and length until sometime during transitional adolescence-often very late in the stage (as in Leptostomias and Flagellostomias) and is one of the most useful means of determining immaturity.

The gonads also develop very tardily, and we have not found it possible to distinguish sex earlier than transitional adolescence. When the gonads have developed to more than transparent ribbons of tissue, it is easy to determine the sex, since the eggs of the female are distinct from the very first, whereas testicular tissue is in contrast superficially homogeneous. However, in adults near breeding condition ripe testicles can easily be mis- 
taken for unripe ovaries by workers not familiar with the group, since the testicles have a semi-granular appearance similar to that of partially developed ovaries in certain other fishes. However, dissection and microscopical examination at once disclose their true nature. On the other hand, under low power, the ovaries of immature fish often resemble testicles; therefore a small piece of gonad should always be dissected and high power used, to avoid mistakes in this important subject.

11. SHRINKING: Reduction in length during the post-larval, metamorphosing stage appears to be relatively slight in the melanostomiatids, compared with that found in Chauliodus, in Stomias and in eels. We have found no evidence in the present material that more than $10 \mathrm{~mm}$. in length is lost during this period. Whereas the reduction in length in eels takes place during early adolescence, in this family it occurs chiefly during the post-larval period.

It may be stated here that good-sized melanostomiatids, around 300 $\mathrm{mm}$. in length, shrink up to $20 \mathrm{~mm}$. after preservation in $70 \%$ alcohol, and specimens of other lengths in proportion. There is a corresponding loss of depth, usually greater in proportion than the length; the head, eye and snout shrink little, however. Measurements given in the following pages, unless otherwise stated, are made from preserved specimens.

\section{E. ECOLOGY.}

1. Horizontal Distribution: Only 7 of the 16 genera of Melanostomiatidae have been taken outside the Atlantic Ocean: Opostomias and Tactostoma, known only from Australia and the eastern Pacific, respectively; Leptostomias, from Hawaii and both North and South Atlantic; Pachystomias, from Australia and the North Atlantic; Photonectes, from Japan and the North Atlantic; Melanostomias, from the Indian Ocean and both North and South Atlantic; and Bathophilus, from the Indian Ocean and both North and South Atlantic. Odontostomias, Echiostoma, Flagellostomias and Eustomias are known from the North and South Atlantic. The remaining genera-Trigonolampa, Chirostomias, Thysanactis, Grammatostomias and Pareustomias - have so far been taken only in the North Atlantic. Some genera will doubtless be found to have a wider distribution when intensive trawling is carried out in other oceans.

Ten of the genera or $62 \frac{1}{2} \%$ have been taken by the Bermuda Expeditions. These include every genus previously recorded from the western Atlantic except Thysanactis and Trigonolampa, the former being apparently a tropical form and the latter boreal. Of the remaining four genera, two (Odontostomias and Pareustomias) are known from the eastern Atlantic only; while Opostomias and Tactostoma, as remarked above, have been taken only in the Pacific.

For observations on the distribution of species, see Regan \& Trewavas, 1930, p. 34. The absence of Trigonolampa, Bathophilus pawneei and several species of Melanostomias in the Bermuda collection is added evidence to their suggestion that these forms are tropical and Antillean, rather than subtropical, in distribution.

It seems worthwhile to reemphasize the fact that the 250 specimens, 32 species and 10 genera composing the present collection, and forming respectively more than a sixth, a third and five-eights of the known specimens, species and genera, were all obtained in what is scarcely more than a drop of water in the Atlantic Ocean: in an area 5 miles south of Nonsuch Island, Bermuda, 8 miles wide and 1 mile deep.

2. Vertical Distribution : As is the case with other families of deep-sea fish, the melanostomiatids around Bermuda seem to live at greater depths than elsewhere. Excluding a few colorless larvae, members of the family were not taken in the trawling nets above 300 fathoms (549 metres), and 
most were taken far below this level, between 500 and 1,000 fathoms (914 to 1,829 metres, whereas other expeditions, notably the Dana, took a great number of specimens "with nets fishing at 200 metres or less below the surface" (Regan \& Trewavas, 1930, p. 34). Thanks to our tests with the pressure gauge (Beebe, 1930, p. 244), we are convinced that the great majority of the Bermuda specimens were taken at the level trawled, and not when the net was on the way to the surface. Because of Bathysphere observations, however, it is also clear that these families are not absent from the upper layers here, but can merely avoid the net better, because of the fact that some light penetrates to these depths. From the Bathysphere, in its dives between the surface and 3,028 feet, members of the family were recognized 26 times, between 750 and 2,750 feet ( 125 and 458 fathoms or 228 and 835 metres), ranging in length from one inch to six feet (counting the six-foot Bathysphaera intacta).

Larvae and post-larvae were taken in the nets between the surface and 1,000 fathoms; it is likely that the few taken at the greater depths were among the minority caught on the way upward.

3. ABUNDANCE: About 1,450 specimens of Melanostomiatidae have been taken, including the 250 in the present collection. The total number is distributed among 16 genera and, in the light of the synonymies proposed in the present paper, about 115 species. We are certain, however, that many of these, especially in the genera Leptostomias and Eustomias, will prove to be invalid, so that the total number of true species known at present comes actually to considerably under 100 .

In numbers of individuals, Bathophilus and Eustomias, with about 500 and 400 specimens, respectively, are the most abundant; Echiostoma, Melanostomias and Photonectes are each known from between 100 and 160 specimens, and Leptostomias from 49 ; less than 25 examples have been taken of every remaining genus. The best known species are Eustomias obscurus and Bathophilus metallicus, of which about 200 and 185 specimens have been taken, respectively.

Melanostomiatids are among the rarest groups of deep-sea fishes taken off Bermuda. In contrast to the thousands of Cyclothone, myctophids and Sternoptyx taken, a total of only 250 melanostomiatids came up in the nets, belonging to 10 genera and 32 species. Of these, Melanostomias spilorhynchus, of which we have 51 specimens, was the most numerous, Photonectes dinema (26 specimens) next, Bathophilus metallicus (22 specimens) third, and Leptostomias gladiator ( 20 specimens) fourth. Of the remaining species, a dozen are represented only by single examples.

In regard to number of species, as opposed to individuals, the Melanostomiatidae are surpassed in the collection only by the Myctophidae, of which about 57 species were taken, as opposed to the 32 species of the present family.

It is interesting to note that in number of individuals it is the plankton eaters-Cyclothone, myctophids and sternoptychids-that are numerically far ahead of eaters of fish and shrimps, such as the large-toothed stomiatoids (Stomias, melanostomiatids, Chauliodus, astronesthids, Idiacanthus), the lyomerids, large-mouthed pediculates, Chiasmodon, etc., just as on land, large carnivores are surpassed in numbers by their herbivorous prey, such as rodents and ungulates.

4. Food AND EnEmies: The food of melanostomiatid larvae is, of course, confined to small organisms such as diatoms and copepods. Toothless, transforming, post-larvae and adolescents, however, probably do not eat at all for a short while; at least, we have found no food in their intestines. Transitional adolescence, however, is again a period of growth, the stomach is well developed, and the food represents on a small scale the food of adults, namely myctophids and other small fish, and good-sized shrimp. 
Although more than 40 stomachs of transitional adolescent and adult melanostomiatids were examined, less than half contained any food at all, although finely digested matter was usually present in the intestine. The likelihood is that these strong fishes digest their food rapidly, even just before death. Myctophids were present in nine stomachs, unidentified small fish in three, Luciosudis in one, Cyclothone microdon in one, a shrimp in one, and ostracods in one. Without exception the fish were swallowed whole, head first, and measured one-half to five-sixths the length of the melanostomiatid.

We have not found melanostomiatids in the stomach of any Bermuda fish. A specimen, the second known, of Trigonolampa was, however, found in the stomach of a swordfish (Parr, 1933, p. 178).

5. Activity : From the Bathysphere these fish appeared agile and eel-like, with rather slow twistings in progression. None of them seemed to be affected by the search-light. Usually only one of these fishes was seen at a time, but occasionally two or three appeared swimming together. When brought up alive they swam about and snapped with all the accuracy of balance and swiftness of surface fish. As with other living deep-sea fish, they would try to burrow downward, bumping their snouts against the bottom of the pan. Always they could be greatly revived by being placed in a pan of ice-cold salt water in the refrigerator. A young Pachystomias atlanticus, $37 \mathrm{~mm}$. long, was the smallest member of the family, and, in fact, the smallest deep-sea fish, taken alive.

\section{F. Phylogeny.}

We agree with Parr (1927, p. 4) and Gregory \& Conrad (1936, p. 23 , fig. 2) that an astronesthid-like form or forms were the ancestors of the Gymnophotodermi, and hence of the Melanostomiatidae. In common with the more primitive stomiatoids, the Astronesthidae have fixed teeth, unspecialized fins and vertebral column, and an adipose fin. Yet they have the barbels, well developed postorbital organs and naked black skin of the Gymnophotodermi. Parr pointed out the variability of the position of the dorsal fin in the Astronesthidae. The later work of Regan \& Trewavas (1929) showed the diversity of other characters in the same family-characters which are found in similar diversity in the Melanostomiatidae, such as the form of teeth on the maxillary and gill-arches. All erect maxillary teeth are found in several astronesthid genera, exactly as in the melanostomiatid Chirostomias, whereas all oblique teeth occur in others-as in the more specialized melanostomiatids. Similarly, both double and single gillarch teeth occur in the family, just as in the Melanostomiatidae. Double gill-teeth are found as well far down the stomiatoid scale in Photichthys, whereas single, raker-like teeth and actual spiny rakers occur in such genera as Gonostoma, as well as in melanostomiatid larvae. In summary, the existing genera of Astronesthidae show all the elements needed by a hypothetical ancestor of the Melanostomiatidae - the various types of maxillary and gill-teeth, a variable dorsal fin trending backwards, and unspecialized finrays, combined with the already specialized naked black skin, barbel and well-developed postorbital organ. The remaining Gymnophotodermi-the Idiacanthidae and Malacosteidae-are doubtless off-shoots of the Melanostomiatidae.

As a family, the Melanostomiatidae have specialized in slenderness, with increased numbers of vertebrae and elongation of the stomach, in elaborate and elongate barbels, in sexual dimorphism in the development of the postorbital cheek light, in specialized luminous or elongate pectoral fins, in the acquisition of depressible teeth, in the reduction and loss of parietals, in the reduction of the opercles and pectoral girdle, in modifica- 


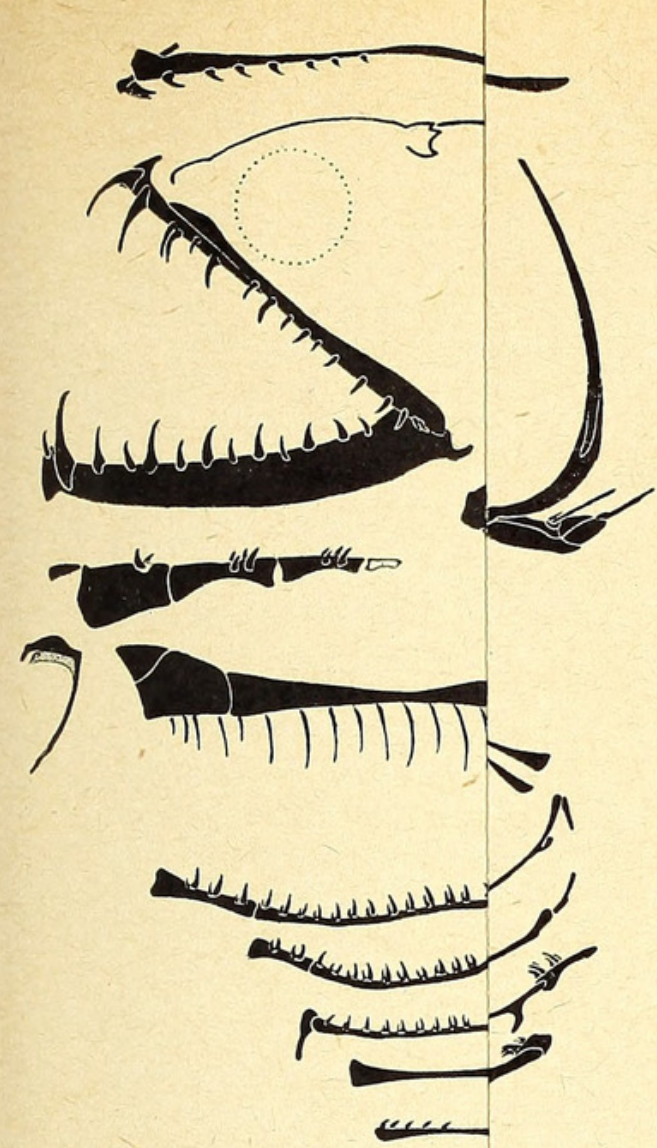

Chirostomias plioplicus.

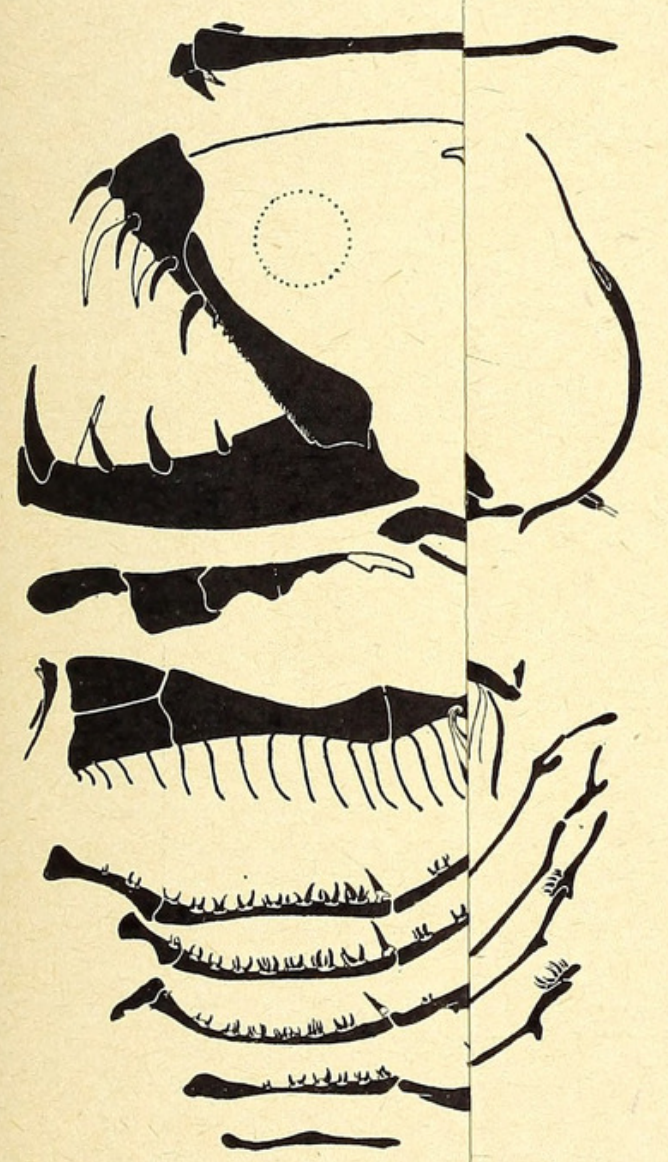

Leptostomias bermı (yg.).

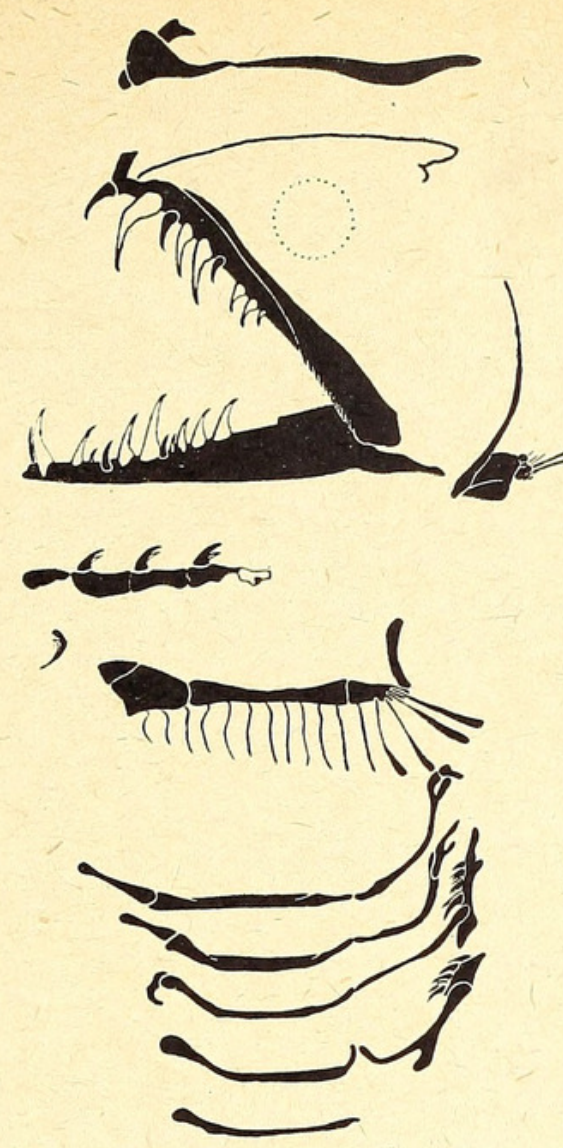

Eustomias fissibarbis.
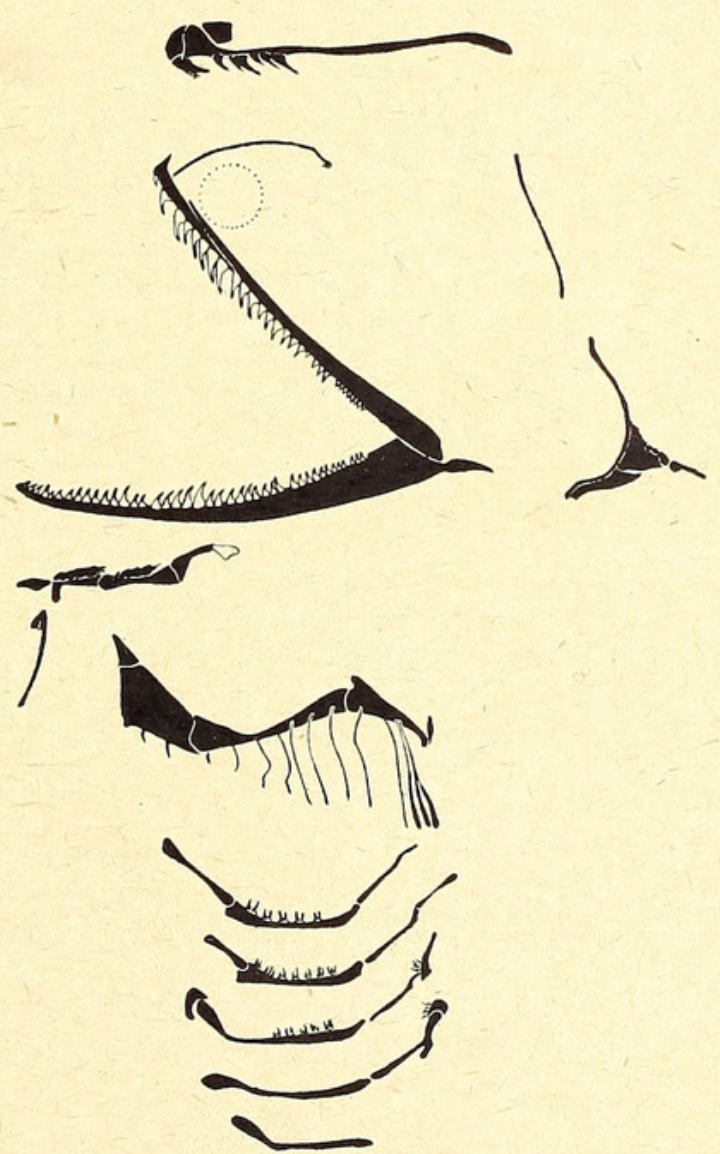

Photonectes margarita. 


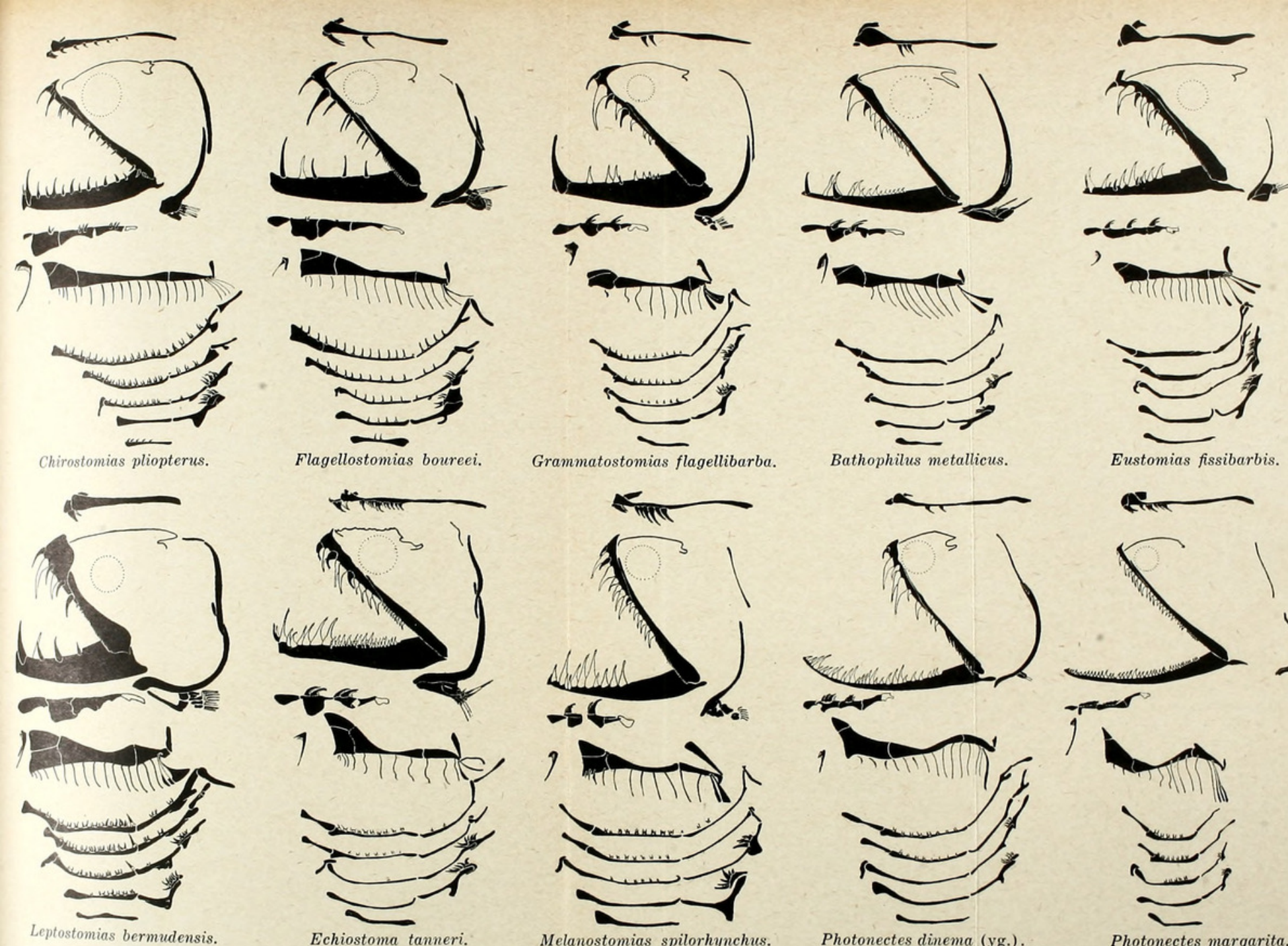

Grammatostomias flagellibarba.

Bathophilus metallicus.
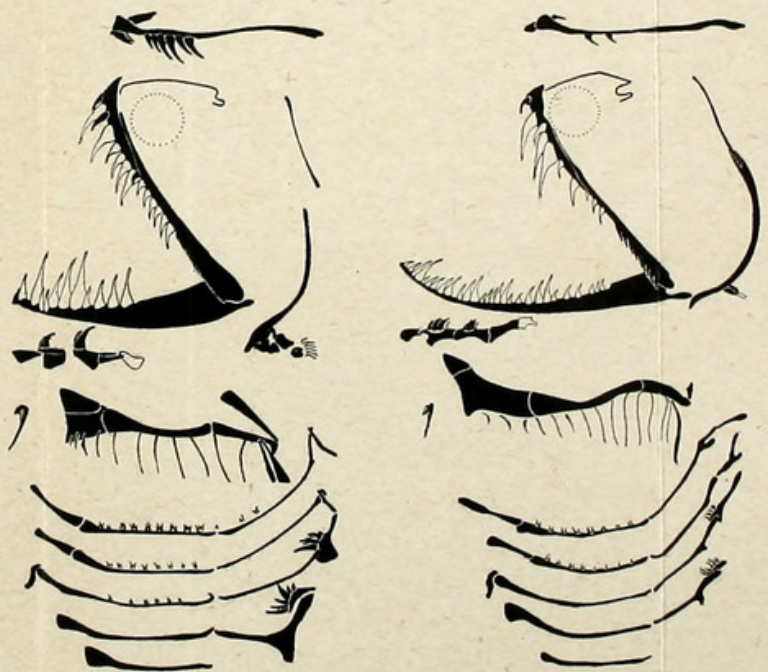

Eustomias fissibarbis.
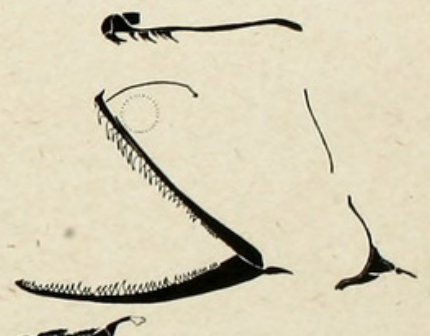

Echiostoma tanneri.

Melanostomias spilorhynchus.

Photonectes dinema (yg.).

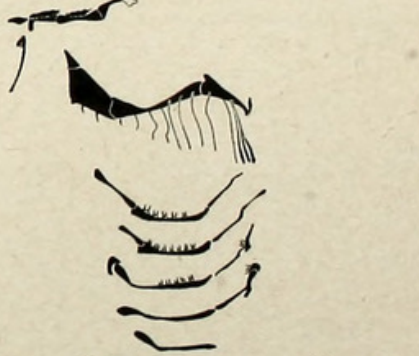

Text-figure 11.

Photonectes margarita.

Jaws, hyoid and branchial arehes, and pectoral girdles of typical Melanostomiatidae. Depressible jaw-teeth unshaded; divisions between palatine and pterygoid, and maxillary and supramaxillary not shown; fourth basibranchial, always unossified, unshaded. For the same illustra
Text-figs. $13,18,23,28,33,34,45,50,55$ and 64. 

tions of the anterior part of the vertebral column, and in the shortening of the caudal peduncle and fin.

Primitive, Specialized and Adventitious Characters: In determining the relationship of the genera to one another, the following characters may unquestionably be considered primitive, with their roots far back in the stomiatoid stock, since they are the rule among the more primitive of existing stomiatoids: Fixed, barbless teeth; an adipose fin; pectoral girdle well developed with a strong post-temporal and a related lack of modification in the anterior part of the vertebral column; pelvics near the middle of the body; parietal present; single or double gill-arch teeth strongly developed, present on all five, or at least four, arches, including hypobranchials and epibranchials as well as ceratobranchials.

The following characters, on the other hand, prove to be of almost no use in determining relationships, since each of them varies greatly, not only in closely related genera, but even within the same genus: body proportions, notably depth and head length; (examples: Leptostomias, Bathophilus) ; barbel length and form (example: Eustomias); pectoral development (example: Bathophilus, Eustomias); presence and distribution of superficial luminous tissue (examples: Photonectes, Bathophilus). Also, these variable characters crop out in specialized form in the most primitive genera, and vice versa. For example, Chirostomias, unquestionably the most primitive genus in the family in fundamental structural characters, is equipped with a highly complex barbel and pectoral fin. Similarly, Bathophilus and Tactostoma, two of the most specialized end-genera, have simple or degenerate barbels.

Several distinct characters may be termed adventitious, since they occur sporadically throughout the family and, indeed, throughout the stomiatoids as a whole. Such are grouped serial photophores, which are common among the gonostomids and sternoptychids, and present in the astronesthid Heterophotus, in the malacosteid Aristostomias and in the melanostomiatids Pachystomias, Eustomias obscurus and Pareustomias. A more or less elongate anal fin, present in Flagellostomias and Eustomias in the Melanostomiatidae and in other genera scattered through related families, is a similar character. An exceptionally high number of vertebrae is a third; among melanostomiatids Leptostomias, Tactostoma and Eustomias, although they have practically nothing else in common besides general family characters, all have many more vertebrae than the average of 50 to 60 .

The atrophy of the postorbital cheek light in females is a most puzzling character, since it does not, as far as is known, occur in lower stomiatoids, and yet is the rule in otherwise primitive melanostomiatids, while in females of the most specialized genera the organ is again functional and even (as in Melanostomias, Echiostoma and Photonectes) as large as in males.

Generic Interrelationships: We support in general the groupings of genera suggested by Regan \& Trewavas (1930). That is, we agree that Chirostomias and Trigonolampa are closely related and the most primitive known genera; that Leptostomias, Thysanactis, Flagellostomias and Opostomias along with Norman's Odonotostomias (1930) form a natural group intermediate in degree of specialization; that Bathophilus is close to Grammatostomias; that Melanostomias, Echiostoma and Photonectes are closely related; and that Pachystomias and Eustomias are both aberrant.

In addition, with our study of characters, such as gill-arch teeth and larval stages, other than those emphasized by these authors, we are able to give a tentative but plausible sketch of the relationships of the groups to each other. As we see it, Bathophilus could not possibly have come from a Chirostomias-like form except insofar as such a form was probably ancestral to the entire family, nor Eustomias from an Echiostoma-like fish- 
Echiostoma itself being one of the most specialized genera, and not at all on the same line of development as that followed by Eustomias. Both of these suggestions have been made by Gregory \& Conrad (1936, p. 26). Parr's (1927) pioneering suggestions as to relationships within the group have of course been largely superseded by the osteological study of the large Dana collection.

From the accompanying diagram (Text-fig. 12) it will be seen that we recognize a number of generic groups, with Tactostoma on the one hand and Bathophilus and Pareustomias on the other as the most specialized end forms in the Melanostomiatidae. The family shows a natural division into genera in which the gill-arch teeth are paired, and those in which they are single or absent. Another main division is into the primitive forms with all of the jaw teeth fixed, and the remaining genera, in which at least a few are depressible. We will now consider the various groups in detail.

Chirostomias, Trigonolampa: These genera, both having paired gillarch teeth, are, as has been said, the most primitive. Their basic, generalized characters are fixed teeth, well-developed parietals, numerous gill-teeth, unspecialized vertebral column, short stomach, strong post-temporal and pectoral arch and, in Chirostomias, an adipose fin. In contrast, the variable characters of barbels and pectoral fins are highly specialized. The postorbital organ is completely atrophied in the female in Chirostomias; its condition in female Trigonolampa is unknown.

Pachystomias, with its small, fixed teeth and unspecialized fins, is placed next on the tree. As Parr, judging only from external appearances, suggested (1927), we think it is close to the line of malacosteid development, with its somewhat similar suborbital lights; exceptionally large, massive head; strong, backwardly-extended jaws joined by only a thin membrane; its general shape and fin arrangement; and its single-gill-arch teeth. In the malacosteids the gill-teeth are single or absent, teeth in the jaws are fixed, the jaw membrane is entirely absent, and the grouped photophores of Aristostomias are similar in pattern to those of Pachystomias. The absence of parietals, post-temporals and pyloric caeca are other characters in common, and although the skulls are dissimilar, they present no significant differences to preclude relationship. The development of the postorbital light organ in females is unknown in Pachystomias.

Odontostomias, Thysanactis, Leptostomias, Opostomias, Flagellostomias: These genera form the somewhat heterogeneous base for the remaining melanostomiatids, just as the dissimilar Astronesthidae form a similar base for the more specialized of the Gymnophotodermi. The five genera have in common the primitive and semi-primitive characters of parietals, massive head and jaws, few depressible teeth, a pair of teeth on the vomer, many gill-teeth on four or five arches, moderately short stomachs, rudimentary caeca, and, with the exception of Thysanactis and Leptostomias, a vertebral column almost unmodified anteriorly, but usually with many vertebrae. We have found small but well ossified post-temporals, not connected with the skull, in both Flagellostomias and Leptostomias; these bones were not discernible in the Dana specimens described by Regan \& Trewavas (1930), probably because those specimens were not cleared and stained; the bone may prove to be present in all five genera. The postorbital organ is atrophied in the adult female at least in Odontostomias, Leptostomias and Flagellostomias. It is probable that the members of this group attain maturity at a greater length than others in the family.

There is a natural division into two sub-groups, the first (Odonotostomias, Thysanactis and Leptostomias) having the gill-teeth paired or in threes and fours on all arches except the last, and the second (Opostomias and Flagellostomias) with all the gill-teeth single. The ancestors of the first division probably gave rise to the Echiostoma-Melanostomias-Photonectes-Tactostoma group, while from Opostomias-Flagellostomias roots came 


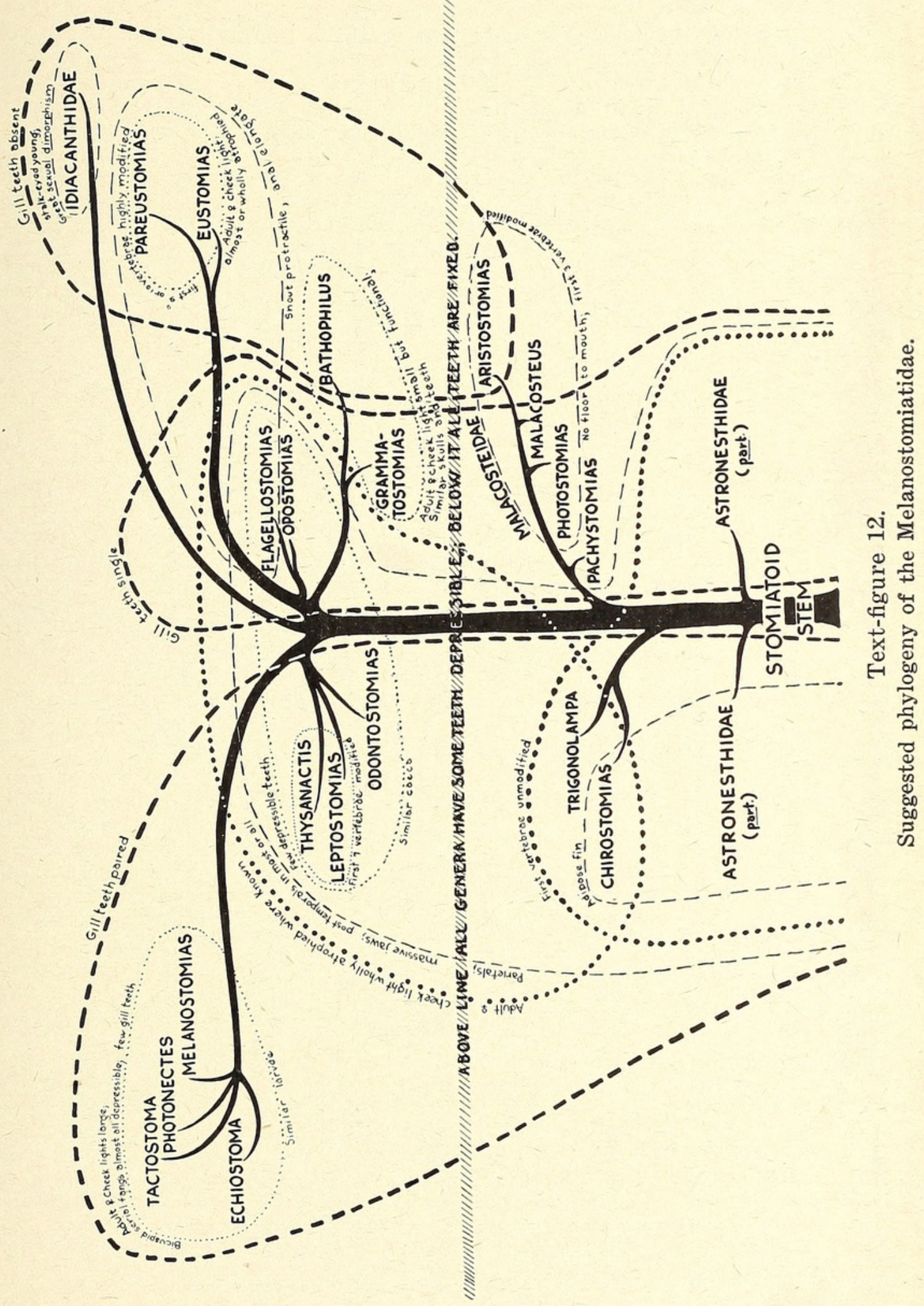


offshoots ending today in Grammatostomias and Bathophilus and in Eustomias and Pareustomias.

Echiostoma, Melanostomias, Photonectes, Tactostoma ${ }^{3}$ : These four genera have in common large but usually slender jaws with numerous teeth, almost all depressible, and with strongly barbed tips; paired or grouped teeth in reduced numbers on only two or three gill-arches; similar, very short skulls without parietals; post-temporals reduced or absent and the rest of the pectoral girdle weakened; anterior part of vertebral column slightly modified; a long stomach with two well-developed caeca; and pelvic inserted far behind the middle of the length. In Melanostomias, Echiostoma and Photonectes the cheek light is exceptionally and equally large in both males and females, apparently the only genera in the family of which this is true, and the larvae are very similar. (Neither of these characteristics is known as yet in Tactostoma, except that the postorbital is not large in the known specimens). Echiostoma and Tactostoma are the only genera in the family having the teeth multi-rowed, although the single rows of other genera are rarely perfectly regular). The teeth of adult Photonectes and of Tactostoma are small, but those of immature Photonectes bear a striking resemblance to those of adult Melanostomias (Text-fig. 9). In all except the latter genus the barbel tends to reduction, being better developed in the young than in the old, and vestigial in Tactostoma.

Grammatostomias, Bathophilus, Eustomias, Pareustomias: The first two and the last two form closely related sub-groups; in fact, Pareustomias may prove to be a sub-genus of Eustomias. Grammatostomias is the only genus in which any gill-teeth at all are found, and these are few and single. Parietals and post-temporals are absent, teeth (except in some Eustomias) are mostly depressible, moderately large and sometimes with rudimentary barbs; stomach moderately elongate; two caeca; postorbital light organs usually large in male, always smaller, sometimes atrophied, in female. Bathophilus is highly specialized in development of fins and body depth, with vestigial serial organs. The semi-primitive genus Flagellostomias has the beginning of the protractile snout which is carried to such high development in Eustomias. There is a questionable trace of the same character in Grammatostomias. All the genera have a tendency toward elaborate barbels, either through simple elongation or through the development of ornate branches and filaments.

Comparison of Specialized End-Genera: Comparison of the two groups of off shoots from the five central genera is interesting. Group A (Echiosto$m a$, and its allies) has kept paired gill-teeth, while Group B (ending in Bathophilus and Pareustomias) has single, Flagellostomias-like gill-teeth or has lost them altogether. In both $\mathrm{A}$ and $\mathrm{B}$ the arch teeth, whether paired or unpaired, are reduced in number, being present at most on the first three ceratobranchials and first epibranchial. In Group A the jaw teeth become all depressible, more or less barbed and very numerous, the extreme being reached in the multi-rowed teeth of Tactostoma, and both the vomerine teeth $^{4}$ and an erect series on the maxillary are kept; in Group B a number of fixed teeth is always kept, the jaw teeth are never numerous, barbs are rudimentary or absent, and both vomerine teeth and erect maxillary teeth are lacking. In Group A the skull is reduced, although there is no jaw reduction, while in Group $B$ the skull remains little shorter than the jaws, as in primitive genera. In both groups the pectoral girdle is reduced, and the anterior part of the vertebral column modified to allow a backward and upward movement of the head, increasing the gape. Sometimes there is a forward thrusting of the lower or upper jaw in capturing food. In Photonectes the curved lower jaw is dislocated and thrust forward, while in Eustomias it is the snout and upper jaw. The pelvics are inserted far back in Group A, while in Group B they have remained near the middle of the

3 Osteological and internal characteristics not yet known in Tactostoma.

4 Except in Tactostoma. 
body. In Group A the barbel tends toward secondary reduction approaching atrophy, while in Group B are found the most elaborate and elongate barbels in the family. Both groups have elongate stomachs and two well-developed caeca.

On the chart the Idiacanthidae are shown as a highly specialized offshoot of the main melanostomiatid stock. The skull and teeth are similar to those of Melanostomias, while the general form, lack of gill-arch teeth, shape and pigmentation of the larva, and unequal development of the postorbital organ in males and females show some resemblance to the Flagellostomias-Eustomias axis.

Conclusions: Most of the specializations of the Melanostomiatidae, both beyond those of the lower stomiatoids and within the family, are in the direction of increased efficiency in the capture, swallowing and digestion of large, living prey. To this end, the body becomes elongate and streamlined with the vertical fins forming a single, powerful, swimming organ. The jaw teeth are enlarged, and efficiency is further increased through the development of depressibility and of barbs. Teeth on the vomer, palatines, basibranchials and gill-arches assume great functional importance. The gape is enlarged both by the flexibility of the jaw angle and by the modification of the anterior vertebrae and the related disconnection of the pectoral girdle from the skull, which enables the head and upper jaw to be swung backward and upward; through these devices the mouth can often be opened to an angle of fully 180 degrees. In addition, the upper jaw with its strong fangs can sometimes be thrust forward; in other cases a similar movement can be made with the lower jaw through the swinging forward of the elements of the hyomandibular arcade. In the genera having these highly specialized modifications, all teeth except those in the jaws themselves are reduced in size and number, in direct ratio: the greater the depressibility of the teeth, the modification of the vertebral column, and the distensibility of snout or mandible, the fewer the teeth on the roof and floor of the mouth. The stomach becomes elongate for the reception of large, whole prey, which is invariably swallowed head first.

Some specializations of luminous organs are probably also concerned in increased efficiency in the hunt for food, but the development of the postorbital organ, at least, is unquestionably of sexual significance, while the same is sometimes true of the barbel.

The following key to the genera of Melanostomiatidae attempts both to be of practical use and to indicate relationships.

\section{G. Synopsis of the Genera.}

A. All teeth in jaws firmly fixed.

B. Teeth on first gill-arch in pairs; parietal present; post-temporal present.

C. Adipose present

Chirostomias (p. 111).

CC. Adipose absent

Trigonolampa.

BB. Teeth on first gill-arch single, parietal absent; post-temporal absent Pachystomias (p. 117).

AA. Some teeth in jaws depressible.

D. Gill-teeth present at least on first 4 arches, and usually on all 5 ; lower jaw with only 1 or 2 depressible teeth; parietal present; post-temporal small or absent.

E. Gill-teeth on first arch mostly in pairs.

F. An isolated pectoral ray; gill-teeth present on 5th arch

Thysanactis.

FF. No isolated pectoral ray. 
G. Gill-teeth present on 5th arch; 32-35 O-V photophores

Odontostomias.

GG. Gill-teeth absent on 5th arch; $39-47$ O-V photophores

Leptostomias (p. 121).

EE. Gill-teeth on first arch single; an isolated pectoral ray.

H. Mandibular fangs perforating premaxillaries; dorsal and anal commencing at same vertical........ Opostomias.

HH. Mandibular fangs not perforating premaxillaries; anal commencing well in front of dorsal

Flagellostomias (p. 179).

DD. Gill-teeth never present on more than first 3 arches; sometimes absent; lower jaw with more than 2 teeth depressible (or, if only 2, the gill-arches are toothless); parietal absent; posttemporal rudimentary or absent.

I. Teeth on first gill-arch paired, or in groups of 3 or 4; vomerine teeth present; some erect teeth on maxillary; jaw teeth slightly or sharply bicuspid.

J. Pectoral of 5 or 6 normal external rays; post-temporal sometimes present Melanostomias (p. 142).

JJ. Pectoral of less than 5 rays.

K. Pectoral of 4 external rays, the first isolated and produced; cleft of mouth straight; post-temporal present Echiostoma (p. 130).

KK. Pectoral of 0 to 3 rays; cleft of mouth more or less strongly curved upward.

L. Jaw teeth in a single row; post-temporal sometimes present.......Photonectes (p. 154).

LL. Jaw teeth in many rows or groups; posttemporal?

Tactostoma.

II. Gill-teeth all single or entirely absent; no erect maxillary teeth; vomerine teeth absent; post-temporal absent; jaw teeth slightly or not at all barbed.

M. Gill-teeth present; a line or loop of luminous tissue on side ..............................

MM.Gill-teeth absent; no line or loop of luminous tissue on side.

N. Dorsal and anal beginning at same vertical; upper jaw not protractile; several teeth on palatines; supracleithrum present.

Bathophilus (p. 196).

NN. Anal originating well in advance of dorsal; upper jaw protractile; palatines toothless; supracleithrum absent.

O. Premaxillary normal.....Eustomias (p. 210).

OO. Premaxillary free of maxillary, curving upward above jaw line Pareustomias. 


\section{H. Report on the Collection of the Bermuda Oceanographic EXPEDITIONS, INCLUDING REVISIONS OF GENERA AND SPECIES.}

Genus Chirostomias Regan \& Trewavas, 1930.

(See also pp. 71, 73, 82-86, 90, 91, 96-99, 102, 104-106, 109). (Text-figs. $3,11,12,13-16$ incl.).

\section{GENERAL Discussion.}

Upon reexamination of the type specimen of Chirostomias lucidimanus Beebe, 1932, and comparison with immature specimens in the same Bermuda collection, we have decided to synonymize it with $C$. pliopterus Regan \& Trewavas, 1930, the only other species which has been described. Our reasons for this step are as follows:

1. The barbel differs from that of $C$. pliopterus only in a manner consistent with growth. The largest specimen described by Regan \& Trewavas was $115 \mathrm{~mm}$. long; $C$. lucidimanus measures $205 \mathrm{~mm}$.; the next largest Bermuda specimen measures $118 \mathrm{~mm}$. and is immature, with a barbel intermediate between that of lucidimanus and pliopterus; barbels of all small specimens ( 35 to $41 \mathrm{~mm}$.) in the Bermuda collection agree excellently with typical pliopterus. The greater length of the stem in the largest specimen, and the greater number of anterior bulb filaments, are both perfectly normal growth differences; it is possible that the third, rather surprising difference - that of the smaller number of posterior bulb filaments - is due to their being literally rubbed gradually away, by contact of the barbel bulb with the isthmus, when the barbel is laid back in its groove. Minor details may also be sexual characters, but since we have only one male, an immature 118 $\mathrm{mm}$. specimen, more material is needed in order to settle the question.

2. A recount of the dorsal fin rays in the type specimen of $C$. lucidimanus gives 18 rays, as in pliopterus, instead of 16 , as stated in the description of C.lucidimanus.

3. Although the eye of $C$. lucidimanus is relatively smaller than in pliopterus, this characteristic again may logically be attributed to the difference in size; in our intermediate, $118 \mathrm{~mm}$. specimen, the proportionate size of the eye is as in typical pliopterus.

Distribution: Chirostomias pliopterus, the single known species, has been taken only in the Atlantic Ocean north of $20^{\circ}$, at depths between 55 and 700 fathoms. Known altogether from 13 specimens, including the present series.

\section{GeNeRIC ChaRACTERS.}

(Since only one valid species is known in this genus, the following characters are also those of the unique species, $C$. pliopterus Regan \& Trewavas).

Color (from freshly caught immature male and two immature and 1 adult females, the adult being alive): General color, velvety black with greenish bronze iridescence on shoulder; iris black; postorbital organ of male white, rimmed dorsally with silver; barbel bulb white and silver with pinkish luminescence anteriorly, white posteriorly (see below under "Barbel"); this organ is greenish-yellow and silver in young females, with no glow observed; serial photophores violet, the lights of the lateral series having gilt caps divided into five successive small sections and, below the lights, single, undivided smaller patches of gilt.

Proportions: Moderately elongate melanostomiatids with adipose fin; depth in length 6 to 7.7 (13\% to $16.7 \%)$; head in length 5 to $6(16.7 \%$ to $20 \%$ ); eye in head 4 to 5.8 (2.9\% to $3.9 \%$ of length); snout to pelvic in length 1.7 to 1.9 ( $53 \%$ to $59 \%$ ). 


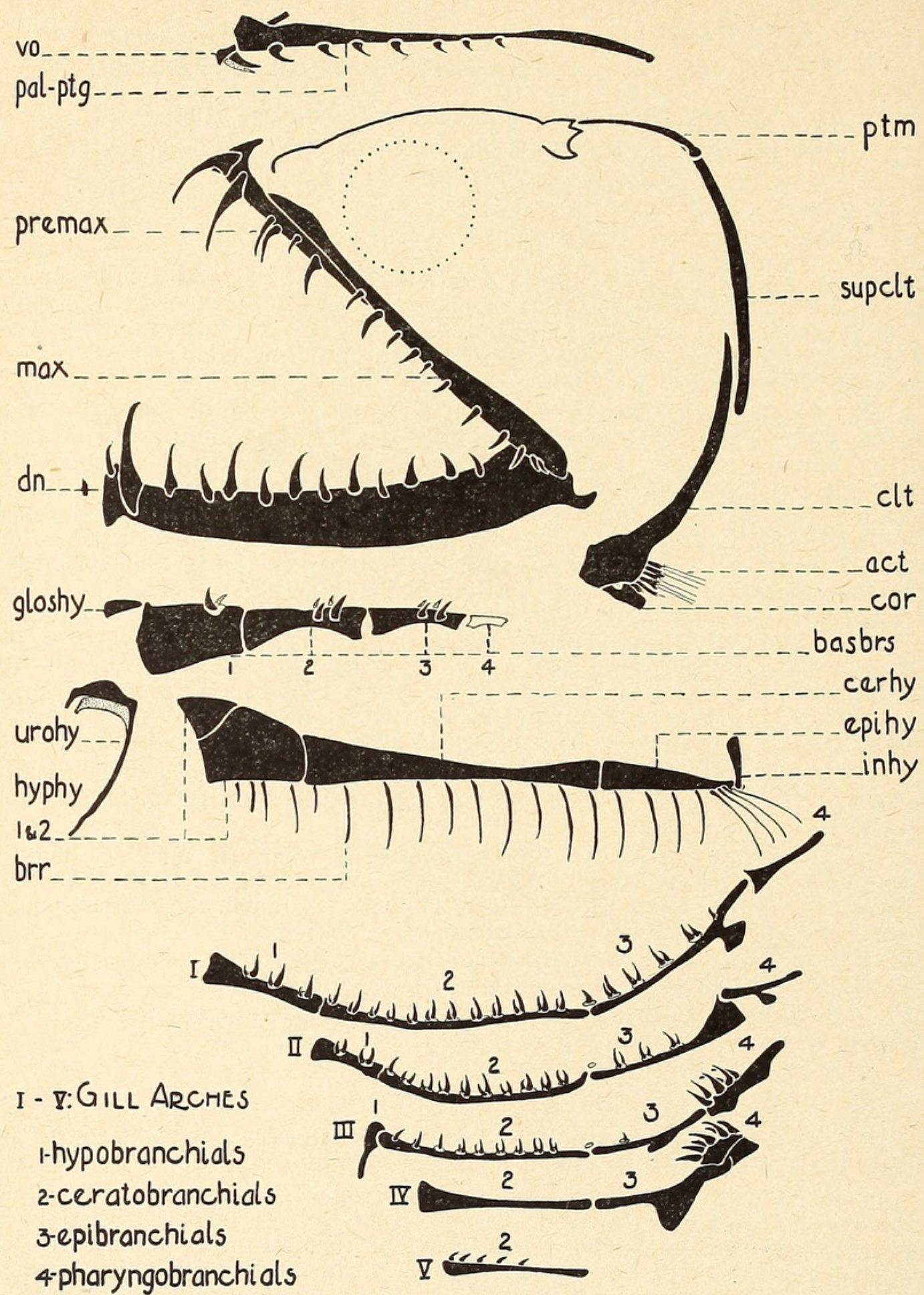

Text-figure 13.

Chirostomias pliopterus. Jaws, hyoid and branchial arches and pectoral girdle of transitional adolescent, standard length $118 \mathrm{~mm}$. Explanation and abbreviation as in Text-fig. 18.

Barbel: Shorter than head, with stout black stem ending in a large, ovate swelling, which is black spotted with luminous tissue, and cleft distally; a terminal, anterior series of simple and compound translucent projections, and a posterior, translucent, fringed flange. 


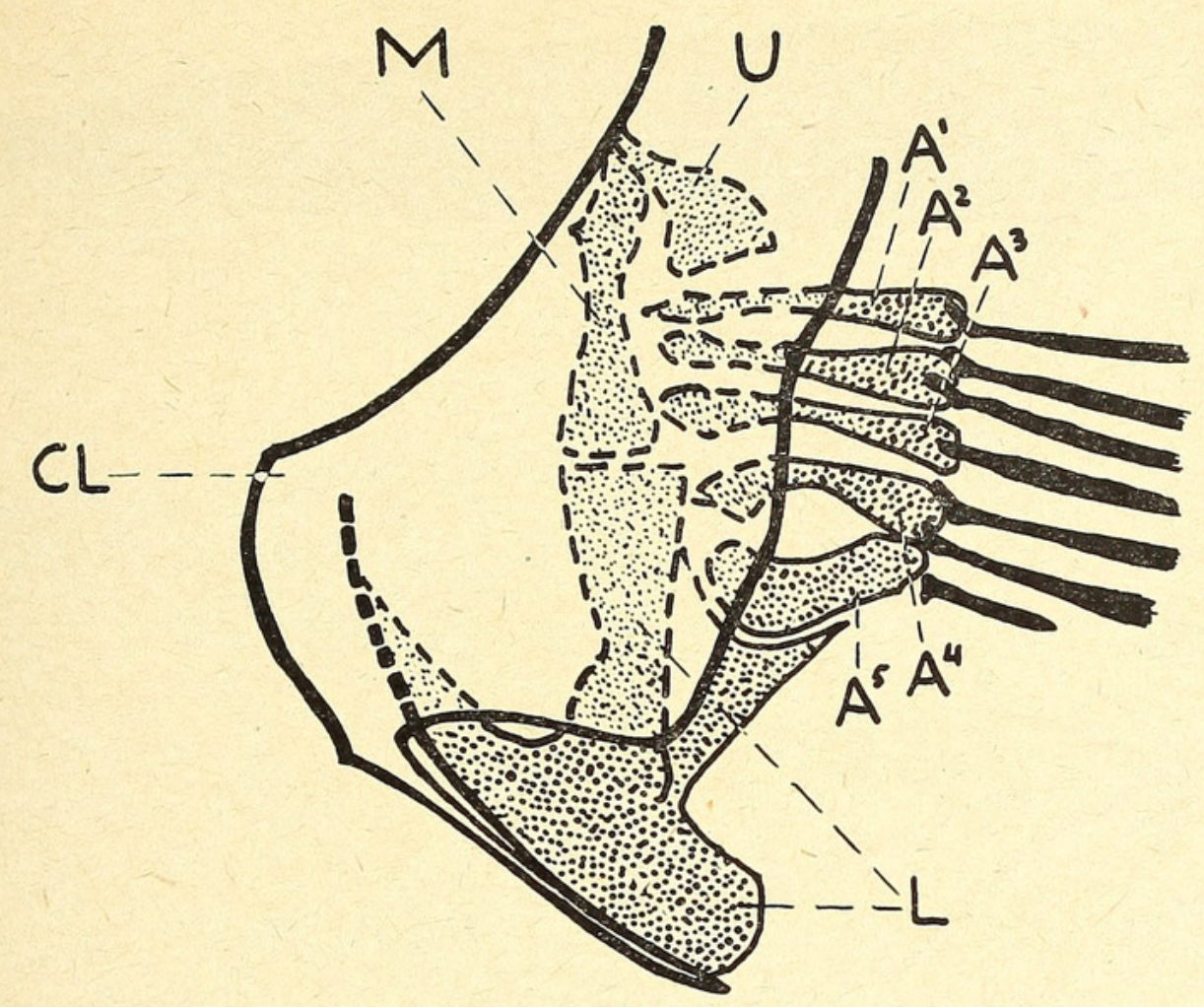

Text-figure 14.

Chirostomias pliopterus. Supporting bones of pectoral fin. $\mathbf{A}^{1}, \mathbf{A}^{2}, \mathbf{A}^{3}, \mathbf{A}^{4}, \mathbf{A}^{5}$, actinosts; CL, cleithrum, L, lower coracoid; $\mathbf{M}$, mesocoracoid; $U$, upper coracoid; fin-rays in solid black; short ray rudimentary, invisible externally. From a transitional adolescent, standard length $118 \mathrm{~mm}$.

The barbel of the largest specimen known, a $205 \mathrm{~mm}$. Bermuda female in breeding condition, differs slightly from those of previously known, younger examples, and hence a description is given in full below. This specimen was formerly described as C. lucidimanus Beebe, 1932 (see under "Discussion," p. 111).

The bulb is blue-black, elongate and somewhat compressed. The terminal part is cleft, forming two large, tubular divisions, the anterior the broader, each tipped with a pair of sharp, tooth-like structures opening toward one another. From the front of the anterior division arises a tuft of 7 filaments from a single base, the upper ones being longest, longer than the bulb itself. Under the ultra-violet light, while the fish was still feebly alive, these filaments gave off a pinkish glow. At the tip of the anterior division, in the position of the club-shaped appendage found in smaller specimens, is a thick, beaded tubercle, while from each of the two extreme distal teeth-like structures arise two or three short filaments. The posterior surface of the bulb shows a number of isolated spots of luminous tissue which consolidate into a thick, luminous, white comb or flange, with only a few very short filaments at the tip in place of the bushy fringe found in smaller specimens; the most distal of these is, however, as usual, a longer, beaded structure. The luminous tissue, which gave off a white glow in this area, dies out on the surface of the mid-bulb in an ever-thinning mass of scattered spots and dots. There is at least a single muscle at the tip of the bulb, which has the power of separating the terminal structures widely, the four tooth-like protuberances showing up strongly through the translucent pink luminous tissue. 


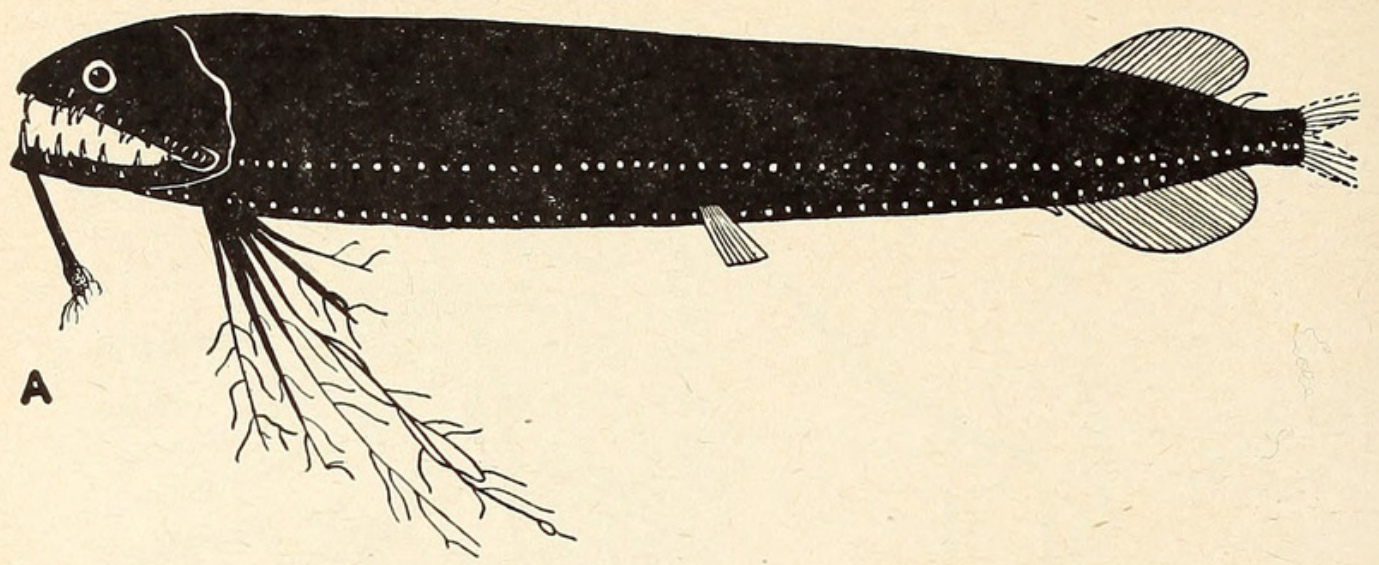

B

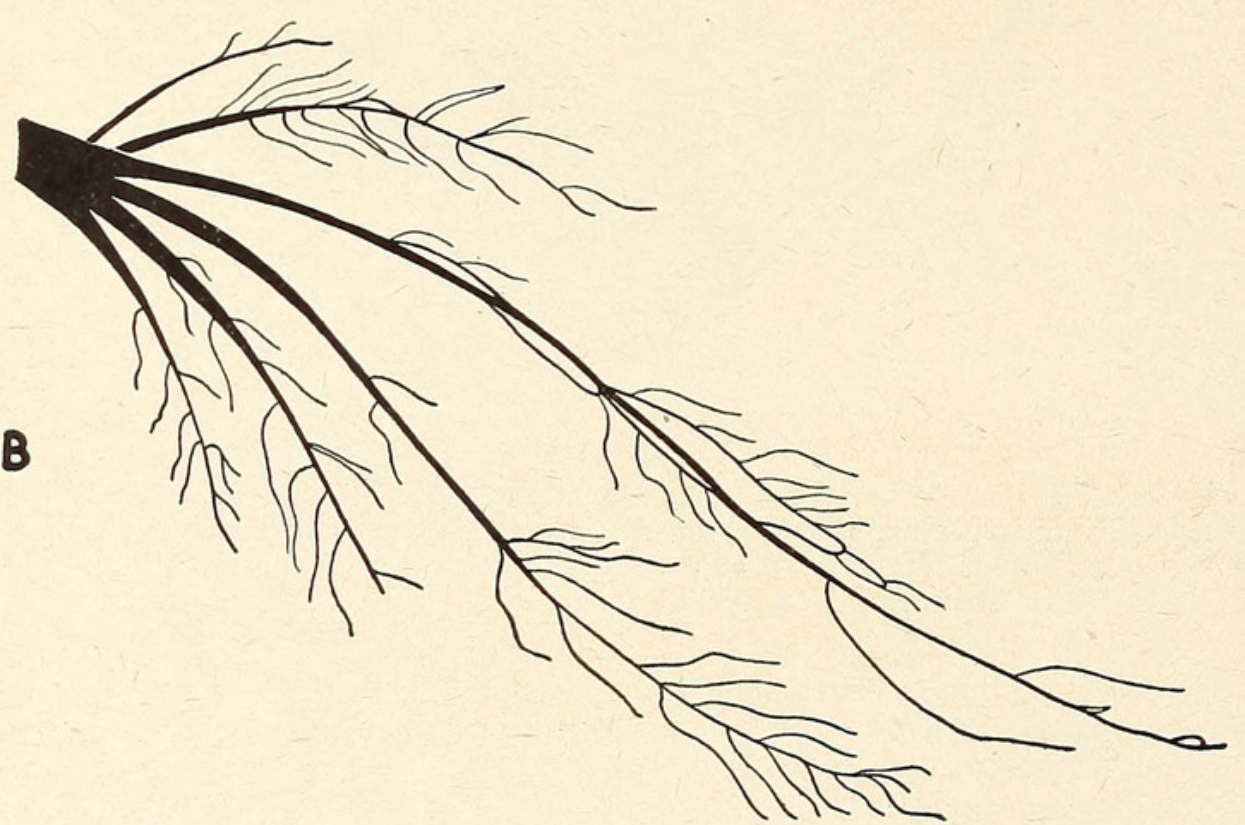

Text-figure 15.

Chirostomias pliopterus. A, adult female, standard length $205 \mathrm{~mm}$.; B, same, pectoral fin, showing luminous material on fourth and fifth rays.

Light Organs: Postorbital moderately large in male, completely atrophied in female. Serial photophores with the following counts: ventral series, I-P 9, P-V 26 to $28, \mathrm{~V}-\mathrm{A} 18$ to 20 , of which 5 to 6 are above the anal, A-C 10 to 11 ; lateral series, O-V 23 to 24 , V-A 18 to 20 . Pectoral fin with luminous tissue.

Teeth: Cleft of mouth straight; all teeth fixed; premaxillary and mandible with about 7 to 13 curved fangs each, set in 2 irregular rows; maxillary with 7 to 12 fangs and several small, oblique teeth at end; a pair of teeth on the vomer; a series of 7 to 9 on each palatine, extending onto the ectopterygoid. Usually 5 to 6 pairs of teeth on basibranchials. Teeth in pairs present on all gill-arches except fourth: on first and second hypobranchials; on first, second, third and fifth ceratobranchials; and on first, second and third epibranchials; 11 to 12 pairs present on first ceratobranchial.

Branchiostegal Rays: 22. 

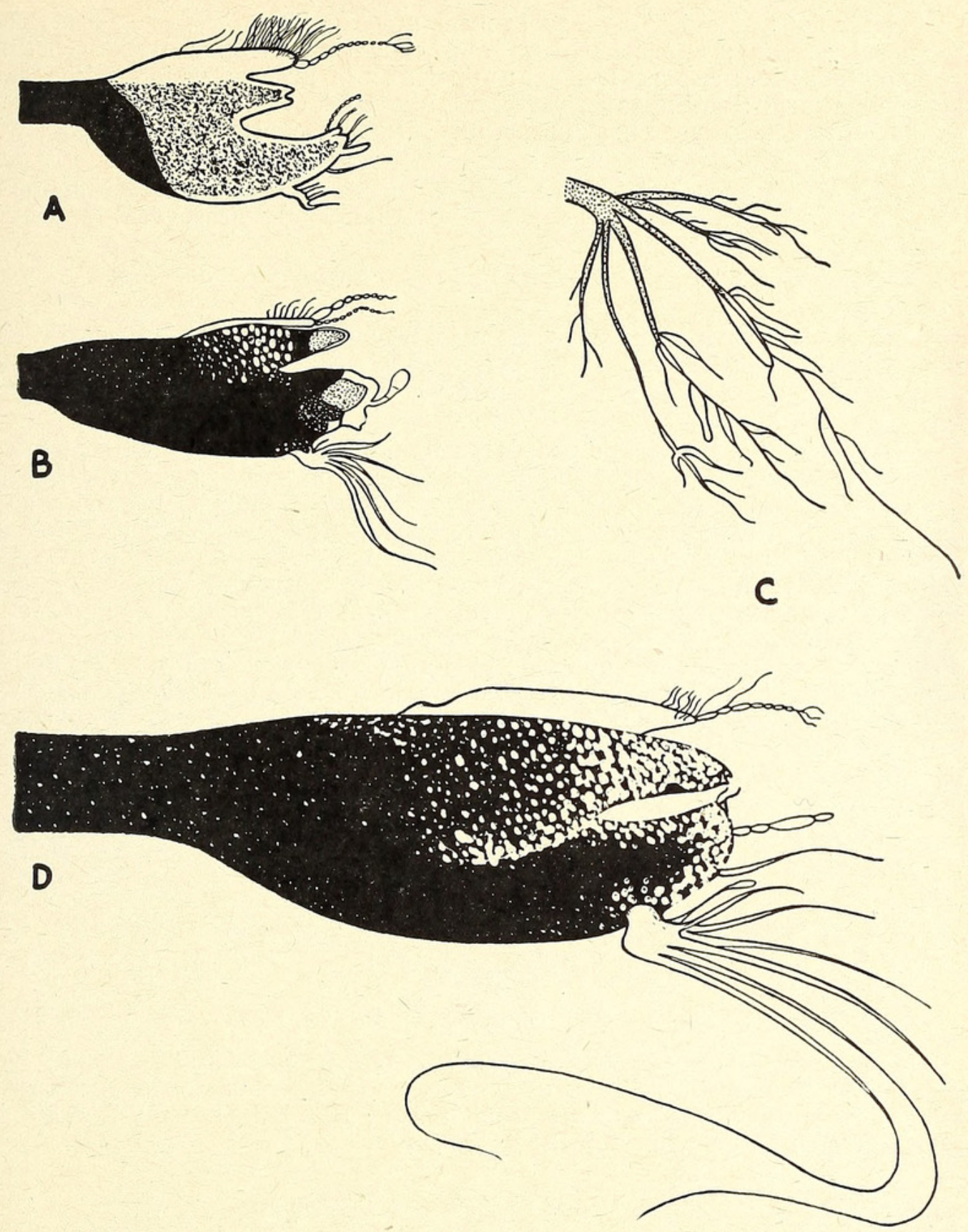

Text-figure 16.

Chirostomias pliopterus. A, end of barbel in adolescent, standard length 41 $\mathrm{mm}$.; B, end of barbel in transitional adolescent male, $118 \mathrm{~mm}$.; C, pectoral fin of same; D, end of barbel in adult female, $205 \mathrm{~mm}$.

Fins: Pectoral of 6 slender rays, the longest more than twice length of head, all branched distally, with one or more luminous swellings; inserted far forward and very low, under opercle; pelvic 7 , inserted slightly behind middle of length at about 29th myomere; dorsal 18 to 20 ; anal 22 to 26 ; dorsal and anal beginning at same vertical, but anal extending farther back; adipose present.

Epidermal Grooves: There is a deep groove in the isthmus for the reception of the barbel, and one in the side for the pectoral fin. 
Osteology: Parietals present; mesethmoid with lateral processes ; posttemporal present; supracleithrum and cleithrum strong; upper coracoid rudimentary; lower coracoid large; upper arm of mesocoracoid rudimentary, lower arm large; actinosts 5 ; vertebrae about 54 (myomeres to end of anal about 56); anterior vertebrae unmodified, the first centrum articulating with skull.

Coelomic Organs: Stomach 26.5 of length of fish, not reaching pelvic origin; 2 pyloric caeca. Nearly ripe ovarian eggs, preserved in alcohol, measure $.5 \mathrm{~mm}$. in diameter.

Sexual Dimorphism: Postorbital light organ well developed in male, atrophied in female.

Size: The largest known specimen measures $205 \mathrm{~mm}$. in length (225 $\mathrm{mm}$. when freshly caught), and is a female near breeding condition; the next largest is a male $118 \mathrm{~mm}$. long, which is immature; both were taken by the Bermuda Oceanographic Expeditions.

Development: Larva and post-larva unknown. Adolescent with no traces of dorsal subdermal pigment blotches; barbel stem short; anterior filaments on barbel bulb few and short; filaments forming fringe on posterior comb of bulb more numerous than in adult; postorbital light organ of females gradually atrophying: In an adolescent measuring about $35 \mathrm{~mm}$. the postorbital organ, although already covered with partly pigmented skin, shone through in the fresh specimen and was blue-white in color; in an older adolescent it was not visible externally, but a small organ, rolled downward, was found upon dissection; in the largest (adult) female, the organ is completely atrophied, leaving a gaping hole beneath the skin, well separated from the eye, surrounded only by muscle fibers. Sex cannot be determined by examination of the gonads of adolescents; we have stated that the specimens in question are females on the basis of their atrophying postorbitals.

Viability: The large female lived for half an hour after reaching the laboratory.

Chirostomias pliopterus Regan \& Trewavas, 1930.

(See also p. 111).

\section{SPECIMENS TAKen by the Bermuda OCEANOGRAPHiC Expeditions.}

8 specimens; May to August, 1929 to 1931; 300 to 700 fathoms; from a cylinder of water 8 miles in diameter ( 5 to 13 miles south of Nonsuch Island, Bermuda), the center of which is at $32^{\circ} 12^{\prime} \mathrm{N}$. Lat., $64^{\circ} 36^{\prime} \mathrm{W}$. Long.; standard lengths from 35 to $205 \mathrm{~mm}$.

\section{SPECIMENS PREVIOUSLY ReCORDED.}

5 specimens; $c a$. 55 to 273 fathoms; eastern and western North Atlantic, between $20^{\circ}$ and $44^{\circ} \mathrm{N}$. Lat.; standard lengths from 33 to $115 \mathrm{~mm}$.

\section{DESCRIPTION OF ADULT.}

With the characteristics of the genus.

\section{DEVELOPMENT.}

Material: The Bermuda collection of Chirostomias pliopterus is divided as follows :

6 adolescents; 35 to $41 \mathrm{~mm}$; 300 to 700 fath.; June, July; females.

1 transitional adolescent; 500 fath.; August; male.

1 adult; 500 fath.; August; female, near breeding condition. 
All are typical representatives of their respective growth stages, (see pp. $000-000)$. The specific characters of the adolescents have already been given on page 000 .

\section{STUdy MATERIAL.}

The following list gives the catalogue number, depth in fathoms, date, length and growth stage of each specimen of Chirostomias pliopterus taken by the Bermuda Oceanographic Expeditions. All were caught in the cylinder of water off the Bermuda coast described in Zoologica, Vol. XVI, No. 1, p. 5 and Vol. XX, No. 1 p. 1.

No. 10,738; Net 194; 600 F.; June 20, 1929; $41 \mathrm{~mm}$.; Adolescent.

No. 10,956; Net 219; 700 F.; June 25, 1929; $35 \mathrm{~mm}$.; Adolescent.

No. 11,464; Net 297; $500 \mathrm{~F}$; July 13, 1929; $37 \mathrm{~mm}$.; Adolescent.

No. 11,752; Net $316 ; 600$ F.; July 23, 1929; 40 mm.; Adolescent.

No. 15,053; Net 587; 500 F.; May 17, 1930; 35 mm.; Adolescent.

No. 21,259; Net 1071; 300 F.; July 10, 1931; 39 mm.; Adolescent.

No. 22,029; Net 1143; $500 \mathrm{~F}$; Aug. 7, 1931; $118 \mathrm{~mm}$.; Trans. Adolescent.

No. 22,200; Net 1157; 500 F.; Aug. 10, 1931; 205 mm.; Adult.

\section{SYNONYMY AND REFERENCES.}

Chirostomias pliopterus:

Regan \& Trewavas, 1930 , p. 54 ; pl. I, fig. 1 ; text-figs. $6 \mathrm{~B}, 8 \mathrm{~B}$ and 30 . (5 specimens; 33 to $115 \mathrm{~mm}$.; $150-1,000 \mathrm{~m}$. wire; Atlantic between $20^{\circ}$ and $40^{\circ}$ N. Lat.).

Beebe, 1933.1, p. 180. (Preliminary list of Bermuda specimens).

Beebe, 1937, p. 199. (Preliminary list of Bermuda specimens).

\section{Chirostomias lucidimanus:}

Beebe, 1932.2, p. 52. (4 specimens from Bermuda included in the present account of $C$. pliopterus).

\section{Genus Pachystomias Günther, 1878.}

(See also pp. 70, 73, 82, 83, 86, 88, 90, 91, 99, 105, 106, 109).

(Text-figs. 12, 17).

\section{General Discussion.}

Only 4 specimens belonging to this genus are known at the present time, including the single, $37 \mathrm{~mm}$. example taken by the Bermuda Oceanographic Expeditions. Two species have been erected, $P$. microdon (Günther, 1878 ), for the $215 \mathrm{~mm}$. specimen taken by the Challenger off Australia, and $P$. atlanticus Regan \& Trewavas, 1930, for the $165 \mathrm{~mm}$. Dana specimen taken from the Caribbean Sea. The latter species is distinguished from $P$. microdon by the longer teeth, broader interorbital region and longer barbel. Differences in photophore and fin counts are very small, and would normally fall within the range of variation of one species. The third specimen, measuring $90 \mathrm{~mm}$. and taken off Nova Scotia, is recorded by Roule \& Angel, 1933 (p. 17), without comment, save that it is in poor condition; they refer it to $P$. microdon.

The present young specimen taken off Bermuda differs from both the described species in a number of ways - the depth is less, head and eye both larger, snout longer, interorbital broader, basibranchial teeth fewer, grouping of serial photophores different, and barbel relatively much longer (1.3 times head instead of two-thirds of it). All except the last two characters are regular characteristics of immature melanostomiatids. Since 
the grouping of the photophores is different even on the two sides of the present specimen, these distinctions cannot be called specifically important. Finally, it is known that in some other genera the barbel grows relatively more rapidly than the standard length during adolescence, hence this peculiarity does not seem a basis for the establishment of a new species; also, it is likely that the delicate barbel is broken in the previously known specimens.

It is probable that the Atlantic and Australian forms will prove to be conspecific when more material has been acquired. For the present, however, we shall regard them as separate species, referring the Atlantic example recorded by Roule \& Angel and our own specimen to P. atlanticus.

\section{GENERIC CHARACTERS.}

Color (from Murray's observation on the living type specimen of $P$. microdon and notes by the present authors on a living immature $P$. atlanticus) : General color, velvety brownish-black; both antorbitals rose (microdon) or greenish-yellow (atlanticus); postorbital red (microdon); serial photophores violet to red.

Proportions (from the 2 largest known specimens): Moderately elongate melanostomiatids with large, broad heads and large eyes; depth in length $5(20 \%)$; head in length 4.5 to 4.7 (21\% to $22.3 \%$ ); eye in head 4 ; snout a little shorter than diameter of eye; snout to pelvic in length ca. $1.7(58 \%)$; interorbital width 4 to 6 in head. adult.

Barbel: Simple, slender, tapering, apparently shorter than head in

Light Organs: A large mass of luminous tissue forming a cushion on each side of palate, and appearing externally as a small luminous patch anteriorly, in the usual position of an antorbital, and a much longer, spindle shaped organ immediately behind, falling directly beneath the eye. Regular postorbital organ small, well separated from eye. Serial photophores in groups with the following counts: ventral series, I-P $8(1+2+-$ $2+3$ ), the last group beginning between the diverging pairs of the preceding, P-V 16 to 17 (in 2 or 3 groups) V-A 14 to 15 (9 to $10+5$, the last 5 in a close-set series above or ending at the vent), A-C 9; lateral series $\mathrm{O}-\mathrm{V} 17$ to 18 (in 4 groups), the first 2 ascending obliquely from the isthmus, V-A 13 to 14 (in 2 or 3 groups) ending above vent.

Teeth: Cleft of mouth slightly curved; jaws slender; premaxillary and mandible with rather small, slender, curved acute, unequal teeth, all fixed; maxillary with small oblique teeth; vomer toothless; 2 to 5 teeth on each palatine; well developed teeth on basibranchials; single teeth present on gill-arches, arrangement not recorded.

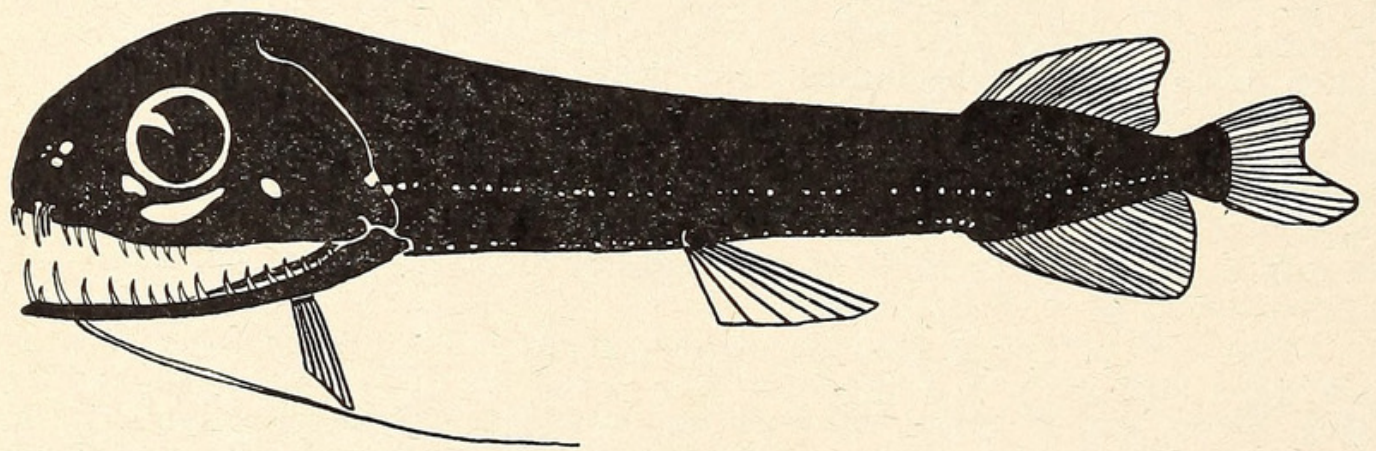

Text-figure 17.

Pachystomias atlanticus. Transitional adolescent, standard length $37 \mathrm{~mm}$. 
Fins: Pectoral 5 to 6 ; pelvics 7 , inserted a little behind middle of length, about equidistant from eye and base of caudal; dorsal 21 to 24; anal 25 to 27; dorsal and anal beginning at same vertical, but anal extending farther back.

Osteology: Parietals absent; mesethmoid with lateral processes; posttemporal absent.

Coelomic Organs: Pyloric caeca represented by 2 pouches.

Sexual Dimorphism: Unknown.

Size and Development: Larva, post-larva and adolescent unknown; a specimen of $37 \mathrm{~mm}$. is in transitional adolescence; the other known specimens measure 90,165 and $215 \mathrm{~mm}$., respectively.

Pachystomias atlanticus Regan \& Trewavas, 1930.

(Sèe also p. 117).

SPECIMEN TAKen By THE BeRmuda OCEANOGRAPHIC EXPEDitions.

1 specimen (Cat. No. 17,769, Net 836); September 3, 1930; 500 fathoms; from a cylinder of water 8 miles in diameter (5 to 13 miles south of Nonsuch Island, Bermuda), the center of which is at $32^{\circ} 12^{\prime} \mathrm{N}$. Lat., $64^{\circ} 36^{\prime}$ W. Long.; standard length $37 \mathrm{~mm}$.

\section{SPECIMENS PREVIOUSLY RECORDED.}

2 specimens; between 0 and 2,200 fathoms; Caribbean Sea and off Nova Scotia; standard lengths 90 and $165 \mathrm{~mm}$.

\section{SPECIFIC ChaRACTERS.}

(From the description of the type specimen, $165 \mathrm{~mm}$. in length). With the characters of the genus.

This species differs from the $215 \mathrm{~mm}$. type specimen of $P$. microdon Günther from Australia in the following particulars: teeth in jaws longer; 2 teeth, not 5 , on each palatine; 2 pairs, not 5 , on first basibranchial; 4 pairs, not 2, on second; interorbital breadth contained 5, not 6 times in length of head; barbel longer, two-thirds, not one-fourth, length of head; pectoral 6 , not 5; dorsal 21, not 24; anal 25, not 27. Serial photophores with following counts: ventral series, I-P $8(1+2+2+3)$, P-V 16 $(4+12)$, V-A $15(10+5)$, A-C 9 ; lateral series, O-V $18(2+4+4+8)$, V-A $13(9+4)$.

\section{DEVELOPMENT.}

The transitional adolescent from Bermuda will be described in detail.

Color in Life: Skin velvety brownish-black; both antorbital light organs yellow-green; postorbital organ blazing dark red; serial photophores purple. Luminescence not observed in dark-room, although all organs appeared fully capable of functioning. Barbel colorless, translucent.

Measurements and Proportions: Total length $41 \mathrm{~mm}$.; standard length $37 \mathrm{~mm}$.; depth $5.3 \mathrm{~mm}$. (in length 7 or $14.2 \%$ ); depth in front of vertical fins $3.5 \mathrm{~mm}$. (in length 10.6 or $9.4 \%$ ); head $11.7 \mathrm{~mm}$. (in length 3.1 or $32 \%$ ) ; eye $3.1 \mathrm{~mm}$. (in head 3.8 or $8.4 \%$ of length) ; snout $3.1 \mathrm{~mm}$. (in head 3.8 or $8.4 \%$ of length); interorbital 2.5 (in head 4.7 or $6.8 \%$ of length); 
interocular $4.8 \mathrm{~mm}$. (in head 2.45 or $13 \%$ of length); snout to pelvic $20 \mathrm{~mm}$. (in length 1.85 or $54 \%$ ); anterior orbital light $1 \mathrm{~mm}$.; median cheek light $2.5 \mathrm{~mm}$; posterior cheek light $1.1 \mathrm{~mm}$.; barbel $15.5 \mathrm{~mm}$. (1.3 times head, $42 \%$ of length).

The outstanding characters of the fish are the very large, thick head, much thicker than the body, and the large, protuberant eyes, which project $1.2 \mathrm{~mm}$. from the side of the head. The frontal crests divide the interorbital space into thirds.

Barbel: The barbel, contained 2.4 times in the length, is slender, unpigmented and tapers gradually to a thread-like tip.

Light Organs: The first of the three orbitals is directly beneath the lower anterior part of the eye, and is a small oval; the second is two and onehalf times as long, and slightly broader, starting under the posterior corner of the first, and ending just before the vertical from the posterior border of the orbit; the third, corresponding to the usual postorbital of melanostomiatids, is very slightly larger than the first and is obliquely set behind the end of the second. Serial photophores with the following counts and groupings: ventral series, both sides of fish, I-P $8(1+2+2+3), \mathrm{P}-\mathrm{V} 17(5+5+7), \mathrm{V}-\mathrm{A}$ $14(9+5)$, A-C 9 ; lateral series, $\mathrm{O}-\mathrm{V}$ right side $18(1+5+4+8)$, left side $18(1+5+5+7)$, V-A right side $14(6+3+5)$, left side $14(4+4+6)$. Numerous small organs are scattered over head and trunk.

Teeth: The teeth, all fixed, are arranged as follows: 13 moderate-sized teeth in each premaxillary, the first, second, third and eighth somewhat enlarged, and the first, second and fifth external. There are about 20 small, oblique denticles on each maxillary; each mandibular ramus holds 16 or 17 teeth similar to those of the upper jaw, the first tooth a fang, the largest in the mouth, the third next largest and external; there are one or two replacement teeth; 2 teeth on right palatine, 3 on left. One pair of teeth on first basibranchial, $1 \frac{1}{2}$ pairs on second. No teeth yet developed on gillarches, but their anlagen appearing beneath the gill-arch skin.

Fins: The pectorals are placed far forward on the body, beneath the posterior part of the maxillary, and are moderately short. The pelvics are well developed, originating behind the middle of the length and extending about two-thirds of the distance between their origin and that of the anal fin. The dorsal and anal have their proximal portions encased in a thick black membrane. Their rays are long, those in the posterior part of the fin reaching well beyond the caudal origin when laid back.

Coelomic Organs: The stomach is fully pigmented, but short, $5.5 \mathrm{~mm}$. long ( $15 \%$ of length of fish), and reaching only about three-fifths of distance between pectoral and pelvic insertions. There is no trace of the two rudimentary caeca described for adult fish of this genus by Regan \& Trewavas $(1930$, p. 44). The gonads are slender, transparent threads.

Viability: This specimen was alive when caught, but died a few minutes after its arrival in the laboratory, about one hour and a half after capture. This is the smallest deep-sea fish ever brought up alive by the Bermuda Expeditions.

\section{REFERENCES AND SYNONYMY.}

Pachystomias atlanticus:

Regan \& Trewavas, 1930 , p. 70 ; pl. VI, fig. 1; (1 specimen; $3,500 \mathrm{~m}$. wire; Caribbean Sea west of St. Lucia; standard length $165 \mathrm{~mm}$.).

Beebe, 1937, p. 199. (Preliminary listing of Bermuda specimen).

Pachystomias microdon (non Günther) :

Roule \& Angel, 1933, p. 17. (1 specimen; 0 to $4,000 \mathrm{~m}$.; southeast of Nova Scotia; standard length $90 \mathrm{~mm}$.). 
Genus Leptostomias Gilbert, 1905.

(See also pp. 70, 73, 75, 79, 80, 81, 85, 86, 88, 90, 97, 99, 101-103, $105,106,110)$.

(Text-figs. 2, 5, 7, 11, 12, 18-22 incl.).

\section{GENERAL Discussion.}

Some authors have included the genus Leptostomias, with or without subgeneric standing, in Melanostomias. Regan and Trewavas, however, in their monograph on the family (1930) established the validity of the genus, and worked out its relationships. Nematostomias Zugmayer, 1911, is a synonym of Leptostomias.

Eleven species of Melanostomiatidae are at present referable to Leptostomias, two, L. macropogon Norman and L. bermudensis Beebe, having been described since the publication of the above mentioned monograph. The delineation of all of the species is most unsatisfactory. Only two characters have been found to be specifically important, the number of P-V photophores and the form of the barbel; both are of dubious value, since the barbel has been found to be very variable in the only species, L. ramosus, of which more than four examples have hitherto been taken, and the number of photophores serves merely to separate groups of species; slight differences in finray counts and proportions cannot be regarded as useful until much more material is obtained. Finally, individuals of this genus do not mature until they attain a considerably greater length than others of the family, judging from the largest specimens we have been able to examine, namely, the holotypes of L. problematicus (Parr) and L. bermudensis Beebe, and the largest examples in the type series of $L$. longibarba Regan \& Trewavas and L. ramosus Regan \& Trewavas. These fish measure from 172 to $270 \mathrm{~mm}$. in length, yet their gonads are so undeveloped as to be almost invisible in all but the $250 \mathrm{~mm}$. specimen of L. longibarba, while the stomachs are all short and distally unpigmented. Since only a single other large specimen has been recorded (the type of $L$. gladiator, $255 \mathrm{~mm}$.), and the majority are much smaller, probably no fully adult Leptostomias has ever been taken. It is almost certain that a number of the species will prove to be synonymous, with the apparently specific differences being due instead to individual variation, age and, possibly, sex.

For the convenience of future students, we include the following annotated list of species, although we can attempt no complete revision ourselves with available material, and feel justified at present in synonymizing only $L$. gladiator, $L$. problematicus and $L$. ramosus.

1. L. macronema Gilbert, 1905 , p. 607. Known only from the type specimen, $74 \mathrm{~mm}$. long, from Hawaii. We have examined it in the U. S. National Museum and, in addition to the pair of filaments at the base of the barbel figured by Gilbert and described by Parr (1927, p. 49), we have found a pair of simple, short filaments on the stem near the bulb, and a single, unpaired one just above the bulb. The bulb itself is somewhat damaged, but, as both Gilbert and Parr have observed, is apparently simple; the tip is narrowed, almost papilla-like. There is no question, however, in spite of the presence of these hitherto unnoticed filaments, that the species, which is the only one so far reported from the Pacific, is distinct from the known Atlantic forms.

2. L. gladiator (Zugmayer, 1911.1, p. 76). Hitherto known from 2 specimens from the eastern Atlantic in the Monaco collection, the $255 \mathrm{~mm}$. type and a $70 \mathrm{~mm}$. example recorded by Roule \& Angel (1933, p. 17). Referred originally to the genus Nematostomias, erected for it; to Melanostomias by both Parr (subgenus Leptostomias) (1927) and Roule \& Angel; correctly placed in Leptostomias by Regan \& Trewavas, 1930, p. 61. Not seen 
by us, but there seems to be no reason for not considering $L$. problematicus and $L$. ramosus synonymous with it. The type is a male, judging from the postorbital organ "of moderate size," described and figured in the type description. (See p. 127).

3. L. problematicus (Parr, 1927, p. 46). Known only from the type specimen, $172 \mathrm{~mm}$. long, from the western Atlantic. We have examined it in the Peabody Museum and find that the barbel appears as figured, save for the following details: there are a number of short, unbranched filaments scattered along the stem, distal to the large basal filament described and figured in the type description. The tip of the barbel bulb is certainly broken off, so that at least one distal papilla is missing, and possibly a good-sized bit of the bulb itself. One of the distal papillae is not at the extreme end, as shown in the figure. Altogether, in spite of a slightly longer barbel, slimmer form, and 1 or 2 more dorsal and anal rays, it appears certain that this form and $L$. ramosus (species no. 9, below) are identical, and that both of them should be synonymized under $L$. gladiator (species no. 2, above). Distally the barbel stem has lost a considerable amount of skin, taking, perhaps, one or more filaments with it. The postorbital is almost completely atrophied externally, and though it is impossible to determine the sex from the condition of the internal organs, due to their immaturity, the specimen is doubtless a female, judging from the atrophy of the postorbital organ. There are 21, not 20, V-A photophores in both lateral and ventral series. There is a small pair of teeth in the vomer. Placed originally in Melanostomias, subgenus Leptostomias.

4. L. haplocaulus Regan \& Trewavas, 1930 , p. 59. Known from a single specimen from the North Atlantic, $100 \mathrm{~mm}$. long. Not seen by us.

5. L. gracilis Regan \& Trewavas, 1930 , p. 59. Known from the 4 specimens in the type series from the North Atlantic, 70 to $75 \mathrm{~mm}$. long. Not seen by us.

6. L. longibarba Regan \& Trewavas, 1930 , p. 60 . Known from the 3 specimens in the type series from the North Atlantic, 53 to $250 \mathrm{~mm}$. long. A $250 \mathrm{~mm}$. immature female examined by us.

7. L. leptobolus Regan \& Trewavas, 1930 , p. 60 . Known from the 2 specimens in the type series, 68 and $95 \mathrm{~mm}$. long, from the North Atlantic. Not seen by us.

8. L. analis Regan \& Trewavas, 1930 , p. 61 . Known from a single specimen, $168 \mathrm{~mm}$. long, from the North Atlantic. Not seen by us.

9. L. ramosus Regan \& Trewavas, 1930, p. 61. Known from 12 specimens in the type series from the North Atlantic, 56 to $180 \mathrm{~mm}$. long. We have examined three, including the largest. All are immature, but females, judging from the atrophying postorbital organs. The variability of the barbel is adequate proof that this species and $L$. problematicus should be synonymized with L. gladiator.

10. L. macropogon Norman, 1930 , p. 311 . Known from a single specimen from the South Atlantic, $165 \mathrm{~mm}$. long. Norman suggests it may prove to be identical with $L$. gracilis. Not seen by us.

11. L. bermudensis Beebe, 1932 , p. 59. Known from a single specimen from Bermuda, $270 \mathrm{~mm}$. long, in the present collection. May prove to be synonymous with $L$. longibarba, L. gracilis or $L$. macropogon. (See p. 125).

Distribution: Leptostomias is one of the seven genera in the family which have been recorded outside the Atlantic Ocean. L. macronema is known only from Hawaii, and $L$. macropogon only from the South Atlantic. All the rest have been taken in the North Atlantic. The depth range of the genus as known at present is undefined, between 0 and 1,500 fathoms. Including the present series, 49 specimens have been recorded, 35 of which are referred to Leptostomias ramosus. 


\section{GeNeric Characters.}

(The immaturity of all specimens from which these characters are derived must be kept in mind).

Color (from fresh specimens of $L$. gladiator and $L$. bermudensis): General color dark brownish-black; barbel bulb yellow; serial photophores violet to maroon.

Proportions: Very elongate melanostomiatids with short heads. Depth in length 10 to $17(5.9 \%$ to $10 \%)$; head in length 7.5 to $11(9.1 \%$ to $13.3 \%)$; eye in head 4.5 to 6 ; snout longer than eye; snout to pelvic in length $c a$. 1.5 to $1.6(62.5 \%$ to $66.5 \%)$.

Barbel: One-fourth to as long as fish; stem with or without filaments; bulb an elongate oval from which arise short filaments and papillae in varying numbers, combinations and arrangements.

Light Organs: Postorbital probably completely atrophied in adult female, moderate in male; serial photophores with the following counts: ventral series, I-P 10 to $11, \mathrm{P}-\mathrm{V} 39$ to 48 , V-A 20 to 23 , A-C 11 to 14 ; lateral series, O-V 39 to 48 , V-A 20 to 23 . Accessory light organs inconspicuous.

Teeth: Cleft of mouth straight, jaws massive; premaxillaries and mandible with a few moderate fangs, each tapering to a point, mostly fixed; first premaxillary tooth moderate, fixed; second long and depressible, followed by several smaller fixed outer teeth and 1 or 2 inner, depressible teeth; maxillary with a few small erect teeth followed by a series of about 20 to 30 oblique denticles. Mandible with a strong, fixed fang followed by a depressible tooth and several smaller fixed teeth. A pair of teeth on the vomer and 0 to 1 on each palatine; 1 to 2 pairs (sometimes rudimentary) on the basibranchials; short, stout teeth present in pairs, three's and four's on first 4 gill-arches: on first and second hypohals, first 4 ceratohyals, and first 3 epihyals; about 9 groups present on first ceratobranchial, the last being elongate and single.

Branchiostegal Rays: 17 to 19.

Fins: Pectoral with 10 to 11 simple, moderately short rays; pelvics 7 , placed well behind middle of length; dorsal 16 to 21 ; anal 20 to 28 , beginning below or very slightly in advance of dorsal and extending farther back.

Epidermal Grooves: A pronounced groove in the isthmus for grasping the stem of the barbel.

Osteology: Premaxillary without median process, but with well developed lateral flanges instead; parietals present; mesethmoid with lateral processes; post-temporal present (at least in both Bermuda species), but weak, not attached to skull; supracleithrum and cleithrum strong; upper coracoid moderate, lower large; mesocoracoid with rudimentary upper arm but well developed lower arm; vertebrae about 75 to 83 ; first 7 vertebrae highly specialized, their centra being absent, and there being only 6 parapophyses; first neural arch represented by a pair of small bones articulating with exoccipital; second neural arch much enlarged; third through eighth smaller, but larger than succeeding ones, and directed straight upward, instead of backward.

Coelomic Organs: Stomach $19 \%$ to $23 \%$ of length, not nearly reaching pelvic fins; distal portion lightly and incompletely pigmented in all specimens examined; gonads rudimentary. Intestine with an anterior pouch and a single caecum.

Sexual Dimorphism: Postorbital light organ completely atrophied in females of $250 \mathrm{~mm}$. and over; male postorbital of moderate size, judging from type description and illustration of L. gladiator (Zugmayer, 1911, pl. III, fig. 5).

Size: The largest known specimen of Leptostomias is L. bermudensis, taken by the Bermuda Expeditions, and measuring $270 \mathrm{~mm}$. long ( 285 $\mathrm{mm}$. when fresh). The gonads are so immature as to be barely distinguish- 

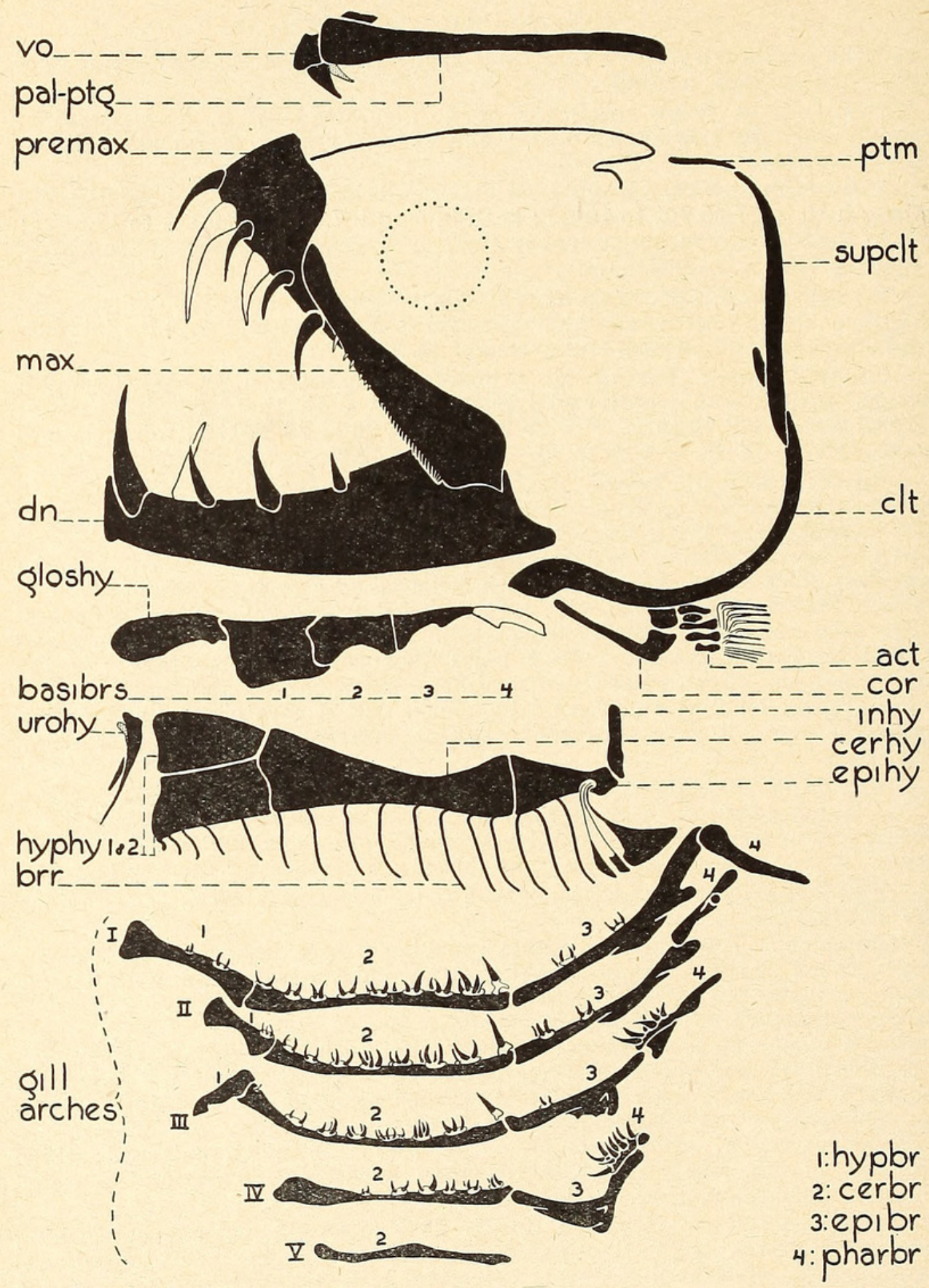

Text-figure 18.

Leptostomias bermudensis. Jaws, hyoid and branchial arches, and pectoral girdle of transitional adolescent, standard length $270 \mathrm{~mm}$. Depressible jaw-teeth unshaded; divisions between palatine and pterygoid, and maxillary and supramaxillary not shown; fourth basibranchial, always unossified, unshaded; act, actinost; basibrs, basibranchials; brr, branchiostegal ray; cerbr, ceratobranchial; cerhy, ceratohyal; clt, cleithrum; cor, coracoid; $d n$, dentary ; epibr, epibranchial ; epihy, epihyal; cerhy, ceratohyal; clt, cleithrum; cor, coracoid; dn, dentary ; epibr, epibranchial ; epihy, epihyal; palato-pterygoid; pharbr, pharyngobranchial; premax, premaxillary; ptm, post-temporal; supclt, supracleithrum; urohy, urohyal: vo, vomer. 


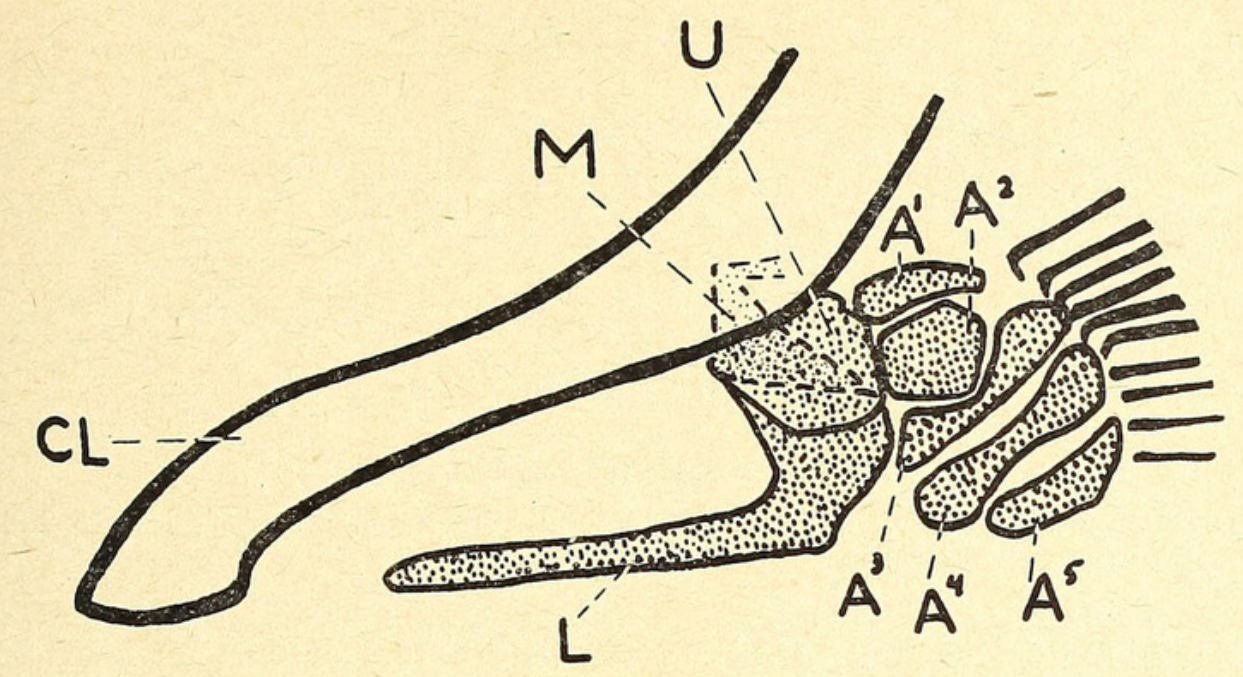

Text-figure 19.

Leptostomias bermudensis. Supporting bones of pectoral fin. From the transitional adolescent holotype, standard length $270 \mathrm{~mm}$. Abbreviations as in Textfig. 14 .

able in this specimen, in the $180 \mathrm{~mm}$. Dana example of $L$. ramosus, in the $170 \mathrm{~mm}$. type of $L$. problematicus and in all smaller examples examined; these organs are only slightly more developed in a $250 \mathrm{~mm}$. specimen of $L$. longibarba, although eggs are distinctly visible. Metamorphosis also occurs when the young are larger than usual (between 30 and $50 \mathrm{~mm}$., instead of between 20 and 30 ). The indications are, therefore, that members of this genus attain relatively large size.

Development: A series of growth stages of $L$. gladiator has been taken by the Bermuda Expeditions, which is probably typical of the genus. The characteristics in brief are, a large number of myomeres ( $c a .75$ to 78) between nape and end of anal (the count is probably greater in other species with higher photophore counts); pigment in a row of blotches immediately below the dorsal mid-line, and from 3 to 10 rows of compact pigment spots, the number of rows depending on the length of the fish; anal fin beginning slightly behind dorsal origin.

\section{Leptostomias bermudensis Beebe, 1932.}

(See also p. 122).

TYPE.

(The unique specimen).

Department of Tropical Research No. 20,826; Bermuda Oceanographic Expeditions of the New York Zoological Society; Net 1015; June 15, 1931; $71 / 2$ miles southeast of Nonsuch Island, Bermuda; 500 fathoms; standard length $285 \mathrm{~mm}$. when fresh, $270 \mathrm{~mm}$. after being preserved in alcohol.

\section{DESCRIPTION.}

With the characteristics of the genus.

Color (from fresh specimen): General color dark, brownish-black; barbel stem proximally pigmented, distally lilac; barbel bulb bright, clear picric yellow, filaments white. Photophores of ventral series maroon with gilt caps, lateral series pale purple, also with gilt caps; small, non-serial photophores pale purple. 


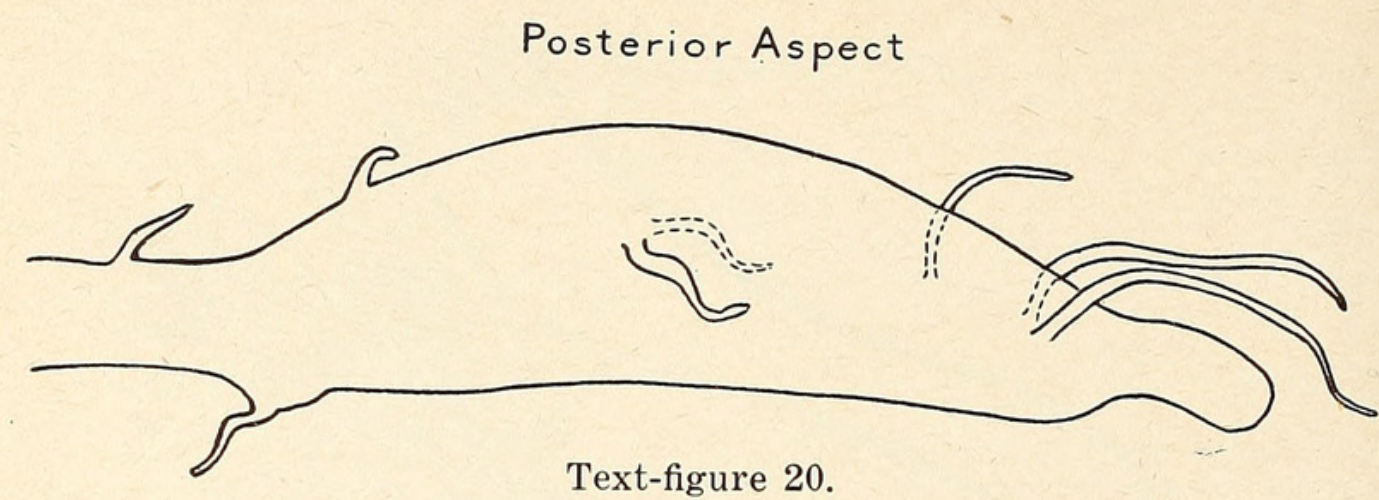

Leptostomias bermudensis. End of barbel in holotype, standard length $270 \mathrm{~mm}$.

Measurements and Proportions (at present): Total length $281 \mathrm{~mm}$; standard length $270 \mathrm{~mm}$; ; depth 17 (in length 15.8 or $6.2 \%$ ); head 26 (in length 10.4 or $9.6 \%$ ) ; eye 4.3 (in head 6 , or $1.6 \%$ of length) ; snout 7.2 (in head 3.6 or $2.7 \%$ of length) ; upper jaw 17 (in head 1.5 , in length 15.9 or $6.3 \%$ ); snout to pelvic 176 (in length 1.53 or $65.4 \%$ ).

Barbel: Length $200 \mathrm{~mm}$. (1.35 in length or $74 \%$ ). Stem without filaments near base, but with at least three short ones, far separated from each other, in the distal three-fourths of stem. The latter is black for about $4 / 5$ of the proximal portion, then this pales and grays, and changes into brilliant lilac with a dark core running through it. The bulb, in the fresh specimen, was abruptly bright, clear, picric yellow, and the filaments translucent white with a scattering of black specks. The bulb arises abruptly from the stem, the lilac and the dark center ceasing at once. The bulb is slender, slightly curved, tapers gently from its center, and resembles in shape a diminutive cucumber. It narrows abruptly near the distal end, forming an elongate, rounded, terminal stem. There are three short, thin, median filaments given off, one from the back of the stem, and the other two from the proximal part of the bulb. Halfway down the bulb a pair of larger filaments arises, one from each side. Still farther a single one appears from the right side and, at the point of narrowing into the terminal stem, there arises a final pair of filaments, the longest of all, about $4 \mathrm{~mm}$. in length.

Light Organs: The postorbital is atrophied. Serial photophores: ventral series, I-P 10, P-V 48, V-A 21, A-C 12; O-V 47 to 48 , V-A 22.

Teeth: Premaxillary with 6 moderately large teeth, the second largest, the second and fourth depressible; maxillary with 5 to 6 tiny erect teeth followed by about 21 oblique denticles on the left side; right side with additional denticles discernible above the erect maxillary teeth; mandible with a moderately large fixed fang followed in turn by a slightly smaller depressible fang and 3 still smaller fixed teeth. Vomer with 1 pair of teeth; palatine toothless; 1 pair of rudimentary teeth on basibranchials.

Branchiostegal Rays: 19.

Fins: Pectoral rays 11 (not 12 as in type description), $12 \mathrm{~mm}$. long; pelvic rays $7 ; 33 \mathrm{~mm}$. long; dorsal rays 20 , anal rays 25 , commencing opposite dorsal and continuing slightly behind it.

\section{Discussion.}

This species closely resembles $L$. macropogon Norman and $L$. longibarba Regan \& Trewavas, but it may be distinguished from both by the structure of the bulb of the barbel and by the presence of $48 \mathrm{P}-\mathrm{V}$ photophores. As has been said, however, it is extremely likely that, when additional material is secured, some of the described species will prove synonymous; the present species will perhaps be included among them. 
Leptostomias bermudensis:

\section{REFERENCES.}

Beebe, 1932.2 , p. 59, fig. 10. (Type description, slightly amended and amplified in the present paper). list).

Beebe, 1937, p. 199. (Record of above specimen in preliminary Bermuda

Leptostomias gladiator (Zugmayer, 1911).

(See also pp. 121-122).

\section{SPECIMENS TAKen By THE BeRmuda OCEANOGRAPHiC EXPEDitions.}

20 specimens; May to September, 1929 to 1931 ; 50 to 1,000 fathoms; from a cylinder of water 8 miles in diameter ( 5 to 13 miles south of Nonsuch Island, Bermuda), the center of which is at $32^{\circ} 12^{\prime} \mathrm{N}$. Lat., $64^{\circ} 36^{\prime} \mathrm{W}$. Long.; standard lengths from 12 to $52 \mathrm{~mm}$.

\section{Specimens PReviously ReCoRded.}

15 specimens; 0 to 2,680 fathoms; North Atlantic between $20^{\circ}$ and $40^{\circ}$; standard lengths from 56 to $180 \mathrm{~mm}$.

\section{DESCRIPTION.}

With the characteristics of the genus.

Color (from fresh, immature, Bermuda specimens): General color blackish-brown; barbel bulb creamy yellow; photophores violet.

Proportions: Depth in length 10 to $13(7.7 \%$ to $10 \%)$; head in length 7.5 to 8.5 ( $11.8 \%$ to $13.4 \%$ ) ; eye in head 5 to 6 (16.7\% to $20 \%)$.

Barbel: About $1 / 2$ length of fish; stem black with luminous patches; 1 or 2 pairs of filaments and usually an unpaired one at base; others scattered variably and irregularly along stem, including a pair slightly above-bulb; bulb unpigmented, more than half length of head, slender, scarcely compressed, usually with narrowed, papilla-like tip and bearing 1 or 2 pairs of stout filaments near the base and 1 to 4 short, swollen filaments, often a pair near the tip and another a little behind them.

Light Organs: Serial photophores with the following counts: ventral series, I-P 10 to $11, \mathrm{P}-\mathrm{V} 39$ to 43 , V-A 21 to 22 , the last 4 being above the anal fin, A-C 11 to 12 ; lateral series O-V 39 to $42, \mathrm{~V}-\mathrm{A} 20$ to 22.

Fins: Dorsal 19 to 22 ; anal 23 to 26.

\section{DEVELOPMENT.}

Material: The Bermuda collection of Leptostomias gladiator is composed entirely of immature fish, a well-graduated series ranging from young larvae to transitional adolescents and measuring between 12 and $52 \mathrm{~mm}$. in length. They are distributed as follows:

9 larvae; 12 to $30 \mathrm{~mm}$; 50 to 1,000 fath.; May to Sept.

8 post-larvae; 38 to $45 \mathrm{~mm}$.; 300 to 1,000 fath.; June to Aug.

1 adolescent; $45 \mathrm{~mm}$.; 500 fath.; July.

2 transitional adolescents; 50, $52 \mathrm{~mm}$.; 600, 1,000 fath.; Sept.

All are typical representatives of their respective growth stages (see pp. 76-79). Their special characteristics are as follows:

Myomere Counts: To end of anal 75 to 78; from nape to pelvic rudiment (when present) 42 to 44 ; from pelvic rudiment to anal origin 16 to 18 .

Pigment: Larval pigment is traceable subdermally even in early transitional adolescence; it reaches its most advanced condition not in the larva 

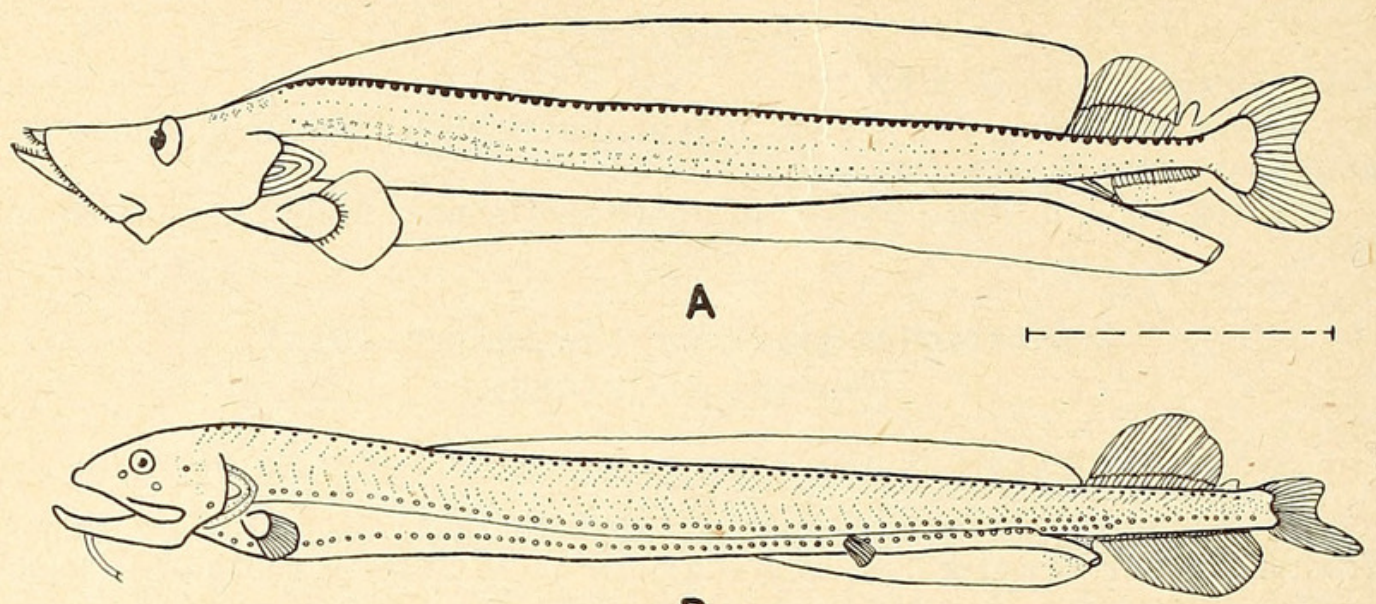

B
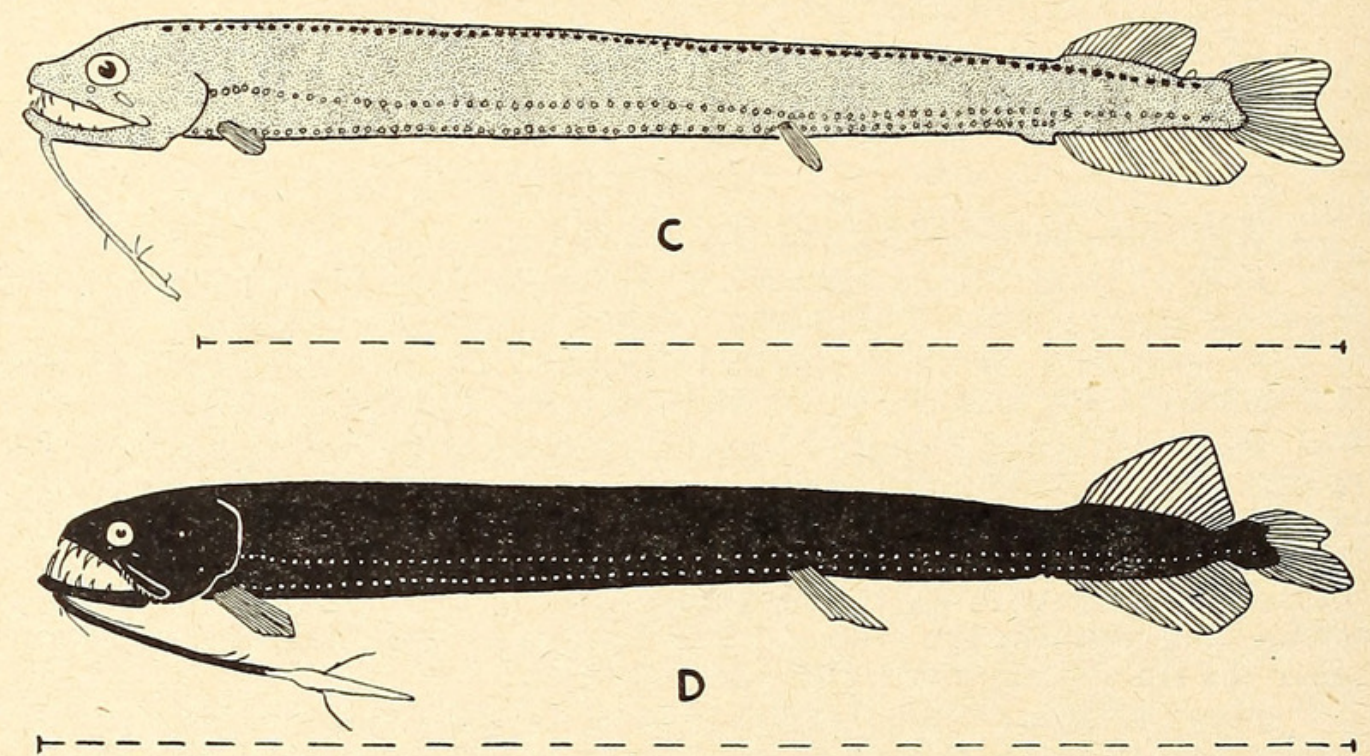

D

Text-figure 21.

Leptostomias gladiator. A, larva, standard length $12 \mathrm{~mm}$; B, post-larva, $42 \mathrm{~mm}$; C, adolescent, $45 \mathrm{~mm}$; D, transitional adolescent, $52 \mathrm{~mm}$. See also Text-fig. 2, A and B.

but in the post-larva. In the larva there are four major longitudinal rows on each side: (1). There is a series of stellate blotches along each side of the dorsal profile from nape to immediately beyond the vertical from the end of the anal fin; each spot occupies an entire myomere and almost fuses with its neighbors, so that the general effect is of a dorsal band of pigment. (2). Well below this, just above the lateral line, are small, compact chromatophores in a sometimes single, sometimes double, line; they extend from the last gill-arch to the vertical from the end of the dorsal fin. ( 3 and 4). Between the lateral line and the intestine, which lies beneath the myomeral body, are two rows of chromatophores, similar, but longer, lying on the lines of myomeral demarcation so that each spot in the upper row is slightly ahead of the corresponding one below. Anteriorly the majority are dendritic, and there is a small amount of pigment between the rows throughout the series. Small chromatophores are sparsely scattered on the crown of the head, on the posterior portion of the ventral finfold, on the 
dorsal surface of the end of the gut and on the anal fin; the isthmus is rather densely pigmented.

In the post-larva the 3 lateral rows of subdermal pigment spots are increased to 8 or 9 , while the dorsal profile series of spots is supplemented by an irregular line of much smaller dots between and above them. All of the lateral spots follow the outlines of the myomeres, as in the larvae, and the main profile series still contains one blotch to each myomere. There is, in addition, a light general coating of pigment. In subsequent stages these chromatophores gradually disappear, the dorsal series remaining longest. In our 50 and $52 \mathrm{~mm}$. transitional adolescents the dorsal row is still visible externally through the skin, and, when the skin is removed, this row alone is sharply marked; the lateral rows are traceable only as dull blotches.

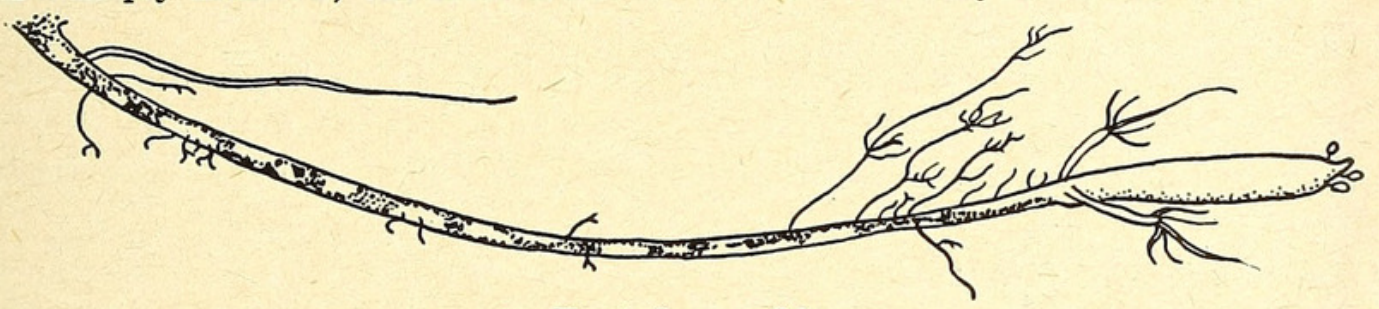

Text-figure 22.

Leptostomias gladiator. Typical barbel of late transitional adolescent (after Regan \& Trewavas).

Larval Teeth: Premaxillary with 7 pairs of teeth all directed straight forward; the maxillary holds 18 teeth, all erect; they are minute and closeset anteriorly, but increase in size posteriorly with progressively larger spaces between; in each half of the mandible are 12 teeth, in the front of the jaw only, placed close together; they are all directed straight outward and increase in size posteriorly.

Larval Gill-rakers: Long, spiny rakers present on first 3 arches, and low, spiny mounds on last $2 ; 8$ or 9 rakers on first ceratobranchial.

Fins: Dorsal and anal rays not of complete number in larva, the anal beginning under the second third of the dorsal, instead of beneath its origin or slightly in advance, as in mature fish. Finfolds moderately deep.

\section{STUDY MATERIAL.}

The following list gives the catalogue number, depth, in fathoms, date, length and growth stage of each specimen of Leptostomias gladiator taken by the Bermuda Oceanographic Expeditions. All were caught in the cylinder of water off the Bermuda coast described in Zoologica, Vol. XVI, No. 1, p. 5 and Vol. XX, No. 1, p. 1.

No. 10,197; Net 131; 800 F.; May 27, 1929; 13 mm.; Larva.

No. 10,481; Net $171 ; 600 \mathrm{~F}$; J June 6,$1929 ; 41 \mathrm{~mm}$.; Post-larva.

No. 10,992; Net 218; $600 \mathrm{~F}$; June 25, 1929; $45 \mathrm{~mm}$.; Post-larva.

No. 11,751 ; Net $316 ; 600 \mathrm{~F}$; July 23,$1929 ; 45 \mathrm{~mm}$.; Post-larva.

No. 11,942; Net $341 ; 700$ F.; July 30,$1929 ; 39,42$ mm.; Post-larvae.

No. 13,105a; Net 424; 600 F.; Sept. 5, 1929; 50 mm.; Trans. Adolescent.

No. 13,396; Net 456; 1,000 F.; Sept. 10, 1929; 52 mm.; Trans. Adolescent.

No. 13,888; Net 518; 1,000 F.; Sept. 28, 1929; $30 \mathrm{~mm}$; ; Larva.

No. 16,174 ; Net $725 ; 500$ F.; June 26,$1930 ; 18$ mm.; Larva.

No. 16,928; Net 776; $500 \mathrm{~F}$;; July 5, 1930; $45 \mathrm{~mm}$.; Adolescent.

No. 16,865; Net 794 ; $800 \mathrm{~F}$.; July 9,$1930 ; 13 \mathrm{~mm}$.; Larva.

No. 17,743 ; Net $834 ; 400$ F.; Sept. 4, 1930; $14 \mathrm{~mm}$.; Larva.

No. 20,863; Net 1021; 600 F.; June 16, 1931; 42 mm.; Post-larva.

No. 21,316; Net 1075; 50 F.; July 11, 1931; 23 mm.; Larva.

No. 21,314; Net 1077; 300 F.; July 11, 1931; 38 mm.; Post-larva.

No. 21,340; Net 1079; 50 F.; July 14, 1931; 12, $16 \mathrm{~mm}$.; Larvae.

No. 21,508; Net 1095; 600 F.; July 24, 1931; 20 mm.; Larva.

No. 24,052; Net 1209; 1,000 F.; Aug. 20, 1931; 45 mm.; Post-larva. 
SYNONOMY AND REFERENCES.

Nematostomias gladiator:

Zugmayer, 1911.1 , p. 76 ; pl. III, fig. 5. (1 specimen; $270 \mathrm{~mm}$; 4,900-0 m.; eastern North Atlantic).

Melanostomias problematicus:

Parr, 1927, p. 46, figs. 26, 27, 28A. (1 specimen; $172 \mathrm{~mm}$; 7,000 ft. wire; Bahamas). Examined by present authors.

Melanostomias gladiator:

Parr, 1927, p. 48, fig. 28 (Résumé of type description of $N$. gladiator). Deep).

Roule \& Angel, 1933, p. 17. (1 specimen; $70 \mathrm{~mm}$; 0-250 m.; Monaco

Fowler, 1936, p. 210. (Résumé of type description of $N$. gladiator).

Leptostomias problematicus:

Regan \& Trewavas, 1930, p. 61, fig. 41A. (Résumé of type description of $M$. problematicus).

\section{Leptostomias gladiator:}

Regan \& Trewavas, 1930, p. 61, fig. 41B. (Résumé of type description of $M$. gladiator).

\section{Leptostomias ramosus:}

Regan \& Trewavas, 1930 , p. 61 , figs. 10B, 11C, 12B, 42. (12 specimens, 56 to $180 \mathrm{~mm}$.; 150 to $1,000 \mathrm{~m}$. wire; north Atlantic between $20^{\circ}$ and $40^{\circ} \mathrm{N}$. Lat.). Several specimens, including the largest, examined by present authors.

Beebe, 1933.1, p. 180. (Preliminary list of Bermuda specimens).

Beebe, 1937, p. 199. (Preliminary list of Bermuda specimens).

\section{Genus Echiostoma Lowe, 1843.}

(See also pp. 70, 73, 75, 79, 80, 82, 84-86, 88-91, 96, 99, 102, 105, $106,108,110)$.

(Text-figs. 2, 11, 12, 23-27 incl.).

\section{General Discussion.}

Five species of melanostomiatids properly referable to Echiostoma have been described, namely, $E$. barbatum Lowe, $1843 ; E$. tanneri Gill, $1883 ; E$. ctenobarba Parr, 1927; E. guentheri Regan \& Trewavas, 1930; and E. calliobarba Parr, 1934. In addition, Parr described a subspecies, E. ctenobarba ramifera, in 1934.

The type specimens of $E$. barbatum and $E$. guentheri differ from the others in having a single, unbranched, terminal appendage at the distal end of the barbel. From each other they differ chiefly in that E. guentheri has longer, more numerous and more extensive stem filaments and a more swollen bulb.

Specimens referred to $E$. tanneri are distinguished by the presence of two well-developed bulbs and very long stem filaments.

$E$. ctenobarba and $E$. calliobarba were erected for specimens each having only one terminal bulb, or none at all, and relatively short stem filaments. $E$. calliobarba and the subspecies of $E$. ctenobarba were differentiated on the basis of details of the extent and length of the lateral filaments, of the branching of the terminal filaments, and of the apparent presence or absence of a whitish body near the end of the barbel, and of the relative size of the postorbital light organ. As our series of barbels shows (Text-fig. 26), all of the barbel characters merge into one other, and may logically be laid to 
individual variation, and to the different lengths at which individuals lose their juvenile characters. Variation, and, to a small extent, sexual dimorphism, is also found in the relative length of the postorbital organ.

The Bermuda specimens divided themselves very readily into this ctenobarba-calliobarba form and into typical $E$. tanneri. When the internal organs were examined, however, it was found that every one of the 8 ctenobarba-calliobarba-like examples (measuring between 268 and $355 \mathrm{~mm}$. in length) was an adult near breeding condition, while the 5 typical specimens of $E$. tanneri (between 60 and $195 \mathrm{~mm}$. in length) were transitional adolescents with scarcely developed gonads and short, partially pigmented stomachs. Furthermore, our $268 \mathrm{~mm}$. specimen, the smallest that could be called an adult, showed distinct remains of 2 barbel bulbs and stem filaments intermediate in length between those of the largest tanneri example and the other adults. Similarly, the type and other specimens of $E$. tanneri at the U. S. National Museum are all small specimens measuring under $200 \mathrm{~mm}$., and the largest Dana example of the species is recorded as being $223 \mathrm{~mm}$. long. In addition, Dr. Parr has permitted us to open his series of E. ctenobarba and E. calliobarba, measuring 275 to $297 \mathrm{~mm}$., with the result that they prove to have adult characters.

In view of the identity of proportions, counts, teeth and osteological characters (allowing only for differences, such as number of maxillary teeth, which are definite age characters), we think it unquestionable that these three species are identical, and hence synonymize them under E. tanneri, the oldest name. An exactly similar case of a reduction of the barbel bulb in adults is found in Photonectes margarita, (see p. 177), and of the reduction of lateral filaments in Chirostomias pliopterus (p. 111).

By analogy, it seems certain that E. guentheri Regan \& Trewavas, 1930, is a young specimen of $E$. barbatum Lowe, 1843.

E. microdon Günther, 1878 is the genotype of Pachystomias; E. richardi Zugmayer, 1911, and E. margarita Goode \& Bean, 1895, belong in the genus Photonectes (see p. 155).

Distribution: E. barbatum (including $E$. guentheri) is known only from 2 specimens, both taken at Madeira. E. tanneri, of which more than 100 specimens have been captured, occurs in both north and south Atlantic, between about 65 and 959 fathoms.

\section{GENERIC ChARACTERS.}

Color (summarized from observations on 6 living adult specimens of $E$. tanneri taken by the Bermuda Oceanographic Expeditions; postorbital light organ color of $E$. barbatum recorded by Lowe, 1843, rosy red): General color blackish-brown. Postorbital rosy red anteriorly, white posteriorly. End of barbel bulb pinkish. Serial and non-serial photophores violet to scarlet; longitudinal luminous bands, bluish-white.

Proportions: Moderately elongate melanostomiatids; depth in length 5.7 to $8(12.5 \%$ to $17.5 \%)$; head in length 6.2 to $7(14.3 \%$ to $16 \%)$; eye in head 5 to 7 (2.1\% to $2.6 \%$ of length); snout less than twice length of eye; snout to pelvic origin in length 1.7 to 1.8 (56\% to $59 \%$ ).

Barbel: Shorter than head with a row of filamentous or papilliform processes (sometimes almost atrophied) on each side of distal part of stem; two bulbs well developed in young, almost or completely atrophied in adults; one or more moderately thick terminal filaments.

Light Organs: Postorbital (measured as length of area of transparent skin) about $1 \frac{1 / 4}{4}$ to 2 times diameter of eye in both sexes, contained 3 to 5 times in head. Serial photophores with the following counts: ventral series, I-P $8+2, \mathrm{P}-\mathrm{V} 25$ to $27, \mathrm{~V}-\mathrm{A} 16$ to 18 , of which only the last one is above the anal fin, A-C 11 to 13; lateral series, O-V 24 to 26 , V-A 16 to 18. Tiny, non-serial photophores well developed. 


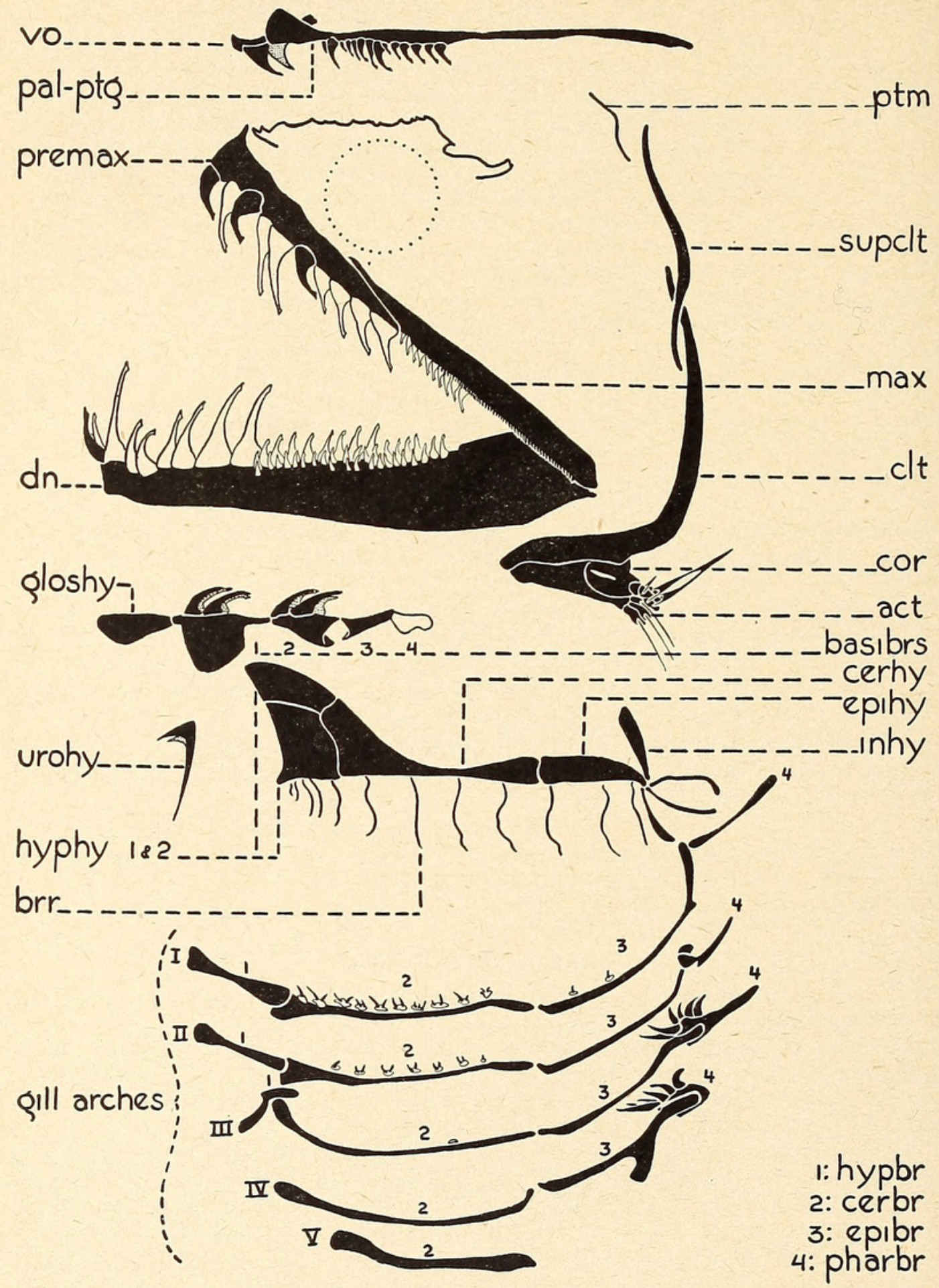

Text-figure 23.

Echiostoma tanneri. Jaws, hyoid and branchial arches, and pectoral girdle of adult, standard length $325 \mathrm{~mm}$. Explanation as in Text-fig. 18.

Teeth: Cleft of mouth straight. Premaxillaries and mandible with close-set, curved, bicuspid fangs, all depressible except 1 to 3 in each jaw; mandibular teeth in 2 or 3 rows posteriorly; maxillary with 5 to 10 erect teeth and a long series (up to 50) of oblique denticles, 


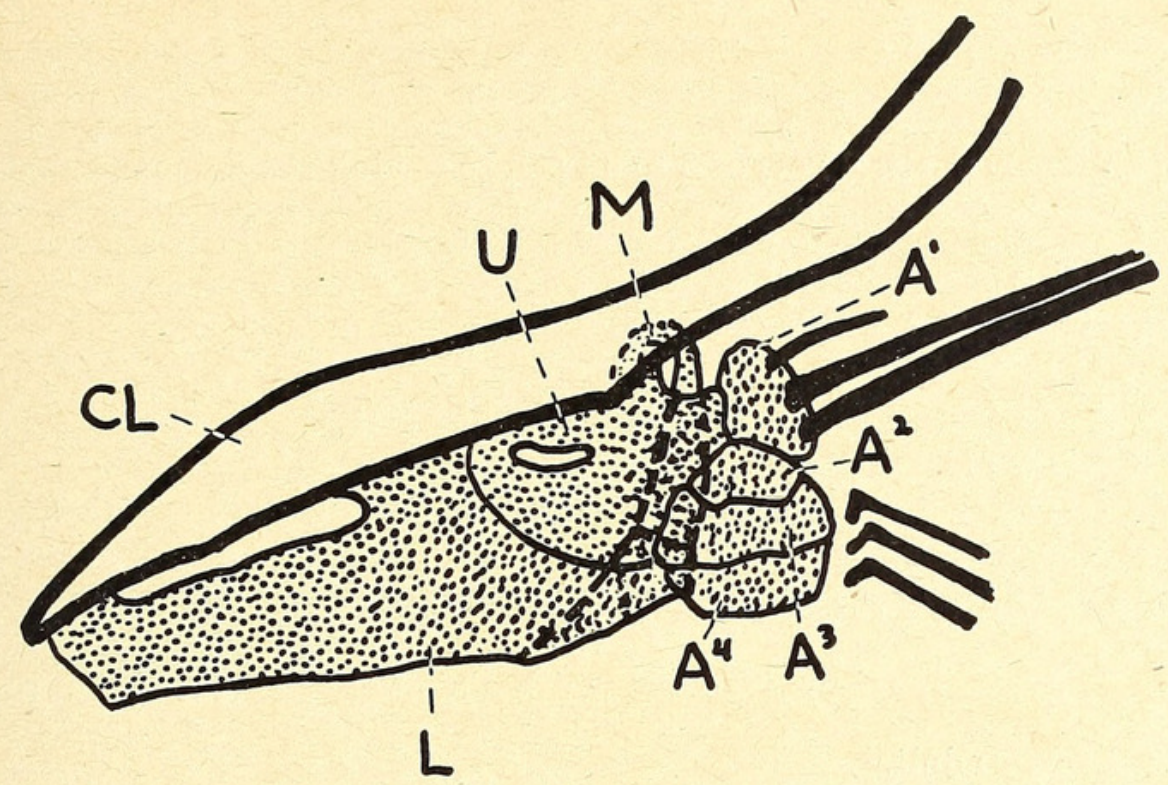

Text-figure 24.

Echiostoma tanneri. Supporting bones of pectoral fin in adult, standard length $325 \mathrm{~mm}$. Abbreviations as in Text-fig. 14.

the anterior ones usually placed above the last few erect teeth; a pair of teeth on the vomer; a series of 3 to 12 teeth on each palatine. Usually 4 pairs on the basibranchials. Teeth, practically all in pairs, present on first and second gill-arches only: on first and second ceratobranchials and on first epibranchial; about 10 pairs on first ceratobranchial.

Branchiostegal Rays: 13 to 15.

Fins: Pectoral with 4 rays apparent externally; 1 isolated and produced, and 3 short rays; cleared and stained specimens, however, show that the isolated ray is composed of two rays united by a common sheath; in addition there is a rudimentary, subdermal ray in front of the isolated pair; the fin is inserted far forward; under the opercle. Pelvic 8, inserted well behind the middle of the length at about the 32nd vertebra. Dorsal 12 to 16 ; anal 15 to 19 ; dorsal and anal beginning at same vertical, but anal extending farther back.

Epidermal Grooves: There is a pronounced groove in the isthmus for the reception of the barbel.

Osteology: Mesethmoid without lateral processes; frontal ridges and pterotic canal-and-pore system strongly developed, with superficial patches of ossification around nostrils and behind pterotics; parietals absent; posttemporal rudimentary; supra-cleithrum and cleithrum moderately strong; all coracoid elements large except upper arm of mesocoracoid; actinosts 3 ; vertebrae 57 to 59 ; first vertebra represented only by a fibrous ring, shorter than a centrum, enclosing the notochord and by a spinal nerve.

Coelomic Organs: Stomach $45 \%$ of standard length, reaching well beyond pelvic origin; 2 pyloric caeca. Apparently ripe ovarian eggs, preserved in alcohol, measure $.72 \mathrm{~mm}$. in diameter.

Sexual Dimorphism: Postorbital light organ of female, although well developed and functional, slightly smaller than that of male.

Size: The largest known specimen measures $355 \mathrm{~mm}$. in length (375 $\mathrm{mm}$. long, weight $12 \mathrm{oz}$., when freshly caught), and is a female in or close to breeding condition, taken by the Bermuda Oceanographic Expeditions. 
Development: Larva and post-larva unknown. Adolescent of $E$. tanneri with subdermal series of pigment spots as follows: Each myomere has, typically, a dorsal, dendritic blotch immediately below the dorsal mid-line, and an obliquely vertical row of 3 to 5 dots, following the myomeral boundary, between the lateral mid-line and the series of photophores. Adolescent and transitional adolescents have two large barbel bulbs which almost or completely disappear in the adult; some of the barbel stem filaments similarly often partially or completely atrophy.

\section{SYNOPSIS OF THE SPECIES.}

The following key may be adopted:

A. Barbel with a single, simple, terminal appendage ......E. barbatum.

AA. Barbel with one or more compound terminal appendages.

B. Barbel with two distinct bulbs; stem filaments well-developed E. tanneri, young.

BB. Barbel without bulb, or with a single, small one; stem filaments reduced in length, and often also in number . . E. tanneri, adult.

\section{Echiostoma tanneri (Gill, 1883).}

(See also p. 130).

\section{SPECIMENS TAKEN By THE BeRMUdA OCEANOGRAPHIC EXPEDITIONS.}

13 specimens; May to September, 1929 to 1931; 500 to 900 fathoms; from a cylinder of water 8 miles in diameter ( 5 to 13 miles south of Nonsuch Island, Bermuda), the center of which is at $32^{\circ} 12^{\prime} \mathrm{N}$. Lat., $64^{\circ} 36^{\prime} \mathrm{W}$. Long.; standard lengths from 61 to $355 \mathrm{~mm}$.

\section{SPECIMENS PREVIOUSLY RECORDED.}

More than 100 specimens; between ca. 65 and 959 fathoms; north and south Atlantic; standard lengths from 20 to $297 \mathrm{~mm}$.

\section{DESCRIPTION OF ADULT.}

With the characteristics of the genus. Barbel with one or more, compound, terminal filaments. Papillae or filaments on stem numbering from one to about a dozen pairs. Three longitudinal bands of luminous material running the entire length of the body from opercle to tail; one, the broadest, immediately below the dorsal mid-line; one, narrow, between the lateral

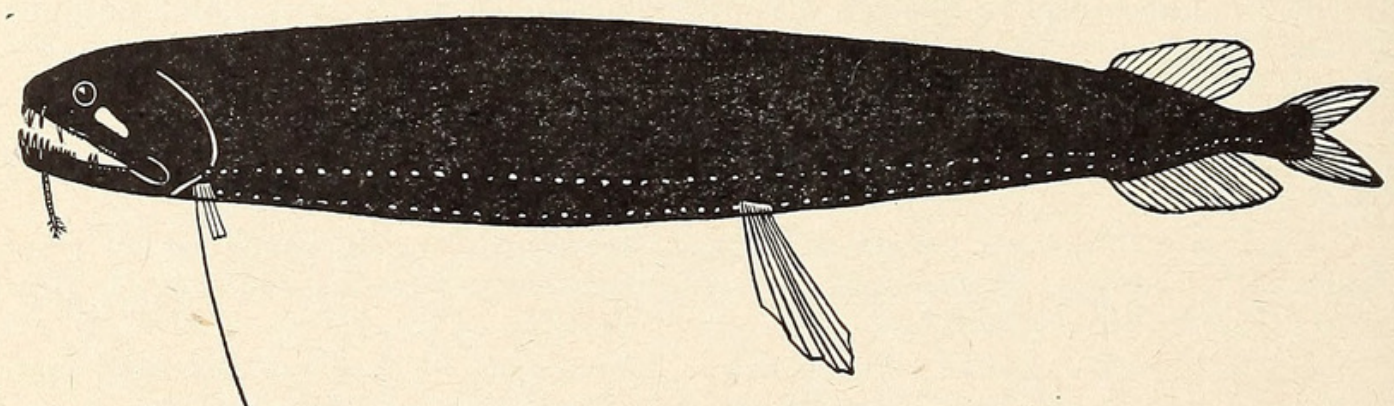

Text-figure 25.

Echiostoma tanneri. Adult, standard length $325 \mathrm{~mm}$. 
and ventral series of photophores; and one, also narrow, between the ventral series and the ventral mid-line.

Color, Luminescence and Behavior: These three topics are so closely connected that it is advisable to treat them together. Five adults, including both males and females, and the largest transitional adolescent (192 mm. long) were captured alive and, with the aid of the refrigerator and, in two cases of adrenalin injections, lived between two and six hours after reaching the laboratory. In the dark-room an ultra-violet lamp was used to aid in the observation of luminous areas. Several fish were in especially good condition, twisting and snapping continually during the entire time they remained alive. Between periods of observation, the fish were placed in the refrigerator, which always revived them greatly. Excellent moving pictures were made.

In the dark-room the fish gave a most wonderful display of lights, from which the following deductions were made. In general, direct correlation was found between the color of the various organs in daylight, and the luminescence given off by them.

General Skin Color: In daylight, blackish-brown. A broad band of whitish tissue along each side of upper part of body, and two duller, narrow stripes on lower part of side (see below).

Barbel: The barbels of adults showed very little color, only faint washes of pink through the unpigmented portions. On the other hand, the barbel bulbs of all of the transitional adolescents taken were emerald green with a buffy sheath, while the stem and terminal filaments were violet blue tipped with bright mallow purple. No luminescence was observed from this organ in young or adults, although the least touch, or even a slight stirring of the water near the barbel, would arouse the fish to the utmost, so that it thrashed about and snapped, striving to reach and bite the source of irritation. Again and again we proved the astonishing sensitiveness of this organ. Obviously the barbel is primarily an organ for detecting vibrations in the water.

Postorbital Light Organ: In the adults, in daylight, the upper anterior portion of this light, and sometimes the entire anterior half, was invariably bright phlox pink and the remainder creamy white, the whole organ having a glistening, waxy look. In the dark room, however, both with and without the use of the ultra-violet lamp, this organ in two cases gleamed dully with a pinkish glow. In two other individuals it gave forth strong bluish or bluish-white flashes, sometimes at long intervals, sometimes almost between winks, both with and without stimulation.

In the living transitional adolescent, on the other hand, while the anterior portion of the organ was pink, as in adults, the posterior was distinctly silvery green, instead of creamy white. Whenever the fish twisted and turned and snapped, the cheek lights blazed out. Eight times this happened and eight times there shot forth a strong, clear, greenish-white light which momentarily lighted up all our faces. Twice we saw a distinct rosy or deep pink light from the same organ. As two-thirds of the photophore is pink in color, there must be an extremely delicate and localized control of the area, and of the color of the light.

The cheek light did not revolve down into its socket, although this movement is possible, in order to obliterate or interrupt a steady gleam, but, as in all the other body lights, the luminescence was thoroughly under the control of the fish. The overhanging, pigmented "eave" of the organ protects the eye from the direct glare. When viewed from directly above, both cheek lights could sometimes be seen full on at once. In one case, the most powerful flashes occurred immediately before death.

Serial and Non-serial Photophores: The organs in daylight were violet in the young with silver or gold caps, and scarlet in the adults. The luminescence in all, however, was rosy to deep scarlet, deepest in the adult. 

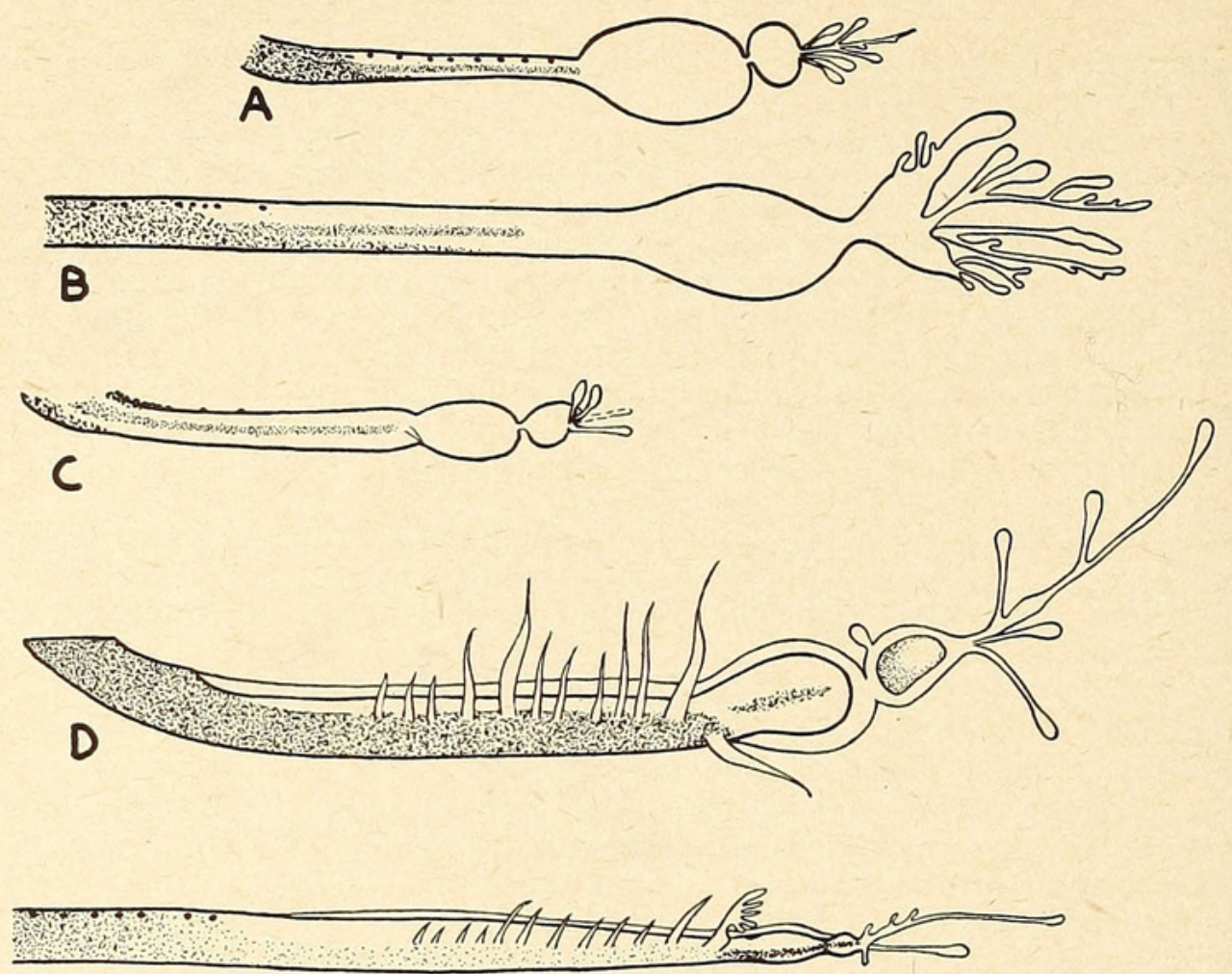

E
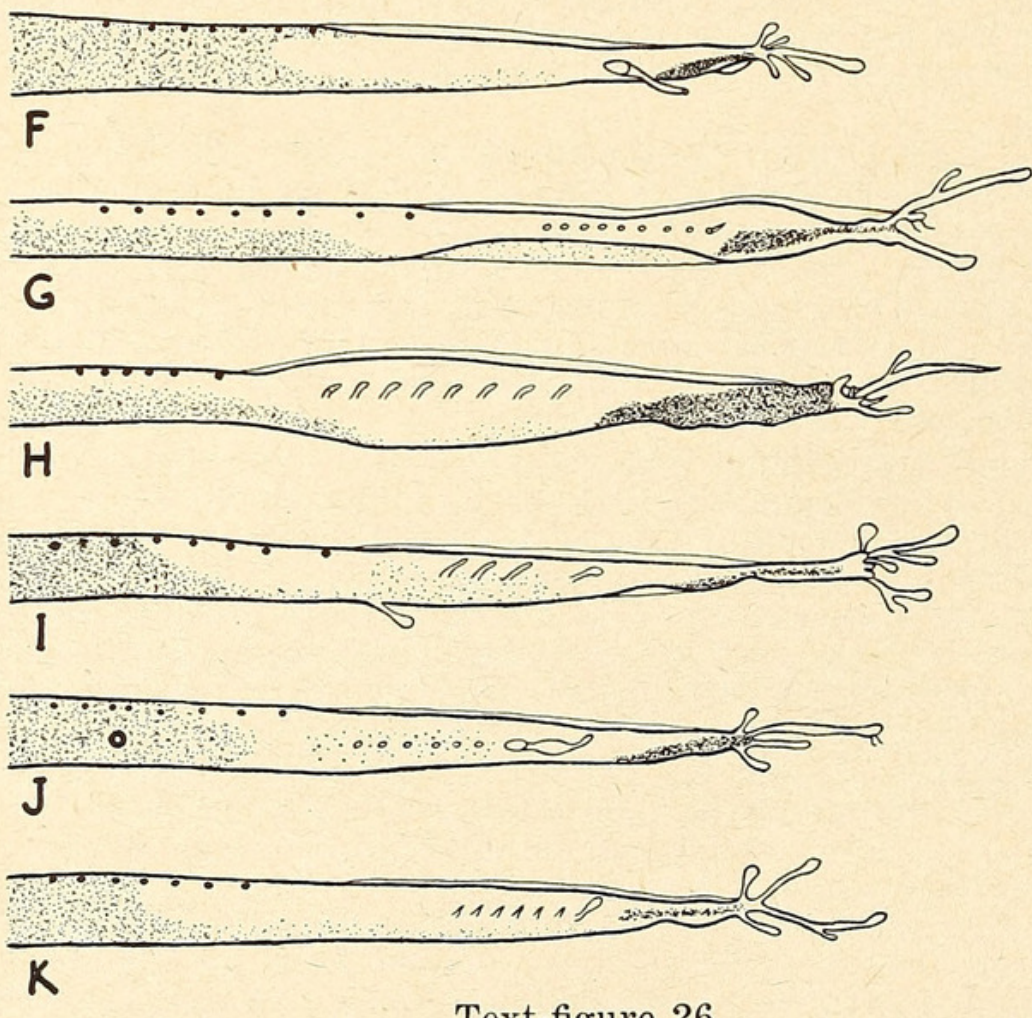

\section{Text-figure 26.}

Echiostoma tanneri. Lateral views of barbels. A, transitional adolescent, standard length $39 \mathrm{~mm}$.; B, same, $61 \mathrm{~mm}$.; C, same, $115 \mathrm{~mm}$. (female); D, same, $192 \mathrm{~mm}$. (male); E, F, G, H, adult males, $268 \mathrm{~mm} ., 273 \mathrm{~mm}$., $285 \mathrm{~mm}$. and $302 \mathrm{~mm}$., respectively; I, J, K, adult females, $315 \mathrm{~mm}$., $333 \mathrm{~mm}$. and $375 \mathrm{~mm}$., respectively. A, after Regan \& Trewavas; others from specimens in present collection. $\mathrm{A}$ and $\mathrm{B}, \times 9.6 ; \mathrm{C}-\mathrm{K}$, incl., $\times 3.9$. 

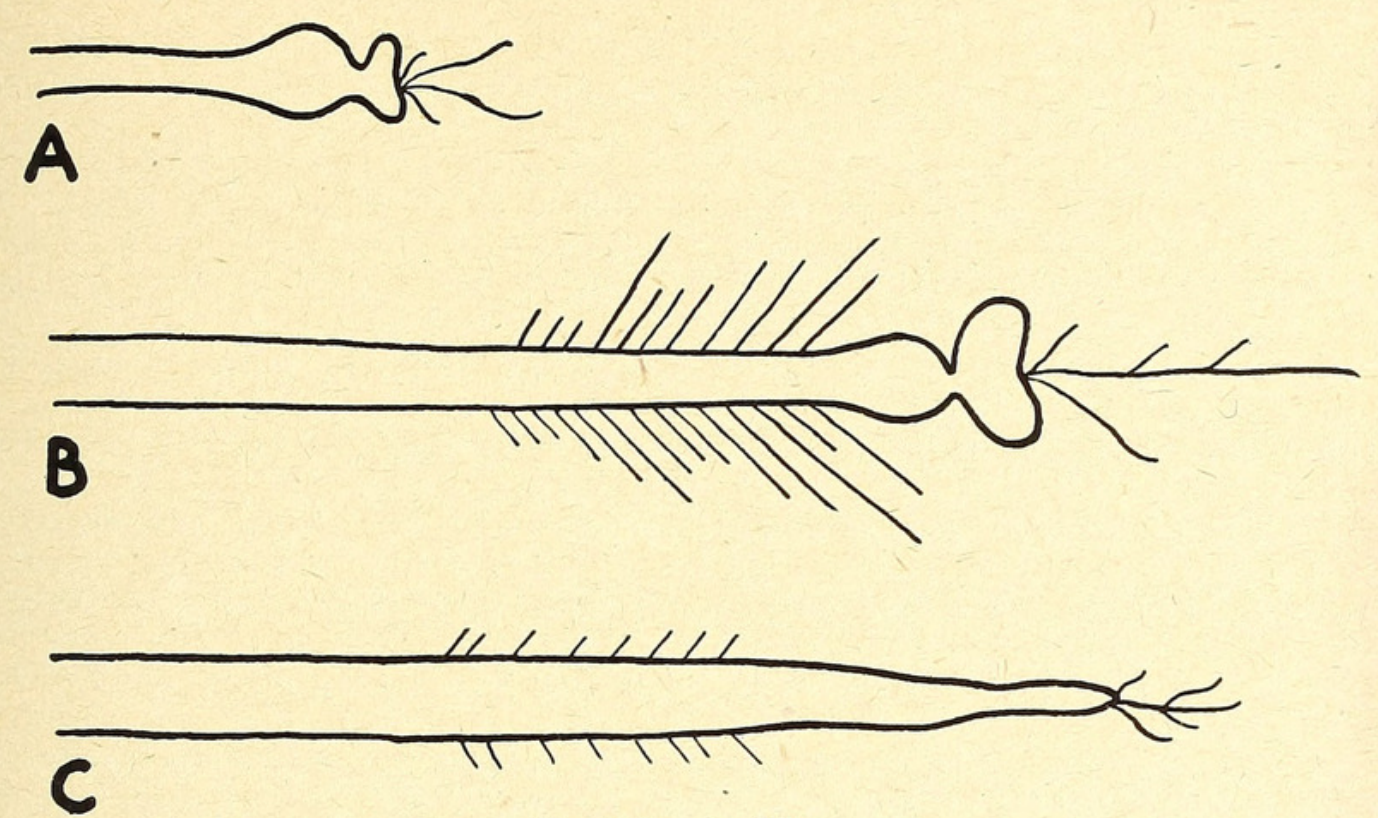

Text-figure 27.

Echiostoma tanneri. Diagrams of barbels, anterior views. A, adolescent and early transitional adolescent; B, late transitional adolescent; C, adult. In the adult the barbel becomes literally reduced in size and is actually smaller than that of moderate-sized transitional adolescents (see Text-fig. 26, D and F).

The small cephalic and trunk photophores of all were rosy red to deep purple. Every light was directed downward. See p. 138 for a description of the distribution of these small organs.

Luminous Tissue: The body light seemed to be of two kinds, illumination of the photophores, which we could see with a hand lens placed close to the surface of the water, and a general illumination of the whole skin by a greenish-white glow, although in the young the actual back was always dark, without a trace of the dorsal luminous bands observed in adults.

When the adults were placed under the fluorescent screen of the ultraviolet lamp, the luminescent areas were very distinct. Down the middle of the back two widely separated lines of bluish-white extended from nape to tail. These were broad and very irregular, narrowing and expanding and sending out short lines at irregular intervals. Below these were two additional pairs of the same type of line, but much narrower and more linear; one pair extended between the lateral and ventral series of photophores, and the second pair close together, on each side of the ventral profile. Over the cheek were scattered small, irregular blotches formed of grayish-white.

All of the fins were unquestionably luminous, and all the rays were permeated with scarlet blood vessels, the corpuscles moving regularly. Even the short webs of the pectoral were luminous, while the long, isolated ray was shining bluish-white, except for an external, broad band of skin which was, in daylight, brown with a series of a dozen or more photophores on its proximal portions; the second or third of these photophores was at least twice as large as the others. The membranes connecting the three short rays contained one or two layers of white, oval, luminous granules; down each ray were scattered about a dozen small glands, probably giving out mucous. Touching or moving the pectorals drew no apparent response from the fish, although a touch on the side of the body, especially near the tail, usually aroused an immediate reaction.

The bases of the teeth appeared pale blue in daylight, and were faintly luminous in the dark-room. 
One specimen gave out a brilliant flash, at least a third as bright as that from the postorbital organ, from an undetermined spot near the beginning of the anal fin.

Special Activity Observations: All of the living specimens were vigorous, swimming strongly and snapping until a short while before death. In the most lively, the breathing was at a rate of 2 to 3 respirations a second; when feeble, only half as fast. The mouth was not seen to close, and the gill openings were never quite shut, the gills protruding beyond the opercle.

Viewed from above, when the fish was swimming normally upright, the gill covers were seen to open widely with all the gills showing expanded and deep red, being much more visible than is the case with any ordinary, adult fish.

When adrenalin was injected, the point of puncture became luminous at once, and little by little the illumination-yellowish in this single casespread along the side. The small organs even along the dorsal profile became distinctly luminous and the hyoid line especially so, while the round granules along the short pectoral rays and all of the pelvic rays shone out clearly. (See Harvey, 1931, p. 67 ff.).

In the light of the above experiences with this species, Gill's only specific description of the fish, although not very scientific, was exceedingly vivid and quite characteristic: "a black fish with formidable teeth, which was so lively when brought to the surface that it twisted itself around in its attempt to bite the commander of the vessel, Captain Tanner."

Arrangement of Small, Non-serial Photophores: An adult male, in or near breeding condition, and measuring $325 \mathrm{~mm}$. in length, was depigmentized in potassium hydroxide solution for about 36 hours, so that even the smallest organs were clearly visible in the now pallid skin. Since the exact arrangement and distribution of these lights has never been described, the following detailed account is given:

Head: In addition to the minute, apparently atrophied, suborbital and the large postorbital photophores, the light organs of the head are of four types:

1. On each side there is an irregular, broken line of about 14 small, dark organs, each about a third the size of a nostril; the line extends, just above the level of the eye, from the nostrils to the upper base of the opercular flap. The separate organs of the two sides correspond to one another in position.

2. The second type, forming the majority of the cephalic photophores, consists of organs also dark, but much smaller, the largest being not more than a fourth as large as the preceding. They are scattered without discernible pattern over the sides of the snout, along the margins of both upper and lower jaws, on the inside of the maxillary, on the roof of the mouth at least as far back as the palatines, around the eye in a close-massed ring (except for a short section of the anterior upper margin), on the cheeks and on the opercles. The organs are densest along the snout and mandible, scarcest in a small area on the posterior portion of the cheek, and completely absent on the top of the snout and head between the two series of larger organs (type 1, above). There are altogether about 300 of these small organs on each side of the head, not counting those on the inside of the mouth. They vary slightly in size and are not found in exactly the same relative position on the twa sides.

3. The third variety is infinitesimal in size and only visible to the naked eye as vertical, pale golden streaks formed by the collection of innumerable organs into irregular lines of varying length, the individuals in each line being set very close together. These are found all over the head, jaws and opercles.

4. Finally, there are numbers of small, whitish luminous patches scat- 
tered over the whole head (with the exception of the cheeks), jaws and opercles. These are thickest and most conspicuous on the snout, between the eyes and around the mandible.

Trunk Organs: (Above the regular, lateral series of photophores): The organs of the trunk may be divided into the same groups as those of the head, except that there are none corresponding in size to those of the first group described above.

Those corresponding to the second group (small, dark, and visible to the naked eye) are arranged in about sixty vertical series which extend from the opercles to the caudal, and from about a fifth of the distance from the dorsal mid-line to immediately above the lateral series of photophores-one series to each myomere. Each series consists of one or two dorsal photophores separated by a considerable gap from the 10 to 20 organs below them. The latter are sometimes arranged in a single, unevenly spaced line, but more often in an irregularly double row. The number in each series decreases toward the tail, and it is there that single rows are dominant.

The smallest, light-colored organs, as on the head, are innumerable, and in general are confined to outlining the myomeres, although there are a few odd ones scattered in the interspaces, and along the back.

The luminous patches seem confined to the broad, longitudinal band described earlier in this account (p. 137).

Ventral Organs: The same groups are found as on the trunk.

The small, dark organs are closely massed in a roughly double row down the midline of the isthmus. Between the lateral and ventral rows of serial photophores they are extremely numerous and quite irregular, the only semblance of arrangement being in the semi-circular arch of six or seven organs above each photophore of the ventral series. Each of the serial photophores is surrounded by a clear space.

The smallest, light-colored organs are comparatively few, and are grouped into short, broken lines similar to those on the head and without apparent pattern, except that a line of them runs between each two photophores.

Two bands of the small, whitish luminous patches present below lateral and ventral series, respectively, as described on p. 000 .

Fins: A single row of small, dark organs, the second or third at least twice as large as the others, extends out along the isolated ray of the pectoral fin for a distance at least equal to the length of the head. The webbings of all the fins contain one or more layers of whitish, luminous granules.

It is probable that the smallest organs described above on both head and body are not strictly photophores, but glands giving off luminous mucous.

\section{DEVELOPMENT.}

The Bermuda collection contains no very young specimens, the youngest being five transitional adolescents measuring between 61 and $192 \mathrm{~mm}$., and differing from adults in the usual details typical of transitional adolescence (see p. 000). Their own particular characteristics are the pronounced development of 2 barbel bulbs and the great number and length of the stem filaments, which pass through a stage when they are literally longer than in the adult. Also, there is an actual shrinking in length of the whole barbel after the specimen becomes adult. The remaining specimens in the collection consist of 5 males between 268 and $325 \mathrm{~mm}$. in length, and 3 females between 315 and $355 \mathrm{~mm}$. All may be counted as adults, since the gonads are very well developed, those of the 2 largest males and 2 largest females being apparently in full breeding condition. The smallest counted as an adult (268 $\mathrm{mm}$.) shows unmistakable connections in the form of the barbel with the 
double-bulbed transitional adolescents (Text-fig. 26E). We were able to determine sex in all specimens of $115 \mathrm{~mm}$. and over.

The Dana collection fortunately contains specimens as small as $20 \mathrm{~mm}$. in length, and Regan \& Trewavas (1930, p. 117) give the following details of the growth of barbels and maxillary teeth in adolescents and transitional adolescents: postocular small (from about 1/20 of head, or half diameter of eye); no filaments above barbel bulb in specimens under $90 \mathrm{~mm}$., or, between 75 and $90 \mathrm{~mm}$., the distal pair may be represented by buds; 2 or 3 pairs of short filaments in specimens of 95 and $96 \mathrm{~mm}$.; at $133 \mathrm{~mm}$. there are 3 or 4 long filaments on each side and 4 to 6 buds; in larger specimens, 142 to $153 \mathrm{~mm}$., there are 12 or 13 pairs of filaments, and in the $223 \mathrm{~mm}$. specimen 15 to 18 , several being branched. Thus the maximum barbel development occurs during late transitional adolescence. It will be noted that in adults it is the more distal stem filaments which persist; often vestiges of the more proximal pairs can be detected subdermally. Maxillary with a few oblique teeth, 6 to 9 in examples of $35 \mathrm{~mm}$.; in specimens of 75 to $95 \mathrm{~mm}$. there are 3 or 4 fangs and 15 oblique teeth; in specimens of 130 to $223 \mathrm{~mm}$., 6 or 7 fangs and 18 to 25 oblique teeth. As has been said, in our largest female $(355 \mathrm{~mm}$.) there are more than 50 oblique maxillary teeth.

Thanks to the kindness of Dr. Norman, we have been able to examine two of the smallest of the Dana series from the British Museum, and to determine the presence of subdermal larval pigment spots. Each myomere is marked by one large stellate blotch immediately below the dorsal mid-line, and an oblique row of 3 to 5 small dots, following the myomeral boundary, between the lateral mid-line and the lateral series of photophores. (Text-fig. $2 \mathrm{H})$.

\section{ECOLOGY.}

Vertical and Season Distribution: The 13 specimens were taken singly from May to September between 500 and 900 fathoms. Specimens apparently in full breeding condition were taken in July and August.

Food: Only two of the stomachs or intestines showed any food. The first, a specimen of $115 \mathrm{~mm}$., contained one fish eye and a piece of crustacean cuticulum; the second, $154 \mathrm{~mm}$. long, held a $67 \mathrm{~mm}$. Lampanyctus polyphotis Beebe, described in 1932 and previously known from the Bermuda type alone, a specimen only $40 \mathrm{~mm}$. in length.

Since six of the specimens were alive and active after trawling, it is reasonable to suppose that at least some of the others may have lived for a time in the net; this would have allowed time for digestion of food before death, which seems a better explanation for the lack of food than the alternative one that these active, well-armed fishes feed only at long intervals. This is especially likely since the abdominal wall is very thick and not as greatly distensible as in some forms, such as Chiasmodon, which can swallow such enormous fish that the food supply thus obtained is presumably adequate for long periods.

Enemies: A specimen of Echiostoma has been taken from the stomach of a swordfish (Xiphias gladius) (Kingsley, 1922, Science, N. S., Vol. LVI, pp. 225-226).

Parasites: Several small round worms, probably nematodes, were usually present in the intestine.

\section{STUDY MATERIAL.}

The following list gives the catalogue number, depth in fathoms, date, length and growth stage of each specimen of Echiostoma tanneri taken by the Bermuda Oceanographic Expeditions. All were caught in the cylinder of water off the Bermuda coast described in Zoologica, Vol. XVI, No. 1, p. 5 and Vol. XX, No. 1, p. 1 . 
No. 10,125; Net $116 ; 900$ F.; May 18, 1929; 315 mm.; Adult Female.

No. 10,882; Net 212; 600 F.; June 24, 1929; $302 \mathrm{~mm}$.; Adult Male.

No. 11,183; Net 245; 800 F.; July 1, 1929; $333 \mathrm{~mm}$.; Adult Female.

No. 12,976; Net 412; 800 F.; Sept. 3, 1929; $154 \mathrm{~mm}$.; Trans. Adolescent Male.

No. 15,054; Net 587; 500 F.; May 17, 1930; 115 mm.; Trans. Adolescent Female.

No. 15,651; Net 657; 700 F.; June 2, 1930; $192 \mathrm{~mm}$.; Trans. Adolescent Male.

No. 17,792; Net 815 ; 900 F.; Aug. 28, 1930; 285 mm.; Adult Male.

No. 20,141 ; Net $839 ; 700$ F.; Sept. 3,$1930 ; 273$ mm.; Adult Male.

No. 21,603; Net 1102; 500 F.; July 25, 1931; $325 \mathrm{~mm}$.; Adult Male.

No. 22,528; Net 1194; 700 F.; Aug. 18, 1931; 82 mm.; Trans. Adolescent.

No. 22,559; Net 1194; 700 F.; Aug. 18, 1931; 355 mm.; Adult Female.

No. 22,798; Net 1228; 500 F.; Aug. 27, 1931; 61 mm.; Trans. Adolescent.

No. 22,974; Net 1243; 700 F.; Aug. 31, 1931; 268 mm.; Adult Male.

\section{SYNONYMY AND REFERENCES.}

\section{Hyperchoristus tanneri:}

Gill, 1883, p. 256. (1 specimen; 959 fathoms; 660 miles northwest of Bermuda). Examined by present authors.

\section{Echiostoma barbatum:}

Goode \& Bean, 1895 , p. 109 ; pl. XXXV, fig. 130. ("Numerous specimens;" east of New Jersey and Old Bahama Channel). Several examples examined by present authors.

Parr, 1927, p. 53, fig. 31. (3 specimens, 28 to $48 \mathrm{~mm}$.; $800,8,000 \mathrm{ft}$. wire; south and southeast of Nassau, Bahamas). Examined by present authors.

Borodin, 1931, p. 65 (part.) (1 female, 255 mm.; 1,500 m.; off Bermuda). Examined by present authors.

\section{Echiostoma tanneri:}

Regan \& Trewavas, 1930 , p. 117 ; fig. 113 . (92 specimens; 20 to 223 mm.; 50 to 2,000 m. wire; Gulf of Mexico, Caribbean and North Atlantic). 2 small examples examined by present authors.

Norman, 1930 , p. 314 . (2 specimens; 170, $200 \mathrm{~mm}$.; 850 to $950 \mathrm{~m}$. wire; off Cape Town, South Africa).

Beebe, 1937, p. 199. (Preliminary note on specimens treated in the present paper).

\section{Echiostoma ctenobarba:}

Parr, 1927, p. 55, figs. 32 and 33. (1 male; $285 \mathrm{~mm}$.; 4,000 to 7,000 ft. wire; Bahamas, southeast of Nassau). Examined by present authors. tion).

Regan \& Trewavas, 1930, p. 117, fig. 112c. (Résumé of type descrip-

Harvey, 1931, p. 67. (Results of stimulation by adrenalin of 2 specimens in the present collection). men).

Parr, 1934, p. 16, fig. 4a. (Supplementary description of the type speci-

\section{Echiostoma ctenobarba ramifera:}

Parr, 1934, p. 17, fig. 4b. (1 female; $297 \mathrm{~mm}$.; 1,050 to $1,100 \mathrm{~m}$.; off Bahamas). Examined by present authors.

\section{Echiostoma calliobara:}

Parr, 1934, p. 15, fig. 4c. (1 female; $290 \mathrm{~mm}$; 610 to $930 \mathrm{~m}$.; off Azores).

The two small specimens ( 70 to $75 \mathrm{~mm}$.) described by Borodin (1931, p. 65) under the heading Echiostoma barbatum prove, upon examination by us, to be Photonectes margarita (see p. 000). 
Genus Melanostomias Brauer, 1902.

(See also pp. 70, 72, 73, 75, 79, 81, 82, 85, 86, 88, 90, 91, 97, 102, 103, $105,106,108-110)$.

Text-figs. 2, 10, 11, 12, 28-32 incl.).

\section{General Discussion.}

Nineteen species of Melanostomiatidae have been referred in original descriptions to the genus Melanostomias. In addition, the two species for which Regan \& Trewavas erected the genus Haplostomias (1930, p. 109) should also be referred to Melanostomias, as will be shown below. Hence a total of 21 species of Melanostomias have been described.

In addition to our study of the specimens taken by the Bermuda Oceanographic Expeditions, all of which prove to be $M$. spilorhynchus and $M$. biseriatus, we have examined all of the specimens of Melanostomias deposited in American museums, as well as two on loan from the British Museum.

Difficulties in the delineation of species are greater than usual in this genus, because only 2 characters have been found to be specifically significant, namely, the number of P-V photophores, which usually serves only to separate groups of species, and the form of the barbel. The latter is one of the last organs to achieve adult shape, since it often continues development far into transitional adolescence; also, it is frequently variable. We are convinced that many of the so-called specific differences between barbels in Melanostomias will prove to be due to growth stage characteristics and to individual variation; it is also likely that sex may be a controlling factor in barbel form, as in the genus Eustomias. Unfortunately, however, an adequate revision of the genus is impossible until additional material has been acquired, particularly fully adult examples, and specimens in European museums examined.

The following annotated list of species described up to the present may be of help to future investigators.

1. M. melanops Brauer, 1902, p. 284. Six specimens have hitherto been referred to this species: the $183 \mathrm{~mm}$. type from the Indian Ocean, 4 small specimens from the Bahamas (Parr, 1927, p. 42), and 1 specimen, $242 \mathrm{~mm}$. long from the Caribbean (Regan \& Trewavas, 1930, p. 114). We have examined Parr's material and decided that his nos. 2,066 and 2,067 are rightly referred to $M$. melanops, while the other two are $M$. melanopogon (species no. 15 below). In addition, $M$. albibarba (species no. 13), of which we have examined one of the type series, is in all probability the transitional adolescent phase of $M$. melanops.

2. M. valdiviae Brauer, 1902, p. 285. Three specimens have hitherto been referred to this species: 2 from the Indian Ocean ( 55 and $165 \mathrm{~mm}$.), and one taken by the Dana in the Caribbean $(24 \mathrm{~mm}$.). Not seen by us. Probably $M$. melanocaulus, $M$. heteropogon, $M$. stewarti and $M$. vierecki (species nos. 10, 11, 18 and 20 below) will prove to be synonymous with $M$. valdiviae. If they are thus synonymized, a hitherto unrecorded female, $101 \mathrm{~mm}$. long, in the U. S. National Museum taken by the Albatross off Brazil (U. S. N. M. No. 2,761) also belongs to this species.

3. $M$. braueri Zugmayer, 1913 , p. 3 . Already rightly referred to the genus Photonectes by Regan \& Trewavas, 1930 p. 121.

4. $M$. niger Gilchrist \& von Bonde, 1924 , p. 6 . Known only from the type specimen, $220 \mathrm{~mm}$. long, from South Africa. Not seen by us.

5. M. bartonbeani Parr, 1927, p. 45. Described from a specimen in the U. S. National Museum in which the specifically important barbel is broken off above the bulb. We have examined it, and find that it is impossible to tell whether it is conspecific with $M$. spilorhynchus, or with $M$. valdiviae, or is actually a different species. 
6. M. problematicus Parr, 1927, p. 46. Already rightly referred to the genus Leptostomias by Regan \& Trewavas, 1930, p. 61.

7. M. tentaculatus (Regan \& Trewavas, 1930, p. 109). It was for this and the following species that the genus Haplostomias was erected. Seven specimens have been referred to this species, 6 measuring between 20 and $100 \mathrm{~mm}$. in the type series, from the North Atlantic and Caribbean, and one, $204 \mathrm{~mm}$. long, from the South Atlantic (Norman, 1930, p. 314). We have examined the latter specimen. By definition, the newer genus differs from Melanostomias chiefly in having the fangs "simple, or with a rudimentary cusp;" the proportions, photophores and finray counts all fall within the limits set by typical species of Melanostomias; also, the barbel is of the same general type-mid-way, in fact, between the simple, terminal bulb of $M$. niger and the more complicated form, with luminous bodies before and behind the terminal axis, found in other species, since in the present species luminous bodies occur only behind the terminal axis. Our examination of the $204 \mathrm{~mm}$. specimen shows that a number of the fangs have cusps considerably more pronounced than shown by Regan \& Trewavas, p. 110, fig. 105 a, although smaller than in typical Melanostomias; also, the tips of a number of the fangs are obviously broken, as is often the case in bicuspid-fanged genera, so that it seems altogether probable that in adult specimens small cusps are present on all the teeth. Also, the number and arrangement of the teeth in both jaws and gill-arches are typical of those occurring in true Melanostomias. Finally, the proposed genus Haplostomias is so much closer to Melanostomias than to any other genus, and the differences so much slighter than those between any other two genera in this family, that the advisability of uniting them seems unquestionable. Hence, we propose to place Haplostomias in synonymy with Melanostomias so that its two species will become Melanostomias tentaculatus and M. bituberatus, respectively.

8. M. bituberatus (Regan \& Trewavas, 1930, p. 110). See preceding species (no. 7). Known from a single specimen, $20 \mathrm{~mm}$. long, taken in the tropical North Atlantic. Not seen by us.

9. M. spilorhynchus Regan \& Trewavas, 1930, p. 112. All except 4 of the specimens in the Bermuda collection are referred without question to this species, the best known in the genus; it appears to be the species typical of the subtropical, as opposed to the tropical Atlantic. A full discussion begins on p. 148. M. bulbosus Beebe, 1933, is a synonym of M. spilorhynchus (see species no. 17, below).

10. M. melanocaulus Regan \& Trewavas, 1930, p. 113. Known only from the type specimen, $55 \mathrm{~mm}$. long, from the Caribbean Sea. Not seen by us. It is likely that this will prove to be conspecific with $M$. valdiviae.

11. $M$. heteropogon Regan \& Trewavas, 1930, p. 113. Known only from the 2 or 3 specimens in the type series, measuring up to $62 \mathrm{~mm}$. long, from the tropical and subtropical west Atlantic, including a station near Bermuda. Not seen by us, but we think it most likely that this species will also prove to be a synonym of $M$. valdiviae.

12. $M$. biseriatus Regan \& Trewavas, 1930 , p. 113. Known only from 4 specimens, 20 to $25 \mathrm{~mm}$. long, from a single station east of Bermuda, and from 4 Bermuda post-larvae and adolescents in the present collection (see p. 152). M. margaritifer (species no. 14, below) or an allied species will probably prove to be a more advanced stage of $M$. biseriatus.

13. M. albibarba Regan \& Trewavas, 1930, p. 114. Known from 11 specimens, 20 to $60 \mathrm{~mm}$. long, in the type series, chiefly from the tropical, rarely the subtropical, Atlantic. Regan \& Trewavas also refer to this species two of the series identified by Parr (1927, p. 42, nos. 2064 and 2065) to $M$. melanops. We have examined the latter specimens, as well as one of the series described by Regan \& Trewavas, and are fairly certain that $M$. albibarba represents merely the young of $M$. melanops. Our basis for this 
conclusion is the fact that in small examples of $M$. spilorhynchus the rounded luminous bodies of the barbel end are much larger and more distinct than in adult specimens; the same is true of barbel bulbs in related genera (e.g. Echiostoma and Photonectes).

14. M. margaritifer Regan \& Trewavas, 1930, p. 115 . Known only from the 2 specimens, 52 and $80 \mathrm{~mm}$. long, in the type series, from the north Atlantic. Not seen by us. May prove to be a more advanced stage of $M$. biseriatus.

15. M. melanopogon Regan \& Trewavas, 1930, p. 115. Known from 3 or 4 specimens, 27 to $153 \mathrm{~mm}$. long, in the type series from the North Atlantic, and by 2 specimens, 66 and $95 \mathrm{~mm}$. long, from the Bahamas. The latter examples were recorded by Parr (1927, p. 42, nos. 2066 and 2067), who referred them to $M$. melanops. We have examined no. 2067 (66 mm. long), and find that without question it should be referred to $M$. melanopogon, as suggested by Regan \& Trewavas.

16. M. macrophotus Regan \& Trewavas, 1930 , p. 115. Known from the 9 specimens, in the type series, 20 to $62 \mathrm{~mm}$. long, from the north Atlantic. Not seen by us.

17. M. bulbosus Beebe, 1933.2 , p. 166. A reexamination of the type, the unique specimen, shows that it is in reality an example of $M$. spilorhynchus in which the barbel has been broken between the distal end of the pigmented swelling and the luminous, terminal expansion. The lateral series of V-A photophores actually numbers about 13, as in typical spilorhynchus, instead of 11 , as stated in the type description, the first 2 or 3 in the series being rudimentary in this specimen on the left side of the fish, which is in all other respects normal.

18. M. stewarti Fowler, 1934, p. 262. Known from a single specimen, $215 \mathrm{~mm}$. long, from the Philippine Islands. After examining this form in the U. S. National Museum, we conclude that $M$. stewarti should be synonymized with $M$. valdiviae. Fowler differentiates it from $M$. valdiviae chiefly because of the presence of apparently only one pair of teeth, not 2 , on the basibranchials. We find, however, that there is a small second pair underneath the skin. The barbel agrees with the figure given by Regan \& Trewavas (1930, p. 112, fig. 108 A), except that the posterior luminous bodies are relatively larger with respect to the anterior one, and there is a minute, second, anterior body immediately in front of the tip of the axis. Finally, there are 5 , not 4 , pectoral rays. The specimen is somewhat shriveled, the measurements not entirely agreeing with those given in the description.

19. M. globulifer Fowler, 1934, p. 263. Known from a single specimen, $180 \mathrm{~mm}$. long, from the Philippine Islands. Examined by us in the U. S. National Museum, and found to be valid, as far as present knowledge goes. Except for the tiny ovoid white bodies along the stem the barbel is, however, exceedingly close to those of $M$. valdiviae and $M$. melanocaulus (see Regan \& Trewavas, 1930 , p. 112, fig. $108 \mathrm{~A}$ and C): at the distal end of the barbel there are 2 luminous bodies behind the axis, the proximal slightly the longer, and 1 in front, short but very slender. Contrary to the statement in the type description, there is a small terminal filament, arising as usual from the posterior translucent portion. Another correction is that when the $\mathrm{V}$-A series is counted, in the customary fashion, to include the 3 to 5 organs which continue the row above the anal fin, there are 13 , not 11 organs in the ventral V-A series, and 10, not 13, in the A-C series; similarly, there are 12 , not 10 , in the lateral V-A series. We count 15 , not 14 , dorsal rays.

20. $M$. vierecki Fowler, 1934, p. 265. Known from a single specimen, $118 \mathrm{~mm}$. long, from the Philippine Islands. After examining this form in the U. S. National Museum, we see no reason why it should not be referred to $M$. valdiviae. The barbel is exactly as figured by Regan \& Trewavas (1930, p. 112, fig. $108 \mathrm{~A}$ ), except that the posterior bulbs are relatively larger, as in $M$. stewarti, the distal being considerably larger than the proximal; 
there is a short, posterior filament in the usual position. There is no trace of a tiny, anterior, terminal body, such as is found in $M$. stewarti. There are 5 , not 4 , pectoral rays. Counting the photophores in the customary manner gives the following results, perfectly concordant with the counts for $M$. valdiviae: ventral series, I-P $8+2$ or 3 , P-V 27 or 26 , (depending upon in which series a subpectoral organ is counted), V-A 12, A-C 10; lateral series as given in the type description ( $\mathrm{O}-\mathrm{V} \mathrm{25}$, V-A 12). The specimen is somewhat shriveled, and the present measurements do not entirely agree with those given in the description.

21. $M$. pauciradius Matusubara, 1938 , p. 39. Known from a single specimen, $98 \mathrm{~mm}$. long, taken off Japan. Not seen by us. Apparently valid.

Distribution: Melanostomias is one of the 7 genera in the family which have been recorded outside the Atlantic Ocean. Two of the species, $M$. valdiviae and $M$. melanops, occur in both the Atlantic and Indian Oceans. Another, $M$. pauciradius, has been taken only off Japan. The depth range as known at present is between approximately 22 and 1,100 fathoms. Including the present collection, 160 specimens of Melanostomias have been taken, of which 99 are referred to $M$. spilorhynchus.

\section{GENERIC CHARACTERS.}

Color (summarized from observations on about 15 transitional adolescent and 2 adult male specimens of freshly caught Melanostomias spilorhynchus): General color brownish-black; antorbital organ yellow; postorbital and snout lights pink to purple; end of barbel with greenish-yellow core, and pink or purple flanges and luminous bodies; serial photophores violet with gold caps; bases of teeth pale blue.

Proportions ${ }^{5}$ : Elongate melanostomiatids with very short, rounded snout; depth in length 8.5 to $11(9.1 \%$ to $11.8 \%)$; head in length 5 to 8 $(12.5 \%$ to $20 \%)$; eye in head 4 to 6 ; snout no longer than eye, sometimes shorter; snout to pelvic in length $c a$. 1.55 to 1.7 (59\% to $67 \%)$.

Barbel: Five-sixths to 3 times length of head, with a simple stem ending in an ovate bulb or a flattened, terminal expansion enclosing one or more luminous bodies; terminal filament present or absent.

Light Organs: Postorbital (measured as length of area of transparent skin) $c a . .75$ to 1.5 times diameter of eye in both sexes. Serial photophores with the following counts: ventral series, I-P $8+1$ to $3, \mathrm{P}-\mathrm{V} 23$ to 29 , V-A 12 to 15 , of which 3 or 4 are above the anal fin, A-C 9 to 11 ; lateral series, O-V 23 to 28, V-A 12 to 15 . Tiny, non-serial photophores well developed. Luminous matter in bases of teeth and on fins usually conspicuous.

Teeth: Cleft of mouth straight, or slightly curved at symphysis; premaxillaries and mandible with depressible, curved, fangs arranged in a single row in 2 or 3 series, the teeth of each series progressing in size posteriorly; barbs usually strongly developed, sometimes weak; 1 or 2 pairs of small, fixed teeth in anterior part of each jaw; maxillary with about 3 to 9 erect teeth and a long series (up to about 45) of oblique denticles; a pair of teeth on the vomer; a series of 3 to 6 teeth on each palatine. Typically 2 pairs of teeth on the basibranchials. Teeth, in pairs, with a few individual teeth single, and in threes and fours, present on first 3 gill-arches only: on first, second and third ceratobranchials and on first epibranchial; 9 or 10 groups on first ceratobranchial.

Branchiostegal Rays: ca. 12 to 13.

Fins: Pectoral with 3 to 6 rays, normal, short. Pelvic 7 , much longer than pectoral, inserted far behind middle of length. Dorsal 13 (10?-M. niger) to 16 ; anal 16 to 20 ; dorsal and anal beginning at the same vertical, but anal extending farther back. 5 The proportions given include those of some obviously immature specimens upon which species
have been founded. 

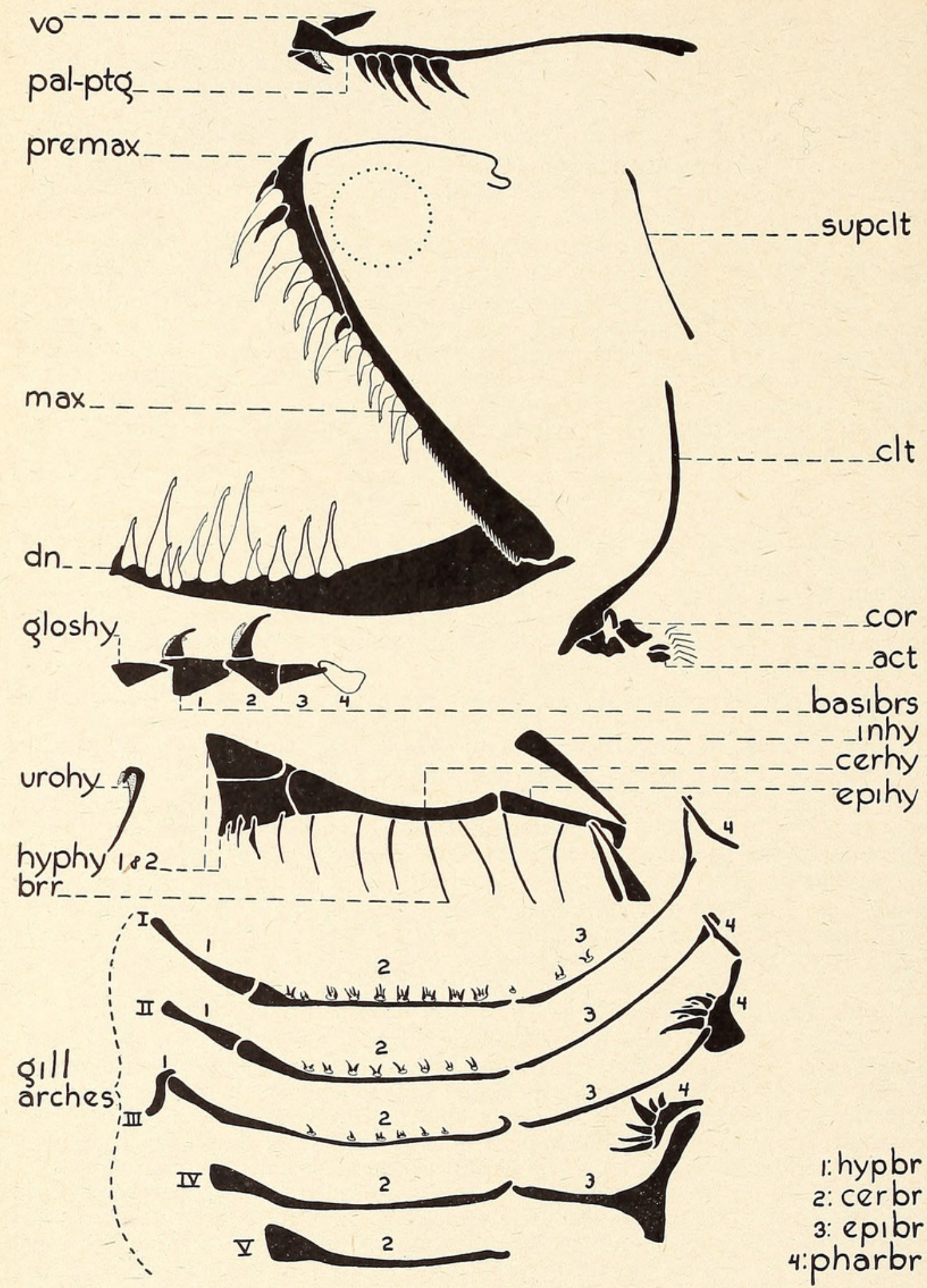

Text-figure 28.

Melanostomias spilorhynchus. Jaws, hyoid and branchial arches, and pectoral girdle of adult, standard length $222 \mathrm{~mm}$. Explanation as in Text-fig. 18.

Epidermal Grooves: There is a shallow groove in the isthmus for the reception of the barbel stem.

Osteology: Mesethmoid with lateral processes; parietals absent; post- 


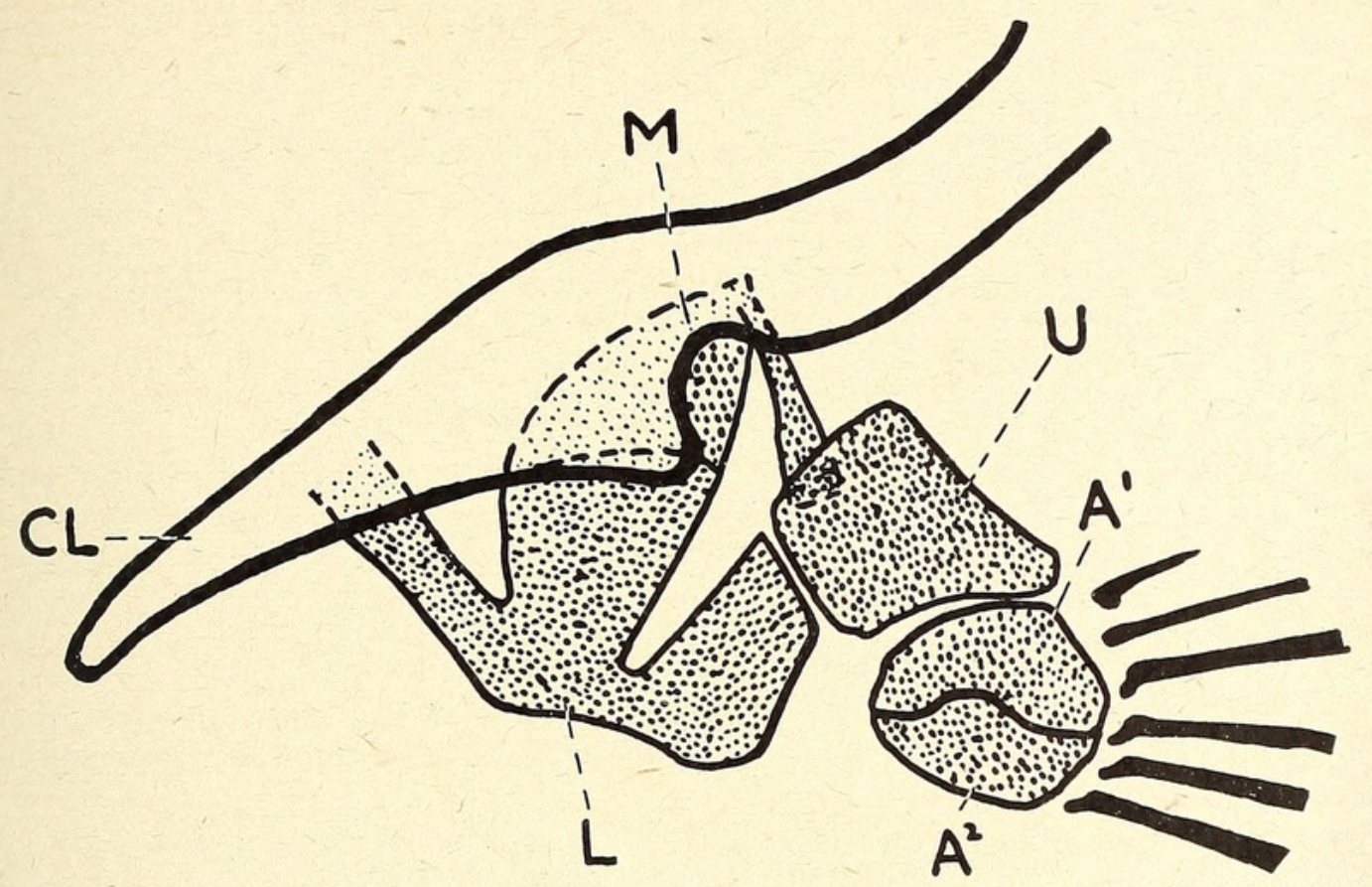

Text-figure 29.

Melanostomias spilorhynchus. Supporting bones of pectoral fin in adult, standard length $222 \mathrm{~mm}$. Abbreviations as in Text-fig. 14 .

temporal absent; supracleithrum and cleithrum moderately strong; all coracoid elements large; actinosts 2; vertebrae about 50 to 55 ; first vertebra represented only by a fibrous ring, shorter than a centrum, enclosing the notochord, and by a spinal nerve.

Coelomic Organs: Stomach ca. $40 \%$ of standard length, reaching almost to the pelvic origin; 2 pyloric caeca.

Sexual Dimorphism: Apparently none, but should be watched for in structure of barbel, and for slight differences in relative size of postorbital.

Size: The largest known specimen is an $M$. melanops $242 \mathrm{~mm}$. long, taken by the Dana in the Caribbean. Examples of 4 or 5 other species, which measure more than $200 \mathrm{~mm}$. in length, have been taken. Sex can be determined in transitional adolescents measuring $100 \mathrm{~mm}$. or more. Male Bermuda specimens of $M$. spilorhynchus of 222 and $240 \mathrm{~mm}$. appear to be adult, although not in full breeding condition. The same is true of the 204 $\mathrm{mm}$. M. tentaculatus, also a male, in the British Museum.

Development: A series of growth stages of $M$. spilorhynchus, from late larva to adult, has been taken by the Bermuda Expeditions; the pigment spots of the early stages are identical with those in post-larval and adolescent $M$. biseriatus and with those remaining subdermally in a borrowed Dana specimen of $M$. albibarba (probably young $M$. melanops-see p. 143) in the adolescent stage, and of those in young Echiostoma: each myomere has, typically, a dorsal spot immediately below the dorsal mid-line, and an obliquely vertical row of three dots, along or near the myomeral boundary, between the lateral mid-line and the series of photophores. The length of the barbel apparently increases with the length of the fish. 
Melanostomias spilorhynchus Regan \& Trewavas, 1930.

(See also p. 143).

SPECIMENS TAKEN BY THE BeRMUdA OCEANOGRAPHiC EXPEDitions.

51 specimens; May to September, 1929 to $1931 ; 400$ to 1,000 fathoms; from a cylinder of water 8 miles in diameter ( 5 to 13 miles south of Nonsuch Island, Bermuda), the center of which is at $32^{\circ} 12^{\prime} \mathrm{N}$. Lat., $64^{\circ} 36^{\prime}$ W. Long.; standard lengths from 17 to $240 \mathrm{~mm}$.

\section{SPECIMENS PREVIOUSLY RECORDED.}

48 specimens; $c a .18$ to 275 fathoms; North Atlantic; Bermuda and eastward to Azores, Madeira and Canaries; standard lengths from 23 to $206 \mathrm{~mm}$.

\section{DESCRIPTION OF ADULT.}

With the characteristics of the genus.

This species is distinct among the members of the genus in having a characteristic barbel (see below), only 23 to $25 \mathrm{P}-\mathrm{V}$ photophores, and 3 luminous spots on the snout.

Color (from observations on about 15 transitional adolescent and 2 adult males, all freshly caught): General color brownish-black. Barbel stem and proximal part of swollen end black; usually 1 or 2 white spots at base of stem; barbel bulb with greenish-yellow core and flanges and luminous bodies phlox pink or purple. Antorbital pale yellow; postorbital and snout lights bright pink to true purple. Serial photophores bluish-violet or violet, with gilt caps. Luminous bases of teeth pale blue.

Proportions: Depth in length 8.5 to $11(9.1 \%$ to $11.8 \%)$; head in length 6 to $8(12.5 \%$ to $16.7 \%)$; eye in head 5 to $6(2.3 \%$ to $2.7 \%$ of length); snout as long as or slightly shorter than eye.

Barbel: 1.2 to 1.5 times length of head with the flattened, terminal expansion enclosing the straight, central axis and two strips of loose, luminous tissue, one in front and one behind the axis; a small ovoid body at proximal end of anterior strip, a second at distal end of posterior strip, at the base of a tapering terminal appendage which usually ends in a filament; a few speckles of pigment at distal end of axis. Stem black, with a row of photophores down posterior side; distal part of stem swollen immediately above junction with the terminal expansion.

Light Organs: Antorbital tiny but apparently functional in transitional adolescent, atrophied in adult; postorbital 1.2 to 1.5 times diameter of eye. Serial photophores with the following counts: ventral series, I-P $8+2$ or 3 , P-V 22 to 25 , V-A 13 to 14 , the last 2 or 3 being above the anal fin, A-C 9 to 10 ; lateral series, O-V 22 to $24, \mathrm{~V}-\mathrm{A} 13$ to 14 .

The non-serial organs of both head and trunk are of two sizes, the first considerably smaller than the serial photophores but clearly visible to the naked eye, the second microscopic. A third variety of luminous organ is the luminous matter. All three kinds are as found in Echiostoma (see p. 138).

Head: The photophores of the larger type (Group A) are scattered without special arrangement all over the head, except on the crown and interorbital region. They are most dense on the lower jaw. The second type (Group B) are everywhere, always arranged in short, irregular lines. On top of the head they run transversely; on the cheeks and opercles they continue transversely (vertically), but less regularly and more obliquely. They are least conspicuous on the lower jaw. There is an unpaired luminous patch in the middle of the snout and a pair of similar ones, almost as large, one in front of each eye, in addition to about six pairs of smaller, but exactly 
similar spots, in front of and below the eye and close to the front teeth; usually a conspicuous unpaired luminous patch in center of crown of head, behind the level of the eyes.

Trunk Series (above the regular lateral photophore series): In the middle of each myomere is a group of A-type organs in a roughly irregular double line. They commence on a level with the opercle and extend to the serial photophores. Between 20 and 30 lights are usually found in each myomeral group. The dorsal part of the fish lacks them entirely. The B-type group of microscopic organs outline in solid, single rows the lines of demarcation between myomeres. Short rows of them similar to those found on the head are scattered through the myomeres themselves. These organs continue without interruption across the dorsal profile.

Ventral Series: A-type organs are massed without special arrangement on the isthmus. Midway between the lateral and ventral series runs a fairly continuous line, extending from opercles to the anal fin, dying out at this point. Above and below this line many other organs of the same type are distributed without apparent arrangement except that scallops are formed below each large, lateral light and above each large ventral one, a short tongue of the small lights thrusting up between each two serial organs. In the ventral midline this same scalloped formation is found but shows no special arrangement except that the lines of segmentation between the myomeres are devoid of organs. B-type organs are here distributed as on the trunk, between myomeres and in short strings.

In general it may be noted that the concentration of organs from snout to caudal is ventral, and that the organs are sparser toward the caudal fin. On each side of the fish there are about 50 to 70 organs in the areas of deepest concentration.

Fins: Pectoral 5 to 6 ; dorsal 14 to 15 ; anal 18 to 20.

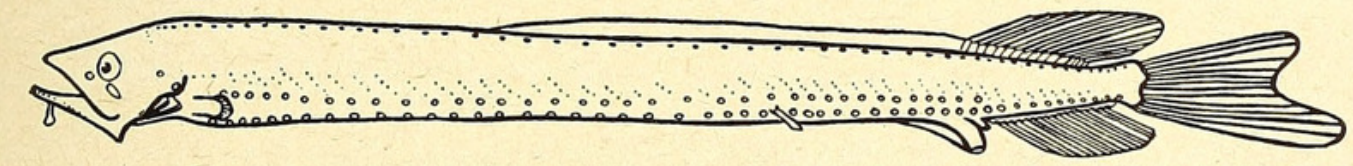

A

$1--1$
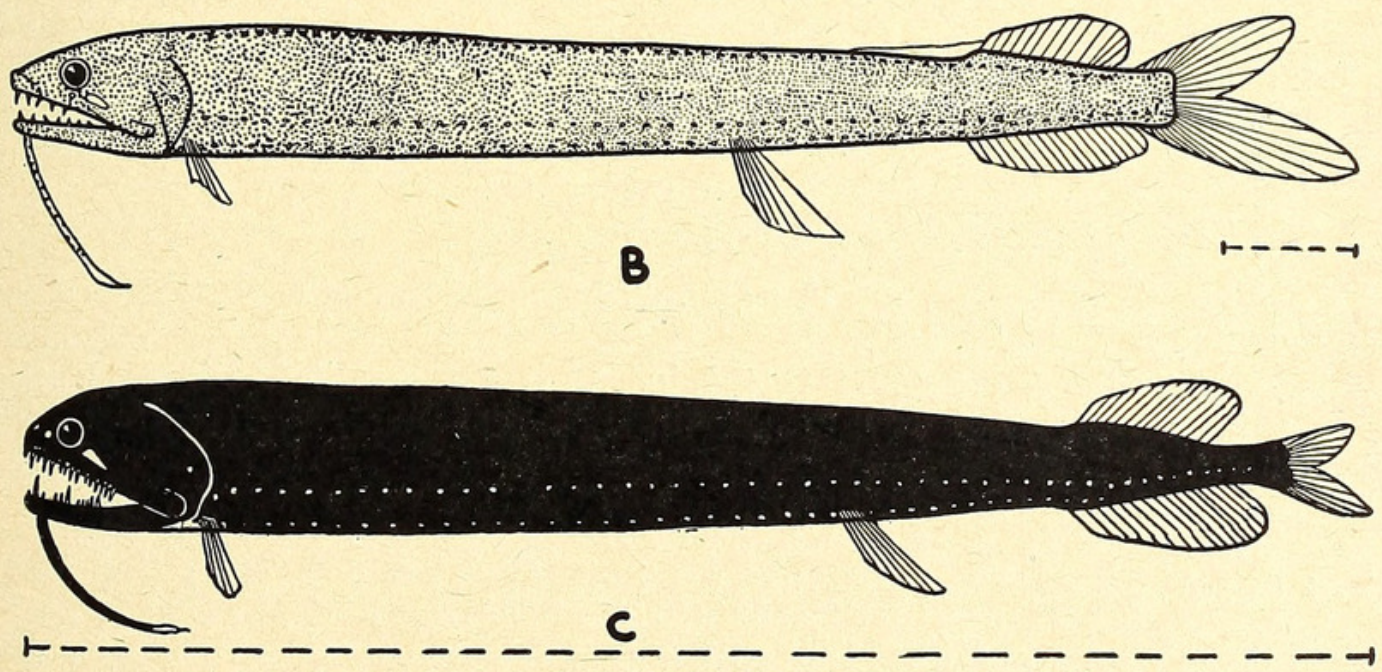

Text-figure 30.

Melanostomias spilorhynchus. A, post-larva, standard length $24 \mathrm{~mm}$; B, adolescent, $25 \mathrm{~mm}$.; C, adult, $222 \mathrm{~mm}$. See also Text-fig. 2 D. 

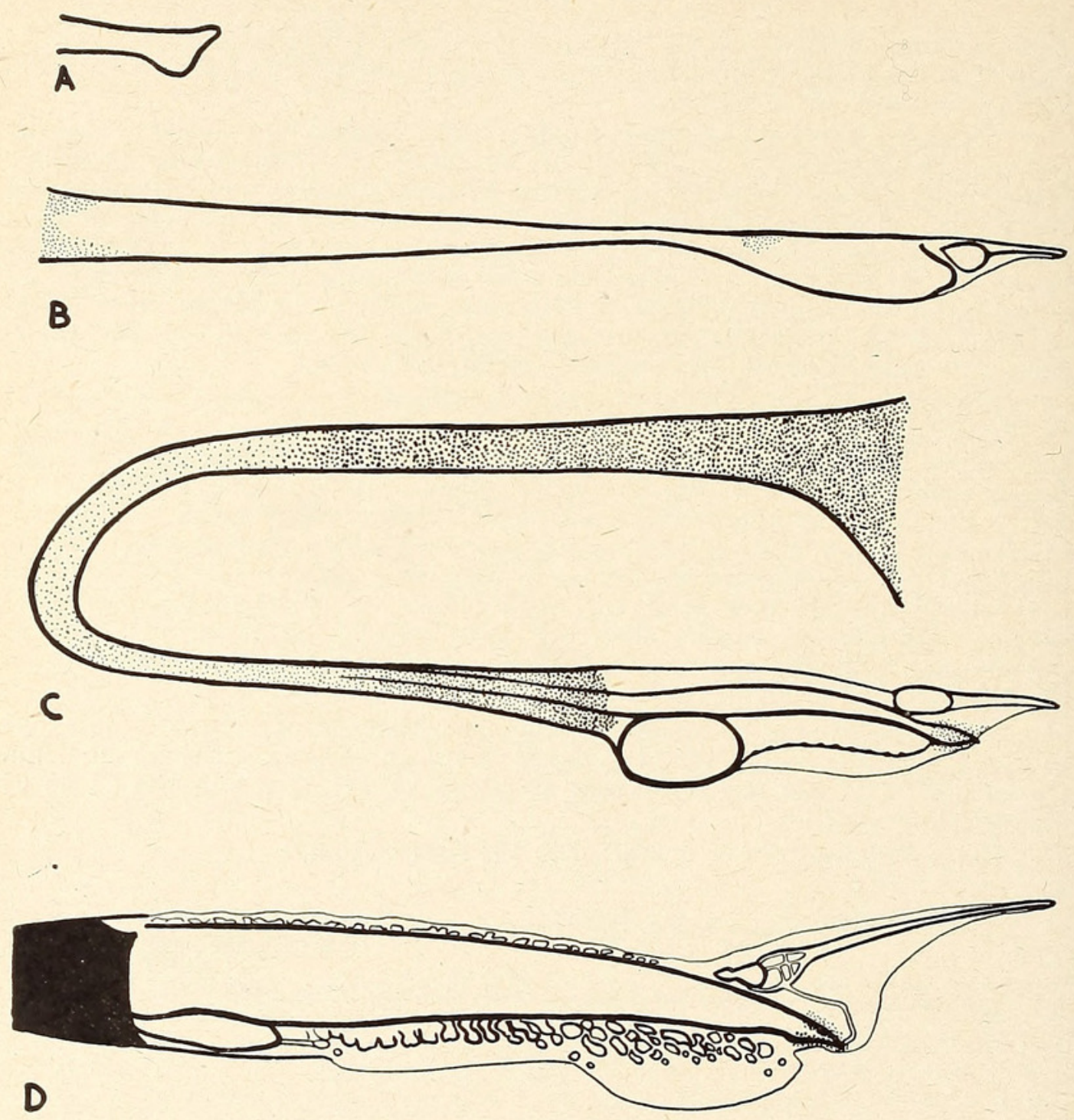

Text-figure 31.

Melanostomias spilorhynchus. Barbels, lateral views. A, post-larva, standard length $24 \mathrm{~mm}$.; B, adolescent, $25 \mathrm{~mm}$.; C, transitional adolescent, $36 \mathrm{~mm}$.; D, adult, $222 \mathrm{~mm}$. (end of barbel only).

\section{DEVELOPMENT.}

Material: All stages are represented in the Bermuda collection, and are distributed as follows:

1 larva; $17 \mathrm{~mm}$.; 500 fath.; July. (In poor condition; identification certain from myomere counts and pigment, but impossible to take body measurements).

12 post-larvae; 21 to $32 \mathrm{~mm}$; 400 to 1,000 fath.; July to Sept.

8 adolescents; 22 to $31 \mathrm{~mm}$.; 500 to 900 fath. July to Sept.

27 transitional adolescents; 24 to $36 \mathrm{~mm}$.; 400 to 1,000 fath.; Aug., Sept.

3 adults; 222 to $240 \mathrm{~mm}$.; 500 to $900 \mathrm{~mm}$.; May to Sept.; males.

All are typical representatives of their respective growth stages (see pp. 77). The special characteristics of their young stages are as follows:

Myomere Counts: To end of anal 49 to 52; from nape to pelvic rudiment (when present) 29 or 30 ; from pelvic rudiment to anal origin 10 to 12 . 
Pigment: The characteristic larval pigment spots of the genus (p. 147) are visible externally or subdermally even well into transitional adolescence.

Larval Teeth: In each premaxillary of the single larva are 7 pairs of larval teeth, all minute, and all directed straight outwards; the maxillary holds 15 teeth, increasing slightly and progressively in size toward the posterior part of the jaw; in each half of the mandible are 7 teeth, corresponding to those of the premaxillary, directed outward and set in the anterior part of the jaw only.

Larval Gill-rakers: Long, spiny rakers present on first 3 arches, vestigial or absent on fourth and fifth, continuing throughout post-larval stage; on the first ceratobranchial they number 11 or 12 .

Fins: Dorsal and anal rays of full number in larva, but in this stage and early post-larvae the anal commences slightly behind the dorsal, under about the fourth dorsal ray.

The barbel of adolescents and transitional adolescents differs from that of the adults noticeably in the relatively large size and conspicuousness of the 2 ovoid, luminous bodies. The stem is only lightly pigmented, and the entire barbel length relatively less than in fully grown fish. The postorbital organ grows slowly, being smaller than the eye well into transitional adolescence.

\section{ECOLOGY.}

Seasonal Distribution: The majority of specimens, practically all of which are young, having been taken in August and September, a summer breeding period may be indicated.

Abundance: The 51 specimens in the collection indicate that this species is by far the most common melanostomiatid off Bermuda. About 1 in 5 of the melanostomiatids was an $M$. spilorhynchus, the rest being distributed among more than 30 species.

Food: Of 12 stomachs examined, only 1, that of a transitional adolescent $34 \mathrm{~mm}$. long, contained food, a Myctophum laternatum measuring more than half the length, and almost twice the thickness, of the Melanostomias.

\section{STUDY MATERIAL.}

The following list gives the catalogue number, depth in fathoms, date, length and growth stage of each specimen of Melanostomias spilorhynchus taken by the Bermuda Oceanographic Expeditions. All were caught in the cylinder of water off the Bermuda coast described in Zoologica, Vol. XVI, No. 1, p. 5 and Vol. XX, No. 1, p. 1.

No. 10,235; Net 136; 700 F.; May 30,$1929 ; 222$ mm.; Adult Male.

No. 11,418; Net 277; 1,000 F.; July 9, 1929; $222 \mathrm{~mm} . ;$ Adult Male.

No. 11,867; Net 311 ; 600 F.; July 22, 1929; 25 mm.; Post-larva.

No. 11,877; Net 315; 500 F.; July 23, 1929; 26 mm.; Post-larva.

No. 11,919; Net $330 ; 900$ F.; July 27, 1929; 25 mm.; Adolescent.

No. 11,920; Net 334 ; 500 F.; July 29, 1929; $23 \mathrm{~mm}$; Post-larva.

No. 11,936; Net $339 ; 500$ F.; July 30,$1929 ; 25 \mathrm{~mm}$.; Adolescent.

No. 12,110; Net 355; 600 F.; Aug. 8, 1929; 31 mm.; Adolescent.

No. 12,339; Net 373; 500 F.; Aug. 15, 1929; 30 mm.; Trans. Adolescent.

No. 12,346; Net 374; 600 F.; Aug. 15, 1929; 26 mm.; Trans. Adolescent.

No. 12,403; Net 378; 500 F.; Aug. 16, 1929; $30 \mathrm{~mm}$.; Trans. Adolescent.

No. 12,464; Net 384; 500 F.; Aug. 17, 1929; 28, 28 mm.; Trans. Adolescents.

No. 12,475; Net 385 ; 600 F.; Aug. 17, 1929 ; 35 mm.; Trans. Adolescent.

No. 12,559; Net 391; 600 F.; Aug. 19, 1929; 25 mm.; Adolescent.

No. 12,815; Net 397; 700 F.; Aug. 31, 1929; 36 mm.; Trans. Adolescent.

No. 12,953; Net 410; 600 F.; Sept. 3, 1929; 25, 26 mm.; Post-larva, Adolescent.

No. 12,969; Net 412; 800 F.; Sept. 3,$1929 ; 26,32 \mathrm{~mm}$.; Trans. Adolescents.

No. 13,049; Net 417; 600 F.; Sept. 4, 1929; 24, $32 \mathrm{~mm}$.; Post-larva, Trans. Adolescent.

No. 13,098; Net 423; 500 F.; Sept. 5, 1929; 27, 27 mm.; Trans. Adolescents. 
No. 13,105; Net 424; 600 F.; Sept. 5, 1929; 28 mm.; Trans. Adolescent.

No. 13,158; Net 430; 500 F.; Sept. 6, 1929; 28, 36 mm.; Trans. Adolescents.

No. 13,211; Net 437; 500 F.; Sept. 7, 1929; 26, $31 \mathrm{~mm}$.; Trans. Adolescents.

No. 13,368; Net 451; 500 F.; Sept. 10, 1929; 22 mm.; Post-larva.

No. 13,376; Net 452; 500 F.; Sept. 10, 1929; 23, 24 mm.; Post-larvae.

No. 13,589; Net 481; 800 F.; Sept. 20, 1929; 26 mm.; Trans. Adolescent.

No. 13,766; Net 500; 900 F.; Sept. 24, 1929; 24 mm.; Trans. Adolescent.

No. 14,969; Net 574; 500 F.; May 14, 1930; 240 mm.; Adult Male.

No. 17,189; Net $804 ; 500$ F.; July 16, 1930; $17 \mathrm{~mm}$.; Larva.

No. 17,874; Net 842; 600 F.; Sept. 4, 1930; 34, 36 mm.; Trans. Adolescents.

No. 20,140; Net $868 ; 900$ F.; Sept. 10, $1930 ; 22$ mm.; Adolescent.

No. 18,349; Net $869 ; 1,000$ F.; Sept. 10, 1930; 21 mm.; Post-larva.

No. 18,494 ; Net 882 ; 700 F.; Sept. 12,$1930 ; 28$ mm.; Trans. Adolescent.

No. 21,676; Net 1113; 400 F.; July 29, 1931; 28 mm.; Post-larva.

No. 22,307; Net 1170; 800 F.; Aug. 12, 1931; 26 mm.; Adolescent.

No. 22,752; Net 1181; 600 F.; Aug. 15, 1931; 24 mm.; Adolescent.

No. 22,696; Net 1187; 400 F.; Aug. 17, 1931; 27 mm.; Trans. Adolescent.

No. 22,796; Net 1227; 400 F.; Aug. 27, 1931; 24, 24 mm.; Post-larvae.

No. 24,053; Net 1228; 500 F.; Aug. 27, 1931; 29 mm.; Trans. Adolescent.

No. 23,290; Net 1287; 1,000 F.; Sept. 10, 1931; $28 \mathrm{~mm}$.; Trans. Adolescent.

No. 23,307; Net 1291; 600 F.; Sept. 12, 1931; 29 mm.; Trans. Adolescent.

No. 23,461; Net 1312; 400 F.; Sept. 16, 1931; 26 mm.; Trans. Adolescent.

\section{SYNONYMY AND REFERENCES.}

\section{Melanostomias spilorhynchus:}

Regan \& Trewavas, 1930, p. 112, fig. 107; pl. X, fig. 1. (48 specimens, the type series, 23 to $206 \mathrm{~mm}$; 65 to $1,000 \mathrm{~m}$. wire; North Atlantic, Bermuda and eastward to Azores, Madeira and Canaries).

Beebe, 1937, p. 199. (Preliminary list of Bermuda specimens).

Melanostomias bulbosus:

Beebe, 1933.2, p. 166. (Description of a single Bermuda specimen, synonymized with $M$. spilorhynchus in the present paper).

Beebe, 1937, p. 199. (Record of the above specimen in a preliminary list of Bermuda specimens).

\section{Melanostomias biseriatus Regan \& Trewavas, 1930.}

(See also p. 143).

\section{SPECIMENS TAKEN By THE BERMUdA OCEANOGRAPHiC EXPEDITIONS.}

4 specimens; September only, 1929 ; 500 to 900 fathoms; from a cylinder of water 8 miles in diameter ( 5 to 13 miles south of Nonsuch Island, Bermuda), the center of which is at $32^{\circ} 12^{\prime} \mathrm{N}$. Lat., $64^{\circ} 36^{\prime} \mathrm{W}$. Long.; standard lengths from 21 to $25 \mathrm{~mm}$.

\section{SPeCimens Previously ReCORDED.}

4 specimens; ca. 22 to 42 fathoms; north Atlantic, east of Bermuda; standard lengths from 20 to $25 \mathrm{~mm}$.

\section{DESCRIPTION.}

(From the description of the type series, none of which can be more advanced than early transitional adolescence; serial photophore counts supplemented by those of our younger examples).

Proportions: Depth in length about $10(10 \%)$; head in length 5 to 6 $(16.7 \%$ to $20 \%)$; eye in head 5 .

Barbel: About twice as long as head; proximal 2/5 pigmented; distal 
part a white axis, with a narrow, translucent band in front and behind, each including a series of white luminous bodies; the posterior series starting proximally with a rather large white body, and ending with a larger one that curves the axis; beyond this white bulb and the end of the axis is an expansion without a filament.

Light Organs: Postorbital longer that diameter of eye. Serial photophores with the following counts: ventral series, I-P $8+2$ to $3, \mathrm{P}-\mathrm{V} 26$ to 28 , V-A 13 to 14, A-C 9 to 11: lateral series, O-V 26 to 27 ; V-A 12 to 13.

Fins: Pectoral 5; dorsal 13 to 16 ; anal 16 to 17 .

\section{DEVELOPMENT.}

The 4 Bermuda specimens of $M$. biseriatus, though comparable in size to those of the type series, are obviously even younger, $2(23,25 \mathrm{~mm}$.) being in the post-larval stage and $2(21,24 \mathrm{~mm}$.) in the adolescent. They are typical of their stages in every way, (see p. 77), and their pigmentation is typical of the genus (see p. 147). They differ from corresponding stages of $M$. spilorhynchus in the following details: $\mathrm{P}-\mathrm{V}$ and $\mathrm{O}-\mathrm{V}$ photophores number 26 to 28 , not 22 to 25 ; myomeres to pelvic origin number 33 to 34 , not 29 to 30 ; myomeres to end of anal number about 55, instead of 49 to 52 ; the barbel of the adolescents shows clearly the specific characters of $M$. biseriatus distally (it differs in lacking stem pigment and in having the proximal luminous bodies very rudimentary and scarcely distinguishable, although the entire distal half of the stem is noticeably expanded; also, the barbel in the most advanced is only a little longer than the head, instead of twice the head length). The post-larvae, too, have the single, oblong, terminal luminous body, anteriorly directed end of barbel core, and non-filamented distal tissue. In this species the barbel seems to develop specific characters earlier and to grow faster than in $M$. spilorhynchus. The present post-larvae could be referred to some closely allied species with the same photophore counts, but they appear to form a continuous series with the adolescents in every particular. It is, of course, probable that $M$. biseriatus will prove to be the young of some other species, also described by Regan \& Trewavas, such as $M$. margaritifer, in which case $M$. biseriatus will take precedence.

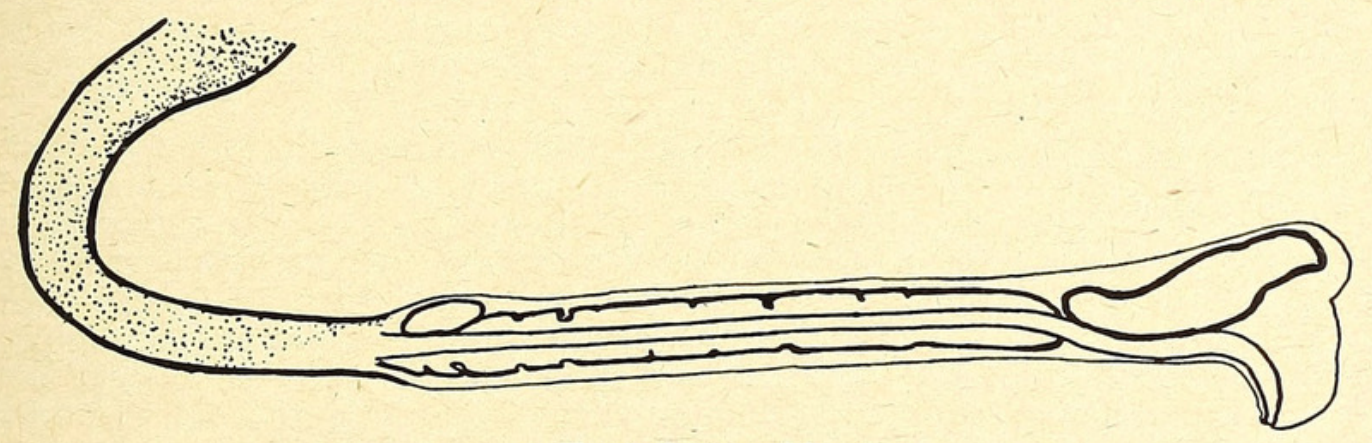

Text-figure 32 . $24 \mathrm{~mm}$.

Melanostomias biseriatus. Barbel, lateral view, of adolescent, standard length

\section{ECOLOGY.}

It is interesting to note that all 4 specimens of $M$. biseriatus were taken in the single month of September, 1929.

\section{STUDY MATERIAL.}

The following list gives the catalogue number, depth in fathoms, date, length and growth stage of each specimen of Melanostomias biseriatus taken 
by the Bermuda Oceanographic Expeditions. All were caught in the cylinder of water off the Bermuda coast described in Zoologica, Vol. XVI, No. 1, p. 5 and Vol. XX, No. 1, p. 1.

No. 24,172; Net $444 ; 500$ F.; Sept. 9, 1929; 23 mm.; Post-larva.

No. 13,376a; Net 452; 500 F.; Sept. 10, 1929; 25 mm.; Post-larva.

No. 13,758; Net 499; 800 F.; Sept. 24, 1929; 24 mm.; Adolescent.

No. 13,772; Net 502; 900 F.; Sept. 24, 1929; 21 mm.; Adolescent.

Melanostomias biseriatus:

\section{REFERENCE.}

Regan \& Trewavas, 1930 , p. 113, fig. 109A. (4 specimens, the type series, 20 to $25 \mathrm{~mm}$.; 80 and $150 \mathrm{~m}$. wire; north Atlantic east of Bermuda).

Genus Photonectes Günther, 1887.

(See also pp. 70, 73, 75, 79, 81-91, 96, 97, 99, 102, 103, 105, 106, 108, 110).

(Text-figs. 2, 11, 12, 33-44 incl.).

\section{GENERAL Discussion.}

The first species referable to this genus was $P$. albipinnis, described by Doderlein in 1882 (p. 26) for a specimen taken off Japan, for which he erected the genus Lucifer. Since the latter name was preoccupied, Günther in the Challenger report substituted the name Photonectes. Afterwards, several species were originally referred wrongly to other genera, Photonectes braueri to Melanostomias, and $P$. richardi and P. margarita both to Echiostoma. Parr (1927) and Regan \& Trewavas (1930) in their monographs correctly relegated all of these to Photonectes.

The genus as now understood includes some species, usually recognized as members of different subgenera, which are so diverse that we considered for a time separating Photonectes into at least two distinct genera. Study of the family as a whole, however, shows that all of the species of Photonectes are so much more closely related to each other than they are to even their closest generic relatives (e.g. Echiostoma, Melanostomias and Tactostoma) that we agree with the above mentioned authors that only a single genus should be recognized, although the maintenance of two subgenera is convenient.

Nineteen species of Photonectes have been recorded, including the two new species taken by the Bermuda Expeditions, which have been described (Beebe, 1933.2) since the publication of the Regan \& Trewavas monograph. As in the case of a number of other genera, we are convinced that some of these species represent merely growth stages or variations of others. We have been able to prove this in several species. The following annotated list, in chronological order, gives the standing of the species as far as known. We are as usual hampered by the immaturity of the majority of recorded specimens.

1. P. albipinnis (Doderlein, 1882, p. 26 ). Known only from the type specimen, $240 \mathrm{~mm}$. long, from Japan. Not seen by us.

2. P. margarita (Goode \& Bean, 1895, p. 109). Only the type specimen, $320 \mathrm{~mm}$. long, from the Gulf of Mexico and one, $340 \mathrm{~mm}$. long, recorded by Borodin (1931, p. 66), from the western Atlantic, have been previously referred to this species. We have examined both, as well as the unique specimen of $P$. flagellatus (species no. 6, below), and several specimens of $P$. intermedius (species no. 7). All of these we have compared with our own representative series of specimens referable to these species, and with the descriptions of $P$. richardi (species no. 5) and $P$. monodactylus (species no. 17 ), with the result that we are certain that the differences between $P$. margarita, $P$. flagellatus, $P$. richardi and $P$. monodactylus are due solely to 
size, individual variation, and damaged barbels, while $P$. intermedius represents only the early transitional adolescent stage of the same species (see Text-fig. 44 for complete barbel series, and p. 175 for a description of the species and the details in regard to our examination of the specimens in other museums). P. margarita was referred originally to Echiostoma.

3. P. gracilis Goode \& Bean, 1895, p. 112. Known only from the type, $167 \mathrm{~mm}$. long, in the U. S. National Museum, and one, $170 \mathrm{~mm}$. long, in the Peabody Museum, recorded by Parr (1927, p. 113). In both the barbel is broken off short. The type is temporarily not available, but we have examined the second specimen, and find that only the extreme tip of the barbel is missing. In addition to the characteristic, conspicuous, horizontal band of metallic blue, there are also definite traces of similar markings in exactly the regions where they occur in $P$. achirus, $P$. caerulescens and $P$. mirabilis. $P$. gracilis is definitely set off from related species, however, by the forward position of the pelvic fins. In $P$. gracilis, the only available large example of the genus which does not belong to the subgenus-Trachinostomias, the premaxillary and mandibular teeth are relatively small and even, exactly as in large $P$. margarita (subgenus Trachinostomias), as opposed to the very uneven, relatively large, Melanostomias-like form of the same teeth in young transitional adolescents throughout the genus. (cf. Text-figs. 32 and 33).

4. P. braueri (Zugmayer, 1913, p. 3). Only the type, $115 \mathrm{~mm}$. long, from the eastern Atlantic, has been previously referred to this species, which was originally placed in the genus Melanostomias. We have a smaller specimen which, by the intermediate form of its barbel, teeth, etc., shows that the 11 specimens, 22 to $31 \mathrm{~mm}$. long, of $P$. ovibarba (species no. 11) should also be referred to $P$. braueri. (For description, see p. 165).

5. $P$. richardi (Zugmayer, 1913, p. 4). Only the type, $170 \mathrm{~mm}$. long, from the eastern Atlantic, has been referred to this species, which was originally placed in Echiostoma. Not seen by us, but from the descriptions we consider it identical with $P$. margarita (see species no. 2, above and p. 175).

6. P. flagellatus Parr, 1927, p. 107 . Only the type, $280 \mathrm{~mm}$. long, from the Bahamas has been referred to this species. We have examined it and consider it identical with $P$. margarita (see species no. 2, and p. 175).

7. P. intermedius Parr, 1927, p. 109. Previously known from the two specimens in the type series and 22 recorded by Regan \& Trewavas (1930, p. 125), all measuring between 20 and $86 \mathrm{~mm}$. in length from the north Atlantic. Unquestionably these represent the early transitional adolescent stage of $P$. margarita (see species no. 2 and p. 175). The type specimens, as well as one from the Dana collection and two from the Atlantis collection have been examined by us.

8. P. mirabilis Parr, 1927, p. 111. Known only from five transitional adolescents up to $60 \mathrm{~mm}$. in length, including three in the present Bermuda collection. Type specimen examined by us.

9. $P$. dinema Regan \& Trewavas, 1930 , p. 120 . Known from 36 specimens, in the type series and the present Bermuda collection, all young transitional adolescents measuring between 23 and $51 \mathrm{~mm}$. in length, from the North Atlantic. (See p. 162).

10. P. leucospilus Regan \& Trewavas, 1930, p. 121. Known from 14 specimens, in the type series and the present Bermuda collection, all young transitional adolescents measuring between 25 and $50 \mathrm{~mm}$. in length; from the North Atlantic. (See p. 164).

11. P. ovibarba Regan \& Trewavas, 1930, p. 121. Known only from the type series, 11 specimens, 22 to $31 \mathrm{~mm}$. long, from the North Atlantic. We have examined one of the series and find that these represent unquestionably the young transitional adolescent stage of $P$. braueri (see species no. 4 and p. 166). 
12. P. achirus Regan \& Trewavas, 1930 , p. 122 . Known only from the type series, four specimens, 20 to $62 \mathrm{~mm}$. long, from the western North Atlantic. We have examined the largest specimen and are sure that this series represents the young transitional adolescent stage of $P$. caerulescens (species no. 13), the barbel and barbel bulb being larger in these more juvenile forms, as in $P$. margarita and $P$. braueri (species nos. 2 and 4 ).

13. P. caerulescens Regan \& Trewavas, 1930 , p. 122 . Known from a single specimen, $116 \mathrm{~mm}$. long, from the Caribbean Sea. Not seen by us, but from the figure and description it seems certain that this specimen is a more advanced stage of $P$. achirus, above.

14. P. phyllopogon Regan \& Trewavas, 1930 , p. 122 . Known only from the type specimen, $21 \mathrm{~mm}$. long, from the Caribbean Sea. Not seen by us.

15. P. parvimanus Regan \& Trewavas, 1930 , p. 124 . Known from 17 specimens in the type series and the present Bermuda collection, all young specimens from larvae to transitional adolescents, measuring between 14 and $55 \mathrm{~mm}$. in length; from the North Atlantic. It is possible $P$. fimbria (species no. 16) and $P$. bifilifer (species no. 18) will prove to be synonymous with $P$. parvimanus. (See p. 170).

16. P. fimbria Regan \& Trewavas, 1930 , p. 125 . Known only from the type specimen, $55 \mathrm{~mm}$. long, from the North Atlantic. Not seen by us. From the description and figure it differs from $P$. parvimanus only in details of the barbel bulb and in having 30 to 34 , not 34 to $38 \mathrm{P}-\mathrm{V}$ and $\mathrm{O}-\mathrm{V}$ photophores. Our series of $P$. parvimanus shows specimens with barbels intermediate in form, therefore the photophore distinction alone remains.

17. P. monodactylus Regan \& Trewavas, 1930 , p. 127 . Known only from 5 specimens in the type series, 180 to $255 \mathrm{~mm}$. long, from the North Atlantic. Not seen by us, but from the description and figure we consider this species identical with $P$. margarita (see species no. 2, and p. 175).

18. P. bifilifer Beebe, 1933.2 , p. 167. Known only from the type specimen, $245 \mathrm{~mm}$. long, from Bermuda, in the present collection. Allowing for the difference in size and growth stage, this adult upon reexamination differs from $P$. parvimanus (species no. 15, above) only in the lack of a crest on the barbel bulb and in the great length of the 2 pectoral rays. Both may prove also to be growth characters, or the barbel crest may have been torn away. Until intermediate stages are secured, however, it seems best to keep the two forms separate (see p. 173).

19. P. cornutus Beebe, 1933 , p. 169 . Known only from the type specimen, $19 \mathrm{~mm}$. long, from Bermuda, in the present collection. In poor condition, and exceedingly close to $P$. mirabilis, but apparently distinct. (See p. 169).

It is possible that sexual differences will be found to have significance in the proper delineation of species.

A synopsis of the species, as now understood, will be found on p. 161 .

Distribution: Photonectes is one of the 7 genera in the family which have been recorded outside the Atlantic Ocean, $P$. albipinnis having been taken off Japan. Otherwise it is known only from the North Atlantic. The depth range indicated at present is between approximately 25 and 1,400 fathoms. A total of 146 specimens of Photonectes are now known, of which almost half (71) were taken by the Bermuda Expeditions.

\section{GENERIC CHARACTERS.}

Color (summarized from observations on about 20 freshly caught, including one living, transitional adolescent and adult specimens of 6 species) : General color blue-black, the skin being very fragile in adult specimens of the subgenus Trachinostomias; barbel bulbs blue, pink, purple, yellow, green or silvery; postorbital organ white, yellow, rose or violet; serial organs violet to purple with gold caps or frames; non-serial organs violet; 
luminous patches on snout and jaws, when present, yellow or purple; luminous shoulder patches, when present, pale blue.

Proportions $^{6}$ : Melanostomiatids of moderate to excessive slenderness, with very short snouts and strongly curved jaws, the mandibles projecting in front of snout. Depth in length 6.5 to $15.5(6.4 \%$ to $15.4 \%)$; head in length 6.5 to $9(11.1 \%$ to $15.4 \%)$; eye in head 4 to 7.7 ; snout about as long as, or a little longer than, diameter of eye; snout to pelvic in length 1.5 to 1.9 (52\% to $67 \%$ ).

Barbel: Usually shorter than head, rarely as long, or slightly longer, almost always unbranched above the bulb, but usually with a distal appendage, varying in shape and degree of branching with the species; the bulb itself may be almost or completely atrophied in the adult.

Light Organs: Postorbital (measured as length of area of transparent skin) .67 to 1.8 times diameter of eye in both sexes, probably always larger than eye in fully adult specimens. Serial photophores with the following counts: ventral series, I-V 30 to 48 , V-A 11 to 18 , A-C 9 to 15 ; lateral series, O-V 17 to 36 ; V-A 11 to 17 . Non-serial photophores usually not conspicuous. Luminous tissue usually present in one or more of the following areas: in spots on snout, jaws, or shoulder; in bands or stripes on body.

Teeth: Cleft of mouth strongly curved upward anteriorly; jaws remarkably slender; the lower projecting far in front of upper premaxillaries and mandible with numerous close-set curved, slightly barbed teeth, all depressible, not large in adults; they are arranged in a single row in 3 to 6 series in each jaw, the teeth of each series increasing in size posteriorly; up to about 25 erect teeth on the maxillary followed by up to 50 very fine, oblique denticles; 1 or 2 pairs of teeth on the vomer; a series of 1 to 7 teeth on each palatine. Six to 10 pairs of teeth on the basibranchials. Teeth, in pairs, with a few individual teeth singly or in threes, present only on first 2 or 3 gillarches, and only on the ceratobranchials. About 5 to 8 pairs on first ceratobranchial.

Branchiostegal Rays: ca. 14 to 15.

Fins: Pectoral with 0 to 3 rays, either short or long; pelvic 7 , well developed, long; inserted far behind middle of length; dorsal 15 to 22 ; anal 15 to 24 ; membranes of dorsal and anal in some species very thick and black with only the tips of the rays visible in the adult; dorsal and anal commencing opposite each other, but anal extending farther back.

Epidermal Grooves: There is a well defined groove in the isthmus for the reception of the barbel stem.

Osteology: Mesethmoid with lateral processes; parietals absent; skull exceedingly short, less than half the length of the upper jaw; mandible with an elongate posterior process projecting behind the end of the maxillary; hyoid and gill-arches short; pectoral girdle much reduced, the postemporal usually absent, rarely vestigial, the supracleithrum and cleithrum weak, sometimes separated from each other, and the mesocoracoid absent; upper and lower coracoids well developed, laminar; actinosts 1 to 4 ; vertebrae 49 to 64 ; first vertebra represented only by a fibrous ring, enclosing the notochord, and by a spinal nerve.

Coelomic Organs: Stomach ca. $33 \%$ of standard length, not reaching pelvic origin; 2 pyloric caeca.

Sexual Dimorphism: Apparently none.

Size: The largest known specimen is a specimen of $P$. marqarita about $340 \mathrm{~mm}$. in length taken by the Atlantis (Borodin, 1931, p. 66) ; the measurement is ours, $100 \mathrm{~mm}$. more than given in the record which is probably a misprint; the example is a female apparently in full breeding condition. Other specimens of the same species of both sexes, examined may be counted as

6 The proportions given include those of some obviously immature examples upon which species have been founded. 

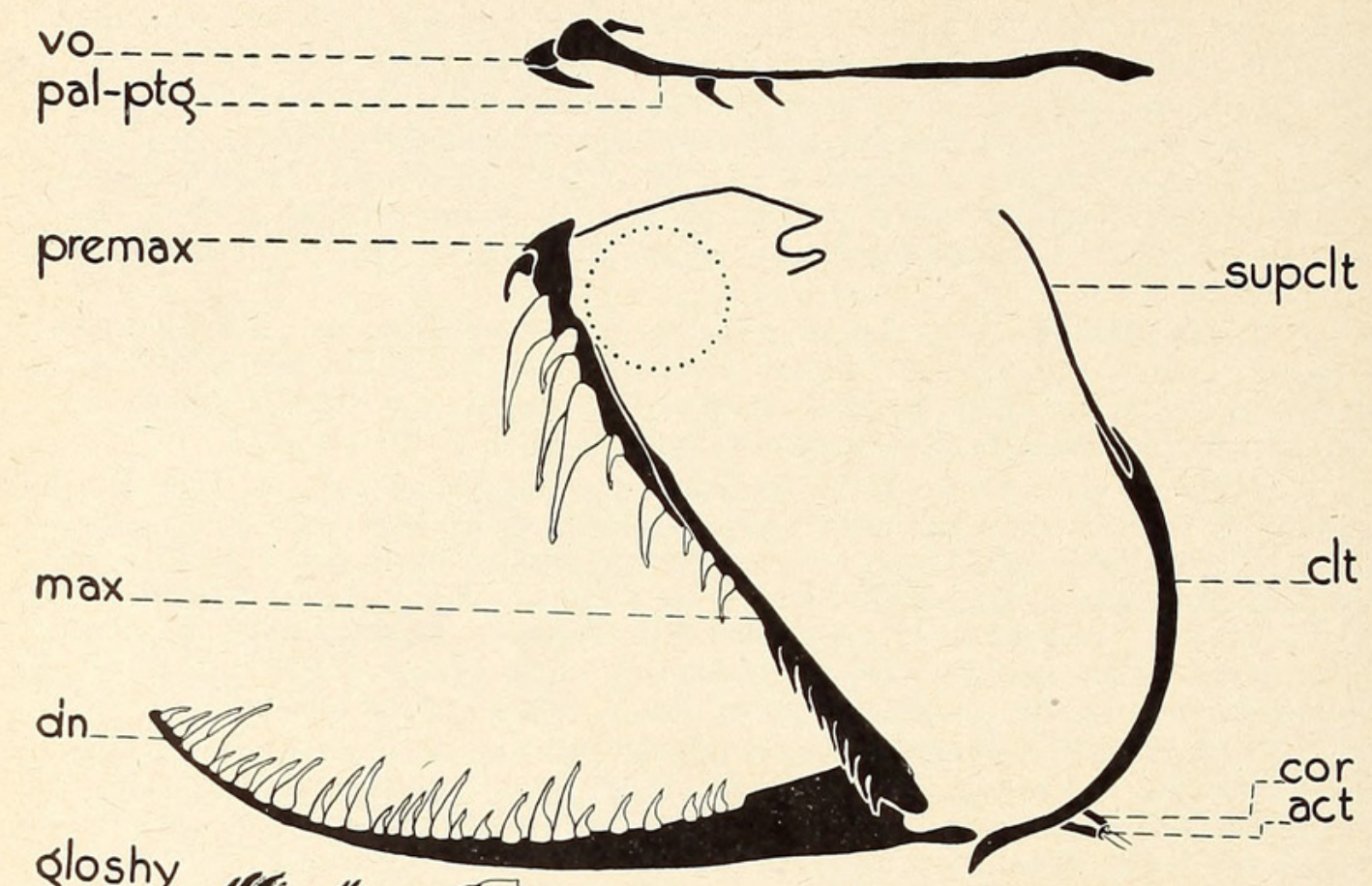
gloshy 

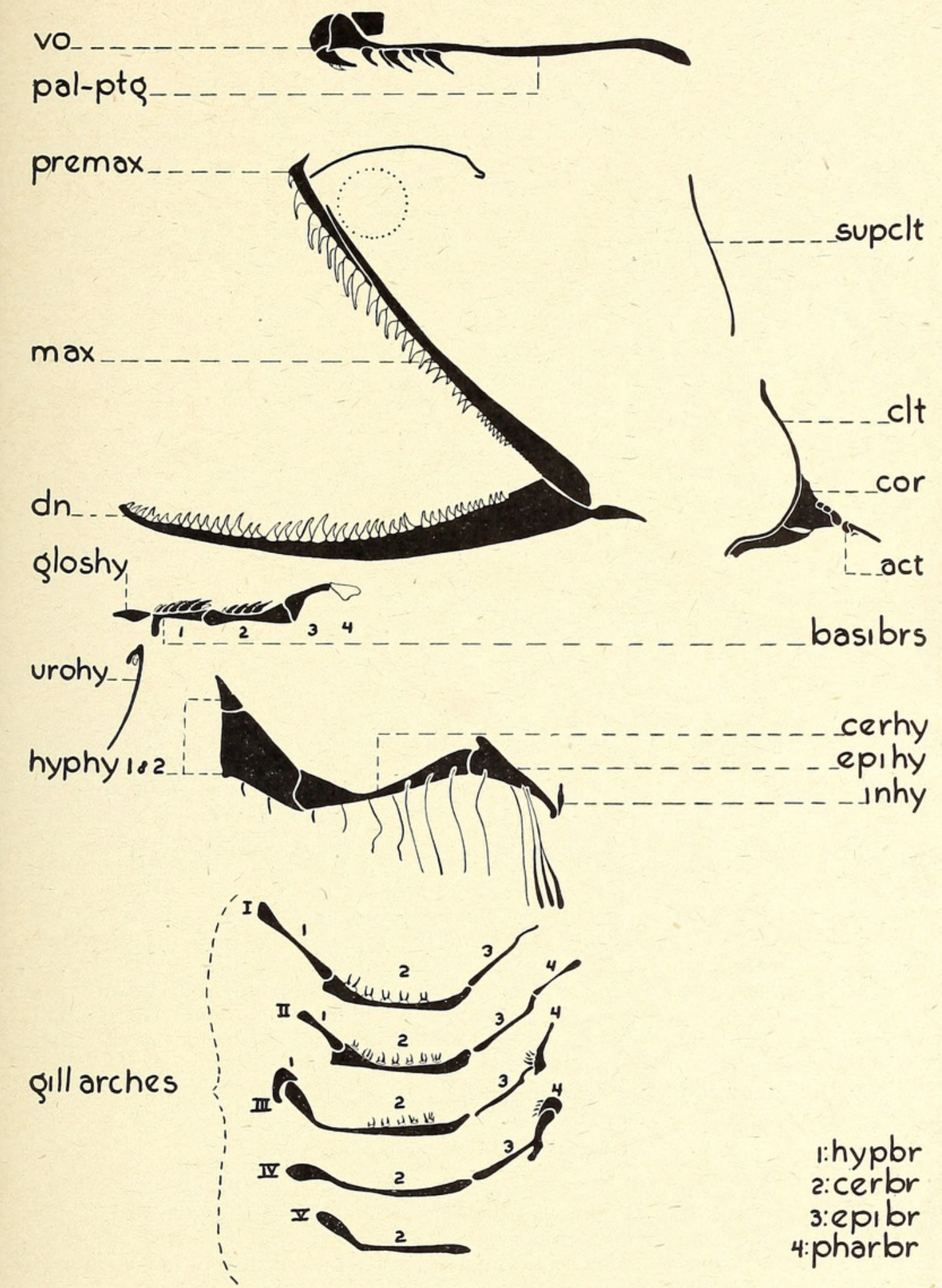

Text-figure 34 .

Photonectes margarita. Jaws, hyoid and branchial arches, and pectoral girdle of adult, standard length $273 \mathrm{~mm}$. Explanation as in Text-fig. 18.

$60 \mathrm{~mm}$. have been examined, and all are so immature that sex cannot be distinguished.

Development: A growth series of $P$. parvimanus from larva to transi- 


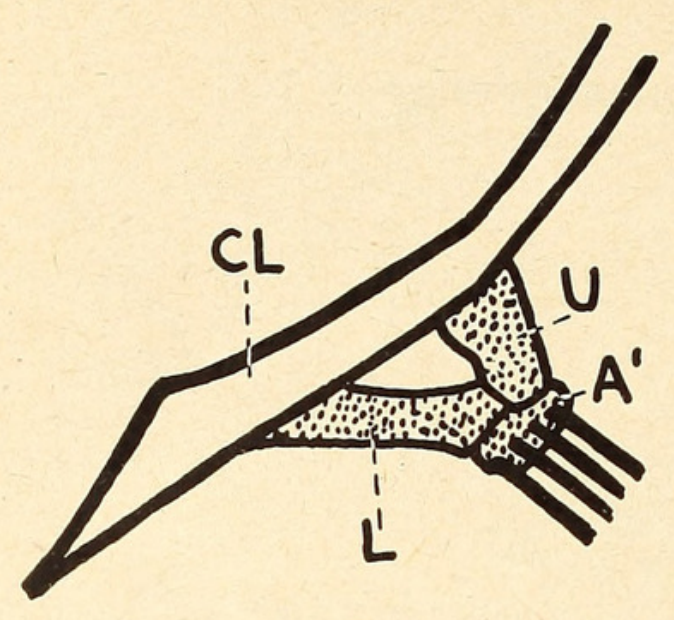

Text-figure 35.

Supporting bones of pectoral fin in Photonectes. Abbreviations as in Text-fig. 14. Upper, $P$. dinema, transitional adolescent, standard length $38 \mathrm{~mm}$.; lower, $P$. margarita, adult, standard length $273 \mathrm{~mm}$.

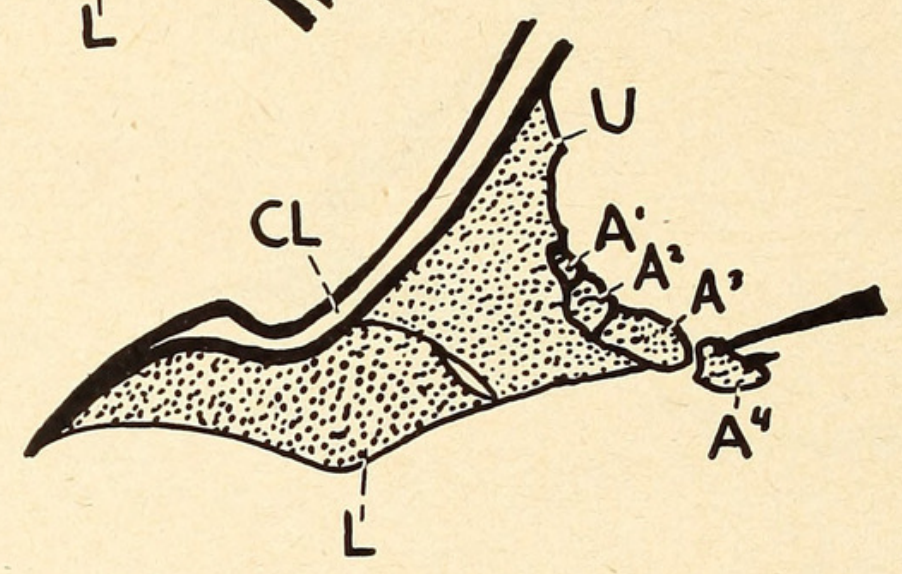

tional adolescent has been recognized in the present collection. The pigment spots of the early stages are very similar to those found in young Echiostoma and Melanostomias; the only distinguishable difference is that the dorsal series of chromatophores, instead of numbering only one large spot or blotch to the myomere, are broken up into small dots; (in transitional adolescents of other species of Photonectes however, are remains of the customary blotches); oblique, lateral rows, 3 or 4 dots, following the outline of the myomeres, are as in the neighboring genera. Identification is based on the number of myomeres, and the tracing of the pigment pattern in specifically identifiable transitional adolescents. (See p. 79). In $P$. leucospilus, $P$. braueri, $P$. parvimanus and $P$. margarita we have shown definitely that the barbel bulb becomes both relatively and actually smaller with growth; we think that the same is doubtless true of $P$. gracilis and $P$. achirus. Sometimes the relative length of the barbel decreases with age-i.e., it attains its full length sooner than the rest of the fish.

\section{SYNOPSIS OF SUBGENERA.}

Parr in 1927 (p. 105) recognized two subgenera, Dolichostomias and Trachinostomias, which Regan \& Trewavas (1930, p. 119) increased to five. In the light of our additional material, we consider that two are sufficient, but adopt the name Photonectes for the first, as taking precedence over Parr's Dolichostomias.

In the subgenus Photonectes we place all those species having only about 49 to 54 vertebrae ( 30 to $37 \mathrm{I}-\mathrm{V}$ photophores), the pectoral absent, or with 2 or 3 small rays, and the membrane of the dorsal and anal fins thin. This grouping will thus include the subgenera Melanonectes and Dolichostomias as defined by Regan \& Trewavas.

In the subgenus Trachinostomias we place all those species having about 62 to 64 vertebrae (I-V 42 to 48 ), 1 to 2 pectoral rays, often (perhaps 
always, in adult) very long, and the membrane of the dorsal and anal fins thick and black, with only the tips of the rays visible in the adult. This subgenus will now include the subgenus Microchirichthys of Regan \& Trewavas.

\section{SYNOPSIS OF SPECIES.}

Following the tentative synonymy adopted in pp. 154 to 156 , we submit this key, adapted from that of Regan \& Trewavas, and applicable both to transitional adolescents and to the known adults.

A. Membrane of dorsal and anal fins thin; rays conspicuous; I-V photophores 30 to 37 .

B. Pectoral fin of 2 rays, and sometimes a minute third ray.

Barbel with small bulb bearing a slender translucent appendage ending in a second bulb, nearly as large as the first, with a pair of short filament; P-V 20

$P$. dinema

(p. 162).

Barbel with rather large bulb bearing a slender translucent appendage ending in a minute bulb without filaments; $\mathrm{P}-\mathrm{V} 23$ to 24

P. leucospilus

(p. 164).

Barbel with a large or very small bulb, bearing a minute knob-like

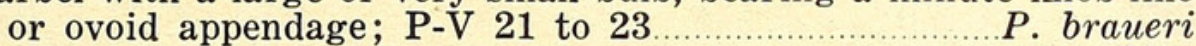

BB. Pectoral fin absent.

(p. 165).

C. Depth 6 to 9 in length; dorsal and anal fins relatively short; pelvics much nearer to caudal fin than to head.

D. Barbel without posterior branch.

Barbel shorter than head; bulb atrophied or absent; a slender, unpigmented terminal appendage.....P. achirus.

Barbel shorter than head; bulb large, white; distal appendage with stalk and translucent leaf-like expansion.

$P$. phyllopogon.

Barbel as long as head; stem short, black; bulb white; distal part long, tapering, with luminous bodies; a terminal translucent expansion with minute white body. P. mirabilis

(p. 167).

Barbel longer than head; stem tapering; bulb small, white, with terminal filament................................ albipinnis.

DD. Barbel with posterior branch; otherwise similar to $P$. mirabilis ................................................ cornutus (p. 169).

CC. Depth $101 / 2$ or more in length; dorsal and anal fins long and low; pelvics nearer to head than to caudal fin............ P. gracilis.

AA. Membrane of dorsal and anal fins thick, black; only tips of rays visible in adult; $\mathrm{I}-\mathrm{V}$ photophores 42 to 48 .

C. Two pectoral rays; barbel bulb without pigmented distal appendages.

E. Pectoral rays minute; barbel bulb with a compressed comb-like unpigmented distal appendage, with a fringe of filaments except in very young specimens.

E. $\mathrm{O}-\mathrm{V} 30$

P. fimbria.

EE. O-V 34 to $36 \ldots \ldots \ldots \ldots \ldots \ldots . .$. . parvimanus. (p. 170).

EE. Pectoral rays elongate; barbel bulb without terminal appendage, except microscopic posterior filaments.

P. bifilifer. (p. 173). 
CC. One very elongate pectoral ray (sometimes, in young, a second ray); barbel bulb with an anterior cluster of short, pigmented filaments, and a posterior appendage in the form of a long, branched, pigmented filament; tips of most filaments with minute, unpigmented bulbs; major bulb sometimes almost or completely atrophied in adult................ . margarita. (p. 175).

\section{Photonectes dinema Regan \& Trewavas, 1930.}

\section{SPECIMENS TAKEN BY THE BeRMUda OCEANOGRAPHIC EXPEDITIONS.}

26 specimens; April to September, 1929 to 1931; 300 to 1,000 fathoms; from a cylinder of water 8 miles in diameter ( 5 to 13 miles south of Nonsuch Island, Bermuda), the center of which is at $32^{\circ} 12^{\prime} \mathrm{N}$. Lat., $64^{\circ} 36^{\prime}$ W. Long.; standard lengths from 24 to $50 \mathrm{~mm}$.

\section{SPECIMENS PREVIOUSLY ReCORDED.}

10 specimens; $c a$. 41 to 1,375 fathoms; North Atlantic between $25^{\circ}$ and $36^{\circ}$ N. Lat.; standard lengths from 24 to $38 \mathrm{~mm}$.

\section{DESCRIPTION OF TRANSITIONAL ADOLESCEnt.}

(No adult known.).

With the characteristics of the genus.

Color (from field notes made upon 10 specimens): Skin brownish-black. Proximal and distal barbel bulbs from bright phlox pink to mallow purple; intervening appendage deep blue to violet proximally, changing distally to pale lemon yellow or whitish; terminal filaments pale yellow speckled thickly with black except for perfectly white tips; all or part of the entire bulb and appendage area may be traversed by scarlet lines (blood vessels?). Postorbital light organ brilliant silvery white, with a small, round, purple light at anterior, inferior end. Serial photophores bright violet or purple with gilt caps above in both lateral or ventral series. Small, non-serial photophores: purple, densely scattered over head, jaws and body. Snout light, bright mallow purple.

Proportions: Depth in length 6.5 to $9(11.1 \%$ to $15.4 \%)$; head in length 5.9 to $7(14.3 \%$ to $17 \%)$; eye in head 5 to 6 ; snout shorter than eye; snout to pelvic in length $c a .1 .8(56 \%)$.

Barbel: About 2/3 length of head; bulb scarcely thicker than the short, pigmented stem, with a long, translucent appendage; at the end of the latter is a somewhat smaller bulb bearing a pair of short filaments.

Light Organs: Postorbital $2 / 3$ to as long as diameter of eye. Serial photophore counts: ventral series, I-P 7 to $8+2$, P-V 20 , V-A 14 to 18 , A-C 11 to 12 ; lateral series, O-V 17 to $20, \mathrm{~V}-\mathrm{A} 14$ to 17 . Non-serial photophores conspicuous. A median luminous spot on snout.

Teeth: Premaxillary with about 8 teeth; mandible with about 22 ; maxillary with 1 to 4 erect and 4 to 10 oblique teeth; 2 pairs on vomer; 1 to 3 teeth on each palatine; 6 pairs on basibranchials; teeth on first and second ceratobranchials only.

Fins: Pectoral 2, short; with sometimes a minute third ray; dorsal 15 to 18 ; anal 18 to 21 .

\section{DEVELOPMENT.}

All of the specimens in the Bermuda collection, (and presumably those in the type series, which are all of comparable length), are typical young 
transitional adolescents (see p. 79 for a definition of the stages), measuring from 24 to $50 \mathrm{~mm}$. in length. Myomeres to the end of the anal fin number about 53. In the younger specimens there are subdermal traces of larval pigment patterns: a row of dendritic blotches, 1 to each myomere, beneath the dorsal profile, and remains of obliquely vertical rows of dots on the lower part of the sides, as usual in this and related genera. Sex cannot be determined, the stomach is only partially pigmented, and the skeleton except for the jaws is but feebly ossified.

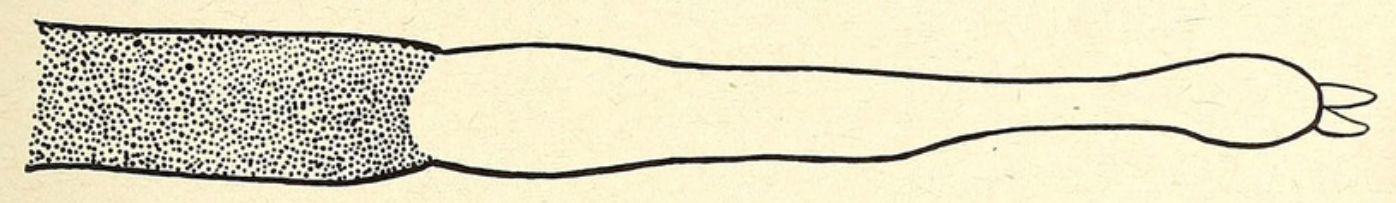

Text-figure 36.

Photonectes dinema. Barbel of transitional adolescent, standard length $43 \mathrm{~mm}$.

\section{STUDY MATERIAL.}

The following list gives the catalogue number, depth in fathoms; date, length and growth stage of each specimen of Photonectes dinema taken by the Bermuda Oceanographic Expeditions. All were caught in the cylinder of water off the Bermuda coast described in Zoologica, Vol. XVI, No. 1, p. 5 and Vol. XX, No. 1, p. 1.

No. 9,539; Net 32; 600 F.; April 24, 1929; 30 mm.; Trans. Adolescent. No. 9,596; Net 39; $600 \mathrm{~F}$; April 25, 1929; $27 \mathrm{~mm}$.; Trans. Adolescent. No. 9,719; Net 45; 500 F.; April 29, 1929; 25 mm.; Trans. Adolescent.

No. 10,315; Net 146; 500 F.; June 1, 1929; 26 mm.; Trans. Adolescent. No. 10,278; Net 147; 600 F.; June 1, 1929; 38 mm.; Trans. Adolescent. No. 10,693; Net 194; 600 F.; June 20, 1929; 33 mm.; Trans. Adolescent. No. 10,833; Net 210; 1,000 F.; June 22, 1929; 28 mm.; Trans. Adolescent. No. 11,151; Net 239; 600 F.; June 29, 1929; 25 mm.; Trans. Adolescent. No. 11,130; Net 241; 800 F.; June 29, 1929; 40 mm.; Trans. Adolscent. No. 11,294; Net 260; 500 F.; July 7, 1929; 43 mm.; Trans. Adolescent. No. 11,433; Net 278; 500 F.; July 10, 1929; 26 mm.; Trans. Adolescent. No. 11,615a; Net 303; 500 F.; July 16, 1929; 50 mm.; Trans. Adolescent. No. 11,921; Net 334; 500 F.; July 29, 1929; 24 mm.; Trans. Adolescent. No. 12,366; Net 377; 1,000 F.; Aug. 8, 1929; 40 mm.; Trans. Adolescent. No. 13,122; Net $426 ; 800$ F.; Sept. 5, 1929; 38 mm.; Trans. Adolescent. No. 14,736; Net 539; 600 F.; May 6, 1930; 26 mm.; Trans. Adolescent. No. 14,968; Net 573; 400 F.; May 14, 1930; 33 mm.; Trans. Adolescent. No. 15,129; Net 596; 600 F.; May 19, 1930; 32 mm.; Trans. Adolescent. No. 15,393; Net $634 ; 600$ F.; May 26, 1930; 28 mm.; Trans. Adolescent. No. 15,409; Net $635 ; 600$ F.; May 26, 1930; 31, 32 mm.; Trans. Adolescents. No. 16,034; Net 703; 900 F.; June 13, 1930; 35 mm.; Trans. Adolescent. No. 20,673; Net 997; $500 \mathrm{~F}$.; June 5, 1931; $34 \mathrm{~mm}$.; Trans. Adolescent. No. 21,023; Net 1,043; $300 \mathrm{~F}$.; June 26, 1931; $31 \mathrm{~mm}$.; Trans. Adolescent. No. 22,874; Net 1,238; $800 \mathrm{~F}$; J June 29, 1931; $40 \mathrm{~mm}$.; Trans. Adolescent. No. 23,359; Net 1297; 700 F.; Sept. 14, 1931; 44 mm.; Trans. Adolescent.

\section{Photonectes dinema:}

\section{REFERENCE.}

Regan \& Trewavas, 1930, p. 120, fig. 114, 115B. (10 specimens: 24 to 38 $\mathrm{mm}$.; 150 to $5,000 \mathrm{~m}$. wire; app. 300 miles northwest of Bermuda; 400 to 900 miles southeast of Bermuda and 300 miles north of Cape Verde Islands).

Beebe, 1933.1, p. 180. (Preliminary list of Bermuda specimens).

Beebe, 1937, p. 199. (Preliminary list of Bermuda specimens). 
Photonectes leucospilus Regan \& Trewavas, 1930.

\section{SPECIMENS TAKEN BY THE BERMUdA OCEANOGRAPHIC EXPEDITIONS.}

15 specimens; April to September, 1929 to 1931; 300 to 1,000 fathoms; from a cylinder of water 8 miles in diameter ( 5 to 13 miles south of Nonsuch Island, Bermuda), the center of which is at $32^{\circ} 12^{\prime} \mathrm{N}$. Lat., $64^{\circ} 36^{\prime}$ W. Long.; standard lengths from 25 to $33 \mathrm{~mm}$.

\section{SPECIMENS PREviously ReCoRded.}

2 specimens; $c a .83$ to 550 fathoms; 400 miles southeast of Bermuda and 200 miles southwest of Cape Verde Islands; standard lengths 28 and $50 \mathrm{~mm}$.

\section{Description of Transitional Adolescent.}

(No adults have been taken).

With the characteristics of the genus.

Color (from field observations upon 5 specimens): General color deep brownish-black. Barbel stem black; bulbs amythyst violet to violet blue, sometimes with pinkish-orange blood vessels showing beneath surface of proximal bulb; core of proximal bulb and entire connecting appendage phlox (lavender) pink. Postorbital light organ bluish or silver white with an anterior, faintly yellow depression. Serial photophores pinkish-purple to amythyst violet with large gilt frames; non-serial photophores violet. Median snout light white.
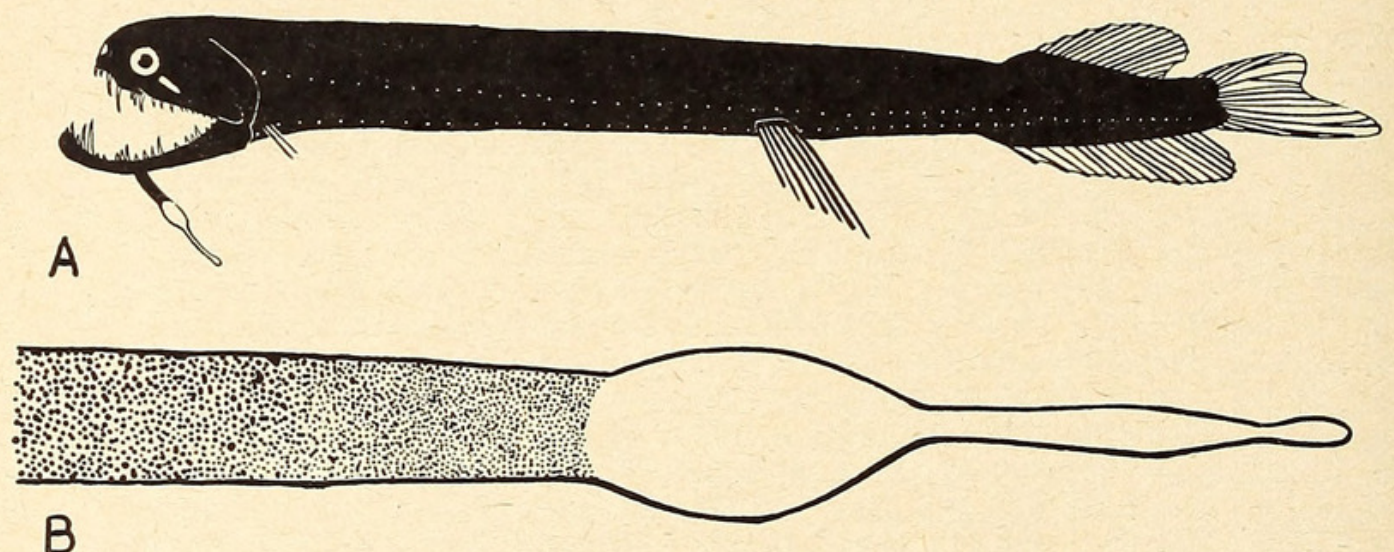

Text-figure 37.

Photonectes leucospilus. A, transitional adolescent, standard length $28 \mathrm{~mm}$; B, barbel of same.

Proportions: Depth in length 8 to 9 (11.1\% to $12.5 \%)$; head in length $7(14.3 \%)$; eye in head 4.7 to $6(1.7 \%$ to $2.1 \%)$; snout shorter than diameter of eye; snout to pelvic in length ca. $1.75(57 \%)$.

Barbel: $1 / 2$ to $2 / 3$ times length of head, the pigmented stem occupying about half its total length; a large proximal bulb is connected with a minute distal bulb by a translucent appendage; no terminal filaments.

Light Organs: Postorbital $1 / 2$ to $2 / 3$ as long as eye. Serial photophores with the following counts: ventral series, I-P $8+2$; P-V 23 to 24, V-A 14 to $15, A-C 10$ to 12 ; lateral series, O-V 21 to 23 , V-A 12 to 14. Non-serial organs conspicuous. A luminous spot in middle of snout.

Teeth: Premaxillary about 8 ; mandible about 20 ; maxillary with 0 to 3 erect and 5 to 7 oblique teeth; 2 pairs on vomer; 2 teeth on each 
palatine; usually 4 pairs of teeth on basibranchials; gill-teeth on first 2 ceratobranchials only.

Fins: Pectoral 2, short, sometimes with a minute third ray; dorsal 16; anal 18 to 20 .

\section{DEVELOPMENT.}

All of the 15 Bermuda specimens, measuring between 25 and $33 \mathrm{~mm}$., are typical young transitional adolescents. The remarks on p. 162-3 concerning the comparable stage of $P$. dinema apply equally well to $P$. leucospilus.

\section{STUDY MATERIAL.}

The following list gives the catalogue number, depth in fathoms, date, length and growth stage of each specimen of Photonectes leucospilus taken by the Bermuda Oceanographic Expeditions. All were caught in the cylinder of water off the Bermuda coast described in Zoologica, Vol. XVI, No. 1 , p. 5 and Vol. XX, No. 1 , p. 1.

No. 9,603; Net 35; 800 F.; April 24, 1929; 29 mm.; Trans. Adolescent.

No. 9,986; Net $101 ; 700$ F.; May 14,$1929 ; 29$ mm.; Trans. Adolescent.

No. 10,381; Net 160; $700 \mathrm{~F}$; June 12, 1929; $30 \mathrm{~mm}$.; Trans. Adolescent.

No. 10,858; Net 204; 1,000 F.; June 21, 1929; $28 \mathrm{~mm}$.; Trans. Adolescent.

No. 10,937; Net 211; 500 F.; June 24, 1929; 25 mm.; Trans. Adolescent.

No. 10,955; Net 219; $700 \mathrm{~F}$;; June 25, 1929; $29 \mathrm{~mm}$.; Trans. Adolescent.

No. 11,012; Net 225; 600 F.; June 26-27, 1929; 26 mm.; Trans. Adolescent.

No. 11,945; Net $342 ; 800 \mathrm{~F}$;; July 30, 1929; $33 \mathrm{~mm}$.; Trans. Adolescent.

No. 20,142; Net 437; 500 F.; Sept. 7, 1929; 31 mm.; Trans. Adolescent.

No. 14,852; Net 563; 600 F.; May 10, 1930; 25 mm.; Trans. Adolescent.

No. 14,892; Net 566; 600 F.; May 12,$1930 ; 27$ mm.; Trans. Adolescent.

No. 21,103; Net 1051; 300 F.; July 6, 1931; 31 mm.; Trans. Adolescent.

No. 21,104; Net 1052; 300 F.; July 6, 1931; $28 \mathrm{~mm}$.; Trans. Adolescent.

No. 21,260; Net 1071; $300 \mathrm{~F}$; July 10, 1931; $28 \mathrm{~mm}$.; Trans. Adolescent.

No. 21,971; Net 1141; 800 F.; Aug. 6, 1931; 25 mm.; Trans. Adolescent.

Photonectes leucospilus:

\section{REFERENCE.}

Regan \& Trewavas, 1930, p. 121, fig. 115a. (2 specimens; 28 and 50 $\mathrm{mm}$.; 300 and $2,000 \mathrm{~m}$. wire; North Atlantic).

Beebe, 1933.1, p. 180. (Preliminary list of Bermuda specimens).

Beebe, 1937, p. 199. (Preliminary list of Bermuda specimens).

Photonectes braueri (Zugmayer, 1913).

SPECIMEN TAKen By THE Bermuda OCEANOGRaphic Expeditions.

1 specimen (Department of Tropical Research No. 16,068; Net 717); June 17, 1930; 900 fathoms; 8 miles south of Nonsuch Island, Bermuda $\left(32^{\circ} 12^{\prime} \mathrm{N}\right.$. Lat., $64^{\circ} 36^{\prime} \mathrm{W}$. Long. $)$; standard length $62 \mathrm{~mm}$.

\section{Specimens Previously Recorded.}

12 specimens; between 0 and 1,100 fathoms; North Atlantic; standard lengths from 22 to $115 \mathrm{~mm}$.

\section{DESCRIPTION.}

(Proportions from the descriptions of the type, $115 \mathrm{~mm}$. long, the largest known; photophore and finray counts from small specimens in addition).

With the characteristics of the genus. 


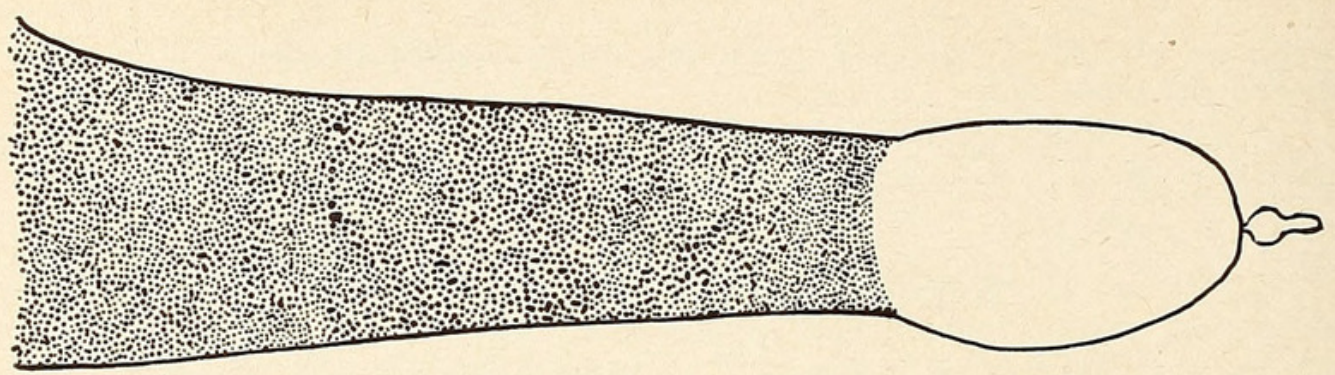

Text-figure 38 .

Photonectes braueri. Barbel of transitional adolescent, standard length 62 $\mathrm{mm}$.

Proportions: Depth in length $8(12.5 \%)$; head in length $7.7(13 \%)$; eye in head 4.3 or 4.6 ; snout to pelvic in length $1.63(61 \%)$.

Barbel: $1 / 5$ or $1 / 6$ length of head with a stout black stem and a small white bulb, not thicker than stem, bearing a minute terminal knob (in smaller specimens this bulb is much larger than the diameter of the stem and the entire bulb is relatively longer).

Light Organs: Postorbital equal to or greater than diameter of eye. Serial photophores with the following counts: ventral series, I-P $8+2$ to 3 , P-V 21 to 23 , V-A 14 to 15 , A-C 10 to 12 ; lateral series, O-V 20 to 23 , V-A 12 to 14 . Non-serial photophores moderately conspicuous. Entire body and unpaired fins sprinkled with minute luminous granules, more apparent than usual in this genus. No luminous spot on snout.

Teeth: Upper jaw with 10 strong teeth, then 7 or 8 of moderate height, followed by minute denticles; mandible with 34 or 35 small teeth, arranged in series of 4 , increasing in size backward; gill-teeth on first 3 ceratobranchials.

Fins: Pectoral 2, short; dorsal 15 to 18 ; anal 17 to 21 .

\section{DEVELOPMENT.}

The single Bermuda specimen, standard length $62 \mathrm{~mm}$., is a perfect intermediate form between the type specimen $(115 \mathrm{~mm}$.) and the 22 to 31 mm. type series of $P$. ovibarba Regan \& Trewavas, 1930, p. 121. This is true both of proportions and barbel structure. The length of the barbel, half the length of the head in $P$. ovibarba and $1 / 5$ to $1 / 6$ in the type of $P$. braueri, is slightly over $1 / 4$ in the present specimen; similarly, the barbel bulb is considerably larger than the stem, in which it differs from the type of $P$. braueri, but not nearly so large as in P. ovibarba. Therefore, we are certain that the enlarged barbel bulb and relatively faster growth of the stem are merely growth characters, similar to those found in other species of this genus and in Echiostoma, and that P. ovibarba should be synonymized with $P$. braueri.

The present $62 \mathrm{~mm}$. specimen is a transitional adolescent so immature that sex cannot yet be determined; it is probable that the type also is not adult.

\section{SYNONYMY AND REFERENCES.}

Melanostomias braueri:

Zugmayer, 1913, p. 3. (Brief preliminary description; 1 specimen; $115 \mathrm{~mm}$.; 1,000-0 m. wire; west of Azores).

Parr, 1927, p. 42. (Résumé of type description). 
Photonectes ovibarba:

Regan \& Trewavas, 1930, p. 121. (11 specimens; 22 to $31 \mathrm{~mm}$; 100 to $4,000 \mathrm{~m}$. wire; North Atlantic).

\section{Photonectes braueri:}

Regan \& Trewavas, 1930, p. 121, pl. XII, fig. 1. (Description of $M$. braueri after an examination of type specimen).

Roule \& Angel, 1933, p. 19, pl. I, fig. 10. (Description of $M$. braueri after an examination of type specimen).

Beebe, 1937, p. 199. (Preliminary listing of Bermuda specimen).

\section{Photonectes mirabilis Parr, 1927.}

\section{SPECIMENS TAKEN BY THE BERMUda OCEANOGRAPHIC EXPEDITIONS.}

3 specimens; August and September, 1930; 600 fathoms; from a cylinder of water 8 miles in diameter ( 5 to 13 miles south of Nonsuch Island, Bermuda), the center of which is at $32^{\circ} 12^{\prime} \mathrm{N}$. Lat., $64^{\circ} 36^{\prime} \mathrm{W}$. Long.; standard lengths from 18 to $26 \mathrm{~mm}$.

\section{SPECIMENS PREviously ReCORDED.}

2 specimens; ca. 83 to 660 fathoms; off Cape Hatteras and Bahamas; standard lengths 18 to $60 \mathrm{~mm}$.

\section{DESCRIPTION.}

(Proportions from the $60 \mathrm{~mm}$. type, the largest known specimen; barbel form, photophore and finray counts supplemented by those of smaller specimens).

With the characteristics of the genus.

Color (from a small Bermuda specimen) : General color brownish-black; major barbel bulb silvery white; small barbel bulblets golden yellow; snout lights, jaw lights and serial photophores all golden yellow.

Proportions: Depth in length $6.7(15 \%)$; head in length $7.5(13.3 \%)$; eye in head 4 (3.3\% of length); snout to pelvic fin in length $1.5(66.7 \%)$.

Barbel: Slightly longer than head; major bulb more or less elongate, shorter than stem in type, longer than stem in small specimens; a tapering terminal appendage, pigmented proximally, which is longer than stem and bulb combined; from the posterior side of the terminal appendage arises a small bulblet, attached by a very short stem, somewhere near the middle of the length of the appendage; usually 2 still smaller bulblets scarcely more than luminous spots, placed anteriorly and posteriorly on the appendage

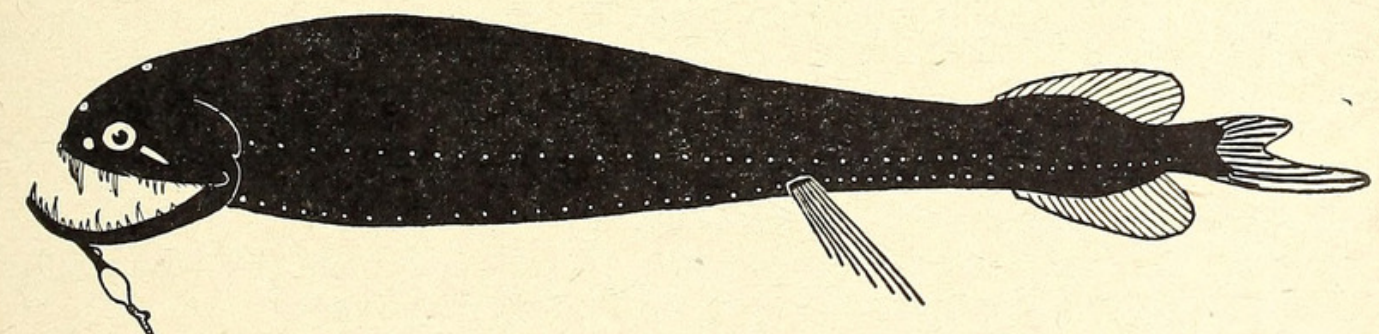

Text-figure 39.

Photonectes mirabilis. Transitional adolescent, standard length $26 \mathrm{~mm}$. 
between the major bulb and the median bulblet just described; extreme tip of appendage ending in a more or less well defined bulblet. On the posterior side of the barbel stem, near the middle of its length, is another luminous spot or bulblet.

Light Organs: Postorbital organ longer than diameter of eye. Serial photophores with the following counts: ventral series, I-V 32 to $34, \mathrm{~V}-\mathrm{A} 11$, A-C 11; lateral series, O-V 21 to $24, \mathrm{~V}-\mathrm{A} 10$. A luminous patch in front of each eye, and 3 pairs, very well developed, on the floor of the mouth, just inside the anterior parts of the lower jaw; the latter series are very symmetrically arranged, the anterior pair smallest and the others increasing in size backwards. Our own reexamination of the type specimen shows the presence of the remains of a line of luminous tissue, below the lateral midline, from the anterior portion of which short vertical bands of similar tissue arise at intervals, exactly as in P. gracilis.

Teeth: In the type (which shows obviously immature dental characters) there are about 7 to 8 teeth in each premaxillary, and 25 in each mandibular ramus; maxillary with 4 erect teeth and 15 oblique denticles; 2 pairs of teeth on vomer; 2 on each palatine; 6 pairs on basibranchials; gill-teeth on first 3 ceratobranchials.

Fins: Pectoral 0 ; dorsal 16 to 17 ; anal 19 to 20.

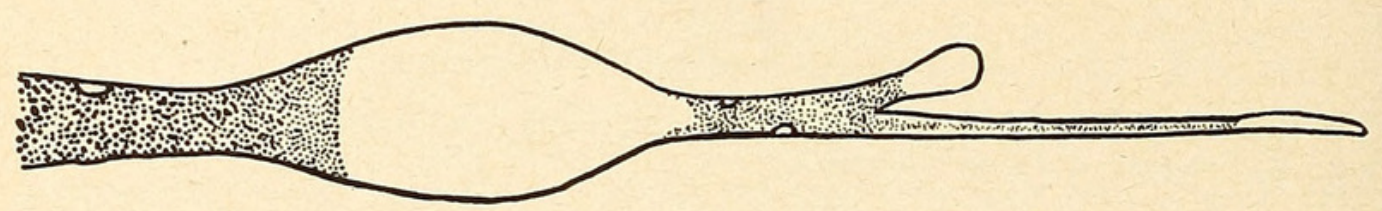

Text-figure 40. $26 \mathrm{~mm}$.

Photonectes mirabilis. Barbel of transitional adolescent, standard length

\section{DEVELOPMENT.}

The 3 Bermuda specimens, measuring between 18 and $26 \mathrm{~mm}$. long, are all young transitional adolescents with characteristics typical of their respective growth stages (see p. 79). The bulb is relatively longer in respect to the stem length than in the $60 \mathrm{~mm}$. type. There are remains of dorsal pigment blotches, one on each myomere. The type specimen is a transitional adolscent, with the gonads too immature to show the sex.

\section{STUdy MATERIAL.}

The following list gives the catalogue number, depth in fathoms, date, length and growth stage of each of the specimens of Photonectes mirabilis taken by the Bermuda Oceanographic Expeditions. All were caught in the cylinder of water off the Bermuda coast described in Zoologica, Vol. XVI, No. 1, p. 5 and Vol. XX, No. 1, p. 1.

No. 17,437; Net 812; 600 F.; Aug. 29, 1930; 18 mm.; Trans. Adolescent.

No. 18,002; Net 842; 600 F.; Sept. 4, $1930 ; 18 \mathrm{~mm}$.; Trans. Adolescent.

No. 18,398; Net $875 ; 600$ F.; Sept. 11, 1930; 26 mm.; Trans. Adolescent.

\section{Photonectes mirabilis:}

\section{REFERENCES.}

Parr, 1927, p. 111, figs. 59 and 60 . (Type specimen, $60 \mathrm{~mm} . ; 8,000$ ft. wire; south of Nassau; examined by present authors).

Regan \& Trewavas, 1930 , p. 123, fig. 117B. (1 specimen, 18 mm.; 300 m. wire; ca. 200 miles off Cape Hatteras).

Beebe, 1937, p. 199. (Preliminary list of Bermuda specimens). 
Photonectes cornutus Beebe, 1933.

TYPE.

(The unique specimen).

Department of Tropical Research No. 17,875; Bermuda Oceanographic Expeditions of the New York Zoological Society; Net 842; September 4, $1930 ; 600$ fathoms ; 10 miles south of Nonsuch Island, Bermuda $\left(32^{\circ} 12^{\prime}\right.$ N. Lat., $64^{\circ} 36^{\prime}$ W. Long.) ; standard length $19 \mathrm{~mm}$.

\section{DESCRIPTION.}

With the characteristics of the genus.

Color (fresh specimen): General color dark brown; barbel bulb white.

Measurements and Proportions: Total length $23 \mathrm{~mm}$.; standard length $19 \mathrm{~mm}$.; depth $2.4 \mathrm{~mm}$. (in length 7.9 or $12.6 \%$ ) ; head $3 \mathrm{~mm}$. (in length 6.3 or $15.9 \%$ ); eye $0.7 \mathrm{~mm}$. (in head 4.3 or $3.7 \%$ of length); snout 0.6 mm.; (in head 5 or $3.15 \%$ of length) ; snout to pelvic measurement impossible on account of damage to specimen.

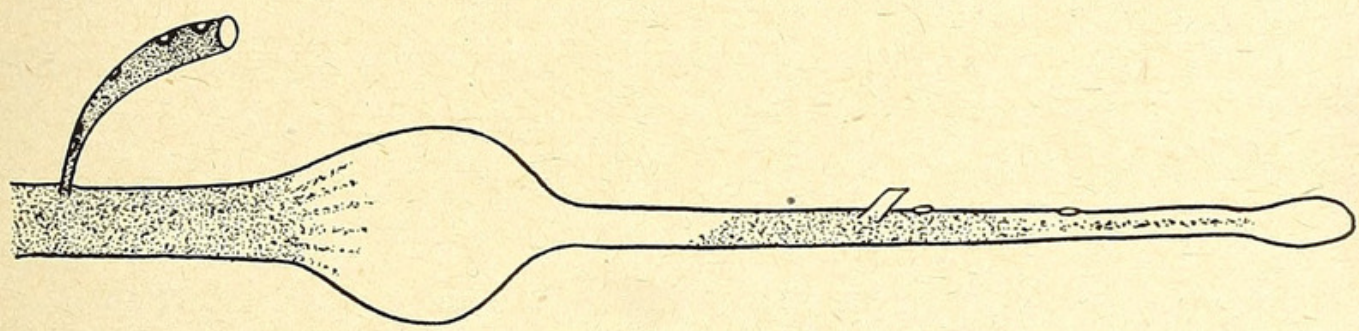

Text-figure 41. $19 \mathrm{~mm}$.

Photonectes cornutus. Barbel of transitional adolescent, standard length

Barbel: Length $4.3 \mathrm{~mm}$., longer than head, which is contained 1.4 times in barbel length; stem black, giving off a thick, short, black, club-shaped appendage posteriorly with several small, proximal photophores, 2 larger distal organs and a large pore at the extreme tip. Below this branch the stem expands into a large, white bulb, then narrows abruptly into a long, terminal filament, pigmented throughout most of its length, with several very small, roundish appendages and a flattened, irregularly rounded tip.

Light Organs: Postorbital inconspicuous, about equal to eye in length. Serial photophores with the following counts: ventral series, I-V ?, V-A 12, A-C 11; lateral series, O-V ?, V-A 12. There is a pair of luminous spots, close together, on the tip of the snout and 2 more pairs on the anterior part of the floor of the mouth. The rudiments of a third pair are located in front of these at the symphysis.

Teeth: There are 8 teeth in each premaxillary, of which the fifth is the largest, and an equal number in the premaxillary, 5 erect and 3 oblique; the mandible holds 15 teeth on each side, the sixth the longest; 2 pairs of teeth on the vomer; 1 on each palatine, set far back; 6 pairs of teeth on basibranchials.

Fins: Pectoral completely absent; pelvic 7; pelvic length $1.9 \mathrm{~mm}$.; dorsal rays 15; anal rays 18 . Caudal still very long, as usual in young fish, being more than a fifth of the standard length.

\section{Discussion.}

In spite of its youth and of serious damage to the fish in the region of the pectoral girdle, the specimen seems unquestionably to represent a 
hitherto undescribed species. It belongs to the subgenus Photonectes, composed of species with the I-V photophores numbering from 30 to $37 \mathrm{~mm}$., and the dorsal and anal fins having thin membranes. It is very close to $P$. mirabilis Parr, but differs in the presence of a well-developed, pigmented branch which springs posteriorly from the stem of the barbel in place of the small, white, luminous spot or knob found in that position in P. mirabilis. There are also minor differences between the two species in the more rounded form of the bulb. In development, it is a young transitional adolescent with the characteristics typical of that growth stage (see p. 79). Differences in the teeth and proportions as compared with Parr's $60 \mathrm{~mm}$. type of $P$. mirabilis may thus be attributed to age. Comparison with our own specimens of $P$. mirabilis, which are of comparable size with $P$. cornutus, proves that the form of the barbel in the present specimen is not a juvenile character of $P$. mirabilis.

\section{REFERENCES.}

Photonectes cornutus:

Beebe, 1933.2 , p. 169, fig. 6. (Preliminary description of the specimen described above). above).

Beebe, 1937, p. 199. (Preliminary listing of the specimen described

Photonectes parvimanus Regan \& Trewavas, 1930.

SPECIMENS TAKEN BY THE BERMUdA OCEANOGRAPHIC EXPEDITIONS.

10 specimens; May to July, 1929 to 1934 ; 0 to 800 fathoms; from a cylinder of water 8 miles in diameter ( 5 to 13 miles south of Nonsuch Island, Bermuda), the center of which is at $32^{\circ} 12^{\prime}$ N. Lat., $64^{\circ} 36^{\prime} \mathrm{W}$. Long.; standard lengths from 14 to $44 \mathrm{~mm}$.

\section{SPECIMENS PREVIOUSLY RECORDED.}

10 specimens; $c a .27$ to 250 fathoms; North Atlantic, approximately 400 miles southwest to 1,500 miles southeast of Bermuda; standard lengths from 26 to $55 \mathrm{~mm}$.

\section{Description of Transitional Adolescent.}

(No adult known).

With the characteristics of the genus.

Color (from 3 fresh specimens): General color brownish-black; postorbital light organ white; barbel bulb bright green, with bluish-green or turquoise core; distal barbel appendage pale green or yellow-green, with black dots at posterior tip, and filaments translucent; serial photophores violet, the ventral series having gilt frames.

Proportions: Depth in length 8 to 10 (10\% to $12.5 \%)$; head in length 6.6 to $8(12.5 \%$ to $15.2 \%)$; eye in head 6 to 7 ; snout to pelvic in length $1.83(58 \%)$.

Barbel: About half length of head; stem black; bulb spherical, or slightly oblong, much less than half the length of the stem, bearing a translucent, compressed distal appendage, which contains a network of branching threads, and, in all except very small specimens, a fringe of filaments along the posterior edge, terminating in a long filament with 1 or 2 pairs of branches; the latter, like the filaments of the fringe, may end in luminous swellings. 


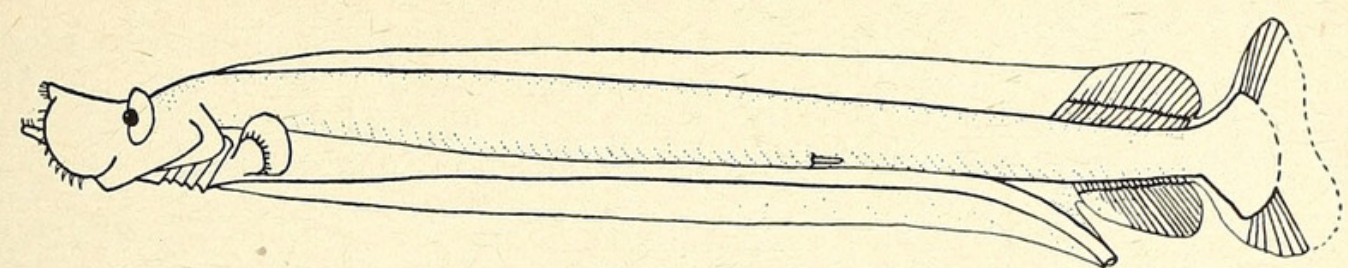

A
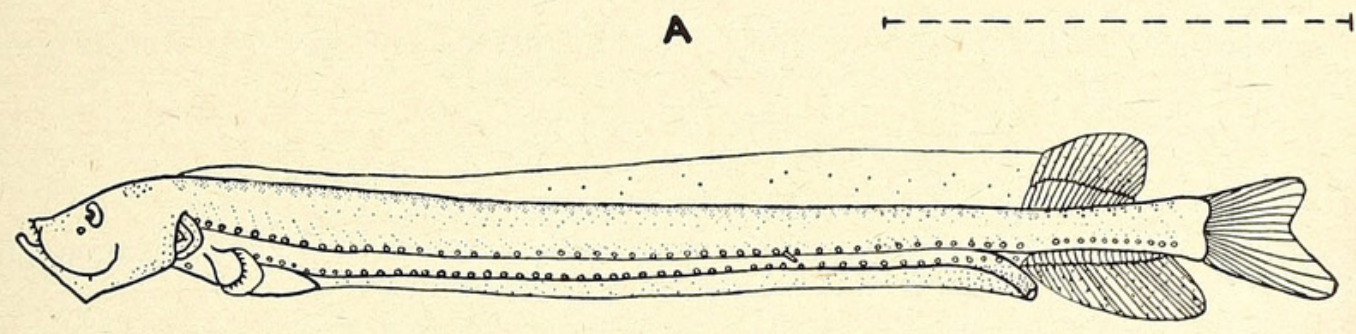

$$
1---\frac{-}{B}-------1
$$
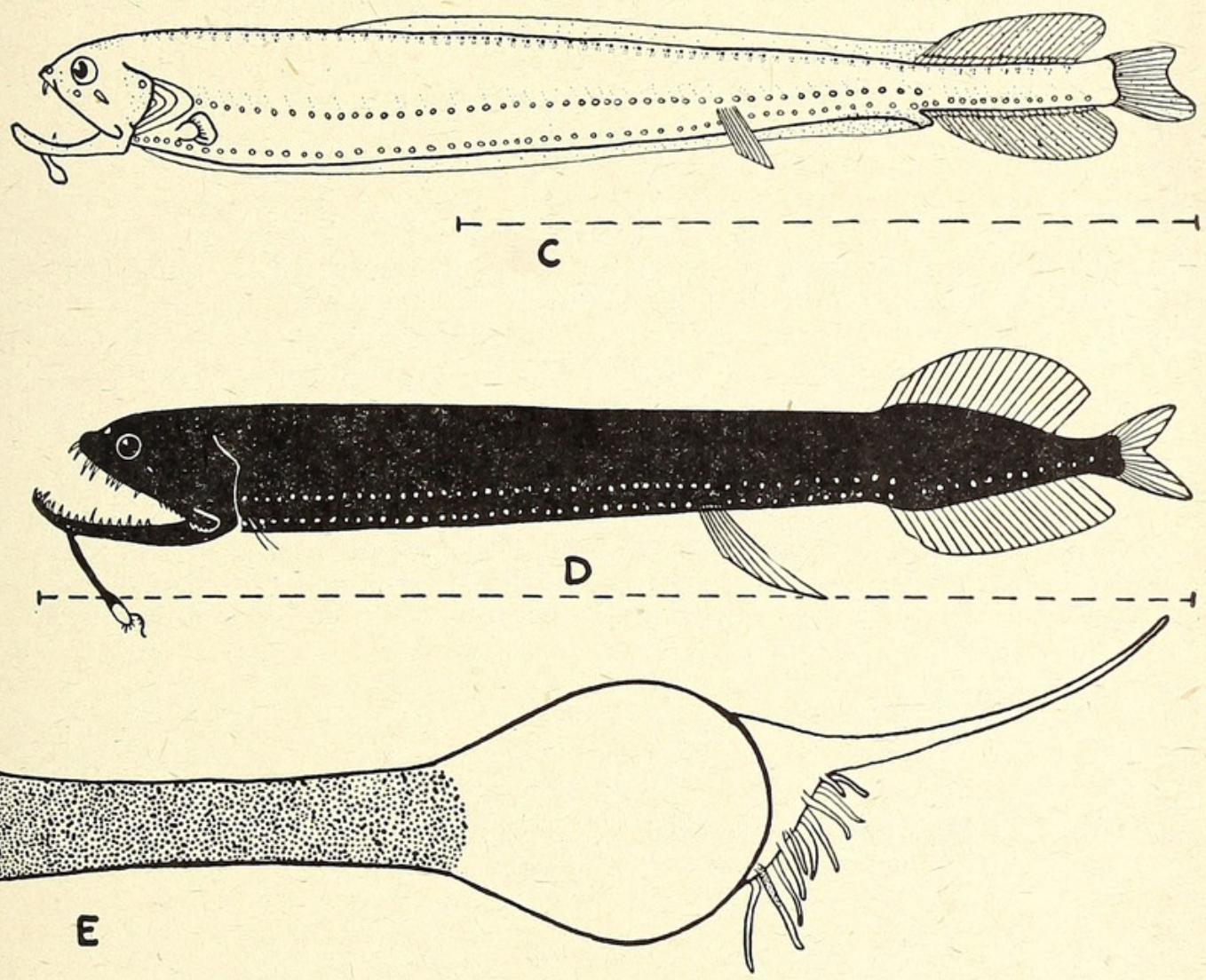

Text-figure 42.

Photonectes parvimanus. A, larva, standard length $14 \mathrm{~mm}$; B, late larva, $26 \mathrm{~mm}$; C C, post-larva, $25 \mathrm{~mm}$.; D, transitional adolescent, $44 \mathrm{~mm}$.; E, same, end of barbel. See also Text-fig. 2, E and F.

Light Organs: Postorbital smaller than eye. Serial photophores with the following counts: ventral series, I-P 10 to $11, \mathrm{P}-\mathrm{V} 35$ to 38 , V-A 12 to 14 , 2 or 3 being above anal fin, A-C 11 to 13 ; lateral series, O-V 34 to 36 , V-A 12 to 13. A small white luminous spot on shoulder. 
Teeth: Maxillary with 2 to 6 erect teeth and 5 or 6 oblique; 2 pairs of teeth on vomer; 4 to 6 teeth on each palatine; gill-teeth present on first, second and third ceratobranchials, there being about 7 pairs on the first.

Fins: Pectoral 2, very short; dorsal 17 to 19 ; anal 22 to 24 .

\section{DEVELOPMENT.}

Material: The Bermuda collection is composed entirely of juvenile specimens, distributed as follows:

2 larvae; 14, 26 mm.; 0,800 fath.; June.

1 post-larva; $25 \mathrm{~mm}$.; 700 fath.; May.

7 transitional adolescents; 30 to $44 \mathrm{~mm}$.; May to July.

All are typical representatives of their respective growth stages (see pp.76-79). Their special characteristics are as follows:

Myomere Counts: To end of anal 64 to 65 ; from nape to pelvic rudiment (when present) 29 to 41 ; from pelvic rudiment to anal origin 12 to 13 .

Pigment: In this species larval pigment seems to be a specific rather than a generic character, since in the other species of Photonectes in which traces of pigment pattern remain, the most dorsal pigment area on each myomere is a single compact or stellate blotch, instead of being broken into several or more dots as in the present species. In detail, the pigment pattern is as follows: (a) a dorsal band immediately below the profile, made up of dendritic and non-dendritic spots, usually of from 3 to 6 per myomere, with the 2 most dorsal spots largest and succeeding each other, and the remainder dwindling in size ventrally; (b) a second series, between lateral mid-line and lateral serial organs, of the usual oblique rows of 3 or 4 small, equal chromatophores placed in or near the intra-myomeral lines, and frequently underlaid by deeply imbedded, continuous lines of pigment. This pigment pattern is still well defined in young transitional adolescents. The finfolds and the anal fin are sprinkled sparingly with tiny dendritic chromatophores.

Barbel: The filaments on the barbel develop in early transitional adolescence.

Larval Teeth: In each premaxillary of the $13.6 \mathrm{~mm}$. larva are 5 teeth all directed outwards; the maxillary holds 10 teeth, with small spaces between, all erect and increasing in size posteriorly; each half of the mandible holds 7 teeth, all in the anterior part of the jaw and directed upward (not outward, as in the premaxillary); the more posterior are slightly larger than the others. The $26 \mathrm{~mm}$. larva is passing into the post-larval stage, having few teeth left.

Larval Gill-rakers: Rakers are present on first 3 arches, mounds on last 2; rakers short in $14 \mathrm{~mm}$. larva, but long and spiny in a $26 \mathrm{~mm}$. late larva and in a $25 \mathrm{~mm}$. post-larva.

Fins: Dorsal and anal rays of full number in larva, but the anterior ones not clearly marked. Finfolds moderately deep.

\section{ECOLOGY.}

Food: Six stomachs of transitional adolescents were examined, of which 2 contained food: a specimen $36 \mathrm{~mm}$. long held a $20 \mathrm{~mm}$. Myctophum laternatum, while the second, $44 \mathrm{~mm}$. long, held 2 Cyclothone microdon. There was a considerable amount of material in the intestines of all 6 specimens.

\section{STUDY MATERIAL.}

The following list gives the catalog number, depth in fathoms, date, length and growth stage of each specimen of Photonectes parvimanus taken by the Bermuda Oceanographic Expeditions. All were caught in the cyl- 
inder of water off the Bermuda coast described in Zoologica, Vol. XVI, No. 1, p. 5 and Vol. XX, No. 1, p. 1.

No. 10,425; Net 165; $600 \mathrm{~F}$; June 14, 1929; $31 \mathrm{~mm}$.; Trans. Adolescent.

No. 11,172; Net 243; 600 F.; July 1, 1929; 30 mm.; Trans. Adolescent.

No. 11,887; Net 329 ; 800 F.; July 27, 1929; 30 mm.; Trans. Adolescent.

No. 15,120; Net 597; 700 F.; May 19, 1930; 25 mm.; Post-larva.

No. 15,276; Net 618; 500 F.; May 22, 1930; $36 \mathrm{~mm}$.; Trans. Adolescent.

No. 17,331; Net 797; 500 F.; July 15, 1930; $31 \mathrm{~mm}$.; Trans. Adolescent.

No. 20,580; Net 989; 0 F.; June 3,$1931 ; 14 \mathrm{~mm}$; Larva.

No. 20,629; Net 993; 800 F.; June 4; 1931; 26 mm.; Larva.

No. 21,372; Net 1083; 300 F.; July 14, 1931; 35 mm.; Trans. Adolescent.

No. 24,363; Net 1501; 400 F.; July 25, 1934; 44 mm.; Trans.Adolescent.

\section{Photonectes parvimanus:}

\section{REFERENCES.}

Regan \& Trewavas, 1930 , p. 124, figs. 118,119 A, 119B. (10 specimens; 26 to $55 \mathrm{~mm}$.; 100 to 1,000 M. wire; North Atlantic).

Beebe, 1933.1, p. 180. (Preliminary list of Bermuda specimens).

Beebe, 1937, p. 199. (Preliminary list of Bermuda specimens).

\section{Photonectes bifilifer Beebe, 1933.}

TYPE.

(The unique specimen).

Department of Tropical Research No. 15,146; Bermuda Oceanographic Expeditions of the New York Zoological Society; Net 598; May 19, 1930; 9 miles south of Nonsuch Island, Bermuda; $\left(32^{\circ} 12^{\prime} \mathrm{N}\right.$. Lat., $64^{\circ} 36^{\prime} \mathrm{W}$. Long.); 800 fathoms; standard length $245 \mathrm{~mm}$.

\section{DESCRIPTION.}

(With the characteristics of the genus). distally.

Color (in fresh specimen): Barbel bulb white at base, rich lavender

Measurements and Proportions: Total length $260 \mathrm{~mm}$.; standard length $245 \mathrm{~mm}$.; depth $37 \mathrm{~mm}$. (in length 6.6 or $15.1 \%$ ); head $35 \mathrm{~mm}$. (in length 7 or $14.2 \%$ ) ; mandible 37 (in length 6.6 or $15.1 \%$ ); eye $5 \mathrm{~mm}$. (in head 7 ,

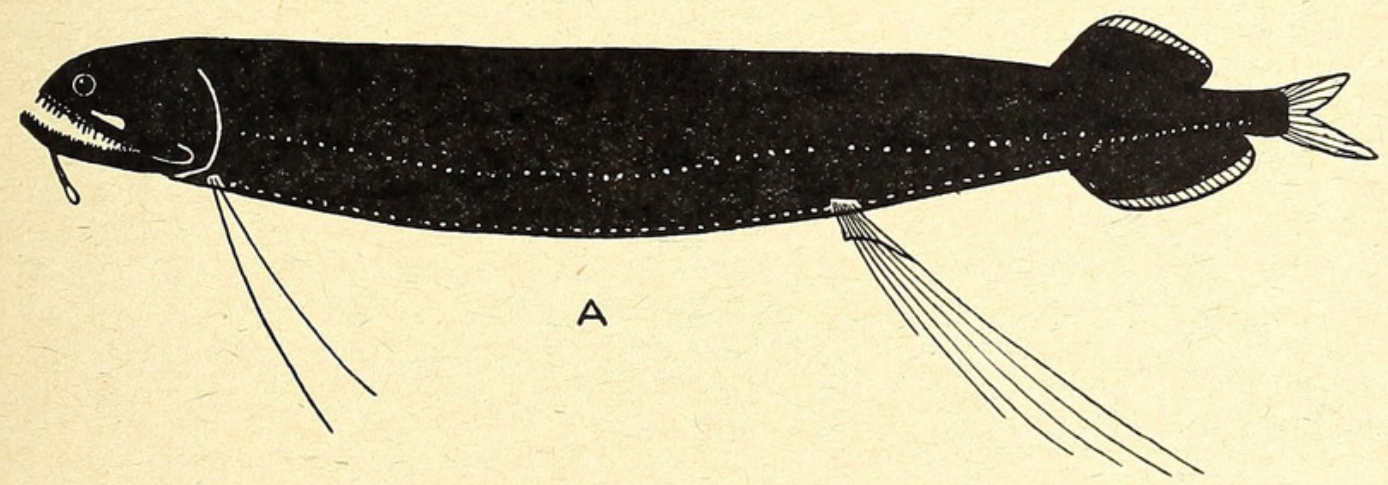

B

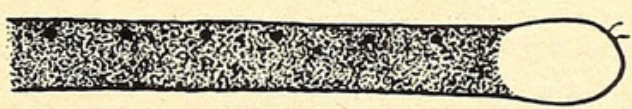

Text-figure 43.

Photonectes bifilifer. A, adult, standard length $245 \mathrm{~mm}$.; B, barbel of same. 
or $2.04 \%$ of length); snout $6 \mathrm{~mm}$. (in head 5.8 or $2.45 \%$ of length); snout to pelvic $156 \mathrm{~mm}$. (1.6 in length or $64 \%$ ).

Barbel: Length $11 \mathrm{~mm}$. (in head 3.2). Stem thick and black, four-fifths the length of the entire barbel; bulb only slightly broader than diameter of stem; 2 very short, thread-like filaments on the posterior surface near tip, with a few specks of pigment on the bulb at their base. Along the posterior side of the stem is a row of half a dozen small photophores.

Light Organs: Postorbital 1.8 times diameter of eye. Serial photophores with the following counts: ventral series, I-P 10, P-V 36, V-A 14, A-C 15; lateral series, O-V 36, V-A 13 . A luminous spot on shoulder.

Teeth: All small, depressible, typical of the teeth of adults in this genus. In the left premaxillary are 6 teeth, the first very small, well separated from the succeeding 5 equal fangs; the left maxillary holds 16 , depressible, erect teeth in graduated series of $4,2,3,3$ and 4 ; the posterior oblique denticles number about 35 and are very small and closely-set. The maxillary teeth of the right side are slightly different in their grouping. In the left side of the mandible are 35 , in the right side 38 ; they are in the usual Photonectes-like groups of from 3 to 5 . There is a single pair of teeth on the vomer and 5 teeth on each palatine. On the basibranchials are 9 pairs, 6 on the first, 3 on the second, the teeth of each group increasing in length backwards. Gill-arch teeth present on first, second and third ceratobranchials, there being 7 groups on the first.

Fins: The pectoral consists of 2 elongated, thread-like rays, widely separated at the base, more than $1 \frac{1 / 2}{2}$ times as long as head. The pelvic, placed far back on the body, has the basal portion of the 7 rays covered with a thick, black membrane similar to those which almost completely enclose the rays of the dorsal and anal; the most anterior pelvic ray is very short, scarcely projecting beyond the membrane, but the succeeding rays increase in length posteriorly, until the seventh reaches the caudal base. Dorsal rays 20 ; anal rays 24 . veloped.

Sex: The specimen is an adult male, with the gonads about half de-

\section{Discussion.}

In form this Photonectes is characteristic of the subgenus Trachinostomias, the body being deep for a melanostomiatid, and thickest toward the middle of its length, while the head is small, lower than the shoulders and somewhat concave dorsally. When the specimen is laid alongside an example of similar size of $P$. margarita there is no apparent difference save for the barbel and the 2 long pectoral rays. Even the skin is fragile, with a characteristic blue-grayness in preservative, which is apparently common to adults of both species. A reexamination of the specimen since the preliminary description shows that, except for differences obviously due to its greater age, $P$. bifilifer differs from $P$. parvimanus, (of which the largest known specimen measures $55 \mathrm{~mm}$.), only in the lack of a crest on the barbel bulb and in the great length of the 2 pectoral rays. Both may prove also to be growth characters, or the barbel crest may have been torn away in the present specimen. Until intermediate stages are secured, however, it seems best to keep the two forms separate.

\section{REFERENCES.}

Photonectes bifilifer:

Beebe, 1933.2, p. 167, fig. 5. (Preliminary description of the specimen described in detail above.)

Beebe, 1937, p. 199. (Preliminary listing of above specimen.) 
Photonectes margarita (Goode \& Bean, 1895).

\section{General Discussion.}

As already indicated on page 154, it is now clear that the following species should be regarded as synonymous with $P$. margarita: $P$. richardi (Zugmayer, 1913) ; P. flagellatus Parr, 1927; P. intermedius Parr, 1927, and P. monodactylus Regan \& Trewavas, 1930 . The only significant differences attributed to these various species were the forms of the barbel. We have examined the types of all except $P$. richardi and $P$. monodactylus, comparing them with Bermuda specimens, with the following results:

1. P. margarita (Goode \& Bean, 1895). $320 \mathrm{~mm}$. long, in the U. S. National Museum. The tip of the barbel has in all probability been broken off and, perhaps, a portion regenerated; the unpigmented distal portion seems to be damaged tissue rather than a true second bulb; parallel instances are found in the present collection except for the shortness of the barbel, (ca. $19 \mathrm{~mm}$. or about half the length of the head, instead of about as long as the head, as in other large specimens), and its slenderness (an established growth character); this organ is identical in basic pattern with the other known forms. Finally, there are indubitable evidences that pectorals were once present, since there are skin pockets for their insertion in exactly the location found on our specimens; in several of the latter, as in two of the Dana specimens of P. monodactylus (see Regan \& Trewavas, 1930, p. 127), a ray is missing from one side of the fish leaving no more trace than in the type of $P$. margarita.

2. P. flagellatus Parr, 1927. $280 \mathrm{~mm}$. long. In the Peabody Museum, New Haven, Conn. The barbel measures $30.5 \mathrm{~mm}$. (head and lower jaw lengths: $37 \mathrm{~mm}$.) in total length. There is an unmistakable bulb in the usual position, immediately proximal to the first tuft of filaments; its anterior (ventral) surface is, as usual in adult specimens, pigmented, so that the bulb is only apparent posteriorly (dorsally); Text-fig. $44 \mathrm{H}$ is from a redrawing of the barbel. The specimen is an adult male near breeding condition.

3. P. intermedius Parr, 1927. These small specimens (44 to $58 \mathrm{~mm}$. long) in the Peabody Museum fit in perfectly with our growth stage series, showing that $P$. intermedius is the young of $P$. margarita.

4. Specimens recorded by Borodin, 1931.

a). Photonectes margarita (p. 66). This specimen, $340 \mathrm{~mm}$. long, is a female in full breeding condition. The end of the barbel (Text-fig. 44I) is obviously broken off, so that its short length $(23 \mathrm{~mm}$., the mandible measuring $50 \mathrm{~mm}$.) is readily explained.

b). Echiostoma barbatum (p. 65), part. The two smaller specimens, 70 and $75 \mathrm{~mm}$., (Text-fig. 44C), are young $P$. margarita with barbels in perfect transitional stages between the juvenile intermedius-type and adult margarita type. The large Echiostoma is E. tanneri (see p. 141).

In view of the above comparisons and our own specimens, we have no hesitation in synonymizing both $P$. richardi (Zugmayer, 1913), and P. monodactylus Regan \& Trewavas, 1930, as well, with $P$. margarita. Of the 5 specimens of $P$. monodactylus in the type series, only one, according to the authors, has a complete barbel; the apparent lack of a barbel bulb is doubtless due to its inconspicuousness, as in some of the present series, or the especial. density of the pigment which more or less conceals the bulb, at least anteriorly, in large specimens.

\section{SPECIMENS TAKEN BY THE BERMUdA OCEANOGRAPHIC EXPEDITIONS.}

10 specimens; May to September, 1929 to 1931; 400 to 1,000 fathoms; from a cylinder of water 8 miles in diameter ( 5 to 13 miles south of Nonsuch 

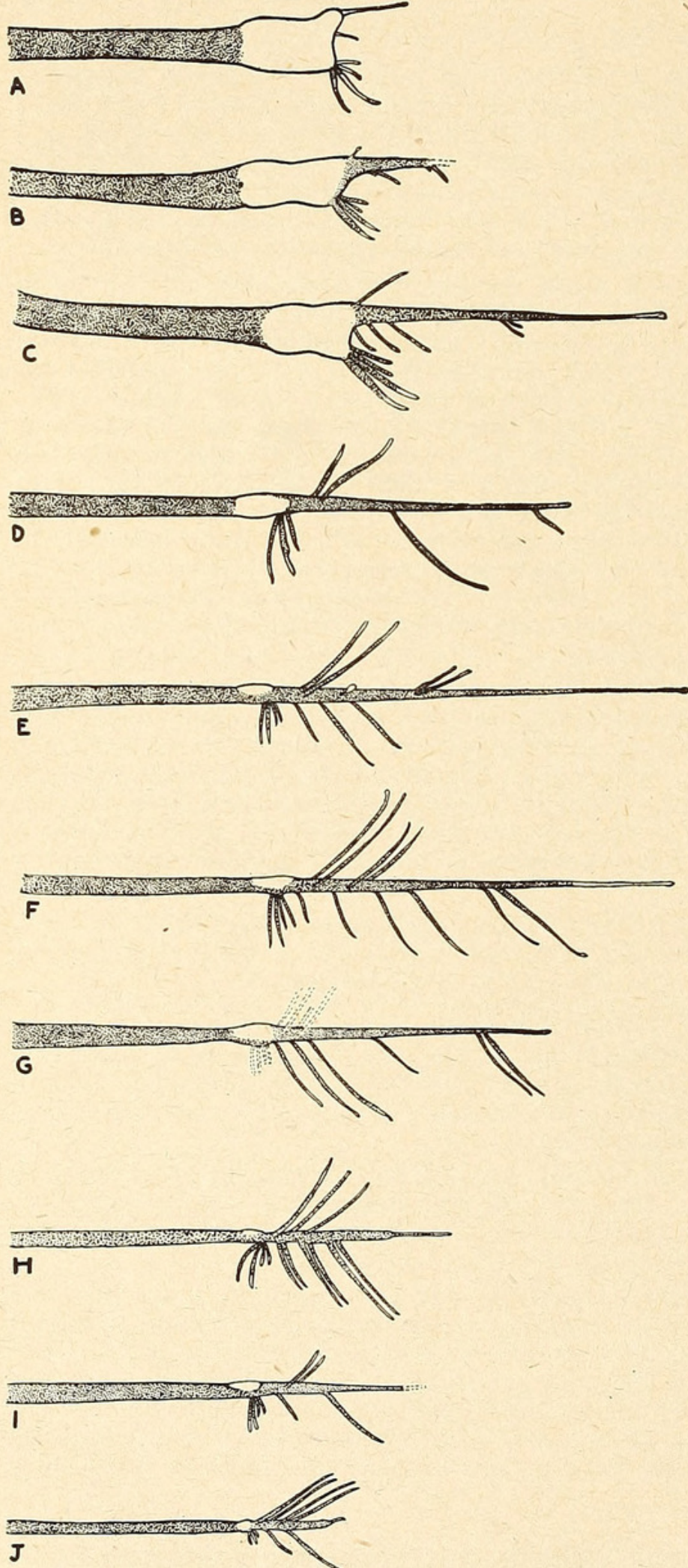

Text-figure 44.

Photonectes margarita. Barbels, lateral views. A, transitional adolescent, standard length $55 \mathrm{~mm}$; B, same, $70 \mathrm{~mm}$.; C, same, $75 \mathrm{~mm}$. (from Museum Comparative Zoology specimen No. 31,602) ; D, type specimen of $P$. richardi, $170 \mathrm{~mm}$. (after Regan \& Trewavas); E, adult male, $235 \mathrm{~mm}$.; $\mathbf{F}$, adult male, $257 \mathrm{~mm}$;; $\mathbf{G}$, adult female, $274 \mathrm{~mm}$.; $\mathbf{H}$, adult male, type of $P$. flagellatus, 280 $\mathrm{mm}$. (from the specimen in the Peabody Museum); I, adult female, $340 \mathrm{~mm}$. (from Museum Comparative Zoology specimen, Atlantis Sta. 321) ; J, type of $P$. margarita (after Parr). A, B, E, F and G, from specimens in present collection. All drawn in proportion to a fixed stem length (to base of bulb). Paired appendages directed dorsally. 
Island, Bermuda), the center of which is located at $32^{\circ} 12^{\prime} \mathrm{N}$. Lat., $64^{\circ} 36^{\prime}$ W. Long.; standard lengths from 49 to $300 \mathrm{~mm}$.

\section{SPECIMENS PREviously ReCORDED.}

36 specimens; $c a .41$ ( -0$)$ to 1,100 fathoms; eastern and western North Atlantic; standard lengths from 20 to $320 \mathrm{~mm}$.

\section{DESCRIPTION OF ADULT.}

With the characteristics of the genus.

Color (from 7 fresh Bermuda specimens): general color black; postorbital light organ rosy in female, yellow in male; barbel bulb purple; serial photophores violet to purple; luminous shoulder spot pale blue.

Proportions: Depth in length 6.5 to $7.6(13.2 \%$ to $15.4 \%)$; head in length 6.5 to $7.8(12.8 \%$ to $15.4 \%)$; eye in head 6 to 7.7 ; mandible almost exactly equal to head; snout to pelvic in length 1.57 to 1.6 (63\% to $64 \%)$.

Barbel: Slightly longer than head when complete; stem usually less than half entire length of barbel, without branches, densely pigmented; bulb progressively reduced with age, scarcely or not at all thicker than stem; anterior portion, and sometimes all of bulb becoming covered with pigment. From the bulb arises a long, tapering, branched, pigmented terminal filament, proximally as thick as the bulb, distally very slender; with an unpigmented tip; traces of a second bulb toward its end have proved, in every example seen, to be merely a damaged section of the appendage. From the anterior (ventral) side of the base of the terminal appendage arises a tuft of short filaments, usually 2 in number, 2 long and 2 short; distal to these, scattered at irregular intervals along the appendage are other filaments or branches, longer than the basal tuft, of varying length, number and arrangement; typically, however, there seem to be 2 paired and 3 to 6 unpaired filaments, the majority arising from the proximal half of the appendage; all of the filaments are pigmented, and almost all have unpigmented (luminous?) tips.

Light Organs: Postorbital longer than eye; serial photophores with the following counts: ventral series, I-P 8 to 11 ; P-V 30 to 35 ; V-A 11 to 13 ; A-C 11 to 12 ; lateral series, $\mathrm{O}-\mathrm{V} 28$ to 34 ; V-A 11 to 13 ; all serial organs reduced and inconspicuous, often difficult to count accurately, especially since the delicate skin is usually in bad condition. A small luminous spot on shoulder, sometimes surrounded by a few similar but much smaller spots.

Teeth: All teeth small, not very unequal; in typical Photonectes series; premaxillary 5 to 8 ; erect maxillary teeth 14 to 25 ; oblique maxillary denticles rudimentary, 12 to 25 ; mandibular teeth 24 to 37 ; usually 2 pairs of teeth on vomer; 3 to 6 teeth on each palatine. 10 pairs of teeth on basibranchials; teeth on first, second and third ceratobranchials; 5 or 6 pairs on first ceratobranchial.

Fins: Pectoral 1, much elongated, about twice length of head, the end expanded and possibly luminous; a rudimentary, subdermal second ray. Dorsal 18 to 20 ; anal 22 to 24 .

\section{DEVELOPMENT.}

The Bermuda collection contains 4 transitional adolescents measuring between 49 and $70 \mathrm{~mm}$. in length, with characteristics typical of that growth stage (see p. 79). Their special peculiarities are in the form of the barbel which does not assume a fully adult aspect until the fish has reached a length of more than $100 \mathrm{~mm}$. In the young the bulb is much thicker than the stem, and very noticeably truncate; the prominent terminal appendage of the adult is represented oniy by a short, unpigmented, unbranched filament arising 
from the posterior distal corner of the bulb; at the anterior, distal corner is a cluster of 3 or 4 short filaments which remain in this relative position throughout development. Text-fig. 44 shows the successive steps in the reduction of the bulb, and in the growth of the terminal appendage and its branches. The barbel bulb of the young is bright violet blue to ultramarine, with a small pink spot at posterior distal edge; postorbital organ purple or magenta; serial photophores violet to purple as in adult, but ventral series with broad gold frames.

Specimens of $P$. margarita measuring about 235 or $250 \mathrm{~mm}$. in length may, from the development of their barbels and coelomic organs, be termed adult.

\section{BEHAVIOR.}

A female, $273 \mathrm{~mm}$. long was taken alive, enabling the following notes to be made:

"This large melanostomiatid was taken on May 21, 1930, at a depth of 610 fathoms at 12 o'clock. It was alive when brought in at 2 P. M. and put on ice in the refrigerator. At 7 P. M. it was breathing regularly, and when put in the dark room, lay quiet, breathing once every two seconds. The cheek light was almost wide open and motionless. I touched the body of the fish halfway to the tail lightly with my finger and instantly the cheek light revolved downward and closed tightly, held shut a second or two and opened slowly. Again and again this happened with no slackening of response. The fish was then turned upon its ventral side so that we could watch both sides at once. When I pressed gently upon the sides the response came as before and simultaneously to both cheek lights, the closing and opening being absolutely synchronous. This response is apparently a guard against detection from attack, obliterating this light at the hint of outside danger. The fish lived 10 hours, although much of the skin had been scraped away."

\section{STUdy MATERIAL.}

The following list gives the catalogue number, depth in fathoms; date, length and growth stage of each specimen of Photonectes margarita taken by the Bermuda Oceanographic Expeditions. All were taken in the cylinder of water off the Bermuda coast described in Zoologica, Vol. XVI, No. 1, p. 5 and Vol. XX, No. 1, p. 1.

No. 10,535; Net 181; 1,000 F.; June 17, 1929; $273 \mathrm{~mm}$.; Adult Male.

No. 12,502; Net 388; 900 F.; Aug. 27, 1929; 278 mm.; Adult Male.

No. 13,581; Net 479; 600 F.; Sept. 20, 1929; $250 \mathrm{~mm}$.; Adult Male.

No. 13,842; Net 514; 800 F.; Sept. 27, 1929; 274 mm.; Adult Female.

No. 14,950; Net 577; 800 F.; May 14, 1930; $70 \mathrm{~mm}$.; Trans. Adolescent.

No. 15,253; Net 613; $600 \mathrm{~F}$; May 21, $1930 ; 300 \mathrm{~mm}$; Adult Female.

No. 19,576; Net 967; 500 F.; Sept. 30, 1930; 250 mm.; Adult Male.

No. 20,516; Net 983; 500 F.; June 2, 1931; 55 mm.; Trans. Adolescent.

No. 20,664; Net 1001; 800 F.; June 5, 1931; 49 mm.; Trans. Adolescent.

No. 21,666; Net 1107; 400 F.; July 27, 1931; 57 mm.; Trans. Adolescent.

\section{SYNONYMY AND REFERENCES.}

\section{Echiostoma margarita:}

Goode \& Bean, 1895, p. 109, fig. 131. (1 specimen, 320 mm.; 420 fath.; Gulf of Mexico; examined by present authors).

\section{Echiostoma richardi:}

Zugmayer, 1913, p. 4 . (1 specimen; $170 \mathrm{~mm}$. 0-2,000 m. wire; eastern Atlantic). 
Photonectes margarita:

Parr, 1927, p. 106, fig. 55 B. (Report on reexamination of type of $E$. margarita).

Regan \& Trewavas, 1930, p. 126, fig. 121 B. (Recapitulation of preceding reference).

Borodin, 1931, p. 66 (1 specimen; $340 \mathrm{~mm}^{7}$; 1,500 m.; off Bermuda; examined by present authors; a female, in or near breeding condition ${ }^{8}$ ).

Beebe, 1937, p. 199. (Preliminary list of Bermuda specimens).

Photonectes flagellatus:

Parr, 1927, p. 107, fig. 55 A. (1 specimen; $280 \mathrm{~mm}$.; 8,000 ft. wire; off Bahamas; examined by present authors; a male).

Regan \& Trewavas, 1930 , p. 127, fig. 121 A. (Recapitulation of preceding reference).

Photonectes intermedius:

Parr, 1927, p. 109, figs. 57, 58. (3 specimens, 44 to $58 \mathrm{~mm} . ; 5,000$ to $10,000 \mathrm{ft}$. wire; off Bermuda; examined by present authors).

Regan \& Trewavas, 1930, p. 126. (22 specimens, 20 to $86 \mathrm{~mm}$; 150 to $2,000 \mathrm{~m}$. wire; North Atlantic; examined by present authors).

Beebe, 1933.1, p. 180. (Preliminary list of specimens in present Bermuda collection).

Beebe, 1937, p. 199. (Preliminary list of specimens in present Bermuda collection).

\section{Photonectes richardi:}

Regan \& Trewavas, 1930 , p. 126 , fig. 120 B. (Report on reexamination of type of $E$. richardi). richardi).

Roule \& Angel, 1931, p. 5. (Report on reexamination of type of $E$.

Roule \& Angel, 1933, p. 17, pl. I, figs. 9, 9a, 9b. (Amplified version of preceding reference).

\section{Photonectes monodactylus:}

Regan \& Trewavas, 1930 , p. 127, pl. XII, fig. 3, text-fig. 122 . (5 specimens; 180 to $255 \mathrm{~mm}$.; 600 to $4,000 \mathrm{~m}$. wire; North Atlantic, Caribbean Sea).

\section{Echiostoma barbatum: (non Lowe) :}

Borodin, 1931, (part.) p. 65 . (2 specimens, 70, $75 \mathrm{~mm}$; 600 fathoms; North Atlantic; examined by present authors).

\section{Genus Flagellostomias Parr, 1927.}

(See also pp. 70, 73, 75, 80, 81, 87, 88, 90, 91, 96, 97, 99, 101, 102, 105-110). (Text-figs. 2, 11, 12, 45-48 incl.).

\section{GENERAL Discussion.}

Two species of Flagellostomias have been described, F. boureei (Zugmayer, 1913), originally placed in the genus Eustomias, and F. tyrannus Parr, 1927.

We have examined the type specimens of $F$. tyrannus in the Peabody Museum, New Haven, and agree with Regan \& Trewavas (1930, p. 57) that

7 Our measurement. Published measurement of $240 \mathrm{~mm}$. is doubtless a misprint.

8 Listed under the heading $P$. marginata; obviously a misprint for margarita. 

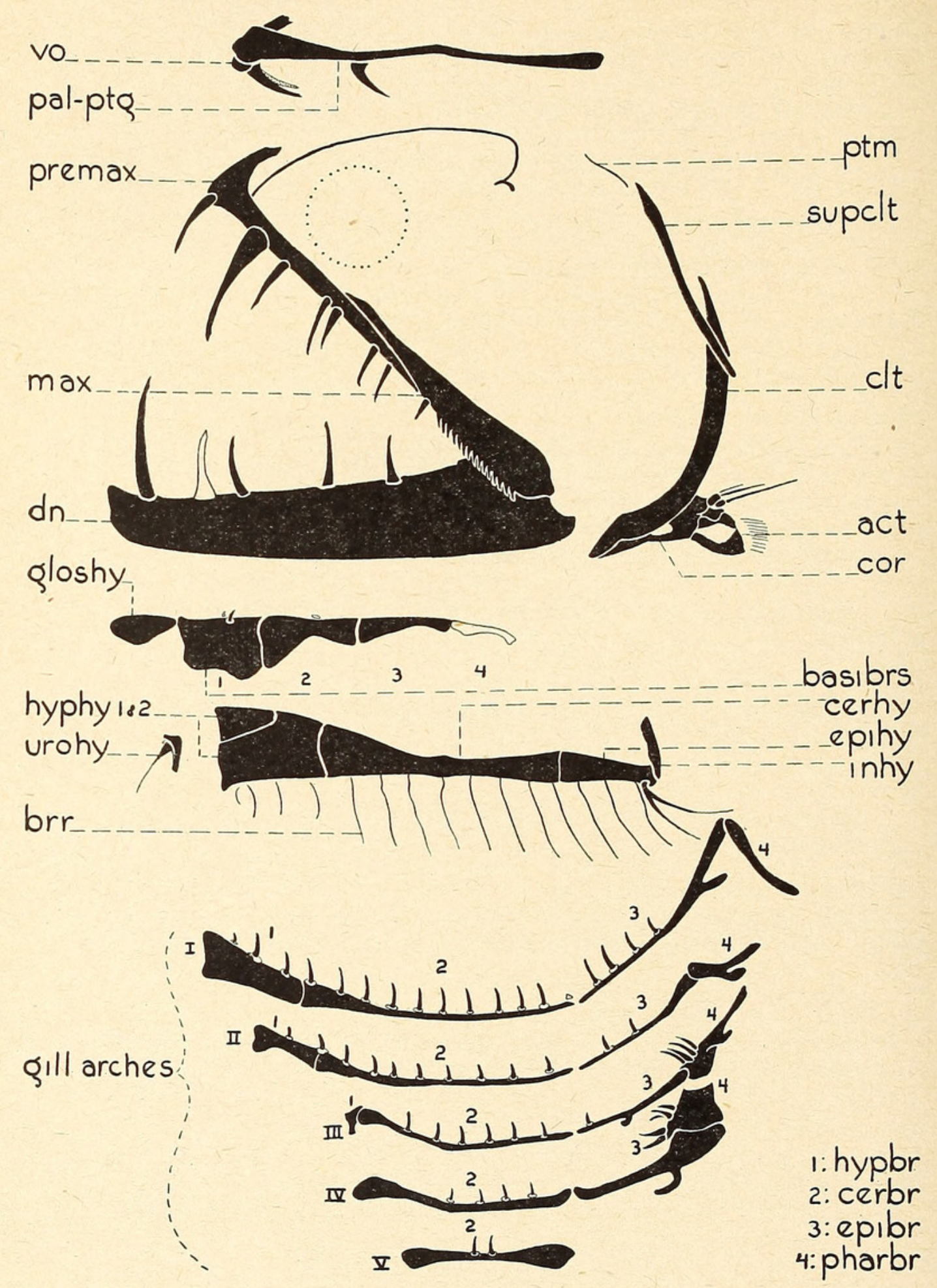

Text-figure 45.

Flagellostomias boureei. Jaws, hyoid and branchial arches, and pectoral girdle of transitional adolescent, standard length $97 \mathrm{~mm}$. Explanation as in Text-fig. 18.

this species is synonymous with $F$. boureei. Parr's $195 \mathrm{~mm}$. specimen, with the barbel seven-tenths of the length, proves to be a male, while the other, $192 \mathrm{~mm}$. long, with barbel only six-tenths of length, is a female. It is inter- 


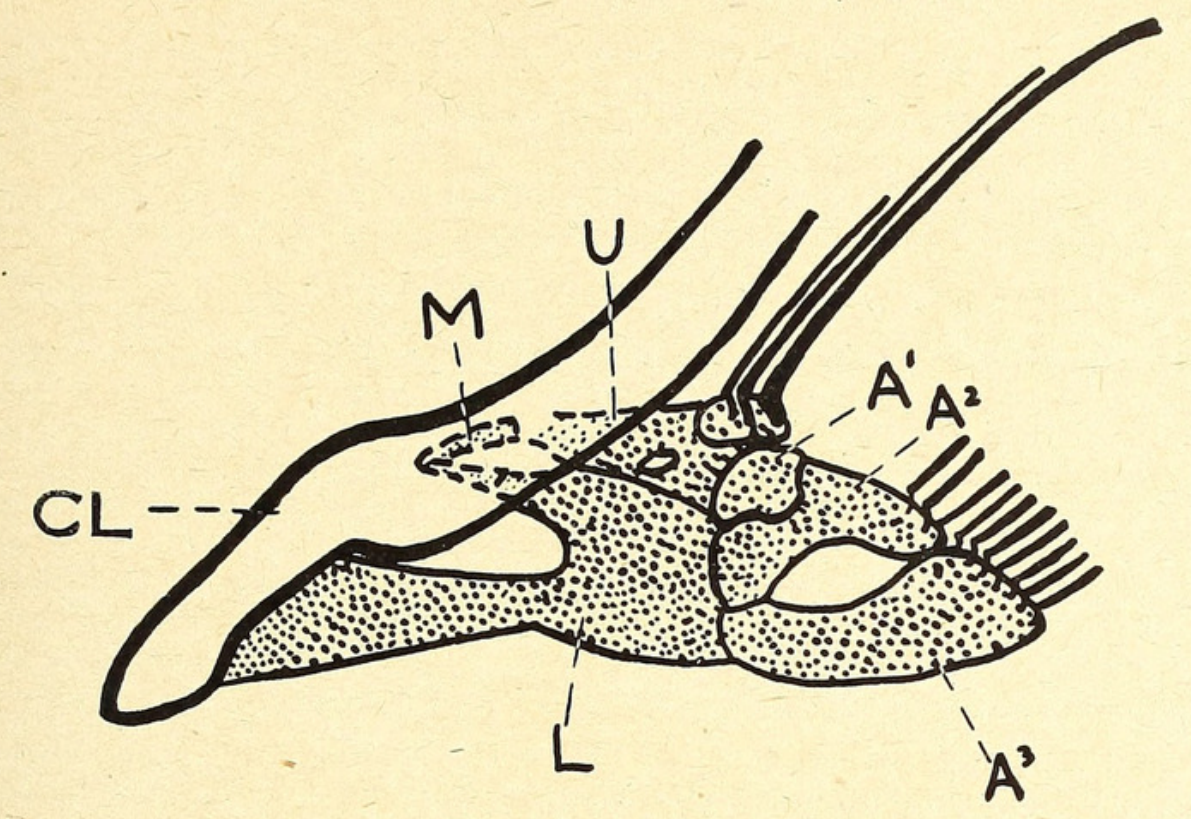

Text-figure 46.

Flagellostomias boureei. Supporting bones of pectoral fin in transitional adolescent, standard length $97 \mathrm{~mm}$. Abbreviations as in Text-fig. 14. The two rays beside the enlarged, isolated ray are not apparent externally.

esting to note that both were taken in the same net, so that it is possible they were swimming together; neither, however, is in breeding condition, the gonads being but slightly developed.

There is considerable variation in the form of the barbel in $F$. boureei (see Regan \& Trewavas, loc. cit., fig. 33 ), which should be borne in mind in relation to other genera, where a number of species have been formed on the basis of relatively slight differences in this same organ. In this case there seems to be no doubt but that individual variation, and perhaps sexual differences as well, are responsible, and that the single species is properly defined.

Distribution: Flagellostomias is known from the eastern and western North Atlantic, and from the eastern South Atlantic, in tropical and subtropical zones. It has been taken, between, roughly, 100 and 1,000 fathoms. Including the present series, 24 or 25 specimens are known.

\section{GENERIC CHARACTERS.}

Since only one valid species is known in this genus, the following characters are also those of the unique species, $F$. boureei (Zugmayer).

Color (from a freshly caught, $97 \mathrm{~mm}$., immature male) : General color brownish-black; postorbital silvery white; barbel bulb and swollen tip of first pectoral ray, pale yellow-green; all photophores purple.

Proportions: Depth in length 9 to 12 ( 8.3 to $11.1 \%$ ); head in length 6.5 to 8.8 ( $11.4 \%$ to $15.4 \%$ ) ; eye in head 5 to 6.2 (ca. $2.2 \%$ to $2.6 \%$ of length); snout less than twice length of eye; snout to pelvic in length 1.6 to $1.7(60 \%$ to $62 \%)$.

Barbel: Barbel about two-thirds length of fish; stem pigmented except distally, spotted with white; bulb ovate or oblong with a much smaller distal bulb; bulb and distal part of stem with many unpigmented filaments, almost always unbranched, varying in number, relative length and arrangement within the single known species. 
Light Organs: Postorbital almost half size of eye in male, completely atrophied in female. Serial photophores with the following counts: ventral series, I-P 8 to $10, \mathrm{P}-\mathrm{V} 31$ to 33 , V-A 14 to 16 , the last 1 or 2 above the anal fin, A-C 15 to 18; lateral series, O-V 30 to 32, V-A 13 to 17 . First pectoral ray bearing an ovate or elongate luminous bulb near the end terminating in a long filament; a lateral nubbin sometimes present on the bulb.

Teeth: Cleft of mouth straight; premaxillary with 4 to 6 rather long, fixed teeth, the second a long fang; maxillary usually with a small erect tooth in addition to a series of 15 or more oblique denticles; mandible with teeth similar to those on premaxillary, except that the first is the long fang, fitting into a groove in the premaxillary, and the second is smaller and depressible; rudimentary barbs present on premaxillary and mandibular teeth; a pair of teeth on the vomer and one or two on each palatine. One pair of small teeth on the basibranchials, sometimes with rudiments of a second; short, slender teeth, not paired or grouped, present on all five gill-arches: on the first and second hypobranchials; on all five ceratobranchials; and on first, second and third epibranchials; 10 to 11 teeth on first ceratobranchial.

Branchiostegal Rays: 16 to 17.

Fins: Pectoral with $1+10$ to 11 rays externally, the first isolated, its total length being about 2.5 times as long as head and 3 times as long as other rays, with a luminous, tentacled, terminal bulb. In a cleared and stained specimen there are 2 additional rudimentary rays visible in front of the prolonged first ray; hence the total number is actually 15 or 16 . Pelvic 7 , inserted well behind middle of length at or near 33rd myomere; dorsal 14 to 17 ; anal 23 to 26 , extending forward well in advance of dorsal origin and ending slightly behind the fin.

Epidermal Grooves: There is no provision in the skin for concealment of the luminous pectoral fin or barbel.

Osteology: Parietals present; mesethmoid with lateral processes; posttemporal rudimentary but present and ossified, well separated from skull; supra-cleithrum and cleithrum strong; coracoid elements all of moderate size: actinosts 3 ; vertebrae about 65 (myomeres to end of anal 67 to 68 ); first centrum represented only by a fibrous ring as long as centrum, enclosing the notochord, and by a spinal nerve; first neural arch enlarged and directed forward.

Coelomic Organs: Stomach $38 \%$ of length of fish, barely reaching pelvic origin (in an immature specimen of $97 \mathrm{~mm}$.). This organ is practically unpigmented at this stage, although the lining of the coelom is perfectly black; a similar lack of pigment is indicated by Regan \& Trewavas (1930, p. 40 , fig. $8 \mathrm{D}$ ), although the length of the specimen in question is not indicated. Intestine with an anterior pouch but no caecum.

Sexual Dimorphism: Postorbital organ well developed in male, atrophied in female. Barbel may prove to be consistently longer in male.

Size: The largest known specimen measures $322 \mathrm{~mm}$. in length and was taken by the Dana Expedition (Regan \& Trewavas, 1930, p. 57).

Development: The youngest Flagellostomias known are our 2 late larvae, 20 and $21 \mathrm{~mm}$. in length, characterized by the following combination of characters: Myomeres to end of anal 67; from nape to pelvic rudiment 32 or 33 ; from pelvic rudiment to anal origin 15. Pigment as follows: a single row of chromatophores on each side of dorsal mid-line, one goodsized blotch to a myomere; in post-larva a second row is present immediately above lateral row of photophores, the spots smaller than but equal in number to those of the dorsal row; in each series they extend to end of dorsal; a few flecks of pigment on crown and on ventral finfold near anus. Larval teeth: premaxillary 4; maxillary 14 , increasing in size backwards; mandible 5, on outer edge of jaw, directed straight forward. Larval gill-rakers: long spiny rakers present on first 3 arches, and low, spiny mounds present on 


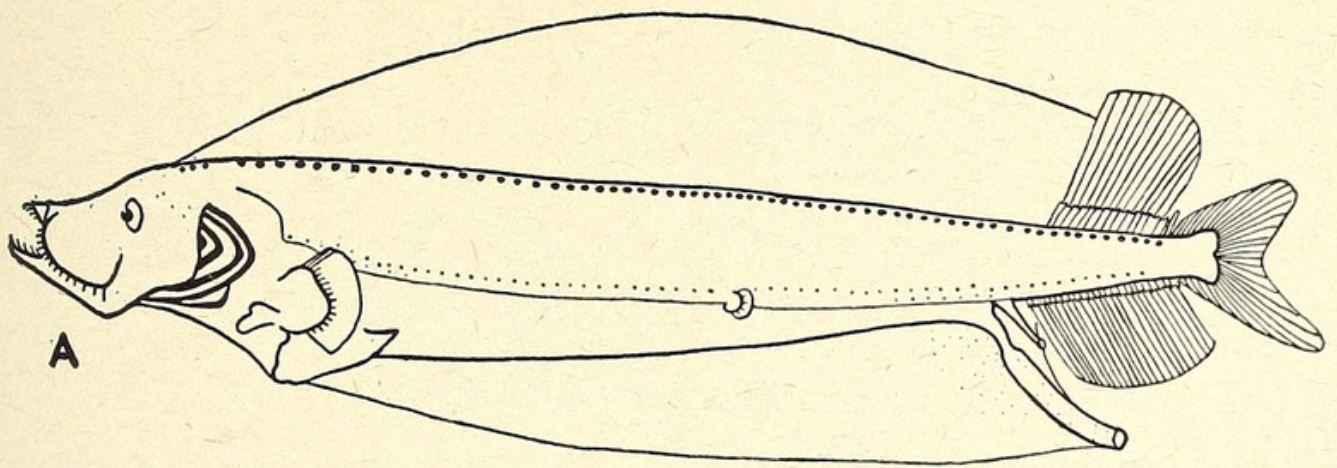

$1-----1$
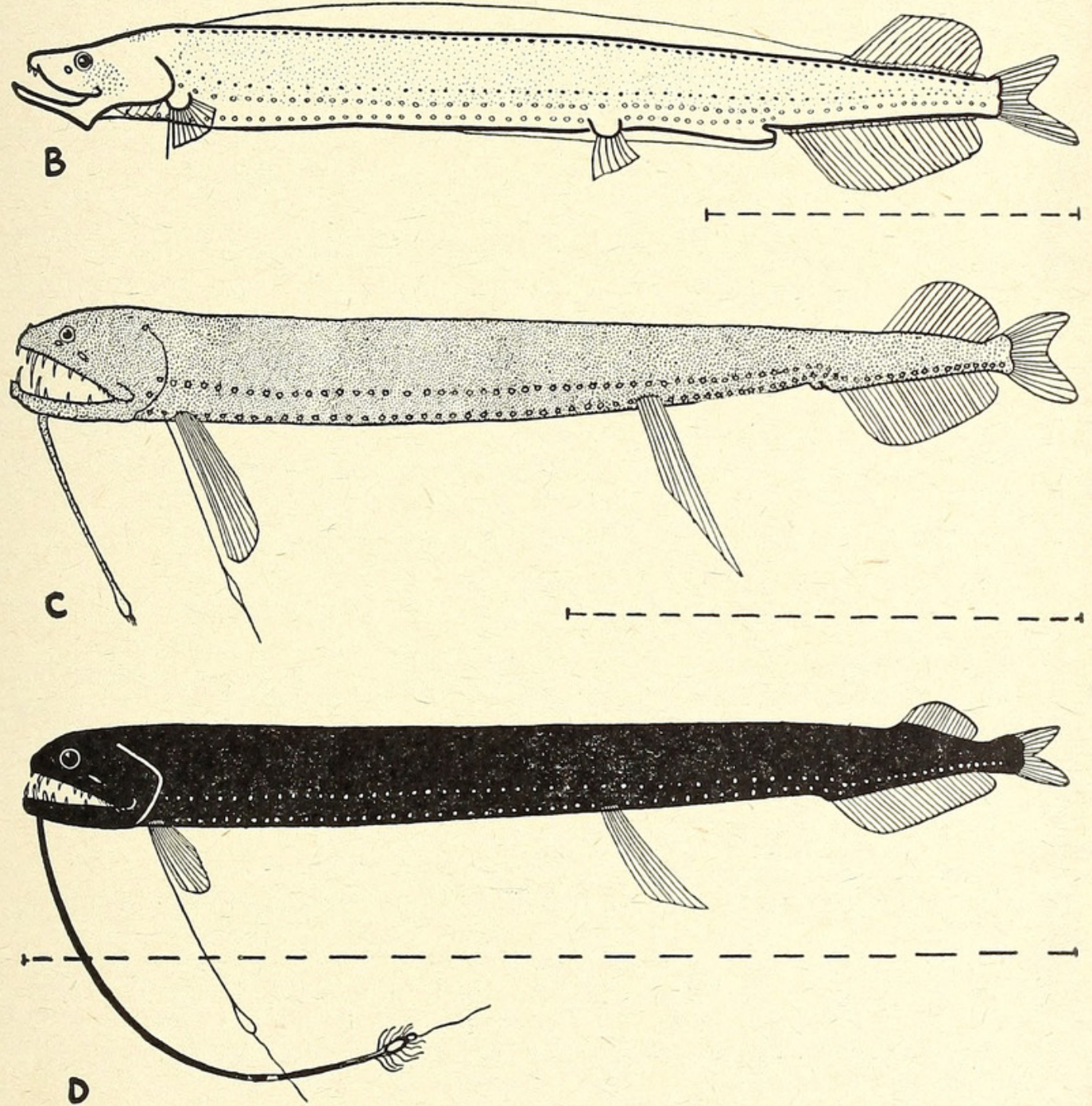

Text-figure 47.

Flagellostomias boureei. A, larva, standard length $21 \mathrm{~mm}$; B, post-larva, $34 \mathrm{~mm}$; C, adolescent, $47 \mathrm{~mm}$.; D, transitional adolescent $97 \mathrm{~mm}$. See also Text-fig. 2 I. 
last 2 arches; 10 rakers on first ceratobranchial. Fins: dorsal and anal of typical numbers, the anal originating slightly in front of dorsal, but not as much as in older fish; finfolds very large. Lengths of Bermuda specimens of succeeding stages post-larvae, 34 and $39 \mathrm{~mm}$.; adolescents, 45 and $47 \mathrm{~mm}$.; transitional adolescent, $97 \mathrm{~mm}$.

As has already been remarked (p. 75), it is likely that the larva described by Roule \& Angel as "Stomiatella D, phase no. 1," (1930, p. 17, pl. I, fig. 10) belongs to this genus.

Flagellostomias boureei (Zugmayer, 1913).

\section{SPECIMENS TAKen by the Bermuda OCEANOGRaphic Expeditions.}

7 specimens; May to September, 1929 to 1931 ; 500 to 1,000 fathoms; from a cylinder of water 8 miles in diameter ( 5 to 13 miles south of Nonsuch Island, Bermuda), the center of which is at $32^{\circ} 12^{\prime} \mathrm{N}$. Lat., $64^{\circ} 36^{\prime} \mathrm{W}$. Long.; standard lengths from 20 to $97 \mathrm{~mm}$.

\section{SPECIMENS PREVIOUSLY ReCoRded.}

17 or 18 specimens; ca. 182 to 1,067 fathoms; North and South Atlantic, Caribbean; standard lengths from (18?) 39 to $322 \mathrm{~mm}$.

\section{DESCRIPTION OF ADULT.}

With the characteristics of the genus.
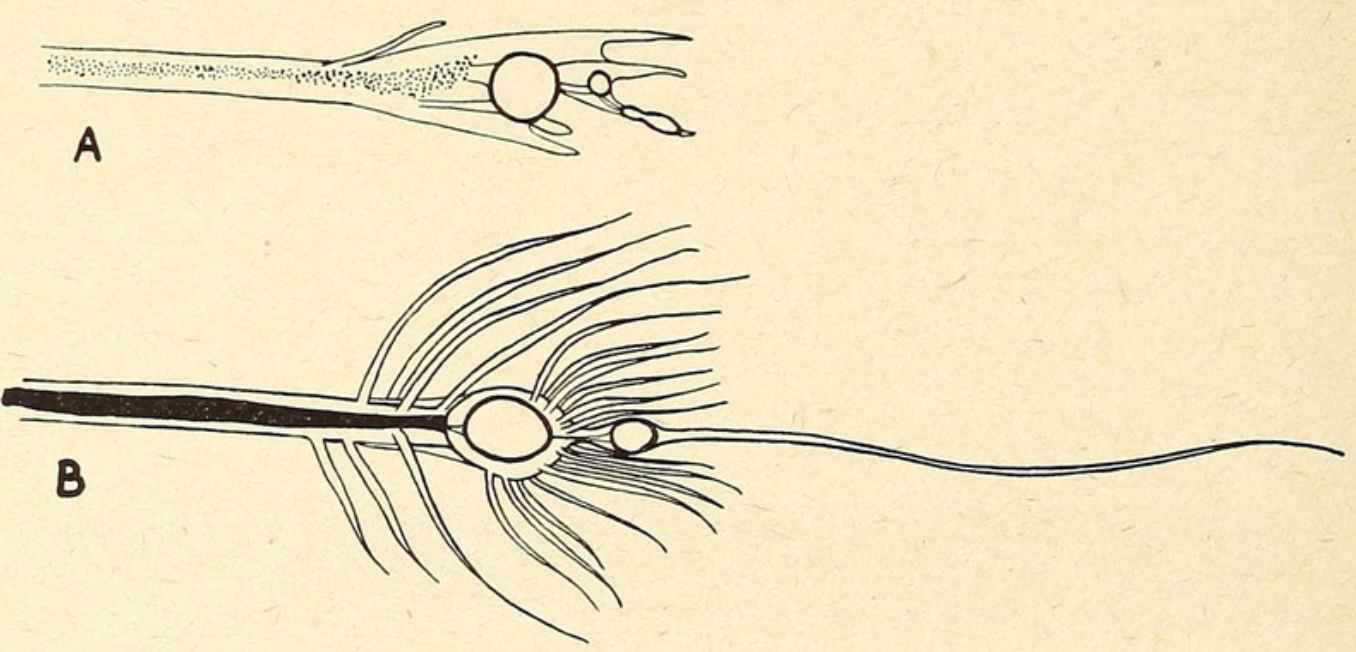

C

Text-figure 48.

Flagellostomias boureei. A, end of barbel in adolescent, standard length $47 \mathrm{~mm}$.; B, end of barbel in transitional adolescent, $97 \mathrm{~mm}$; C, end of isolated pectoral ray in same.

\section{DEVELOPMENT.}

Material: The Bermuda collection of Flagellostomias is divided as follows :

2 larvae; 20, $21 \mathrm{~mm}$; 500, 1,000 fath.; June, Sept.

2 post-larvae; $34,39 \mathrm{~mm}$; 800,900 fath.; June, Sept. 
2 adolescents; 45, $47 \mathrm{~mm}$; 700, 1,000 fath.; July.

1 transitional adolescent; $97 \mathrm{~mm}$.; 900 fath.; May. A male.

All are typical representatives of their respective growth stages (see pp. 76-79). The specific characters of the larvae have already been given on p. 182 .

\section{STUDY MATERIAL.}

The following list gives the catalogue number, depth in fathoms, date, length and growth stage of each specimen of Flagellostomias boureei taken by the Bermuda Oceanographic Expeditions. All were caught in the cylinder of water off the Bermuda coast described in Zoologica, Vol. XVI, No. 1, p. 5 and Vol. XX, No. 1, p. 1.

No. 10,249; Net 138; 900 F.; May 30, 1929; 97 mm.; Trans. Adolescent.

No. 10,889; Net $214 ; 800 \mathrm{~F}$; June 6,$1929 ; 39 \mathrm{~mm}$.; Post-larva.

No. 11,181 ; Net $244 ; 700 \mathrm{~F}$.; July 1,$1929 ; 45 \mathrm{~mm}$.; Adolescent.

No. 11,415; Net 277; 1,000 F.; July 9, 1929; $47 \mathrm{~mm}$.; Adolescent.

No. 12,888; Net 407; 900 F.; Sept. 2, 1929; $34 \mathrm{~mm}$.; Post-larva.

No. 16,462; Net $750 ; 1,000$ F.; June 30,$1930 ; 21$ mm.; Larva.

No. 16,642 ; Net 766 ; 500 F.; July 3,$1930 ; 20$ mm.; Larva.

\section{SYNONYMY AND REFERENCES.}

\section{Eustomias boureei:}

Zugmayer, 1913 , p. 3. (1 specimen; $90 \mathrm{~mm}$.; 3,000 to $0 \mathrm{~m}$.; off western Azores. Type specimen).

Flagellostomias tyrannus:

Parr, 1927, p. 50; figs. 29 and 30. (2 specimens; 192 and $195 \mathrm{~mm} . ; 7,000$ ft. wire; Bahamas).

\section{Flagellostomias boureei:}

Regan \& Trewavas, 1930, p. 57; pl. II, fig. 3; text-figs. 8D, 9B, 11A, 12A, 33 , 34. (10 specimens; 39 to $322 \mathrm{~mm}$.; 200 to 5,000 m. wire; North Atlantic, Gibraltar to West Indies).

Norman, 1930 , p. 310 . (4 specimens 60 to $85 \mathrm{~mm}$.; 800 (-0) m.; east coast of Africa from Angola to Cape Town). type).

Roule \& Angel, 1933, p. 11; pl. I, fig. 5. (Amplified description of the

Beebe, 1937, p. 199. (Preliminary list of Bermuda specimens).

\section{?Stomiatella $D$ (part.)}

Roule \& Angel, 1930, p. 17-18 ("Phase no. 1") ; pl. I, fig. 10. (1 larva; $18 \mathrm{~mm}$; 0-2,000 m.; south-west of Azores).

Genus Grammatostomias Goode \& Bean, 1895.

(See also pp. 70, 72, 73, 75, 81, 83, 85, 87-91, 96, 97, 102, 105, 108, 110). (Text-figs. 2, 11, 12, 49-54 incl.).

\section{GENERAL DiscusSion.}

An examination of the type and unique specimen of Grammatostomias dentatus at the U. S. National Museum (U. S. N. M. No. 37,370) has shown that it is exactly the same species as Lamprotoxus angulifer Beebe, 1932, which forms a part of the present Bermuda collection. The luminous body line with the downward curving hook anteriorly, characteristic of $L$. angulifer, is clearly apparent in the Grammatostomias type specimen (although faded out of all semblance to the luminous organ which it really is), in exactly the same position as in our Bermuda example; it was, indeed, noted 


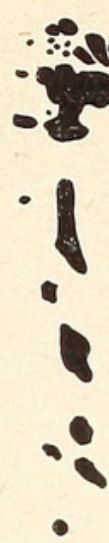

A
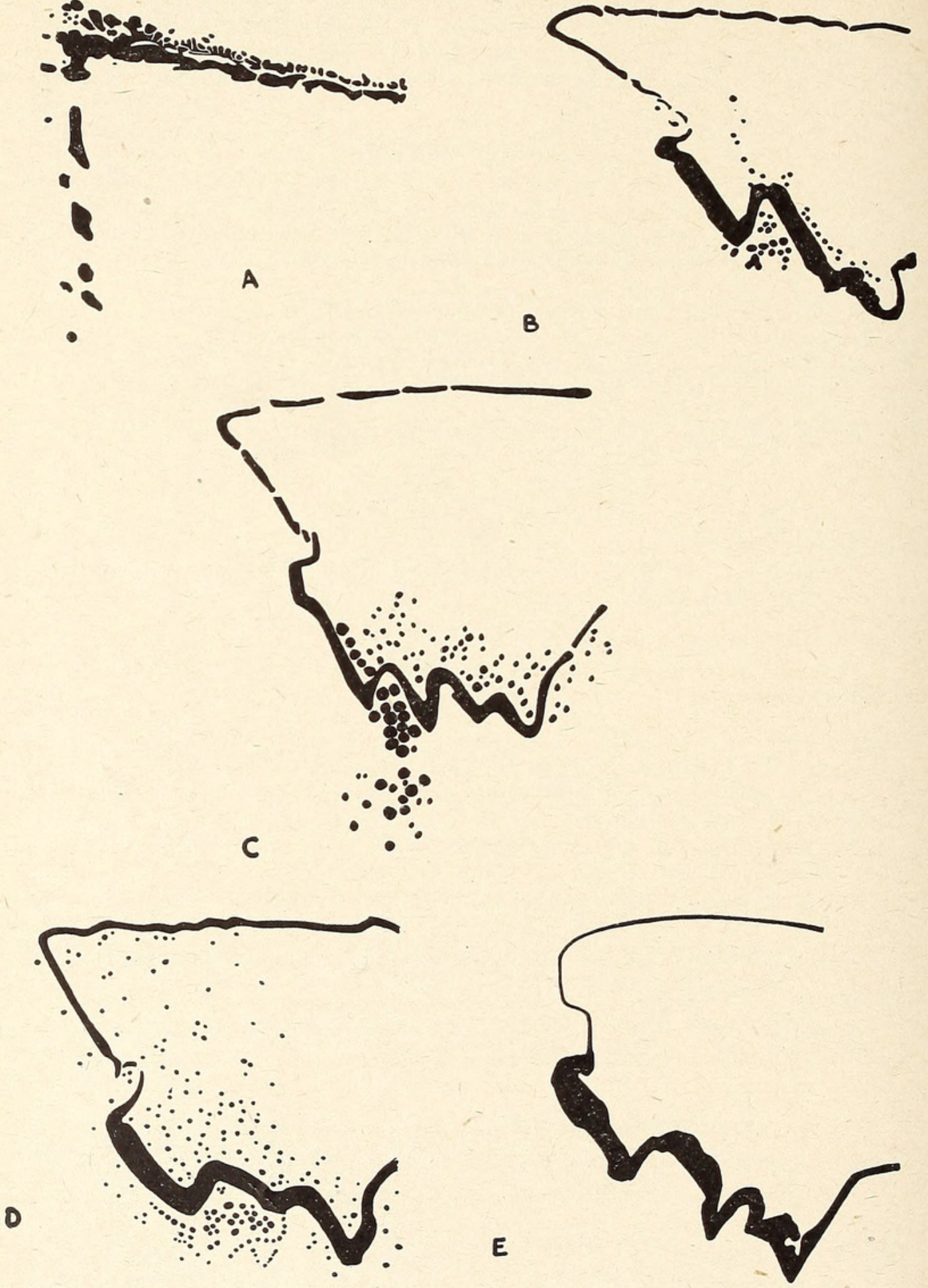

Text-figure 49.

Anterior part of lateral luminous pattern in Grammatostomias. A, G. dentatus, transitional adolescent, standard length $139 \mathrm{~mm}$.; B, G. flagellibarba, adult male, $206 \mathrm{~mm}$.; C, same, transitional adolescent female, $106 \mathrm{~mm}$.: D, transitional adolescent, $62 \mathrm{~mm}$; E, transitional post-larva, $29 \mathrm{~mm}$. (loop incomplete, as shown). C, from specimen in Bingham Oceanographic Collection, Peabody Museum; all others from present collection. 
by Goode \& Bean in their type description (1895, p. 110) as "a series of pigment cells along the median line of the body, so arranged as to simulate a lateral line." In reality, however, this streak falls well below the usual position of a true lateral line. It is now, of course, apparent that all species since referred to Lamprotoxus should be placed in Grammatostomias, the older genus, since the absence of luminous tissue on the side was the only character definitely separating the two genera. The type species, G. dentatus (synonym: L. angulifer), is the most primitive species known in regard to the form of the lateral luminous organ.

The remaining three species which have been described are G. flagellibarba Holt \& Byrne, 1910; G. phanobrochus (Regan \& Trewavas, 1930); and G. paucifilis (Regan \& Trewavas, 1930). All have a closed luminous loop on the side. G. paucifilis is described as being distinctly set off by the small number of rays in the pectoral fin (4 to 6 instead of 10 or 11), and by having 4 instead of only 3 downward angles in the anterior end of the luminous loop. Both of these characters turn out to be valueless: First, the specimen of L. flagellibarba recorded by Parr (1927, p. 93) has proved, upon examination at the Peabody Museum, to have 4 loops on the left side and $3 \frac{1}{2}$ on the right. Second, an examination of the larger $(49 \mathrm{~mm}$.) of the two specimens in the type series shows that the full numbers of rays found in flagellibarba are present, instead of only 4 to 6 ; since the 4 last rays arise in a cluster, their bases in a single sheath of skin, as usual in flagellibarba, a superficial appearance of a single split ray is given in this young specimen, but the arrangement of all, under a high power lens, is seen to be exactly as in flagellibarba. Therefore, paucifilis is a synonym of the latter species.

G. phanobrochus is described as differing from G. flagellibarba significantly only in minor details of the anterior part of the loop (the zig-zag portion being thicker and with a short hook or projection at its anterior end), and in having only one pectoral ray embedded in luminous tissue. The very minor differences in proportion as well as the feeble development of luminous tissue on the pectoral must be laid to the small size of the four known specimens of $G$. phanobrochus (27 to $43 \mathrm{~mm}$.), one of which we have examined. The Bermuda series of G. flagellibarba shows luminous loops both typical of G. flagellibarba and intermediate between G. flagellibarba and $G$. phanobrochus. This latter intermediate specimen has the 3 slender angles of G. flagellibarba, but in addition there is a distinct, anterior hook, exactly as in G. phanobrochus. We think, therefore, that there is no doubt as to the synonymy of the two species. lows:

The valid species of Grammatostomias may therefore be keyed as fol-

A. Linear luminous matter on side a straight line from opercle to beyond anal origin with a simple, anterior, downward hook; pectoral 5 G. dentatus (p. 190).

AA. Linear luminous matter on side a closed loop; pectoral 9 to 11

G. flagellibarba (p. 192).

Distribution: Grammatostomias is known only from 17 specimens, including the present series, all taken in the north Atlantic from the West Indies to the coast of Ireland. The depth range is from about 25 to 2,069 fathoms.

\section{GeNeric Characters.}

Color (from freshly caught specimens of G. dentatus and G. flagellibarba) : General color brownish-black; barbel pigmented only basally; postorbital silvery white or yellow; luminous line or loop white or blue-violet; serial photophores violet with gilt caps; non-serial photophores pinkish.

Proportions: Moderately elongate melanostomiatids; depth in length 7 

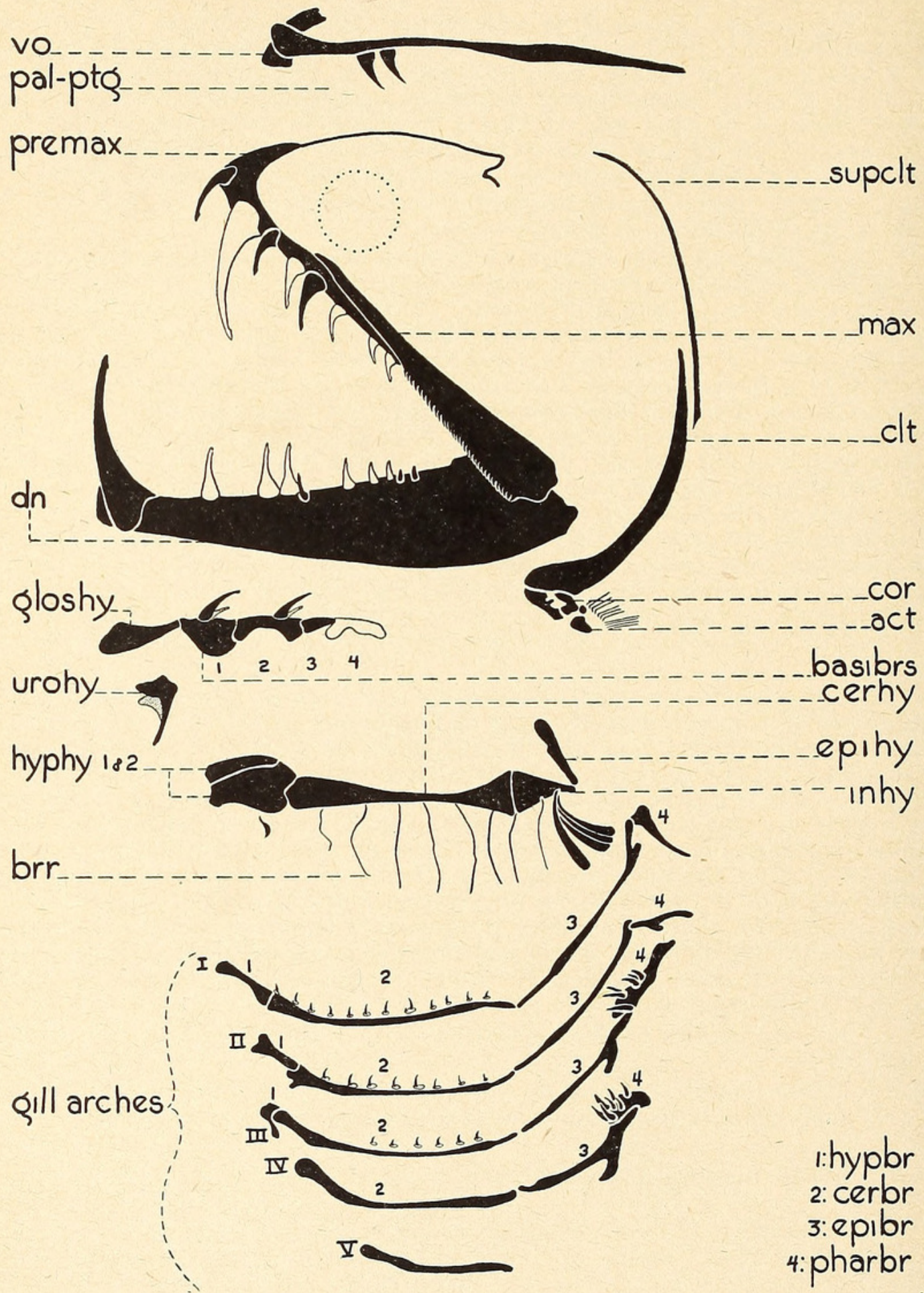

Text-figure 50.

Grammatostomias flagellibarba. Jaws, hyoid and branchial arches, and pectoral girdle of adult, standard length $206 \mathrm{~mm}$. Explanation as in Text-fig. 18.

to $9(11.1 \%$ to $14.2 \%)$; head in length 5 to $6.3(15.9 \%$ to $20 \%)$; eye in head 6 to $8(2.24 \%$ to $3.15 \%$ of length); snout equal to or a little longer than eye, slightly protractile; snout to pelvic in length 2.3 to 2.4 (42\% to $43 \%$ ). 


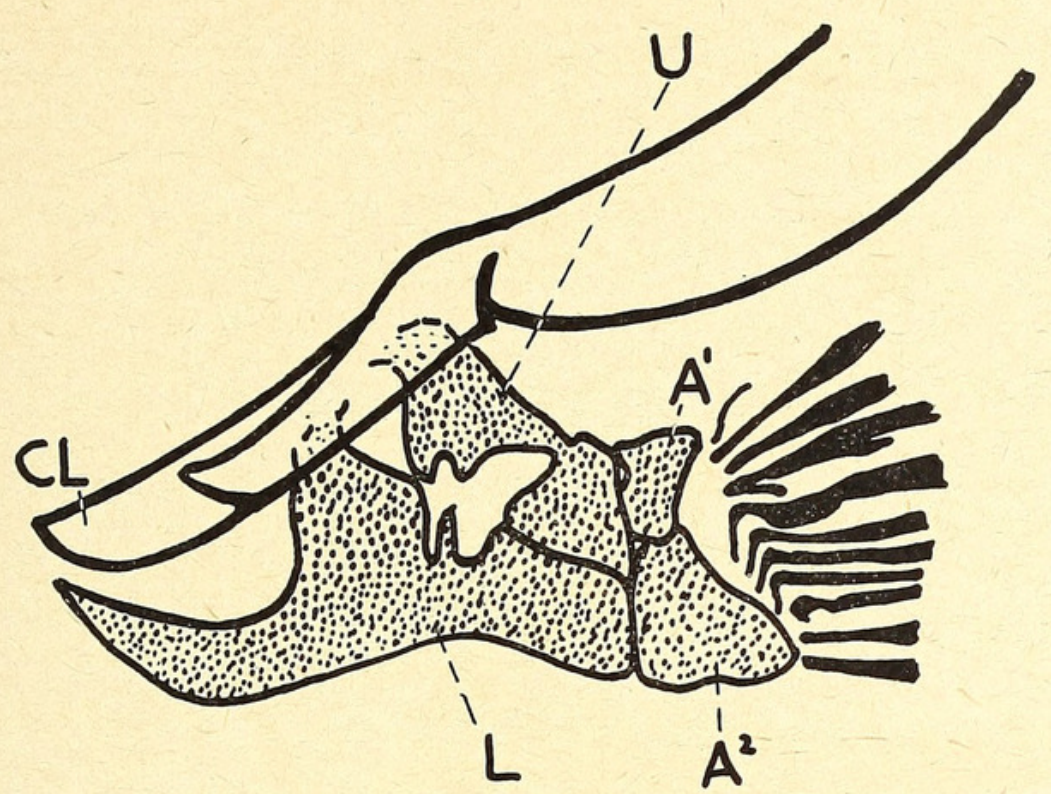

Text-figure 51.

Grammatostomias flagellibarba. Supporting bones of pectoral fin in adult, standard length $206 \mathrm{~mm}$. Abbreviations as in Text-fig. 14. Note laminated rays, which doubtless help support luminous tissue, and rudimentary first ray.

Barbel: Simple, very slender, up to 7 times length of fish.

Light Organs: Postorbital much smaller than eye in female, larger than eye in male. Serial photophores with the following counts: I-P 6 to 7, P-V 16 to $17, \mathrm{~V}-\mathrm{A} 19$ to 22 , of which 2 are above the anal fin, A-C 10 to 12 ; lateral series, O-V 15 to $18, \mathrm{~V}$-A 20 to 22 . Non-serial photophores moderately well developed. A line or loop of luminous tissue on each side of body extending from opercle to pelvic origin or beyond; luminous tissue also present in streaks and spots on cheeks, opercles and sides. One or more pectoral rays embedded in luminous tissue.

Teeth: Cleft of mouth straight. Premaxillary and mandible with acute teeth of very unequal size, both fixed and depressible, most of them slightly barbed; first maxillary tooth moderate, fixed; second tooth very long, depressible; first mandibular tooth the longest in both jaws, fixed, resting in a groove of the pre-maxillary when mouth is closed; remaining teeth in both jaws relatively small, the majority depressible, numbering from about 6 to 14 behind the above mentioned anterior fangs in each jaw; maxillary teeth all small, oblique denticles numbering between 28 and 35. Vomer toothless; 2 to 4 teeth on each palatine. Two to 3 pairs of teeth on basibranchials. Small, slender teeth, all single except 1 pair on first ceratobranchial, present on first 3 gill-arches, on the ceratobranchials only; 9 to 12 individual teeth set in the first ceratobranchial.

Branchiostegal Rays: 11.

Fins: Pectoral with 4 to 11 short rays, one or more of them being imbedded in luminous tissue; pelvics 7 , inserted a little in advance of middle of length; dorsal 18 to 21 ; anal 20 to 24 , dorsal and anal beginning at same vertical, but anal extending farther back.

Osteology: Mesethmoid with lateral processes; parietals absent; posttemporal absent; supra-cleithrum and cleithrum moderately strong; upper and lower coracoids large; mesocoracoid rudimentary; actinosts 8; vertebrae about 50 ; first centrum represented only by a fibrous ring enclosing notochord, and by a spinal nerve. 
Coelomic Organs: Stomach $31 \%$ to $32.5 \%$ of length, ending about midway between pelvic and anal origins; intestine with 2 pyloric caeca.

Sexual Dimorphism: Postorbital light organ large in male, almost atrophied in female.

Size: The largest known specimen is a male Grammatostomias flagellibarba, not very near breeding condition and measuring $206 \mathrm{~mm}$. in length; it was taken by the Bermuda Oceanographic Expeditions. A female 106 $\mathrm{mm}$. long recorded by Parr (1927, p. 93) has the ovaries very slightly developed and is apparently in late transitional adolescence. A female $G$. dentatus in the present collection measuring $139 \mathrm{~mm}$. appears also to be slightly immature.

Development: Larva unknown. Very late post-larve and adolescents with traces of subdermal dorsal blotches, and of pigment spots in middle of sides. The anterior portion of the luminous line or loop is apparent in late post-larvae.

Grammatostomias dentatus Goode \& Bean, 1895.

(See also p. 185).

\section{SPECIMENS TAKEN By THE BeRMuda OCEANOGRAPHiC EXPEDitions.}

4 specimens; July to September, 1929 to 1931; 400 to 700 fathoms; from a cylinder of water 8 miles in diameter ( 5 to 13 miles south of Nonsuch Island, Bermuda), the center of which is $32^{\circ} 12^{\prime} \mathrm{N}$. Lat., $64^{\circ} 36^{\prime} \mathrm{W}$. Long.; standard lengths from 34 to $139 \mathrm{~mm}$.

\section{Specimen Previously Recorded.} $145 \mathrm{~mm}$.

1 specimen; 2,069 fathoms; southeast of New York; standard length

\section{Description of LaRgest KNOWN SPECIMENS.}

(From the $145 \mathrm{~mm}$. type and the largest Bermuda specimen, $139 \mathrm{~mm}$. long, formerly described as Lamprotoxus angulifer Beebe, 1932).

Color (from fresh specimen): Skin blackish-brown with the body segments marked off by lines of black pigment; postorbital light organ silvery; branchiostegal photophores pale violet; serial photophores deeper purple with very large, concave gold caps; non-serial small photophores pale pinkish; all lines and spots of luminous tissue white.

Proportions: Depth in length 8 to 8.6 (11.6\% to $12.5 \%$ ) ; head in length $5.8(17.2 \%)$; eye in head 6.1 to $8(2.24 \%$ to $3.1 \%$ of length); snout longer than eye; snout to pelvic in length $2.3(43 \%)$.

Barbel: Broken in both specimens. In a $61 \mathrm{~mm}$. Bermuda transitional adolescent it is complete, and reaches to the middle of the anal fin, ending in two short equal filaments.

Light Organs: Postorbital much smaller than eye, the Bermuda specimen having been sexed and found to be a female; O-V photophores, the only series differing from the other species in the genus, numbering 15 to 16 instead of 16 to 18 . Hundreds of minute accessory photophores covering the fish from head to tail, resembling the serial photophores in everything but size and regularity of position. Middle 3 of the 5 pectoral rays imbedded in white, opaque, luminous tissue.

Luminous tissue along the sides of the body in the shape of a longhandled, angled crook, the anterior part of which is formed by a solid line. The crook extends straight downward close to the posterior edge of the gill opening, breaking up into several elongate spots toward the end. The handle extends down the body below the midline and ends above the middle 
of the anal fin. It consists of two divisions, a ventral, solid line for much of the distance, and a dorsal line, very close to it, of small, separate spots. The line becomes single at the level of the tenth lateral photophore beyond the ventral fin. Besides this, there is an almost solid line of luminous tissue from the tip of the snout back along the premaxillary to the level of the middle of the eye, and a third, very thin and wavering but solid line arising back of the eye and curving back and down toward the anterior end of the maxillary denticles.

Teeth: Anterior fixed and depressible fangs characteristic of the genus. Premaxillary about 11, fixed and depressible teeth irregularly alternating; mandible with about 17 teeth, the majority depressible, after the anterior fang. It is difficult to label the most posterior, small teeth in both jaws as either fixed or depressible, although the fangs, as usual, are clearly referable to one group or the other.

Fins: Pectorals short with first, second and fifth rays equal and longest, thread-like and brown; second, third and fourth imbedded in luminous tissue. Dorsal 20 to 21 ; anal 23 to 24 (not 19, as in type description of L. angulifer), both covered thickly with dark body pigment.
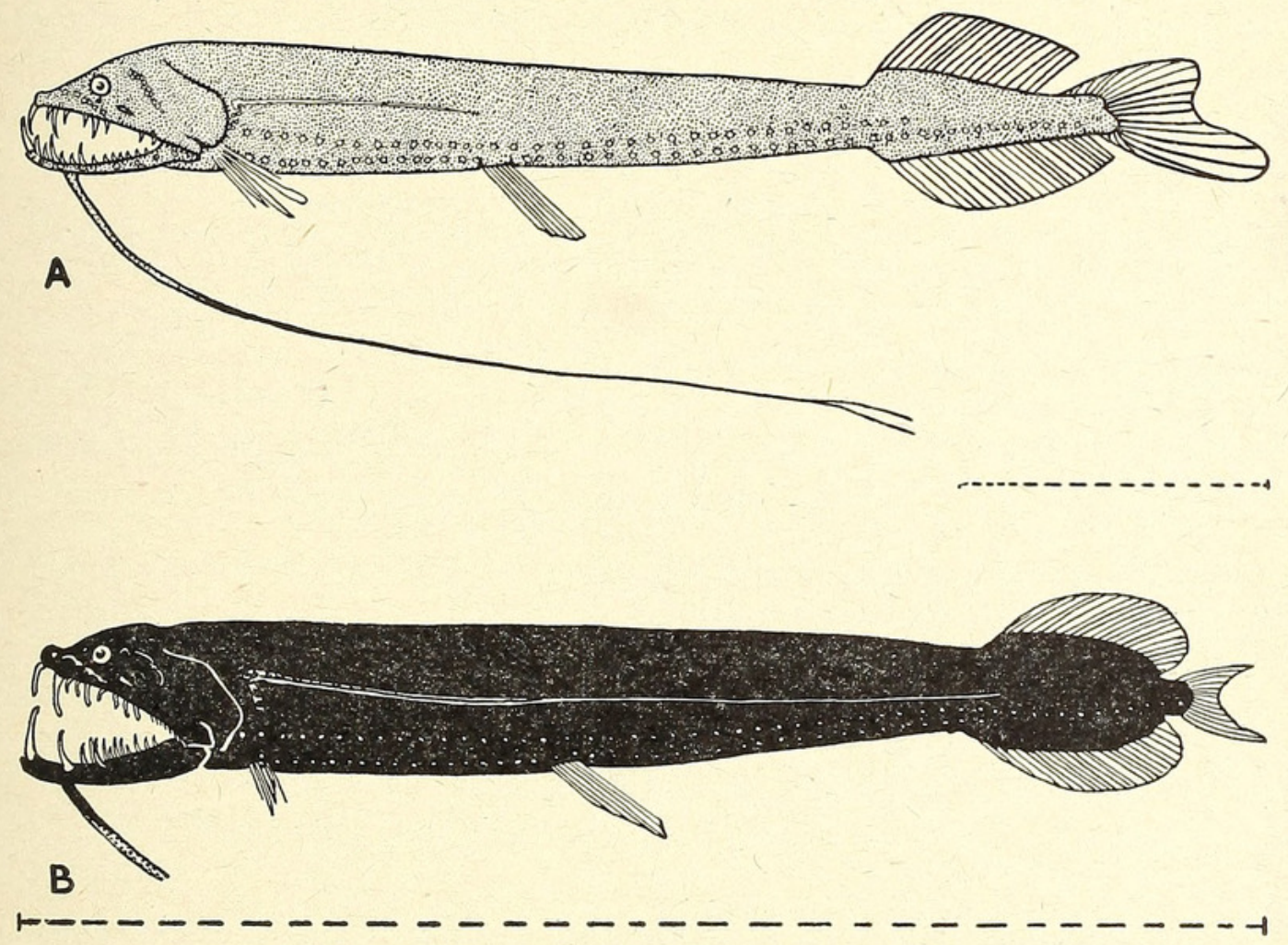

Text-figure 52 .

Grammatostomias dentatus. A, adolescent, standard length $34 \mathrm{~mm}$.; B, transitional adolescent, standard length $139 \mathrm{~mm}$.

\section{DEVELOPMENT.}

Besides the $145 \mathrm{~mm}$. female included in the foregoing description, the Bermuda collection includes 2 adolescents of $34 \mathrm{~mm}$. and a transitional adolescent of $61 \mathrm{~mm}$. All show their immaturity in the fashion typical of their respective growth stages (see p. 77). The luminous tissue on the pectoral fins in a $34 \mathrm{~mm}$. specimen is asymmetrically arranged on the right and left sides of the fish: on the left side there is a relatively small amount surrounding the second ray and partially attaching the first, while the third 
and fourth rays are both imbedded in the same, very large mass; on the right side the first ray is free and lacks tissue, the second and third are imbedded in a single mass, and the fourth ray is imbedded by itself. The luminous line is as in large specimens, except that it is not traceable so far back. Traces of dorsal and median subdermal pigment spots are discernible in the small specimens, but are too obscure to furnish any possible identification mark for larvae, which so far have not been caught. However, it is apparent that this genus in its early stages possesses pigment in the general regions characteristic of the family-i.e., along the back and, in a second series, on the sides.

\section{ECOLOGY.}

Food: The stomachs of the three smallest specimens all contained remains of small fish; in addition, one of the $34 \mathrm{~mm}$. specimens held a number of ostracods.

\section{STUDY MATERIAL.}

The following list gives the catalogue number, depth in fathoms, date, length and growth stage of each specimen of Grammatostomias dentatus taken by the Bermuda Oceanographic Expeditions. All were caught in the cylinder of water off the Bermuda coast described in Zoologica, Vol. XVI, No. 1, p. 5 and Vol. XX, No. 1, p. 1.

No. 13,219 ; Net $439 ; 700$ F.; Sept. 7,$1929 ; 61 \mathrm{~mm}$.; Trans. Adolescent.

No. 13,313 ; Net 444 ; 500 F.; Sept. 9 , $1929 ; 34$ mm.; Adolescent.

No. 21,667; Net 1108; 500 F.; July 27, 1931; 139 mm.; Trans. Adolescent. Female. No. 22,483; Net 1187; 400 F.; Aug. 17, 1931; 34 mm.; Adolescent.

\section{SYNONYMY AND REFERENCES.}

Grammatostomias dentatus:

Goode \& Bean, 1895, p. 110; pl. XXXV, fig. 133; (1 specimen; 2,069 fath., east of New Jersey, $145 \mathrm{~mm}$.; examined by present authors).

Parr, 1927, p. 92 ; figs. 10, 52. (Redescription of type).

Regan \& Trewavas, 1930 , p. 63. (Record of type; recapitulation of description).

\section{Lamprotoxus angulifer:}

Beebe, 1932.2 , p. 56 ; fig. 9. (Description of the $139 \mathrm{~mm}$. specimen described in the preceding pages from the Bermuda collection).

Beebe, 1933.1, p. 180. (Preliminary list of Bermuda specimens).

Beebe, 1937, p. 199. (Preliminary list of Bermuda specimens).

\section{Grammatostomias flagellibarba Holt \& Byrne, 1910.}

(See also p. 187).

\section{SPecimens Taken by the Bermuda OCEANOgRaphic EXPeditions.}

3 specimens; July to September, 1929 and $1930 ; 500$ to 700 fathoms; from a cylinder of water 8 miles in diameter ( 5 to 13 miles south of Nonsuch Island, Bermuda), the center of which is at $32^{\circ} 12^{\prime} \mathrm{N}$. Lat., $64^{\circ} 36^{\prime} \mathrm{W}$. Long.; standard lengths from 29 to $206 \mathrm{~mm}$.

\section{Specimens Previously Recorded.}

9 specimens; ca. 40 to 1100 fathoms; north Atlantic; standard length from 26 to $168 \mathrm{~mm}$. 

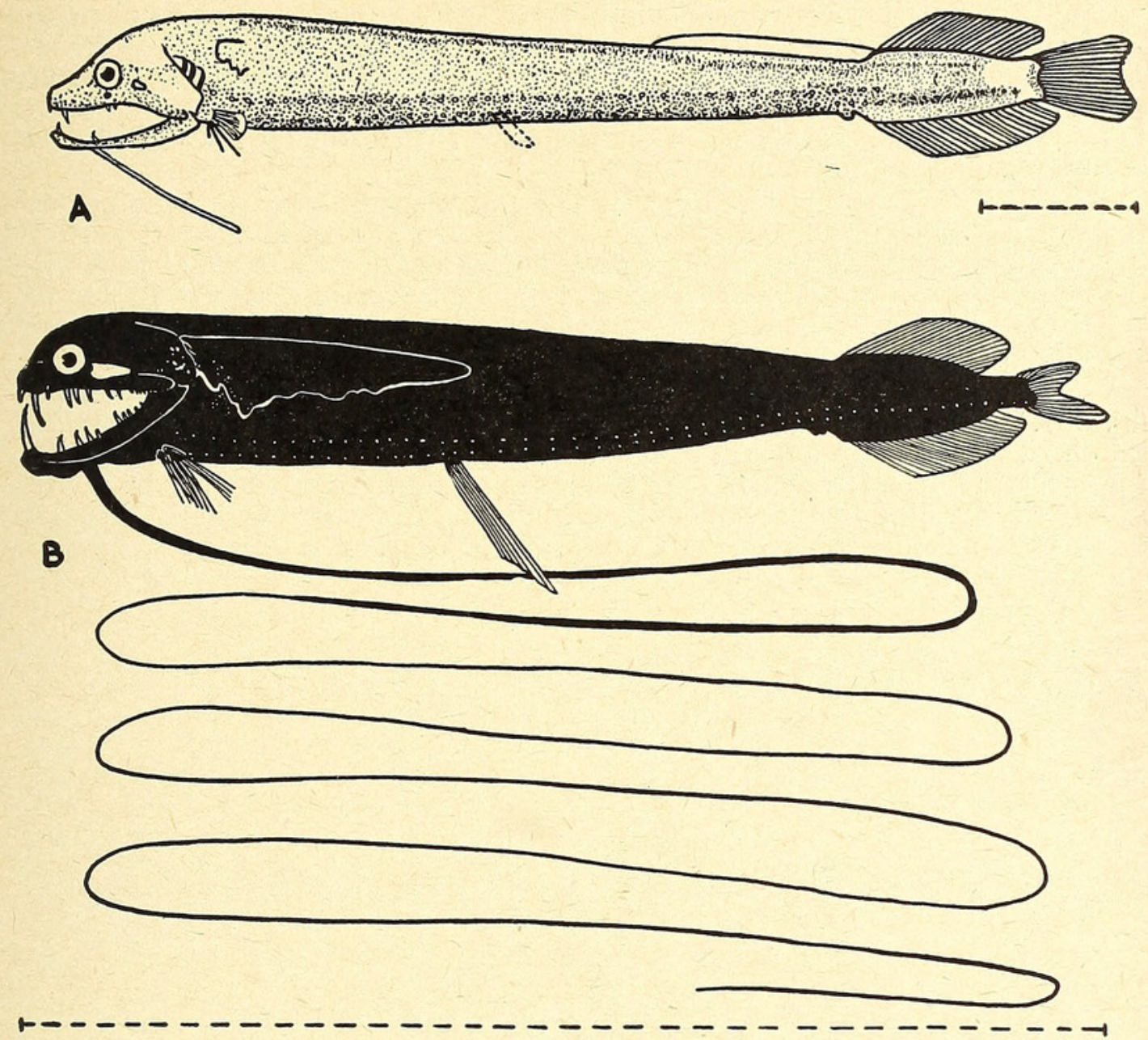

Text-figure 53.

Grammatostomias flagellibarba. A, transitional post-larva, standard length $29 \mathrm{~mm}$.; B, adult, standard length $206 \mathrm{~mm}$. See also Text-fig. $2 \mathrm{~J}$.

\section{DESCRIPTION OF ADULT.}

With the characteristics of the genus.

Color (from the Bermuda adult male and a $62 \mathrm{~mm}$. transitional adolescent, both freshly caught): General color, rich brownish-black; barbel white, sprinkled with brown pigment basally, which dies out gradually, disappearing before the middle of the length; postorbital light organ bright yellow in male; serial photophores violet; luminous matter on pectoral fin yellow; luminous loop on side of body rich blue-violet.

Proportions: Depth in length 7 to 7.6 (13.1\% to $14.3 \%)$; head in length 5.7 to 6.3 ( $15.8 \%$ to $17.5 \%$ ) ; eye in head 5.5 to 7.5 (ca. $3.15 \%$ of length); snout longer than eye; snout to pelvic in length $2.4(42 \%)$.

Barbel: When complete, at least 7 times as long as fish, as in the Bermuda specimen; it is translucent white, sprinkled with brown pigment basally; distally it has a silvery, corded appearance.

Light Organs: Postorbital very large in adult male, almost twice length of eye and contained 4 times in length of head; almost atrophied, apparently non-functional, in adult female. Serial photophore counts typical of the genus. Accessory photophores numerous and conspicuous.

Luminous tissue along sides of body in the shape of a completely closed 
loop with 3 or 4 downward angles anteriorly which form a conspicuous zigzag pattern; luminous tissue scattered in dots in the region of the zigzag. The posterior margin of the loop is found at or slightly behind the level of the pelvic base. Pectoral rays more or less imbedded in luminous tissue. Luminous tissue also spattered on the posterior part of the opercles and below the zigzag part of the luminous loop.

Teeth: Anterior fixed and depressible fangs characteristic of the genus. In the adult (206 mm.). Bermuda male, there are 7 teeth in the left half of the premaxillary, 8 in the right; about alternately depressible and fixed; in the mandible, after the first enormous fixed fang, comes a series of 9 or 10 teeth, most depressible, one-third (anteriorly) to one-tenth (posteriorly) the size of the fang.

Fins: The 9 to 11 pectoral rays are arranged almost in a circle (Textfig. 54). In the Bermuda specimen, on the left side, the first ray is simple, the third with a large amount of luminous tissue, ending in a short filament, the most in the fin; second, fourth, fifth and sixth rays similar, but with progressively diminishing amounts of luminous matter; seventh through tenth rays arising transversely from a single base. The rays of the right
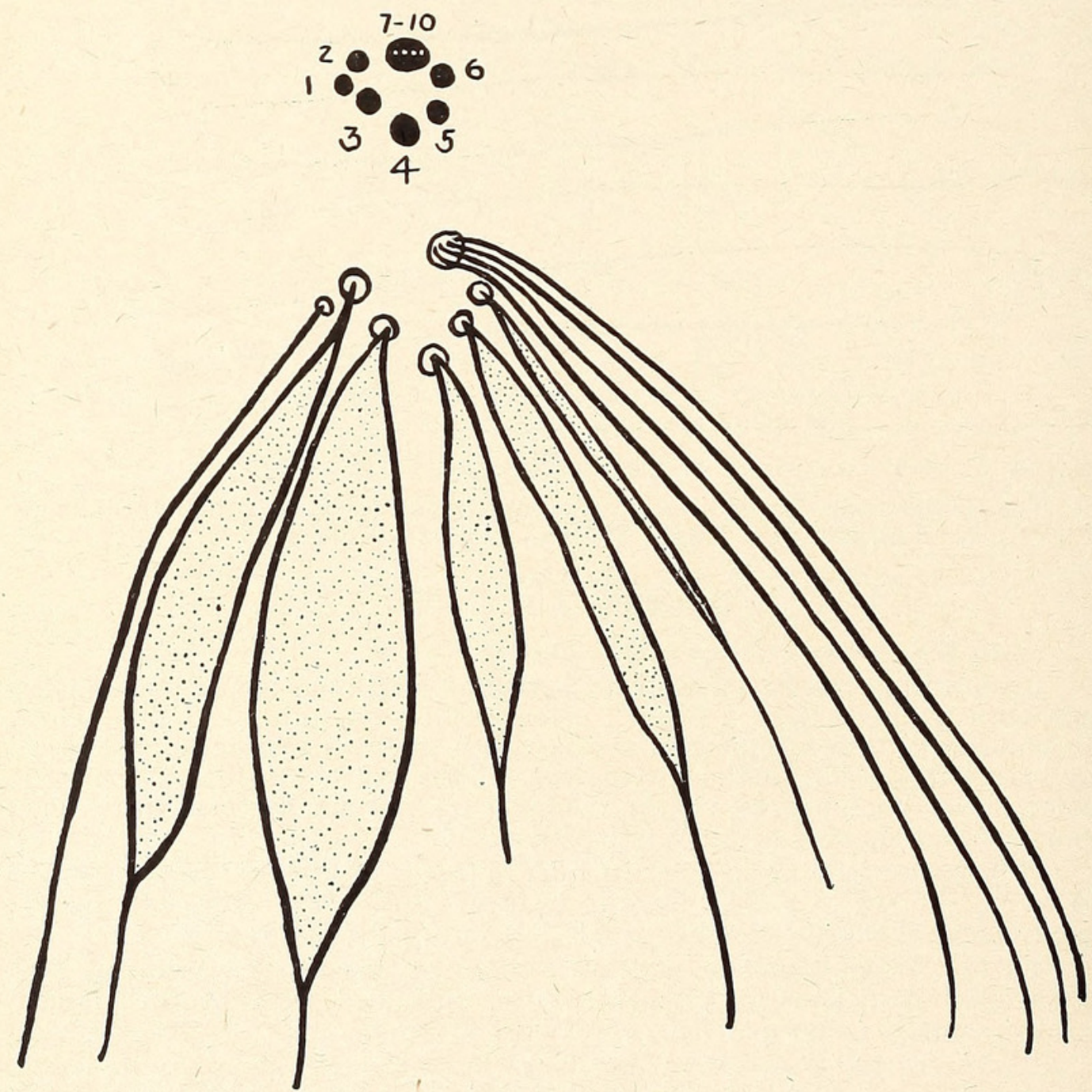

Text-figure 54 .

Grammatostomias fagellibarba. Arrangement of pectoral rays of left side of adult, standard length $206 \mathrm{~mm}$. Luminous tissue shown by stippled areas. 
side are identically arranged, but the seventh through the tenth rays have traces of luminous matter also.

The pelvics extend more than two-fifths of the distance between their insertion and the anal origin. The membranes of the dorsal and anal fins are thick and blackish, the body skin extending well up beyond their actual bases.

\section{DEVELOPMENT.}

The Bermuda collection consists of a transitional post-larva $29 \mathrm{~mm}$. long, a transitional adolescent $62 \mathrm{~mm}$. long, and an adult male $206 \mathrm{~mm}$. long, the largest specimen ever taken. The young specimens are typical of their respective growth stages (see p. 77 ), the transitional post-larva combining the post-larval characters of finfold remains and partially developed fins, with the adolescent traits of growing teeth, barbel and specialized luminous organs, including a partially developed lateral loop and traces of luminous matter on the anterior pectoral rays; the postorbital organ is very small, less than the diameter of the lens of the eye. In the $62 \mathrm{~mm}$. transitional adolescent the postorbital organ about equals the diameter of the entire eye; sex cannot yet be determined at this stage.

\section{STUDY MATERIAL.}

The following list gives the catalogue number, depth in fathoms, date, length and growth stage of each specimen of Grammatostomias flagellibarba taken by the Bermuda Oceanographic Expeditions. All were caught in the cylinder of water off the Bermuda coast described in Zoologica, Vol. XVI, No. 1, p. 5 and Vol. XX, No. 1, p. 1.

No. 11,558; Net 297; 500 F.; July 13, 1929; 62 mm.; Trans. Adolescent.

No. 13,876; Net 512; 700 F.; Sept. 25, 1929; 29 mm.; Trans. Post-larva.

No. 17,491; Net 816; 600 F.; Aug. 29, 1930; 206 mm.; Adult Male.

\section{SYNONYMY AND REFERENCES.}

\section{Grammatostomias flagellibarba:}

Holt \& Byrne, 1910, p. 294. (1 specimen; $168 \mathrm{~mm}$.; ca. 700 fathoms; off southwest Ireland).

Lamprotoxus flagellibarba:

Holt \& Byrne, 1912 (1913), I, p. 8, pl. I. (Further discussion of type specimen).

Boulenger, 1913, p. 1, pl. I. (Histology of luminous organs of type specimen).

Parr, 1927, p. 93. (1 specimen; $106 \mathrm{~mm}$. 7,000 feet wire; 100 miles south of Nassau). Examined by present authors; a female.

Regan \& Trewavas, 1930, p. 63, fig. 13 A, 43, 44 A. (Description from examination of type specimen).

Roule \& Angel, 1933, p. 14, pl. I, fig. 7. (1 specimen; $136 \mathrm{~mm}$.; 0 to 4,500 m.; Bay of Biscay).

Beebe, 1937, p. 199. (Preliminary list of Bermuda specimens).

Lamprotoxus paucifilis :

Regan \& Trewavas, 1930, p. 64, fig. 44B. (2 specimens; $26,49 \mathrm{~mm}$.; 200 to $300 \mathrm{~m}$. wire; North Atlantic). Larger specimen examined by present authors.

\section{Lamprotoxus phanobrochus:}

Regan \& Trewavas, 1930, p. 64, fig. 44C. (4 specimens, 27 to $43 \mathrm{~mm}$.; 150 to $4,000 \mathrm{~m}$. wire; West of St. Lucia, North of Barbuda, $c a .800$ to 1,000 miles southeast of Bermuda). 1 specimen examined by present authors. 
Genus Bathophilus Giglioli, 1884.

(See also pp. 70, 73-75, 81, 83-85, 87, 90, 91, 95-97, 103, 105, 108, 110).

(Text-figs. 2, 8, 9, 11, 12, 55-63 incl.).

\section{GENERAL Discussion.}

Seventeen species referable to Bathophilus have been described, including the following three which have appeared since the publication of the monograph by Regan \& Trewavas in 1930 (p. 65): B. irregularis Norman, 1930 ; B. alberti (Roule \& Angel, 1931; amplified in 1933) and B. altipinnis Beebe, 1933. $B$. alberti is almost certainly a synonym of $B$. metallicus. $B$. irregularis and $B$. altipinnis will fit into the key given by Regan \& Trewavas, as follows:

B. altipinnis, in section B of group I:

B. Pelvic fins about equidistant from dorsal and ventral profile (Bathophilus).

P. 34 to 47 ; Pv. 18 to 26 ; O-V photophores $13 \ldots \ldots \ldots \ldots \ldots$ nigerrimus.

P. 24 to 25 ; Pv. 15 ; O-V photophores $13 \ldots \ldots \ldots \ldots \ldots \ldots \ldots \ldots \ldots \ldots$ altipinnis.

P. 16 to 19 ; Pv. 16 ; O-V photophores $10 \ldots \ldots \ldots \ldots \ldots \ldots \ldots \ldots$ proximus.

B. irregularis in section A of group II :

A. Pectoral rays in two well-separated groups (Trichostomias).

P. 3 to $6+7$ to 11 ; Pv. 7 to 10 ; no photophores above pelvic base

P. $3+7$; Pv. 21; photophores above pelvic base

longipes.

P. $3+4$ to 5 ; Pv. 16 to 20 ; no photophores above pelvic base

schizochirus.

- etc. -

We have considered placing the highly aberrant $B$. brevis in a separate genus, because of its exceedingly great depth, forwardly placed pelvic, and atrophied serial photophores. We have retained it, however, because it is so obviously in the main line of development of Bathophilus, because traces of serial photophores were visible in fresh specimens, and because no adult or even large transitional adolescent has ever been taken, so that its mature characteristics are somewhat problematical.

We have examined the type specimen of $B$. simplex Parr, in the Peabody Museum, New Haven, and agree with Regan \& Trewavas that it is synonymous with $B$. metallicus, of which we have also examined the type, in the U. S. National Museum. B. simplex was separated from B. metallicus chiefly because of its lack of lustre; however, it seems likely that preservative may bring out lustre, because at the present time the head and nape of $B$. simplex have considerable gloss. As Regan \& Trewavas noted, it is a very variable character. The type of $B$. pawneei Parr, also examined, has a metallic lustre over the entire body.

The following names are synonymous with Bathophilus: Dactylostomias Garman, 1899; Trichostomias Zugmayer, 1911, and Gnathostomias, Pappenheim, 1911. Stomiatella A. Roule \& Angel (1930, p. 14, pl. 1, fig. 6) is probably Bathophilus brevis (see p. 75).

Five of the 17 species of Bathophilus have been taken by the Bermuda expeditions, namely, B. brevis, B. altipinnis, B. metallicus, B. longipinnis and B. chironema.

Distribution: Bathophilus is one of the seven genera of Melanostomiatidae which have been taken outside the Atlantic Ocean, since B. filifer (Garman) is known only from the eastern Pacific; the remaining species are all known only from the North and South Atlantic. The depth range appears to 

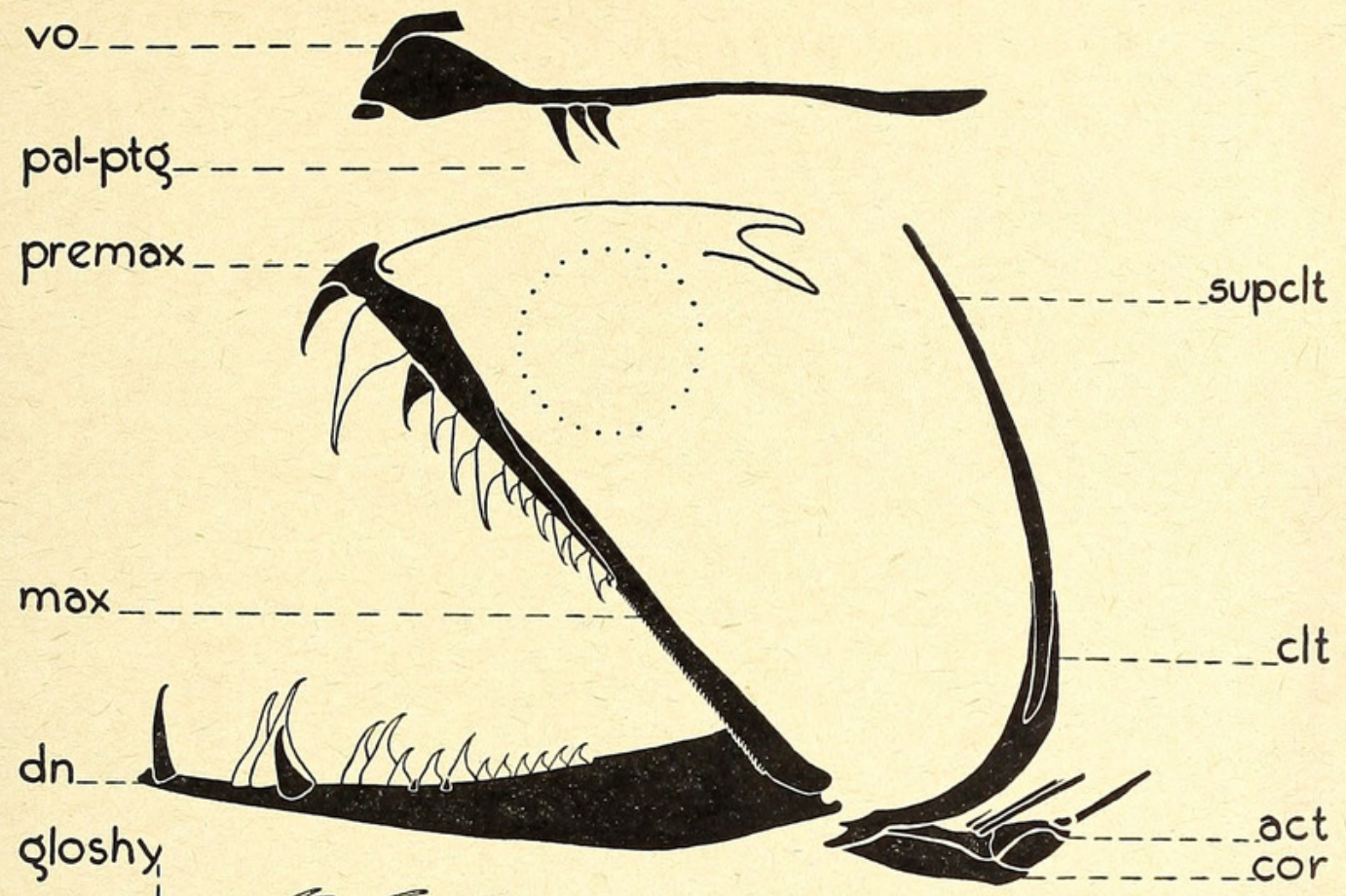

o̧loshy

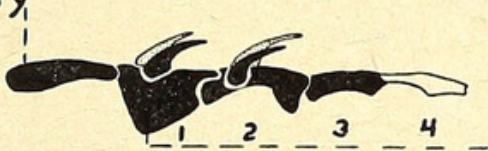

act

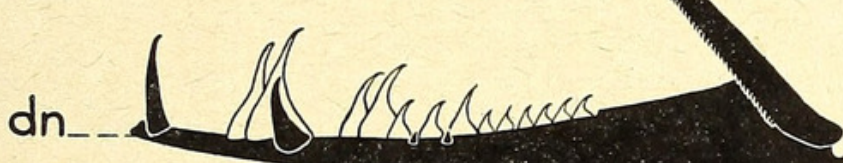
basibrs
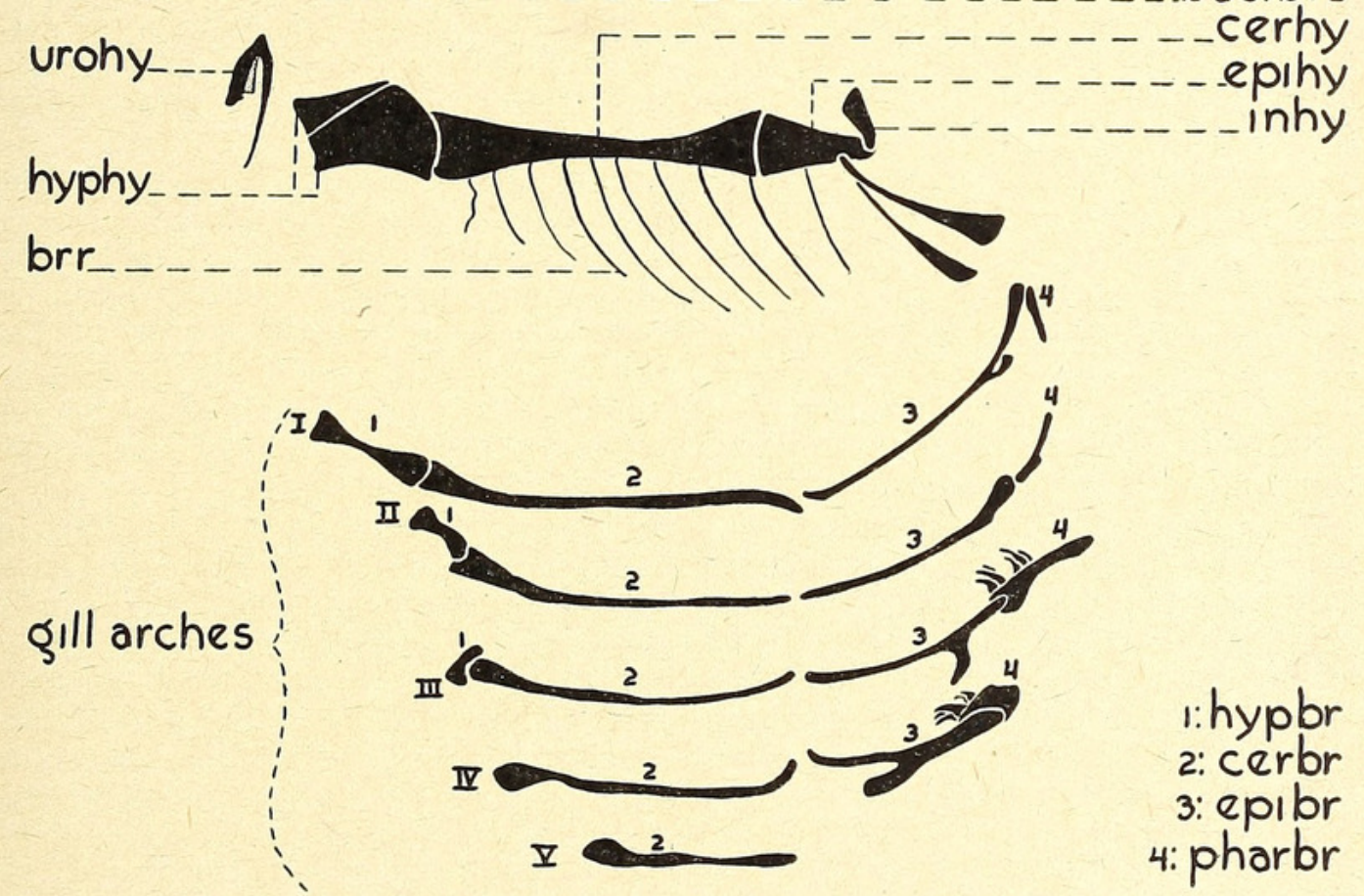

Text-figure 55 .

Bathophilus metallicus. Jaws, hyoid and branchial arches, and pectoral girdle of transitional adolescent, standard length $105 \mathrm{~mm}$. Explanation as in Textfig. 18.

be between the surface and about 1,900 fathoms. A total of about 500 specimens has been reported, of which almost 200 are referred to $B$. metallicus. 


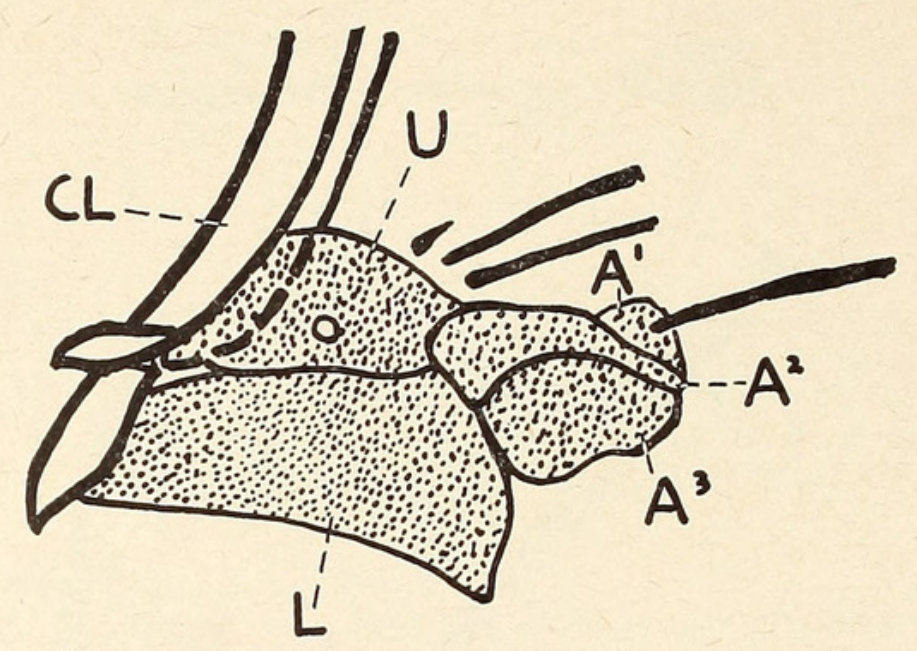

Text-figure 56 .

Bathophilus metallicus. Supporting bones of pectoral fin in transitional adolescent, standard length $105 \mathrm{~mm}$. Abbreviations as in Text-fig. 14. Note rudimentary first ray.

\section{GENERIC CHARACTERS.}

With the characteristics of the family.

Color (from field observations on 15 immature individuals belonging to four species): General color brownish-black; often with a metallic iridescence; barbel translucent white, sometimes with a few speckles of pigment, especially basally; postorbital green, yellow or reddish; serial photophores golden yellow; luminous patches on head or body white.

Proportions $^{9}$ : Elongate to very deep melanostomiatids; depth in length $21 / 4$ to 12 ( $81 / 3 \%$ to $441 / 2 \%$ ); head in length $22 / 5$ to $62 / 3$ ( $15 \%$ to $42 \%$ ); eye small, deeply sunken, usually badly preserved; snout considerably longer than eye; snout to pelvic exceedingly variable, since the latter fin is inserted in varying positions from the opercle to behind the middle of the length.

Barbel: Always (when complete) much longer than head, often longer than body, slender, simple, unpigmented; bulb absent, the end of the barbel tapering to a point or terminating in two short filaments.

Light Organs: Postorbital of varying size, smaller in female than in male, but functional in both sexes; often separated more or less completely into two parts by a vertical black partition; serial photophores usually indistinct, always small, sometimes absent; the rows tend to be highly irregular. Small non-serial organs highly developed. Luminous patches usually present on head or body, their position varying with the species.

Teeth: Cleft of mouth straight, each premaxillary with an anterior fixed tooth followed by a series of unequal, depressible fangs, of which the first is longest, fitting down over the mandible; maxillary without erect teeth, but with a series of up to 35 or more oblique denticles; each half of mandible with a moderately strong anterior and a tiny lateral fixed tooth, and an inner series of depressible teeth; teeth all simple, pointed, without barbs; vomer toothless; 1 or 2 teeth (rarely more) on each palatine; 2 pairs on basibranchials; gill-arches entirely toothless.

Branchiostegal Rays : ca. 8 to 12.

Fins: Pectoral and pelvic rays highly variable, sometimes even within the same species, pectoral 1 to 47 , long, filamentous; pelvic 4 to 26 , usually

\footnotetext{
9 Including those of some immature specimens upon which species have been founded.
} 
inserted immediately above the lateral series of photophores, and toward the middle of the length; sometimes, however, they are placed far above the line of photophores and forward on the body, almost on the shoulder; like the pectorals they are long and filamentous; both fins lack webbing entirely. Dorsal and anal subequal, of 9 to 18 rays.

Superficial Grooves: The groove for the reception of the barbel is highly developed in this genus, continuing from the isthmus to the anus, and continuing to one side of the anal fin, in the case of long-barbeled species such as B. metallicus.

Osteology: Mesethmoid with lateral processes; parietals absent; posttemporal absent; supra-cleithrum and cleithrum moderately well developed; upper and lower coracoids large and laminar; mesocoracoid absent; 2 actinosts; 38 to 45 vertebrae; first centrum represented only by a fibrous ring enclosing notochord, and by a spinal nerve.

Coelomic Organs: Stomach (in slightly immature specimens; no mature examples available) $25 \%$ to $29 \%$ of standard length, reaching beyond pelvic origin; two pyloric caeca.

Sexual Dimorphism: Postorbital light organ of female smaller than that of male, but functional. The supramaxillary luminous patch is found in both sexes.

Size: The largest known Bathophilus is a specimen of B. metallicus, 140 $\mathrm{mm}$. in length, taken by the Dana Expeditions. Judging by the specimens in the present collection, most or all of the known examples in the genus are immature.

Development: The larvae of the genus are known from examples of about 5 species and are all easily recognizable by the low total number of myomeres to the end of the anal, ( $c a .38$ to 46), and the small number of prepelvic myomeres (less than 22); external pigment is present only on the back, one large or several small dots occurring on each myomere immediately below the dorsal mid-line. A row of spots along the kidney is also the rule. Short larval gill-rakers are present at least on the first 2 or 3 arches; they are represented by mounds or are absent on the remaining arches; the exception is the $7 \mathrm{~mm}$. larva in Text-fig. 57, which has no trace of rakers, probably because of its youth. For the characteristics of this specimen and of the older larva in Text-fig. 58, see table, p. 81. For characteristics of the growth stages, see p. 76 .

\section{Bathophilus brevis Regan \& Trewavas, 1930.}

\section{SPECIMENS TAKEN BY THE BERMUdA OCEANOGRAPHIC EXPEDITIONS.}

4 specimens; May and July, 1929 and 1930; 300 to 900 fathoms; from a cylinder of water 8 miles in diameter ( 5 to 13 miles south of Nonsuch Island, Bermuda), the center of which is at $32^{\circ} 12^{\prime} \mathrm{N}$. Lat., $64^{\circ} 36^{\prime} \mathrm{W}$. Long.; standard lengths from 13 to $26 \mathrm{~mm}$.

\section{SPECIMENS PREVIOUSLY RECORDED.}

6 specimens; approximately between 25 and 175 fathoms; North Atlantic; standard lengths from 15 to $48 \mathrm{~mm}$.

\section{DESCRIPTION OF TRANSITIONAL ADOLESCENT.}

(No adults known).

Color (from a single fresh Bermuda specimen frosted with metallic bronze): General color brownish-black; barbel translucent white with a thin thread of red (doubtless blood) down the center; postorbital pale green; non-serial photophores light violet. 


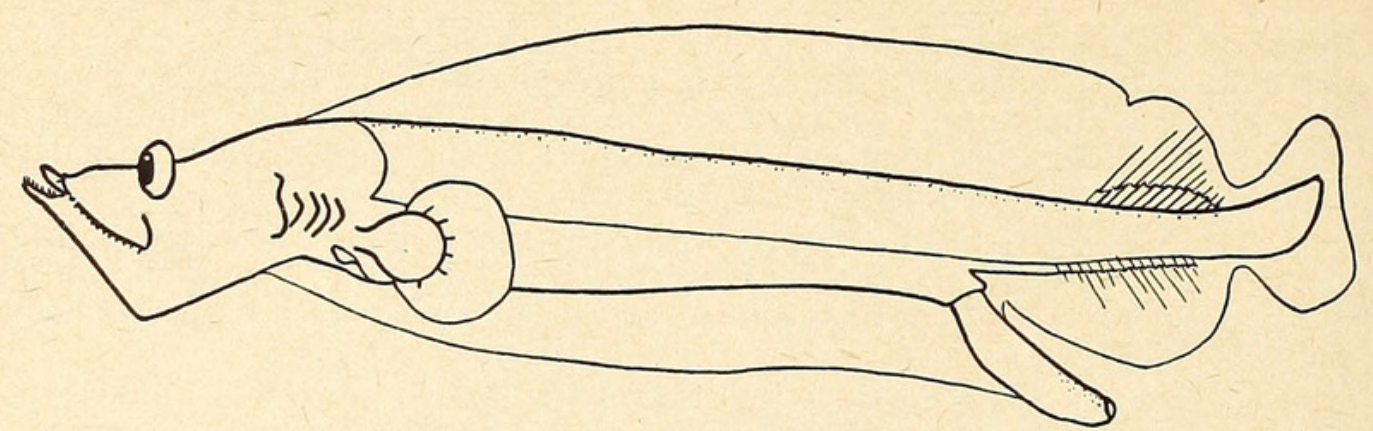

Text-figure 57.

Bathophilus sp. Larva, standard length $7 \mathrm{~mm}$. See also Text-fig. $2 \mathrm{~K}$.

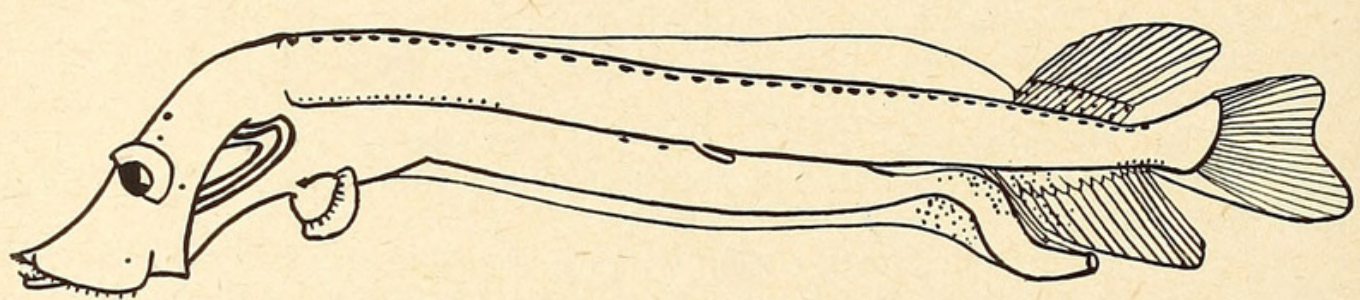

Text-figure 58.

Bathophilus sp., near longipinnis. Larva, standard length $11 \mathrm{~mm}$. See also Text-fig. 2 L.

Proportions: Depth in length 2.25 to 2.75 (36.5\% to $44.5 \%)$; head in length 2.4 to 3 (33.3\% to $41.5 \%$ ).

Barbel: 1.5 times length of fish, with a tapering end.

Light Organs: Postorbital well separated from eye, probably much larger than eye in males; a small luminous patch in front of or below it; another luminous patch on middle of side, between origin of dorsal and anal fins. Serial photophores traceable (but not countable) in fresh specimens only, appearing on lower part of sides in two irregular rows, differentiated from the numerous small non-serial organs by their slightly larger size and brighter violet coloring. All trace of this demarcation, however, is lacking in the same example after preservation; small, non-serial photophores highly developed, distributed all over head and body, (see p. 202).

Teeth: Relatively larger than in other members of the genus of corresponding stages of development, but in position and character typical of the genus.

Fins: Pectoral $2+9$ to 11 ; inserted very low, under opercle; pelvic 11 to 14 , inserted much nearer dorsal than ventral profile and about equidistant from end of snout and origin of dorsal; dorsal 10 to 11 ; anal 9 to 10 .

\section{DEVELOPMENT.}

Material: The Bermuda collection of Bathophilus brevis consists of 1 post-larva ( $13 \mathrm{~mm}$. long), 2 adolescents (13 and $14 \mathrm{~mm}$.) and 1 transitional adolescent $(26 \mathrm{~mm}$.). All are typical of their respective growth stages (see p. 77).

There is no trace of serial photophores in the post-larva or adolescent, although the body organs are rudimentary in the former, well developed in the latter. The apparent decrease in the size of the postorbital organ noted by Regan \& Trewavas is probably explained by the fact that there was a sexual difference in the specimens examined by these authors; the same is 

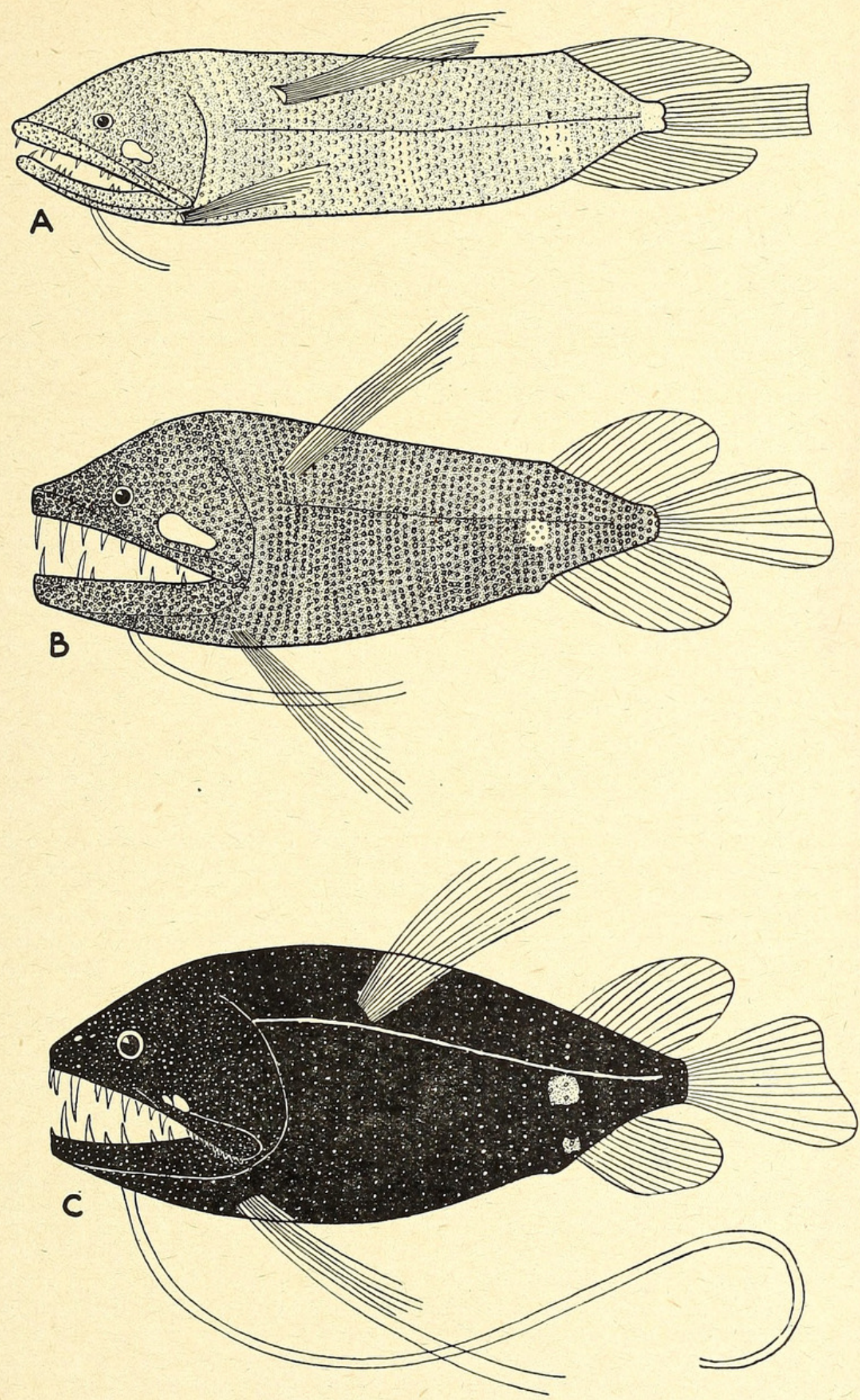

Text-figure 59.

Bathophilus brevis. A, post-larva, standard length $13.3 \mathrm{~mm}$.; B, adolescent, $13.3 \mathrm{~mm}$.; C, transitional adolescent, $26 \mathrm{~mm}$. 
true of our own collections, but the examples are too undeveloped internally to determine the sex by genital examination. In the $26 \mathrm{~mm}$. specimen luminous mucous is abundant all over the skin. There is no trace of an antorbital organ in any of the specimens.

Non-serial Photophores of Head and Trunk: It seems worth while to describe the non-serial organs of head and trunk, as observed in the Bermuda specimens. As has been said, there are no serial photophores present in this species in the usual sense of branchiostegal, lateral and ventral series. However, the head and body are completely covered with minute organs which are scattered apparently without arrangement over the head, but with the largest of them (Group A below) arranged in more or less regular, single, vertical rows, about 1 to each myomere) on the trunk. The organs may be divided by size into three groups. They appear to be precisely similar all over the fish, both in relative numbers and relative size.

Group A: Large Photophores: These are the organs referred to above as occurring in vertical rows from gill-opening to caudal base. They are much smaller than regular serial photophores in allied species. All are directed forward, sometimes obliquely upward. In the young adolescent specimen the tips, set in conspicuous black sockets, were pale bluish. In the 25.7 $\mathrm{mm}$. specimen they were mauve. The numbers of this series found on each side of the trunk between gill-opening and caudal base of each of the three specimens is approximately as follows:

$\begin{array}{lccc} & \text { Post-larva } & \text { Adolescent } & \text { Trans. Adolescent } \\ \text { Standard length …......13.3 mm. } & 13.3 \mathrm{~mm} . & 25.7 \mathrm{~mm} . \\ \begin{array}{l}\text { No. vert. rows. ........ } \\ \text { Average no. in row }\end{array} & 53 & 56 & 63 \\ \begin{array}{l}\text { at deepest part....... } \\ \text { Average no. in row }\end{array} & & 45 & 46 \\ \text { at narrowest part. } & 6 & 9 & 9 \\ \text { Estimated total. ....... } & 850 & 1,400 & 1,500\end{array}$

It will be noted that there are approximately the same number of photophores in each of the two older specimens, and more than a third more than in the post-larva. This indicates that new organs are actually developed between the post-larval and early adolescent stages (with no increase in length), but that during the adolescent stage, when the increase in size is great, the number of organs remains constant,- that is, the same number of organs is spread over a much larger expanse of skin.

Group B: Middle-sized Photophores: Scattered at random between those described above, are at least as many similar lights, varying in size, but on the average less than half the size of the Group A organs. Centers are distinctly visible in the older specimens, but instead of all or even a majority being directed forward, they may be pointed upward, backward, or downward as well. Downward seems to be the least common direction.

Group $C$ : Minute Photophores: Finally, between these, there are innumerable, minute, slightly elevated pigment spots, at least some of which seem to be luminous organs, since a center is occasionally visible under very high power. It is a question in this fish as to whether there are any epidermal chromatophores which are not luminous organs.

Development of Head and Trunk Photophores: In the post-larval specimen the sockets of the Group A organs are developed, as has been stated above, to the number of about two-thirds of those found in the older specimens. No centers, however, are visible, and they are hence probably unfunctional. A comparatively small number of tiny pigment spots scattered among them, some of which are slightly elongate and curved, is the only indication of Groups B and C. The posterior end of the caudal peduncle is entirely destitute of pigment of any kind. 
In the early adolescent specimen the centers of all lights of Group A are well-developed, but groups B and $C$ are still almost undifferentiated from each other, with the luminous centers of Group B only rarely developed.

In the largest specimen of $26 \mathrm{~mm}$. all the lights of Groups A and B are fully developed, and, as has been stated, centers are occasionally visible in even the minute organs of Group C.

\section{STUDY MATERIAL.}

The following list gives the catalogue number, depth, date, length and growth stage of each specimen of Bathophilus brevis taken by the Bermuda Oceanographic Expeditions. All were caught in the cylinder of water off the Bermuda coast described in Zoologica, Vol. XVI, No. 1, p. 5 and Vol. XX, No. 1 , p. 1.

No. 9,897; Net $91 ; 300 \mathrm{~F}$; May 11, 1929; $14 \mathrm{~mm}$.; Adolescent.

No. 9,930; Net 99; 500 F.; May 14, 1929; 26 mm.; Trans. Adolescent.

No. 11,228; Net 252; 900 F.; July 4, 1929; $13 \mathrm{~mm}$.; Adolescent.

No. 14,993; Net 572; 300 F.; May 12, 1930; 13 mm.; Post-larva.

\section{Bathophilus brevis:}

\section{REFERENCES.}

Regan \& Trewavas, 1930 , p. 66 , Pl. III, fig. 1. (6 specimens; 15 to 48 $\mathrm{mm}$.; 150 to $1,000 \mathrm{~m}$. wire; off French Guiana, West of Bermuda, southeast of Bermuda, southwest of Cape Verde Islands and south of Azores).

Beebe, 1933.1, p. 280. (Preliminary list of Bermuda specimens).

Beebe, 1937, p. 199. (Preliminary list of Bermuda specimens).

Bathophilus altipinnis Beebe, 1933.

TYPE.

(The unique specimen).

Department of Tropical Research No. 10,885; Bermuda Oceanographic Expeditions of the New York Zoological Society; Net 214; June 24, 1929; 8 miles south of Nonsuch Island, Bermuda; 800 fathoms; standard length 63 mm.; a transitional adolescent male.

\section{DESCRIPTION.}

The resemblance of this species to $B$. nigerrimus and $B$. proximus precludes the necessity of a detailed description.

Measurements: Total length $70.4 \mathrm{~mm}$.; standard length $63 \mathrm{~mm}$.; depth $10.7 \mathrm{~mm}$. (in length 5.9 or $17 \%$ ) ; head $12.6 \mathrm{~mm}$. (in length 5 or $20 \%$ ) ; eye $2.4 \mathrm{~mm}$. (in head 5.3 or $3.8 \%$ of length; snout $3.3 \mathrm{~m}$. (in head 3.8 or $5.2 \%$ of length; pectoral length $14.3 \mathrm{~mm}$.; pelvic length $17.1 \mathrm{~mm}$.; snout to pelvic $29.5 \mathrm{~mm}$.; caudal length $7.4 \mathrm{~mm}$.; suborbital length $2.3 \mathrm{~mm}$. (in head 5.5 ) ; barbel length $21.4 \mathrm{~mm}$. (in standard length 2.9 or $34.5 \%$ ).

Barbel: In the freshly caught specimen the barbel, which is undoubtedly complete, was slender and pure white, tapering very gradually and ending in two short, slender filaments.

Light Organs: The suborbital photophore is of a flattened, oval shape, and when fully rolled up into view exposes two luminous areas, a small, inferoposterior triangle and a large anterior area, the extreme upper front of which shows in the preserved specimen a white surface, which in the fresh specimen is deep red.

Serial Photophores: lateral series, O-V 13, V-A 11; ventral series, I-P 5, P-V 13, V-A 11, A-C 10. 


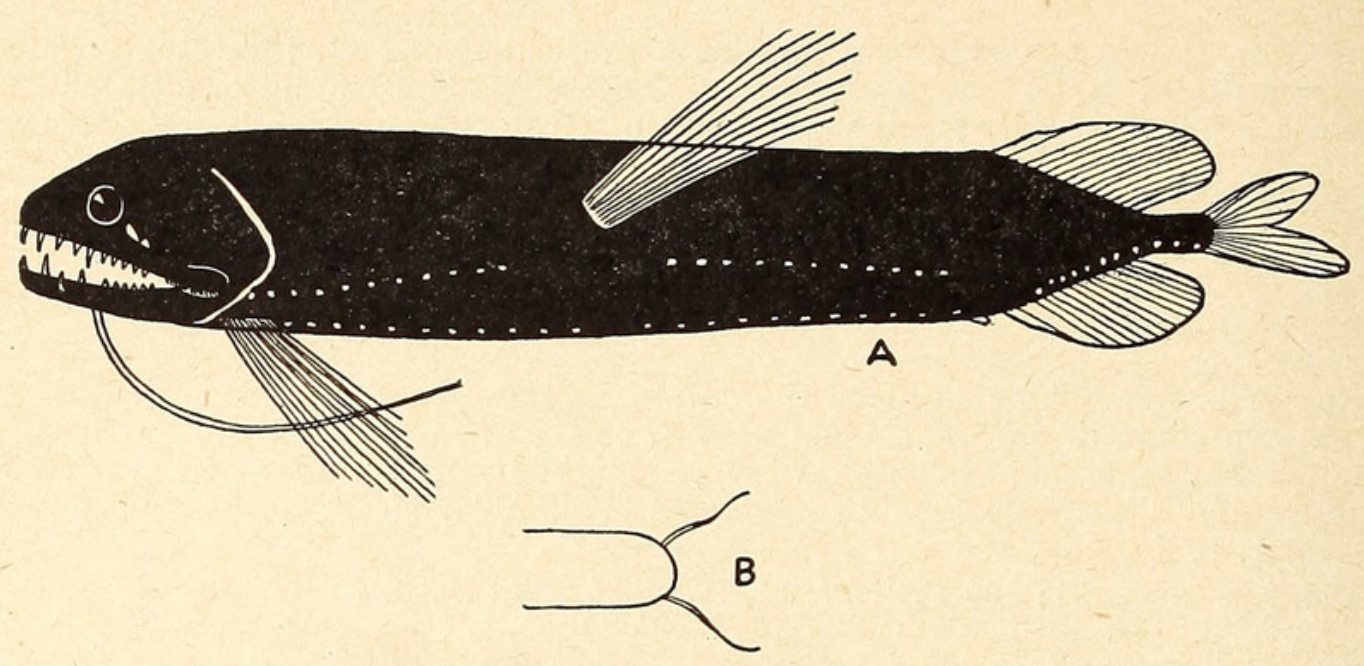

Text-figure 60.

Bathophilus altipinnis. A, transitional adolescent, standard length $63 \mathrm{~mm}$.; B, same, end of barbel.

Teeth: There are 10 premaxillary teeth on the left and 9 on the right side. On each side the second, first and fifth are successively larger, in that order. About 40 small denticles are scattered along the maxillary, the posterior 10 scarcely projecting from the bone. In the mandible, 2 fangs are followed by 8 smaller teeth, the second fang largest, then in succession the first, fourth and third. The vomer is edentulous. There are 2 curved teeth on each palatine, the anterior one the larger. The mandibular symphysis projects as a sharp keel, far ahead of the teeth.

Fins: The pectorals have 24 rays in the left and 25 in the right fin. On each side the anterior ray is slightly separated from its fellow, while another slight but bilaterally symmetrical gap occurs between the fifth and sixth rays. Pelvic rays 15 ; dorsal rays 15 ; anal rays 15 ; caudal rays 23 .

\section{Discussion.}

This species is closest to $B$. nigerrimus Giglioli and $B$. proximus Regan \& Trewavas, having in common with them a moderately deep body (depth 5 to 6 in length), pelvic fins inserted extremely high on the sides of the body, about equidistant from dorsal and ventral profiles, and a large number of rays in the pectoral fins ( 16 to 50$)$.

From $B$. nigerrimus it differs principally as follows: In the smaller number of rays in the paired fins (pectoral 24 to 25 , not 34 to 50 , pelvic 15, not 18 to 26 ) in the shorter barbel, contained nearly 3 times in the length and having 2 short terminal filaments (the most complete barbel of Balducci's ${ }^{10}$ series is contained 1.8 times in the length, that in the figure of Regan \& Trewavas ${ }^{11} 1.3$, no filaments being mentioned in either case; in Giglioli's ${ }^{12}$ type the barbel was entirely missing) ; in the complete partioning of the suborbital into anterior and posterior luminous triangles and in the absence of a "small, pearl-like protuberance below it;" in the shorter head (contained 5 times in the length, not 4 to 4.5 ). B. nigerrimus is known from about 25 specimens up to $111 \mathrm{~mm}$. in length, taken in the Caribbean Sea, the Gulf of Mexico, the Atlantic and the Mediterranean.

From $B$. proximus the new species differs in the greater number of rays in the pectoral fins ( 24 to 25 , not 16 to 19 ) ; in the greater number of photo-

10 Balducci, 1915 : 1-15, pl. 1.

11 Regan and Trewavas, 1930: 66, pl. 3 fig. 2.

12 Giglioli, 1884 : 261, fig. 
phores in the lateral series (O-V 13, not 10; V-A 11, not 10) and in the smaller number in the ventral series (V-A 11, not 13); in the shorter barbel with 2 terminal filaments (contained almost 3 times in the length, not 2.4, as shown in the figure of Regan \& Trewavas ${ }^{13}$ ); in the smaller size and peculiar partition of the suborbital (the figure just mentioned shows a simple

13 Regan \& Trewavas, loc. cit., 66, pl. 3 fig. 3.

oval, larger than the eye; in the present specimen the organ about equals the eye). B. proximus is known from a single specimen, $55 \mathrm{~mm}$. in length, from the Atlantic, west of Bermuda.

\section{REFERENCES.}

Bathophilus altipinnis: above).

Beebe, 1933.2, p. 162. (Preliminary description of specimen described

Beebe, 1937, p. 199. (Listing of the same specimen).

Bathophilus metallicus (Welsh, 1923).

SPECIMENS TAKEN BY THE BERMUdA OCEANOGRAPHIC EXPEDITIONS.

22 specimens; May to September, 1929 to 1931; 300 to 900 fathoms; from a cylinder of water 8 miles in diameter ( 5 to 13 miles south of Nonsuch Island, Bermuda ), the center of which is at $32^{\circ} 12^{\prime}$ N. Lat., $64^{\circ} 36^{\prime}$ W. Long.; standard lengths from 25 to $105 \mathrm{~mm}$.

\section{SPECIMENS PReviously ReCORded.}

163 specimens; 0 to $c a .2,700$ fathoms; North Atlantic, between $20^{\circ}$ and $43^{\circ}$ N. Lat.; standard lengths from 25 to $140 \mathrm{~mm}$.

\section{DESCRIPTION.}

(From the largest known specimens, which are probably immature).

Color (from field observations upon 5 specimens): General color black, usually with a general greenish or bluish-bronze iridescence and, in addition, with a frosted appearance along the dorsal and ventral profiles, caused by mucous. Barbel translucent white with minute, black framed, pink-centered photophores in distal portion. Postorbital light organ ranging from pale green to lemon yellow. Serial photophores golden yellow. Small, non-serial organs violet.

Proportions: Depth in length 7 to $11(9.2 \%$ to $14.3 \%)$; head in length 4 to 5.5 ( $18 \%$ to $25 \%)$.

Barbel: In the largest Bermuda specimen the barbel is slightly longer than the body; the tip is obviously broken; there is a row of tiny photophores in the distal portion.

Light Organs: Postorbital at least as large as eye in male, only half as large (though apparently functional) in female. In front of or below this organ an elongate, superficial luminous patch of varying size is usually present; when absent, it has probably been rubbed away accidentally; there seems to be no connection between the size of the patch and the sex of the specimen. Serial photophores with the following counts: ventral series, I-P 5, P-V 13 to 15, including about 2 above the anal fin, V-A 16 to 20 , A-C 6 to 7; lateral series, O-V 12 to 14 , V-A 14 to 17.

Fins: Pectoral $2+1$ or 2 , the first 2 rays close together, the third isolated, sometimes with a minute fourth ray at its base, which always seems to be present subdermally; pelvic 4 to 6 , inserted equidistant from tip of 
snout and some part of anal fin; dorsal (11?) 13 to 16 ; anal (12?) 14 to 17. Vertebrae: 45.

\section{DEVELOPMENT.}

Material: The Bermuda specimens are all immature, distributed as follows :

2 post-larvae; $25,29 \mathrm{~mm}$; $500,600 \mathrm{~F}$; May.

11 adolescents; 30 to $38 \mathrm{~mm}$.; 300 to $900 \mathrm{~F}$.; May to July.

9 transitional adolescents; 44 to $105 \mathrm{~mm}$.; May to September.

They are all typical of their respective growth stages (see p. 77). Their special characteristics are as follows: Myomeres: From nape to end of anal, 45; from nape to pelvic insertion, 19; from pelvic insertion to anal origin, 17. Pigment: Three or more fine dots on each myomere immediately below dorsal profile. Gill-rakers: Moderately long rakers are present in the post larva on the first and second arches; absent on third, fourth and fifth in all specimens. Sex: Can be determined in specimens of $68 \mathrm{~mm}$. and over.

\section{ECOLOGY.}

Of the dozen stomachs which were examined (from specimens measuring between 30 and $105 \mathrm{~mm}$.), five contained food-in every case single myctophids, from one-third to one-half the length of the Bathophilus. Two
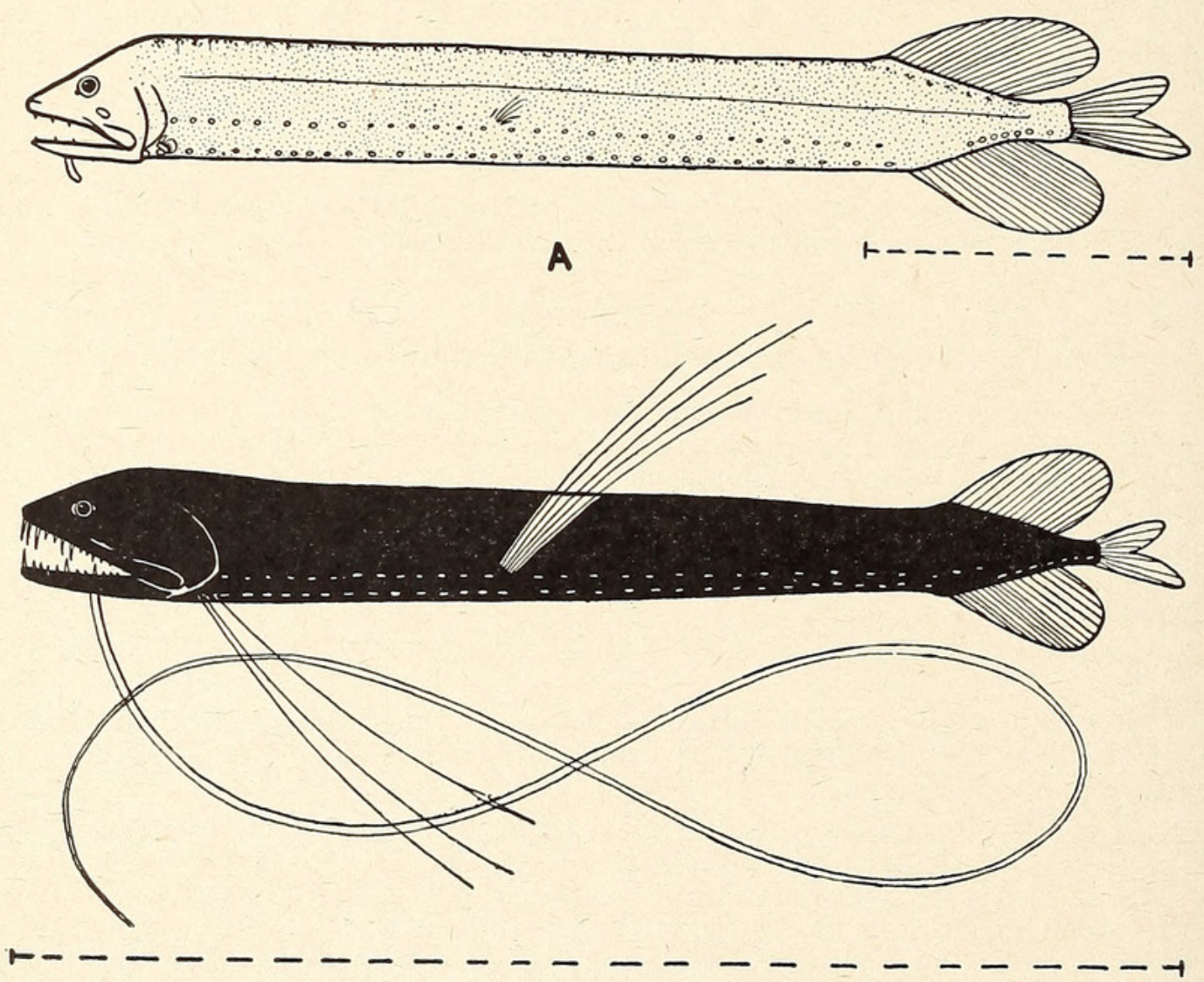

B

Text-figure 61.

Bathophilus metallicus. A, post-larva, standard length $29 \mathrm{~mm}$.; B, transitional adolescent, standard length $105 \mathrm{~mm}$. See also Text-fig. $2 \mathrm{M}$. 
of these ingested fish were species of Lampanyctus, one of Diaphus, one Myctophum hygomi and one unidentifiable. In each one of the 12 Bathophilus there was a considerable amount of intestinal material, indicating recent feeding, even when the stomach was empty.

\section{STUdY MATERIAL.}

The following list gives the catalogue number, depth in fathoms, date, length and growth stage of each specimen of Bathophilus metallicus taken by the Bermuda Oceanographic Expeditions. All were caught in the cylinder of water off the Bermuda coast described in Zoologica, Vol. XVI, No. 1, p. 5 and Vol. XX, No. 1, p. 1.

No. 9,889; Net 94; 600 F.; May 11, 1929; 105 mm.; Trans. Adolescent.

No. 9,997; Net $103 ; 600 \mathrm{~F}$.; May 15, 1929; $25 \mathrm{~mm}$.; Post-larva.

No. 10,188; Net 130; 500 F.; May 27, 1929; $68 \mathrm{~mm}$.; Trans. Adolescent.

No. 10,203; Net 132; 400 F.; May 28, 1929; 96 mm.; Trans. Adolescent.

No. 10,556; Net $182 ; 500 \mathrm{~F}$; June 18, 1929; $30 \mathrm{~mm}$.; Adolescent.

No. 10,557; Net 183; $600 \mathrm{~F}$; June 18, 1929; $33 \mathrm{~mm}$.; Adolescent.

No. 10,938; Net 211; 500 F.; June 24, 1929; 30, 30 mm.; Adolescents.

No. 11,562; Net 297; 500 F.; July 13, 1929; 34 mm.; Adolescent.

No. 11,575; Net 301; 900 F.; July 13, 1929; $37 \mathrm{~mm}$.; Adolescent.

No. 11,700; Net $311 ; 600$ F.; July 22, 1929; 84 mm.; Trans. Adolescent.

No. 12,545; Net $390 ; 500$ F.; Aug. 8, 1929; 44 mm.; Trans. Adolescent.

No. 12,860; Net 404; 600 F.; Sept. 2, 1929; 95 mm.; Trans. Adolescent.

No. 12,948; Net 409; 500 F.; Sept. 3, 1929; $87 \mathrm{~mm}$.; Trans. Adolescent.

No. 15,353; Net 624; 400 F.; May 23, 1930; 38 mm.; Adolescent.

No. 15,496; Net $645 ; 600$ F.; May 29, 1930; $34 \mathrm{~mm}$.; Adolescent.

No. 15,577; Net 652; 500 F.; May 30, 1930; 29 mm.; Post-larva.

No. 15,738; Net 677; 800 F.; June 5, 1930; $37 \mathrm{~mm}$.; Adolescent.

No. 15,739; Net 679; 400 F.; June 7, 1930; 32 mm.; Adolescent.

No. 16,461; Net 753; 700 F.; July 1, 1930; 105 mm.; Trans. Adolescent.

No. 21,315; Net 1077; 300 F.; July 11, 1931; 35 mm.; Adolescent.

No. 22,199; Net 1158; 600 F.; Aug. 10, 1931; 51 mm.; Trans. Adolescent.

\section{SYNONYMY AND REFERENCES.}

?Trichostomias vaillanti:

Zugmayer, 1911.1 , p. 6. (1 specimen; $80 \mathrm{~mm}$; off southern Portugal; preliminary description).

Zugmayer, 1911.2, p. 78, pl. III, fig. 4. (Full description of the type).

Trichostomias metallicus:

Welsh, 1923, p. 10, fig. 10. (9 specimens; 33 to $46 \mathrm{~mm}$.; 50 to $1,000(-0)$

M.; between Cape Hatteras and Bermuda; examined by present authors).

Bathophilus simplex:

Parr, 1927, p. 87, fig. 9. (1 specimen; $85 \mathrm{~mm}$.; 5,000 ft. wire; off Bermuda; examined by present authors).

Bathophilus metallicus:

Regan \& Trewavas, 1930, p. 67, pl. IV, fig. 1, text-figs. 1, 13 and 14. (151 specimens; 25 to $140 \mathrm{~mm}$.; 10 to $7,000 \mathrm{~m}$. wire; North Atlantic between 20 and 43 degrees N. Lat.; including the Bermuda region).

Beebe, 1933.1, p. 180. (Preliminary list of Bermuda specimens).

Beebe, 1937, p. 199. (Preliminary list of Bermuda specimens).

Trichostomias alberti:

Roule \& Angel, 1931, p. 7. (1 specimen; $96 \mathrm{~mm}$.; 0-1000 m.; eastern North Atlantic). 
Bathophilus alberti:

Roule \& Angel, 1933, p. 13. Pl. I, fig. 6.

(Amplified description of preceding specimen).

?Bathophilus vaillanti:

Fowler, 1936, p. 204. (Résumé of type description of $T$. vaillanti).

\section{Bathophilus longipinnis (Pappenheim, 1914).}

\section{SPECIMENS TAKEN BY THE BERMUdA OCEANOGRAPHIC EXPEDITIONS.}

2 specimens; May and September, 1929 and $1930 ; 400$ and 900 fathoms; from a cylinder of water 8 miles in diameter ( 5 to 13 miles south of Nonsuch Island, Bermuda), the center of which is at $32^{\circ} 12^{\prime} \mathrm{N}$. Lat., $64^{\circ} 36^{\prime}$ W. Long.; standard lengths 48 and $58 \mathrm{~mm}$.

\section{Specimens Previously Recorded.}

9 specimens; ca. 18 to 270 fath.; North and South Atlantic; standard lengths from 26 to $110 \mathrm{~mm}$.

\section{DESCRIPTION.}

(All of the recorded specimens are, in all probability, immature).

With the characteristics of the genus.

Color (from freshly caught Bermuda specimens): General color, pearly gray (probably with mucous); barbel creamy white, with the 2 tiny terminal filaments translucent; postorbital light organ bright yellow in male, pinkish-silver in female, with a silver rim; serial photophores golden yellow; small, non-serial organs pink.

Proportions: Depth in length 6.1 to $8(12.5 \%$ to $16.4 \%)$; head in length 4 to 5 ( $20 \%$ to $25 \%$ ).

Barbel: About $5 / 6$ as long as fish in a $58 \mathrm{~mm}$. Bermuda specimen, apparently complete, ending in two minute filaments.

Light Organs: Postorbital as large as eye in a $58 \mathrm{~mm}$. male, only about half as large in the $48 \mathrm{~mm}$. female. Serial photophores with the following counts: ventral series, I-P $6, \mathrm{P}-\mathrm{V} 14$ to 15 , V-A 11 to 13 , A-C 5 (starting at

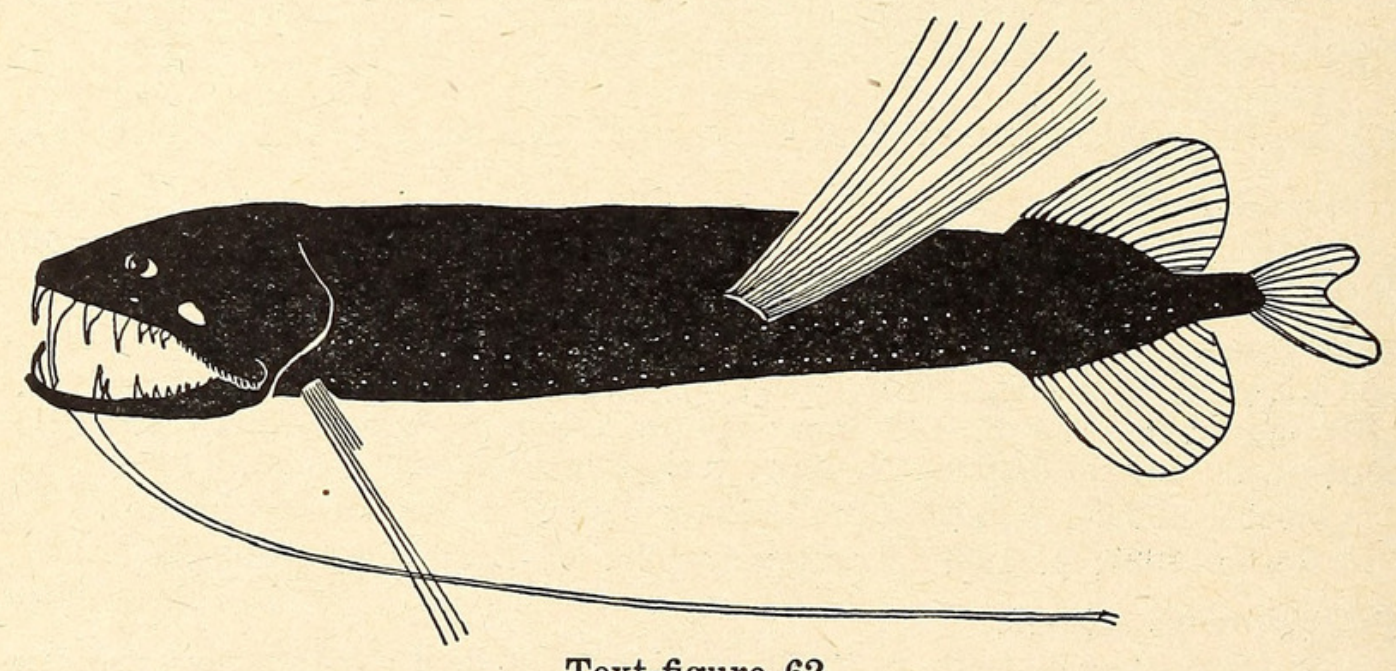

Text-figure 62.

Bathophilus longipinnis. Transitional adolescent, standard length $58 \mathrm{~mm}$. 
about 8 th anal ray; lateral series, O-V 14 to $15, \mathrm{~V}-\mathrm{A} 10$ to 11 . There are no conspicuous luminous patches, although there are traces of a general covering of probably luminous mucous here and there on the body.

Fins: Pectoral 5 to 8 , the first 3 rays stronger than the rest; pelvic 11 to 14, inserted slightly behind middle of length; dorsal 14 to 16 ; anal 15 to 16.

\section{DEVELOPMENT.}

The 2 specimens in the present collection are both transitional adolescents, moderately advanced, with characteristics typical of their growth stage (see p. 000).

\section{STUDY MATERIAL.}

The following list gives the catalogue number, depth in fathoms, date, length and growth stage of each specimen of Bathophilus longipinnis taken by the Bermuda Oceanographic Expeditions. Both were caught in the cylinder of water off the Bermuda coast described in Zoologica, Vol. XVI, No. 1, p. 5 and Vol. XX, No. 1, p. 1.

No. 9,867; Net 87; 400 F.; May 10, 1929; 58 mm.; Trans. Adolescent Male.

No. 19,431; Net 951; 900 F.; Sept. 26, 1930; 48 mm.; Trans. Adolescent Female.

\section{REFERENCES AND SYNONYMY.}

Bathophilus longipinnis:

Regan \& Trewavas, 1930 , p. 68, Pl. V, fig. 1 . (6 specimens; 26 to 110 $\mathrm{mm}$.; 65 to $1,000 \mathrm{~m}$. wire; Florida St., off Leeward Islands and from 700 to 1,300 miles east and southeast of Bermuda).

Norman, 1930, p. 312. (1 specimen, $102 \mathrm{~mm}$; 650 (-0) M.; 600 miles west of Cape Town).

Beebe, 1933.1, p. 180. (Preliminary list of Bermuda specimens).

Beebe, 1937, p. 199. (Preliminary list of Bermuda specimens).

Melanostomias longipinnis:

Pappenheim, 1914, p. 170. (1 specimen, 26 mm.; $20 \mathrm{~m}$.; between Bermuda and Rio d'Oro).

Gnathostomias longifilis:

Pappenheim, 1914, p. 172. (1 specimen, $47 \mathrm{~mm}$; between Bermuda and Rio d'Oro).

\section{Bathophilus longifilis:}

Fowler, 1936, p. 204. (Résumé of type description of G. longifilis).

\section{Bathophilus chironema Regan \& Trewavas, 1930.}

\section{SPECIMEN TAKEN BY THE BeRMUdA OCEANOGRAPHIC EXPEDITIONS.}

1 specimen; Department of Tropical Research No. 18,350; Bermuda Oceanographic Expeditions of the New York Zoological Society; Net 869; September 10,$1930 ; 1,000$ fathoms; from a cylinder of water 8 miles in diameter, 5 to 13 miles south of Nonsuch Island, Bermuda, the center of which is at $32^{\circ} 12^{\prime} \mathrm{N}$. Lat., $64^{\circ} 36^{\prime} \mathrm{W}$. Long.; standard length $34 \mathrm{~mm}$.

\section{SPECIMENS PREVIOUSLY RECORDED.}

5 specimens; ca. 41 to 83 fathoms; North Atlantic; standard lengths from 29 to $53 \mathrm{~mm}$. 


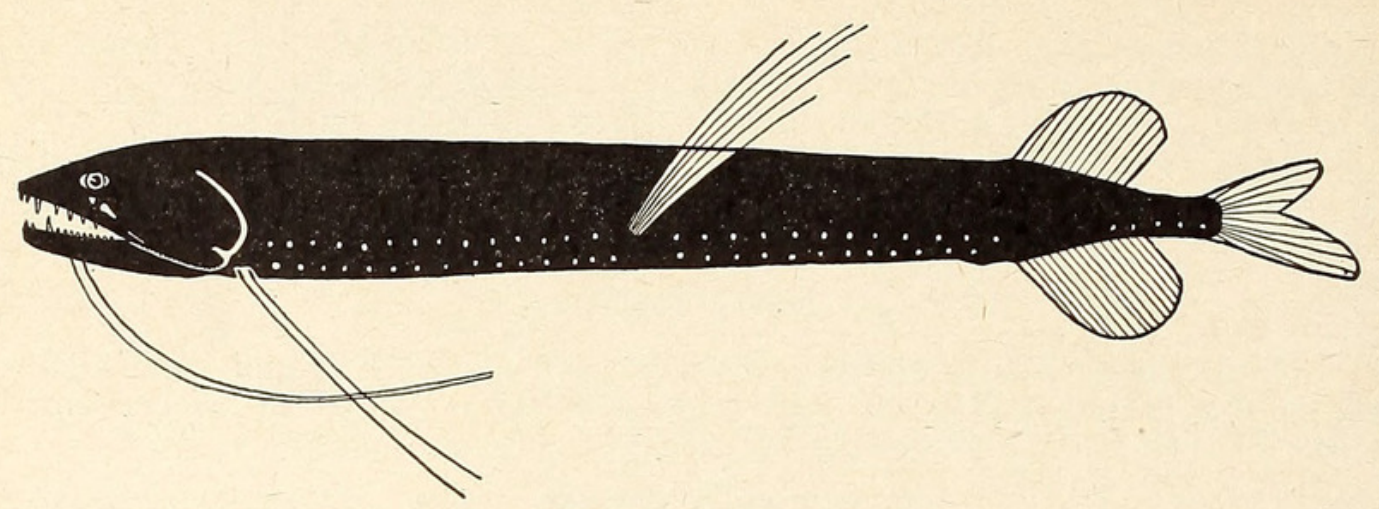

Text-figure 63.

Bathophilus chironema. Transitional adolescent, standard length $34 \mathrm{~mm}$.

DESCRIPTION.

(Doubtless all of the known specimens are immature).

Proportions: Depth in length 7 to $9(11.1 \%$ to $14.2 \%)$; head in length $5(20 \%)$.

Barbel: About half as long as fish in the Bermuda specimen, but end is probably broken off.

Light Organs: Postorbital light organ with a round luminous spot in front of it, below eye; usually another small luminous spot behind pelvic fin; serial photophores with the following counts: I-P 5; P-V 15; V-A 12 to 13; A-C 5 to 7; lateral series, O-V 14 to 15 ; A-C 12 to 13.

Fins: Pectoral 2, inserted close together; pelvic 6 to 8, inserted at about the middle of the length; dorsal 14 to 16 ; anal 15 to 16 .

\section{DEVELOPMENT.}

The single Bermuda specimen, $34 \mathrm{~mm}$. long, is a young transitional adolescent with characteristics typical of that growth stage (see p. 79). Sex cannot yet be determined.

\section{Bathophilus chironema:}

\section{REFERENCES.}

Regan \& Trewavas, 1930 , p. 69, Pl. V, fig. 3. (5 specimens, 29 to 53 $\mathrm{mm}$.; 150 to $300 \mathrm{~m}$. wire; Florida Strait and from approximately 300 miles west to 1,300 miles south and east of Bermuda).

Beebe, 1937, p. 199. (Preliminary listing of Bermuda specimens).

Genus Eustomias Vaillant, 1888.

(See also pp. 70-75, 79-84, 87-91, 95-97, 99, 102, 103, 105-110).

(Text-figs. 2, 4, 11, 12, 64-77 incl.).

\section{General Discussion.}

The genus Eustomias in the broad and usual sense (as understood, for instance, in the monograph by Regan \& Trewavas, 1930 , p. 71 ff.) is so large and diverse that superficial study indicates that it should be divided into two or more genera. The form varies from moderate to elongate, the teeth from almost all fixed to all depressible, the barbel from long and simple to short and elaborately branched, and the pectoral from having numerous rays to none. Three authors, namely, Gilchrist in 1908 and 
Roule \& Angel in 1933, felt that these differences were sufficient to divide the genus into two parts, proposing the names Neostomias and Parastomias respectively for the more specialized species, with the teeth mostly depressible, heads broad, pectorals reduced and barbels elaborate.

A comparative study of the characteristics of all the species, however, shows that they overlap to such an extent that it is impossible to draw a satisfactory generic line between two or more groups of species; also, all of the numerous forms resemble one another in fundamental skeletal characters and general appearance so much more than they do members of other genera that we agree with Regan \& Trewavas that it is inadvisable to split the genus, except to the extent of recognizing the subgenera, which the latter authors have proposed.

A total of 52 species is admitted in their monograph ${ }^{14}$. Although the outlines of the main groups (e.g. subgenera) are fairly distinct, neighboring species are often described as differing only in small details of the barbel structure. Both because of lack of adequate new material, and because of our inability to examine the large number of specimens deposited in European museums, we cannot undertake a revision of the genus at the present time. However, from the examples at hand, the need for an extensive reduction in the number of species is clearly apparent, since we have found that, not only the size of the postorbital organ, but the form of the barbel varies extensively with both growth and sex.

Most of the species we have examined belong to the subgenus Dinematochirus, characterized chiefly by a barbel having three more or less well developed posterior branches and two pectoral rays. Examination of examples referred to different species, but varying in size and sex, gives the following general results: 1 . The final barbel form is assumed only in very late transitional adolescence; specimens which appear adult externally, even to a complicated barbel, actually do not reach their full internal and barbel development until they are much larger. 2. The barbels of adult females differ from those of adult males in having the central branch relatively short-always shorter than the lateral branches, whereas the reverse is true in males; also, this median branch in females has near the tip a well developed bulblet which is small or absent in the male. In the female the major barbel bulb is smaller than in the male, and tends to be oblong rather than round. The postorbital light organ is always very large-as large as or larger than the eye-in the adult male, and atrophied, or at least subdermal, in the corresponding female. In the more primitive subgenera, such as Nominostomias, the postorbital is smaller in the male and does not quite atrophy in the female.

We have not seen enough material belonging to other subgenera to generalize on growth and sex characters of the barbels.

Tentative synonymies, some guessed, some adequately proven, for the species to which we have had access are as follows:

$E$. obscurus Vaillant, 1888. We have examined the type specimen of E. proximus Welsh, 1923, in the U. S. National Museum and agree with Regan \& Trewavas $(1930$, p. 81$)$ that it is identical with E. obscurus. Our own Bermuda material is insufficient to determine how much, if any, of the barbel variation shown by the latter authors (text-fig. 58) is sexual.

E. bibulbosus Parr, 1927, p. 71; E. bibulbosus arborifer (loc. cit.); E. bibulbosus micraster (loc. cit.) ; E. bituberatus Regan \& Trewavas, 1930, p. $83 ; E$. bimargaritatus Regan \& Trewavas, 1930, p. 84 . We have examined specimens in our own collection and all of Parr's types, given full specific rank by Regan \& Trewavas (1930, pp. 82-85). All specimens with bibulbosus forms of barbel are males; those with arborifer forms are females. The

14 Since then the following species have been described: $E$. radicifilis Borodin, 1930; E. regani Norman, $1930 ; E$. trewavasae Norman, $1930 ; E$. schiff $i$ Beebe, 1932; E. satterleei Beebe, 1933. 
barbel of the type specimen of arborifer has characters identical with those shown in the figures of $E$. bimargaritatus Regan \& Trewavas, 1930, p. 84, fig. 63. The type of $E$. bibulbosus micraster is a female; judging by analogy with $E$. bibulbosus, $E$. bituberatus Regan \& Trewavas, 1930, p. 83, with a simple end to the terminal filament, may turn out to be the male of this longbarbeled form, which certainly requires specific rank. (See p. 219 for description of $E$. bibulbosus).

E. simplex Regan \& Trewavas, 1930, p. 87 . The single Bermuda specimen is a female (p. 221).

E. polyaster Parr, 1927, p. 74 ; E. dubius Parr, 1927, p. 66; E. schiffi Beebe, 1932. We have examined the types of all of these species, the first two in the Peabody Museum, the last in our own Bermuda collection. It is possible that all are synonymous. The types of $E$. dubius and $E$. schiffi are females, that of E. polyaster a male. Parr's figure of the barbel of latter species is somewhat simplified; the figure given by Regan \& Trewavas (p. 89, fig. 71, especially the lower cut) from the Dana examples represents the type more accurately. It is probable, judging from $E$. bibulbosus, that the lower barbel in the latter figure represents a male, the upper, with branched tip, a female. If this is so, E. polyaster and $E$. dubius are distinct; at any rate, they will be so considered in this paper. The specimens referred by Regan \& Trewavas (p. 88) to E. dubius are probably males, Parr's type of the species, and Beebe's type of $E$. schiff $i$ being females.

The figure given by Parr of the barbel of E. dubius is misleading in some respects; his description saying that the barbel is about $3 / 5$ as long as the fish is correct, not the figure, which shows a barbel $1 / 3$ as long as the fish. Also, under fairly high power, the bases of 10 or 11 separate filaments are seen to form the "fan," including two from the anterior and posterior sides of the terminal appendage, respectively, there are, in addition, distinct traces of damage to the organ. Judged in this light, there is not the slightest question but that $E$. schiffi is an undamaged example of the same species (and sex). The difference in barbel lengths between the examples of Parr and of Regan \& Trewavas is probably due to different growth rates between barbel and body length, as is known to occur in other genera. (See p. 222).

E. longibarbus Parr, 1927, p. 64; E. microcephalus, Parr, 1927, p. 75. We have examined the types of these specimens at the Peabody Museum. As Regan \& Trewavas (1930, p. 86) suggest, E. microcephalus is probably the young of $E$. longibarba, although due to the youth of the latter, an early adolescent, their identity cannot be proved; at least 10 or 11 pairs of larval spots remain on the young example. Both the type specimens of $E$. longibarba are immature females; in both the terminal papilla on the barbel has nodules as in the figure given by Regan \& Trewavas (1930, p. 86, fig. 66 A, B) ; the postorbital is almost atrophied, being minute and barely visible beneath lightly pigmented skin-considerably smaller and less conspicuous than in the figure given by Parr (p. 64, fig. 35).

E. brevibarbatus Parr, 1927, p. 68 . The type specimen has, as Regan \& Trewavas (1930, p. 92) suggest, some pigment on the stem between the bulbs, but not on the bulbs themselves. Also, the fish is definitely juvenile, in the middle of the adolescent stage. E. micropterygius is more likely to be the young of this species than of $E$. macrophthalmus.

E. micropterygius Parr, 1927, p. 65. We have examined the $57 \mathrm{~mm}$. type, which Regan \& Trewavas (1930, p. 93) suggested was the young of $E$. macrophthalmus or an allied species. It proves to be an early adolescent, with the specific characters as yet undeveloped. There is a distinct trace of a smaller bulb anterior to the larger terminal one; to the latter is attached a long, slender, almost filamentous papilla. There are traces of 8 larval pigment spots situated well below the dorsal profile.

E. macrophthalmus Parr, 1927, p. 67, figs. 36c, 39. We have examined 
the $104 \mathrm{~mm}$. type, which is an immature female. The postorbital organ is minute. The end of the barbel in the type figure is somewhat too thick, the illustration given by Regan \& Trewavas (1930, p. 93, fig. 77) being more representative.

E. lipochirus Regan \& Trewavas, 1930, p. 95. The Bermuda collection contains a single specimen, too young to sex. In all probability this species will prove to be identical with one or more of its neighbors (p. 224).

E. bigelowi Welsh, 1923 , p. 6 ; E. bigelowi paucifilis Parr, 1927, p. 79; E. bigelowi parvibulbus Parr, 1927 , p. $79 ;$ E. triramis Regan \& Trewavas, 1930 , p. 99. We have examined the types of all these species except the last, at the U. S. National and Peabody Museums, and compared them with our own specimens. We are convinced that all are the same species, their differences being due solely to age and sex. E. bigelowi and E. bigelowi parvibulbus are females, the parvibulbus type being the older, near breeding condition. In the latter specimen the terminal ends of the barbel are much more elaborately branched than could be shown in the small figure given by Parr (fig. 46). Also, there is more of a definite bulb, with the transparent outer covering of the bulb continuing farther back than the figure shows. The lateral branchlets have three to five small filaments. The type of E. bigelowi paucifilis, on the other hand, is a male, with gonads less than half developed; the figure given with the type description is accurate. $E$. triramis probably represents a growth stage still younger than that of the original $E$. bigelowi. (See p. 225.)

E. binghami Parr, 1927, p. 80; E. frondosus Regan \& Trewavas, 1930, p. 103. We have examined the type of the former in the Peabody Museum, and find that there is a median, short, simple, barbel branch, just as in frondosus, the end microscopically swollen. Also, along each branch (except the median one) there are from 2 to more than 6 minute, but perfectly distinct, filaments; of these 1 near the tip of 3 of the 4 branches, has a distinct bulblet, the whole being as in fig. 92 given by Regan \& Trewavas. There are traces of even smaller bulbs on several of the filaments. Therefore, binghami and frondosus are synonymous, binghami taking precedence. The type of the latter is a male, the gonads being less than one-half developed. It is probable, judging from analogy in other species, that in the figure given by Regan \& Trewavas the upper barbel is of a female, and the two lower ones of males.

E. silvescens Regan \& Trewavas, 1930 and $E$. satterleei Beebe, 1933. Judging again by analogy of barbel structure, we synonymize $E$. satterleei, a female, with $E$. silvescens, which, from the size of the postorbital organ in the illustration of the type (Regan \& Trewavas, 1930, pl. IX, fig 2), is undoubtedly a male. (See p. 228).

E. fissibarbis (Pappenheim, 1914, p. 175); E. nigrifilis Parr, 1927, p. $81 ; E$. dendriticus Regan \& Trewavas, 1930 , p. 104 . We have examined the type of $E$. nigrifilis at the Peabody Museum, and agree with Regan \& Trewavas $(1930$, p. 103$)$ that it is synonymous with $E$. fissibarbis. It is a female with the gonads about one-half developed. The figure of the type does not show the tipped filament on the posterior surface of the bulb, which is in about the same position as one in the Bermuda collection. There are also, in nigrifilis, two very slender, simple filaments from the anterior face of each of the two minor branches, just before they divide, this is another characteristic of the Bermuda specimens. We think it likely that $E$. dendriticus will prove to be the male of $E$. fissibarbis. (See p. 232).

Distribution: Eustomias is known only from the North and South Atlantic, from about 390 specimens. Of the 60 -odd species which have been described, probably less than half will prove to be valid, when adequate material has been obtained. The known vertical range of distribution is between the surface (young) and 1,000 fathoms. 

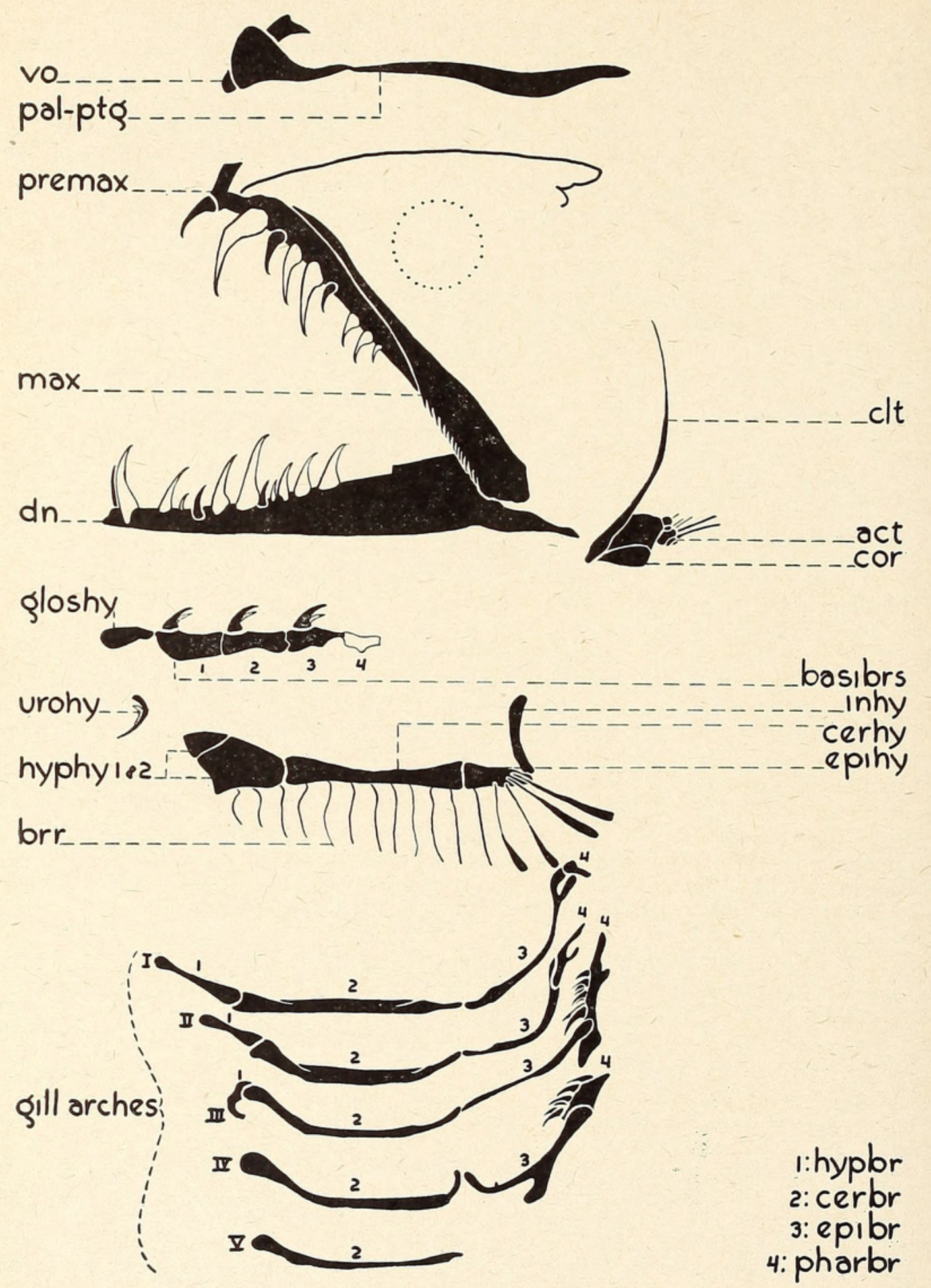

Text-figure 64.

Eustomias fissibarbis. Jaws, hyoid and branchial arches, and pectoral girdle of adult, standard length $130 \mathrm{~mm}$. Explanation as in Text-fig. 18.

\section{GENERIC CHARACTERS.}

Color (from fresh specimens of 7 species): General color brownishblack; postorbital light organ silvery- or opalescent-white; barbel bulb 


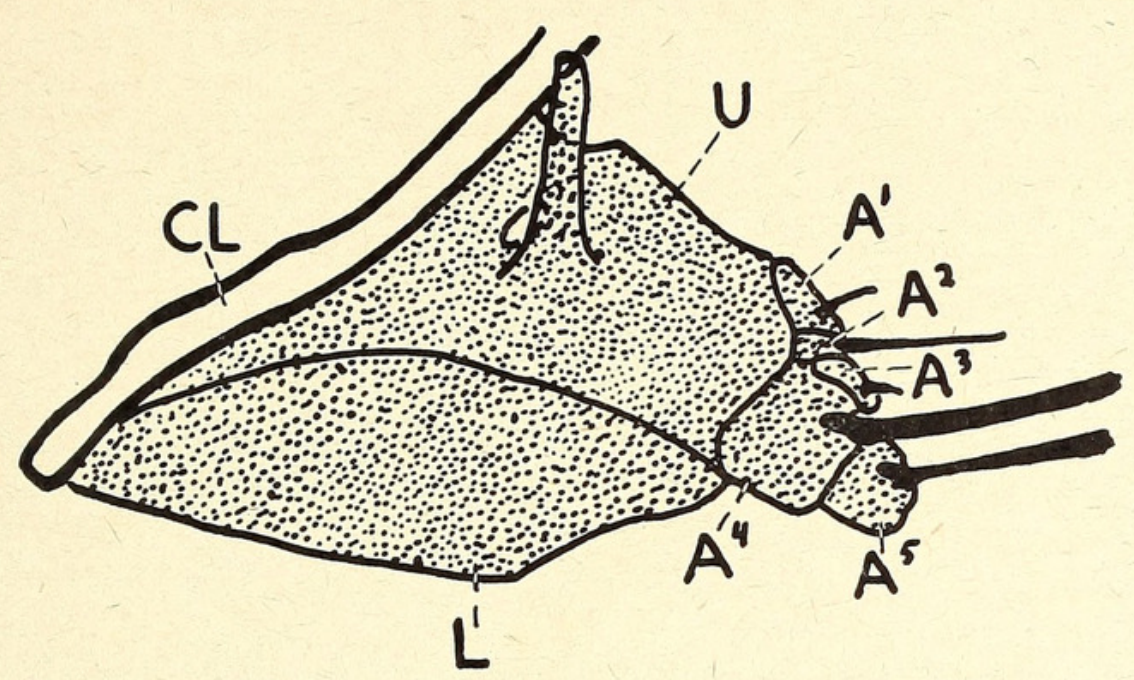

Text-figure 65 .

Eustomias fissibarbis. Supporting bones of pectoral fin in adult, standard length $130 \mathrm{~mm}$. Abbreviations as in Text-fig. 14 .

and branches pink, yellow, green or blue; serial photophores violet with gold frames.

Proportions: Elongate melanostomiatids with protractile snouts. Depth in length 10 to $15(6.7 \%$ to $10 \%)$; head in length 4.5 to $7(14.3 \%$ to $22.2 \%$ ); eye in head 4.5 to 7 ; snout when extended much longer than eye; snout to pelvic in length $c a .1 .8$ to $2(50 \%$ to $56 \%)$.

Barbel: From shorter than head to almost as long as fish; stem with or without branches above the bulb; bulb simple or filamented; a second bulb sometimes present.

Light Organs: Postorbital almost or completely atrophied in adult female, moderate to very large in male; serial photophores with the following counts: I-P 7 to 8 ; P-V and O-V 24 to 31 ; V-A 12 to 21 , A-C 16 to 25. Non-serial light organs usually inconspicuous.

Teeth: Cleft of mouth straight; teeth in jaw very variable, ranging from mostly fixed and relatively few to mostly depressible and rather numerous; no teeth on vomer or palatine; three pairs on basibranchials; no teeth on gill-arches.

Branchiostegal Rays: About 16.

Fins: Pectoral with 0 to 13 rays, short or long; pelvic 7 ; placed about middle of length or behind it; dorsal 21 to 30 ; anal 33 to 46, beginning far in front of dorsal and ending slightly behind it.

Epidermal Grooves: A pronounced groove in the isthmus for grasping the stem of the barbel.

Osteology: Mesethmoid with lateral processes; parietals absent; palatine and ectopterygoid loosely attached by ligaments to mesethmoid and quadrate, respectively, but firmly fastened to premaxillary and maxillary; this arrangement permits the forward projection of the jaw; post-temporal absent; supra-cleithrum absent; upper and lower coracoids large and laminar; mesocoracoid absent; actinosts 5 in species with 2 pectoral rays, with rudiments of 3 other rays; vertebrae about 66 to 77 ; anterior 9 or 10 vertebrae highly modified; centra of all except third vertebra absent; no neurapophyses before the third, which are large and meet above; behind this the notochord bends sharply in a ventrally convex loop which includes the displaced centrum of the third vertebra; four pairs of strong neurapophyses behind the loop, belonging to the sixth to ninth vertebral segments; some- 

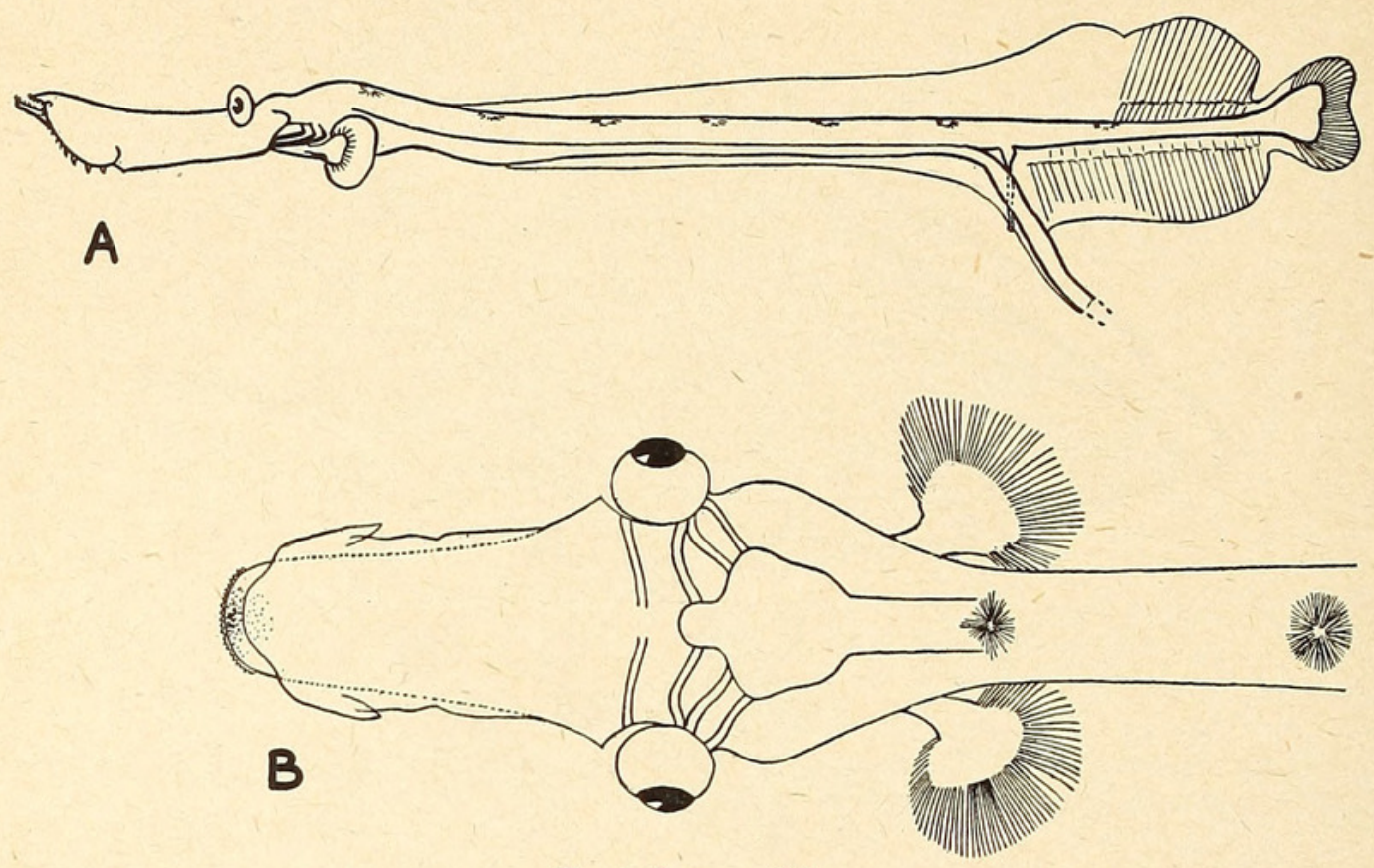

Text-figure 66.

Eustomias sp. Larva, standard length $13 \mathrm{~mm}$. A, lateral view; B, dorsal view of head. See also Text-fig. 20.

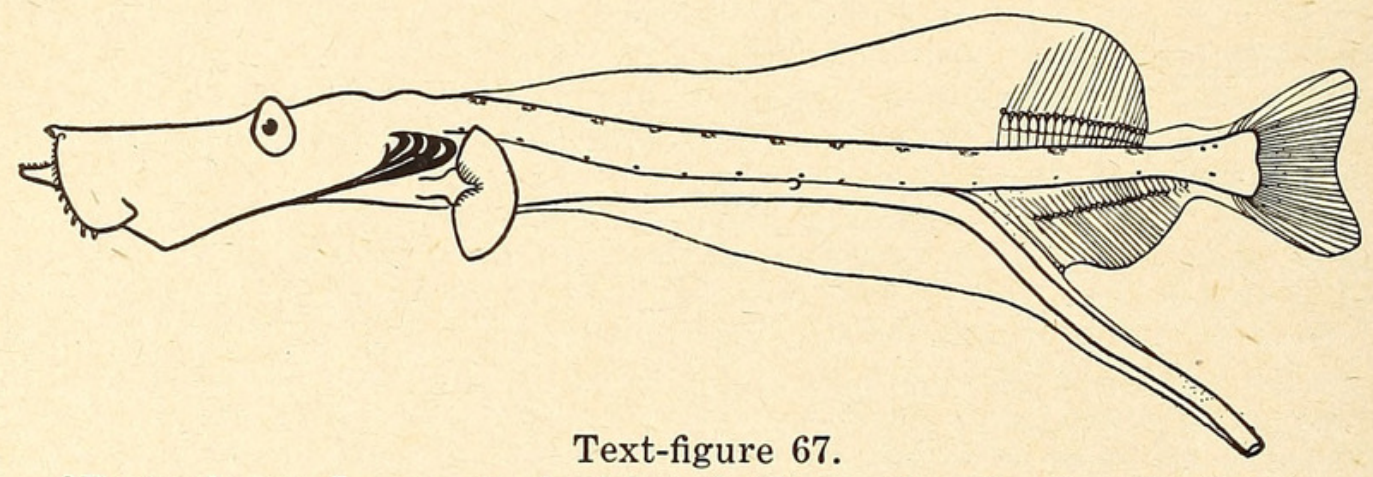

?Eustomias sp. Larva, standard length $12 \mathrm{~mm}$. See also Text-fig. $2 \mathrm{~N}$.
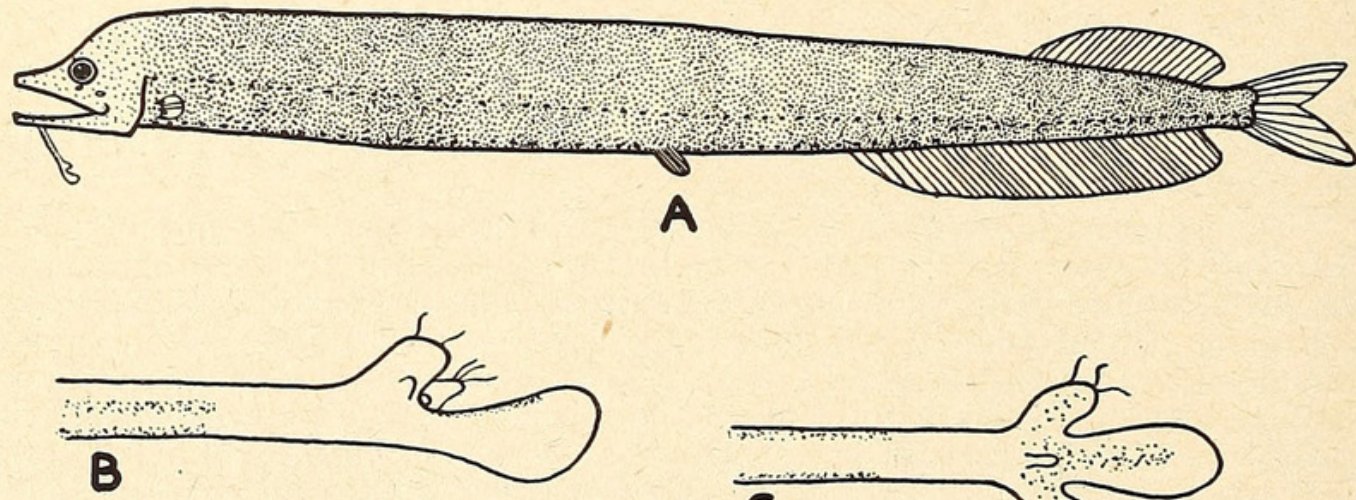

Text-figure 68.

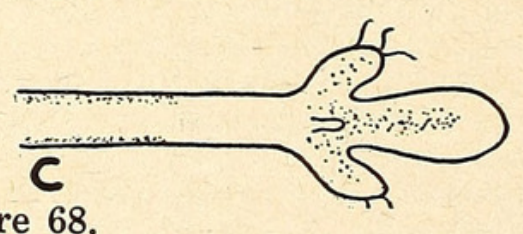

Eustomias sp. Subgenus Dinematochirus. Transitional post-larva, standard length $43 \mathrm{~mm}$. A, lateral view; B, barbel, lateral view; C, barbel, posterior view. 
times a smaller loop behind these, formed by the last 2 modified and first normal vertebrae; no parapophyses before third vertebra; subsequent ones in modified portion small or minute, with or without pleural ribs and epipleurals, sometimes absent posteriorly.

Coelomic Organs: Stomach 22\% (subgenus Dinematochirus) to $38 \%$ (subgenus Nominostomias) of standard length. Two pyloric caeca.

Sexual Dimorphism: Postorbital light organ almost or completely atrophied in adult female. Barbel branches and filaments different in the sexes, the trend of variation depending on the subgenus. (See p. 211).

Size: The largest known specimen of Eustomias is the type of E. bigelowi parvibulbus (adult female $E$. bigelowi), $204 \mathrm{~mm}$. long, taken by the Bingham Oceanographic Expeditions. It is near breeding condition. Sex can be determined in transitional adolescents measuring from around 90 or $100 \mathrm{~mm}$. Two Bermuda males, $E$. bigelowi and $E$. fissibarbis, measuring 138 and $118 \mathrm{~mm}$. , are apparently adult, with gonads well, but not fully, developed.

Development: The larvae of Eustomias are very distinct, bearing a close resemblance to those of Idiacanthus, except that the eyes are not stalked and the pigment spots are fewer (no more than 5 to 11 pairs), instead of one to each myomere, and dorsally instead of laterally located. The snout is long and flattened, with a small, terminal mouth; the head is correspondingly large; the finfolds are small, and the gut is longer than usual, extending behind the caudal fin when unbroken; larval gill-rakers are well developed at least on the first arch; on succeeding arches they are in the form of spiny mounds or are rudimentary; they are usually absent on the fifth arch.

The Bermuda Expeditions took 4 larvae and 12 post-larvae, none of which can be specifically identified because of the lack of a barbel. In the future complete life-histories will perhaps be worked out by tabulating the myomeral positions of the pigment spots when adequate material has been obtained. The subgenus of post-larvae can usually be determined through photophore counts; it is certain that the number of pairs of spots is not constant or even similar in each subgenus: in Nominostomias we have young with spots ranging from 7 to 10 ; in Dinematochirus from 5 to 10.

It is highly probable that the larva in Text-fig. $66 \mathrm{~B}$ does not belong to Eustomias, since it has only about 55 myomeres to the end of the anal, instead of more than 70 ; if it is not a Eustomias, it may belong to some genus hitherto undiscovered, since its characteristics are otherwise definitely eustomiad. In addition to the usual paired dorsal spots, this specimen has an internal row of dots, along the kidney, as in Bathophilus. (See table, p. 81, for other Eustomias characters, and p. 76 for characteristics of the growth stages).

Subgenus Eusłomias Vaillant, 1888.

Eustomias obscurus Vaillant, 1888.

\section{SPECIMENS TAKEN BY THE BERMUdA OCEANOGRAPHIC EXPEDITIONS.}

5 specimens; May to September, 1929 and 1930; 500 to 700 fathoms; from a cylinder of water 8 miles in diameter ( 5 to 13 miles south of Nonsuch Island, Bermuda), the center of which is at $32^{\circ} 12^{\prime} \mathrm{N}$. Lat., $64^{\circ} 36^{\prime} \mathrm{W}$. Long.; standard lengths from 51 to $98 \mathrm{~mm}$.

\section{Specimens PReviously Recorded.}

About 195 specimens; 0 to 2,011 fathoms; North and South Atlantic; standard lengths from 52 to 180 ? $\mathrm{mm}$. 


\section{DESCRIPTION OF ADULT.}

With the characteristics of the genus.

This species is the only known Eustomias having some of the photophores of the lateral series in pairs.

Color (from a fresh transitional adolescent): Skin dark brownishblack; postorbital light organ brilliant silvery-white; barbel stem, terminal filaments and outer covering of bulb translucent white; core of bulb violet proximally yellowish, green distally.

Proportions: Depth in length 12 to 20 (5\% to $8.5 \%$ ); head in length 7.3 to 9.5 ( $11 \%$ to $13.7 \%$ ) ; eye in head 4.5 to 7 ( $14.3 \%$ to $22.2 \%$ ) ; interorbital in head 8 to $13(7.7 \%$ to $12.5 \%)$.

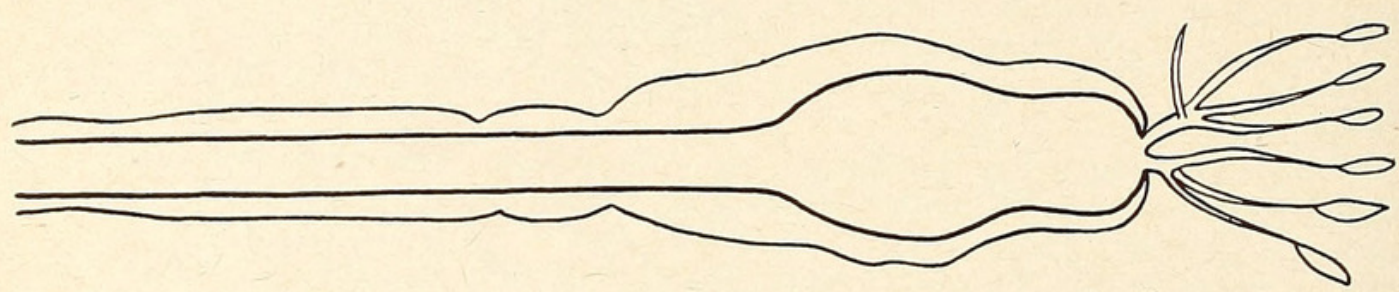

Text-figure 69. $98 \mathrm{~mm}$.

Eustomias obscurus. Barbel of transitional adolescent, standard length

Barbel: From less than $1 / 4$ to more than $1 / 2$ length of fish; stem unpigmented with a terminal, oval or pear-shaped bulb; the latter is very variable in shape, sometimes having a deep median constriction; there are a number (usually 3 to 8 ) of distal, translucent filaments with swollen tips, which sometimes arise from a single, distal stalk and sometimes separately, and are often in 2 groups. Sexual dimorphism probably plays a part in the variation.

Light Organs: Postorbital apparently small even in males. Serial photophores with the following counts: ventral series, I-P 7, P-V 33 to 35; V-A 15 to $16, \mathrm{~A}-\mathrm{C} 19$ to 22 ; lateral series $\mathrm{O}-\mathrm{V} 30$ to $37, \mathrm{~V}-\mathrm{A} 15$ to 18 . Many of the organs in the lateral series are paired, the arrangement varying in individual fish.

Teeth: First tooth in upper jaw and second in lower fixed fangs, directed slightly forward and outward; separated by a gap from second tooth which is about the same size, no larger, and depressible; following are depressible teeth and 1 or 2 outer, fixed teeth.

Fins: Pectoral 3; pelvic 7, inserted behind middle of length; dorsal 23 to 30 ; anal 34 to 36 .

\section{DEVELOPMENT.}

The five specimens of the Bermuda collection consist of 2 post-larvae (51, $55 \mathrm{~mm}),$.2 adolescents $(55,57 \mathrm{~mm}$.), and 1 transitional adolescent $(98 \mathrm{~mm}$.). All have the characteristics of their respective growth stages (see p. 77). In the post-larvae are at least 9 pairs of pigment spots. The transitional adolescent too young to be sexed.

\section{STUDY MATERIAL.}

The following list gives the catalogue number, depth in fathoms, date, length and growth stages of each specimen of Eustomias obscurus taken by the Bermuda Oceanographic Expeditions. All were caught in the cylinder of water off the Bermuda coast described in Zoologica, Vol XVI, No. 1, p. 5 and Vol. XX, No. 1, p. 1. 
No. 9,951 ; Net $100 ; 600 \mathrm{~F}$. ; May 14, 1929; $55 \mathrm{~mm}$; Adolescent.

No. 14,944; Net 574; 500 F.; May 14, 1930; 98 mm.; Trans. Adolescent.

No. 15,006; Net 583; 700 F.; May 15, 1930; 55 mm.; Post-larva.

No. 15,191; Net 606 ; 500 F.; May 20, 1930; 57 mm.; Adolescent.

No. 19,111; Net $922 ; 600$ F.; Sept. 20, 1930; $51 \mathrm{~mm}$.; Post-larva.

\section{REFERENCES AND SYNONYMY.}

Eustomias obscurus:

Vaillant, 1888 , p. 113 ; pl. VIII, figs. 3, 3a. (1 specimen; $165 \mathrm{~mm}$; $2,792 \mathrm{~m}$.; off Azores). lantic).

Zugmayer, 1911.2, p. 75. (1 specimen; $180 \mathrm{~mm}$. ; 3,660-0 m. ; eastern At-

Parr, 1927, p. 63. (Résumé of type description).

Regan \& Trewavas, 1930 , p. 81 ; pl. VII, fig. 4 (191 specimens; 52 to ? $\mathrm{mm} . ; 25$ to $5,000 \mathrm{~m}$. wire; North Atlantic).

Norman, 1930, p. 313 . (1 specimen; $156 \mathrm{~mm}$. $250(-0) \mathrm{m}$.; tropical South Atlantic).

Roule \& Angel, 1933, p. 11 (2 specimens; 150 and $170 \mathrm{~mm}$.; 0-550 m.; off Azores).

Fowler, 1936, p. 208. (Copy of type description).

Beebe, 1937, p. 199. (Preliminary list of Bermuda specimens).

Eustomias macrorhynchus:

Pappenheim, 1914 , p. 173 , figs. 2, 3. (3 specimens; 42 to $105 \mathrm{~mm}$.; 0-20 mm.; eastern Atlantic).

Parr, 1927, p. 62 (Résumé of type description).

Fowler, 1936, p. 207. (Copy of type description).

Eustomias proximus:

Welch, 1923 , p. 5, figs. 3, 4. (6 specimens; 75 to $132 \mathrm{~mm}$.; 100 to $0 \mathrm{~m}$.; western North Atlantic). Examined by present authors in U. S. National Museum.

Parr, 1927, p. 63. (Résumé of type description).

\section{Eustomias zugmayeri:}

Parr, 1927, p. 62. (Elevation of Zugmayer's specimen of E. obscurus to a new species).

\section{Subgenus Nominostomias Regan \& Trewavas, 1930. \\ Eustomias bibulbosus Parr, 1927.}

(See also p. 211).

\section{SPECIMENS TAKEN BY THE BERMUdA OCEANOGRAPHIC EXPEDITIONS.}

8 specimens; April to September; 1929 and 1930; 500 to 900 fathoms; from a cylinder of water 8 miles in diameter ( 5 to 13 miles south of Nonsuch Island, Bermuda), the center of which is at $32^{\circ} 12^{\prime} \mathrm{N}$. Lat., $64^{\circ} 36^{\prime}$ W. Long.; standard lengths from 42 to $123 \mathrm{~mm}$.

\section{SPECIMENS PREVIOUSLY RECORDED.}

4 specimens; ca. 83 to 550 fathoms; western North Atlantic; standard lengths from 105 to $136 \mathrm{~mm}$. 


\section{DESCRIPTION OF ADULT.}

With the characteristics of the genus.

Color (from field notes made on two specimens, of which one was living): General color black with bronze iridescence; distal barbel bulb of male clear pink, but giving off pale green light in dark-room; proximal bulb and stem translucent white without visible luminescence; postorbital of male silver white; serial photophores purple, the ventral series having broad gold frames.

Proportions: Depth in length 12 to 13.6 (7.3\% to $8.3 \%)$; head in length 7.5 to $8(12.5 \%$ to $13.3 \%)$; eye in head 4.3 to almost 5 (20\% to $23.3 \%$ ).

Barbel: Slightly shorter or longer than fish; stem unbranched; two bulbs and a long tapering terminal appendage, about half length of head; unbranched proximally in both sexes, but with distal filaments in female. Bulbs subequal or the distal larger, separated by a distance 2 or 3 times the diameter of the larger.

Light Organs: Postorbital smaller than eye in both sexes, but apparently functional in both; much smaller in female than in male. Serial photophores with the following counts: ventral series, I-P 7 or 8, P-V 30 to 32, V-A 18, A-C 17 to 19; lateral series, O-V 30 to 33 ; V-A 17 to 19.

Teeth: Anterior fangs (first tooth in upper jaw, second in lower) fixed; second fang in upper jaw fixed or depressible, larger than first; behind these in both jaws a series of depressible teeth and a few small, outer fixed ones.

Fins: Pectoral 3; dorsal 23 to 25; anal 38 to 39.

\section{DEVELOPMENT.}

The Bermuda collection is composed of 2 post-larvae $(42,52 \mathrm{~mm}$.), 3 adolescents ( 52 to $58 \mathrm{~mm}$.), 2 transitional adolescents (64 and $95 \mathrm{~mm}$.)
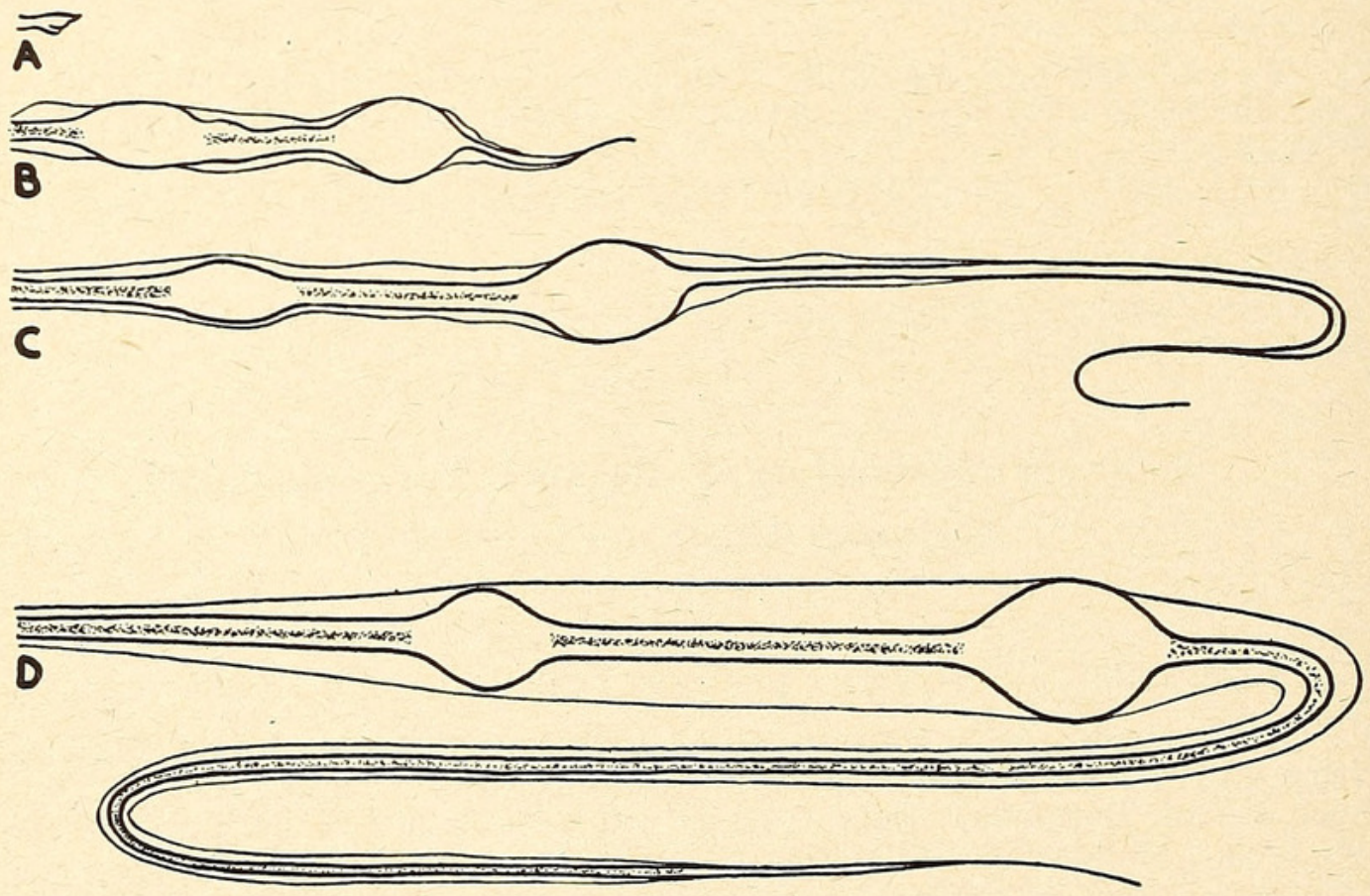

Text-figure 70.

Eustomias bibulbosus. A, post-larva, standard length $52 \mathrm{~mm}$.; B, adolescent, standard length $58 \mathrm{~mm}$.; C, transitional adolescent, standard length $64 \mathrm{~mm}$; D, adult male, standard length $123 \mathrm{~mm}$. 
and 1 adult male $(123 \mathrm{~mm}$.$) . The post-larvae could be referred to other$ closely related species (such as $E$. bituberatus), but $E$. bibulbosus is the only one which has been taken by the Bermuda Expeditions, and for the sake of completing the series they are referred to bibulbosus. All the young are characteristic of their respective stages (see pp. 76-79). Remains of 8 pairs of larval spots are found, and an additional small pair at base of caudal.

\section{STUDY MATERIAL.}

The following list gives the catalogue number, depth in fathoms, date, length and growth stage of each specimen of Eustomias bibulbosus taken by the Bermuda Oceanographic Expeditions. All were caught in the cylinder of water off the Bermuda coast described in Zoologica, Vol. XVI, No. 1, p. 5 and Vol. XX, No. 1, p. 1 .

No. 8,798; Net 23; 600 F.; April 15, 1929; 95 mm.; Trans. Adolescent.

No. 10,134 ; Net $122 ; 700$ F.; May 25, 1929; 52 mm.; Post-larva.

No. 10,293; Net 148; $700 \mathrm{~F}$; J June 1, 1929; $123 \mathrm{~mm}$.; Adult Male.

No. 13,131; Net 427; 900 F.; Sept. 5, 1929; 50 mm.; Adolescent.

No. 17,738; Net 828; 500 F.; Sept. 2, 1930; 58 mm.; Adolescent.

No. 17,770; Net 836 ; 500 F.; Sept. 3,$1930 ; 64$ mm.; Trans. Adolescent.

No. 17,901; Net 841 ; 500 F.; Sept. 4, $1930 ; 57 \mathrm{~mm}$.; Adolescent.

No. 18,589 ; Net $889 ; 500$ F.; Sept. 15,$1930 ; 42$ mm.; Post-larva.

\section{SYNONYMY AND REFERENCES.}

Eustomias bibulbosus bibulbosus:

Parr, 1927, p. 70 (1 specimen; $121 \mathrm{~mm}$; 7,000 ft. wire; southeast of Nassau). A male; examined by present authors.

Eustomias bibulbosus:

Regan \& Trewavas, 1930 , p. 82 , fig. 61A. (2 specimens; 132 and 136 $\mathrm{mm}$.; $300,1,100 \mathrm{~m}$. wire; northwest and southeast of Bermuda). Atlantic).

Fraser-Brunner, 1931, p. 218. (1 specimen; $54 \mathrm{~mm}$; tropical South

Beebe, 1937, p. 199. (Preliminary list of Bermuda specimens).

Eustomias bibulbosus arborifer:

Parr, 1927, p. 70. (1 specimen, 115 mm.; 6,000 ft. wire; Bahamas). A female; examined by present authors.

Eustomias arborifer:

Regan \& Trewavas, 130, p. 85. (Résumé of preceding description).

Eustomias simplex Regan \& Trewavas, 1930.

SPECIMEN TAKen By THE BeRMUda OCEANOGRAPHIC EXPEDITIONS.

1 specimen (Department of Tropical Research No. 9,750; Net 64); May 4, 1929; 600 fathoms; from a cylinder of water 8 miles in diameter ( 5 to 13 miles south of Nonsuch Island, Bermuda), the center of which is $32^{\circ} 12^{\prime}$ N. Lat., $64^{\circ} 36^{\prime}$ W. Long.; standard length $91 \mathrm{~mm}$., a female.

\section{SPECIMENS PREVIOUSLY RECORDED.}

3 specimens; ca. 22 to 83 fathoms; western North Atlantic; standard lengths from 50 to $75 \mathrm{~mm}$. 

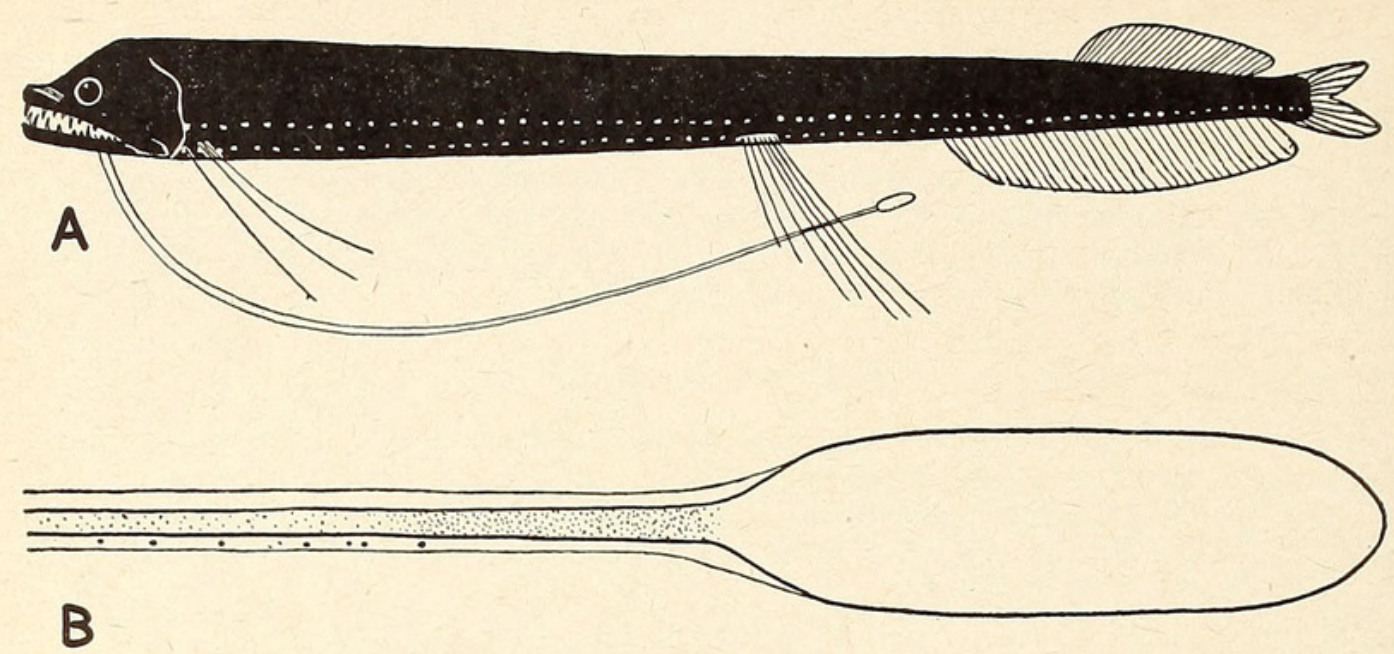

Text-figure 71.

Eustomias simplex. Transitional adolescent, standard length $91 \mathrm{~mm}$. A, lateral view; B, end of barbel.

\section{DESCRIPTION OF TRANSITIONAL ADOLESCENT.}

(No adults known).

With the characteristics of the genus.

Proportions: Depth in length 10 to $12(8.3 \%$ to $10 \%)$; head in length 7 to $8(12.5 \%$ to $14.3 \%)$; eye in head 5.7 to $6(16.7 \%$ to $17.6 \%)$, equal to interorbital width.

Barbel: From $1 / 2$ to $2 / 3$ as long as fish, terminating in a simple, oval bulb without appendages. The stem is translucent with a lightly pigmented, core. In the Bermuda specimen the bulb is an elongate oval, without the slight constriction shown in the illustration of the type specimen (Regan \& Trewavas, 1930, fig. 66C).

Teeth: The teeth of the Bermuda specimen are very similar in arrangement to that shown in the diagram accompanying the type description (loc. cit., fig. 67B). However, the second premaxillary fang seems to be fixed, not depressible, and there are several more teeth in the posterior part of the mandible. Two pairs of teeth on the palatines.

Fins: Pectoral 3, the first and second set close together; dorsal 23 to 26 ; anal 32 to 36 .

The Bermuda female is a typical advanced transitional adolescent (see p. 79).

Eustomias simplex:

\section{REFERENCES.}

Regan \& Trewavas, 1930 , p. 87, figs. 66C, 67B. (Type description).

Beebe, 1937, p. 199. (Preliminary listing of Bermuda specimens).

Eustomias dubius Parr, 1927.

(See also p. 212).

\section{SPECIMENS TAKEN BY THE BERMUdA OCEANOGRAPHIC EXPEDITIONS.}

3 specimens; May to October, 1930 and $1931 ; 600$ fathoms; from a cylinder of water 8 miles in diameter ( 5 to 13 miles south of Nonsuch Island, Bermuda), the center of which is at $32^{\circ} 12^{\prime} \mathrm{N}$. Lat., $64^{\circ} 36^{\prime} \mathrm{W}$. Long.; standard lengths from 43 to $115 \mathrm{~mm}$. 


\section{SPECIMENS PREVIOUSLY ReCORDED.}

4 specimens; $c a$. 250 to 585 fathoms; western Atlantic; standard lengths from 72 to $122 \mathrm{~mm}$.

\section{DESCRIPTION OF TRANSITIONAL ADOLESCENT.}

- (No completely mature specimens have been taken, judging by the $115 \mathrm{~mm}$. Bermuda example).

With the characteristics of the genus.

Color (from the freshly caught, $115 \mathrm{~mm}$. Bermuda specimen): General color dark brown; barbel bulb with the predominating colors peacock and turquoise blue; postorbital light organ silvery-white; serial photophores reddish-violet.

Proportions: Depth in length 11 to $15(6.7 \%$ to $9.1 \%)$; head in length 7.5 to 8 (2.5\% to $13.3 \%)$; eye in head 5 to 6 (16.7\% to $20 \%)$.

Barbel: $1 / 3$ to $3 / 5$ as long as fish; stem translucent with a thin core speckled with dendritic chromatophores; bulb divided by a deep distal notch into an anterior short lobe and a posterior longer lobe, the latter being long, slender, and tipped with two short, simple filaments, or shorter, and tipped with an elaborately branched cluster of filaments. The difference is in all probability sexual, the elaborate form belonging to the female in the specimens we have examined.

Light Organs: Postorbital of female much smaller than eye but apparently functional. Serial photophores with the following counts: ventral

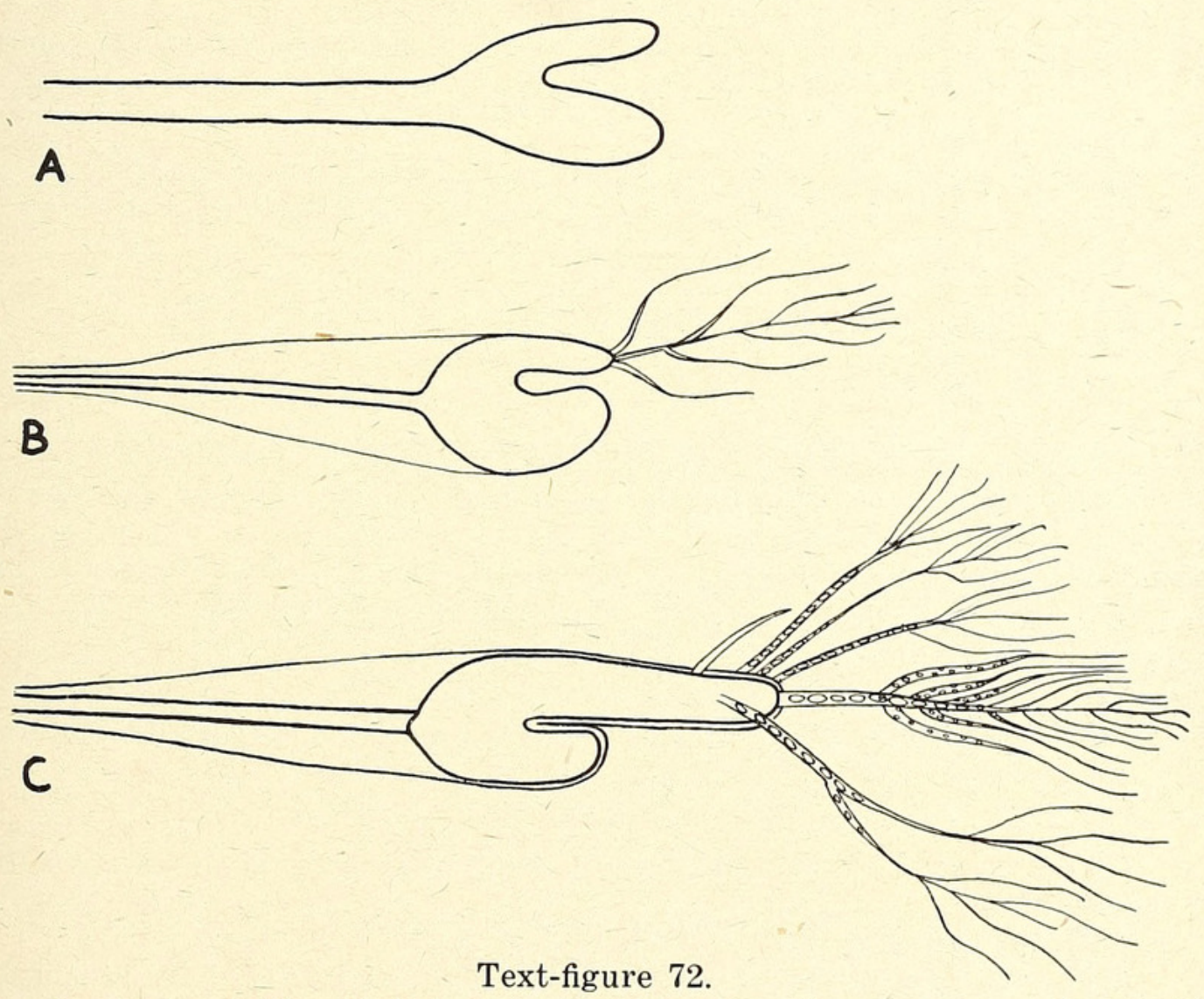

Eustomias dubius. Barbels, lateral view. A, post-larva, standard length 43 mm.; B, adolescent, $58 \mathrm{~mm}$; C, transitional adolescent, $115 \mathrm{~mm}$. 
series, I-P 7 to $8, \mathrm{P}-\mathrm{V} 32$ to 35 ; V-A 13 to 16 ; A-C 18 ; lateral series, $\mathrm{O}-\mathrm{V} 33$ to 35 ; V-A 15 to 17 . Non-serial photophores unusually prominent, in vertical bands.

Fins: Pectoral 2; dorsal 23; anal 37.

\section{DEVELOPMENT.}

The Bermuda collection consists of a late post-larva (43 mm.), and 2 transitional adolescents ( 58 and $115 \mathrm{~mm}$.), the larger being a female. Their characteristics are typical of their respective growth stages (see p. 77). On the post-larva are 7 pairs of subdermal larval pigment spots.

\section{STUdy MATERIAL.}

The following list gives the catalogue number, depth in fathoms, date, length and growth stage of each specimen of Eustomias dubius taken by the Bermuda Oceanographic Expeditions. All were caught in the cylinder of water off the Bermuda coast described in Zoologica, Vol. XVI, No. 1, p. 5 and Vol. XX, No. 1, p. 1.

No. 15,653; Net 646; $600 \mathrm{~F}$.; May 29, 1930; $115 \mathrm{~mm}$; trans. adolescent; female. No. 17,419; Net $810 ; 600 \mathrm{~F}$; Aug. 28,$1930 ; 43 \mathrm{~mm}$; post-larva.

No. 23,942; Net 1336; 600 F.; Oct. 29, 1931; 58 mm.; trans. adolescent.

\section{Eustomias dubius:}

\section{SYNONYMY AND REFERENCES.}

Parr, 1927, p. 66, figs. 36D, 38. (1 specimen, $84 \mathrm{~mm}$.; 7,000 ft. wire; Bahamas). A female; examined by present authors.

Regan \& Trewavas, 1930, p. 88, fig. 68. (3 specimens, 72 to $122 \mathrm{~mm}$; 600 to $1,500 \mathrm{~m}$. wire; western Atlantic.)

\section{Eustomias schiffi:}

Beebe, 1932.2, p. 54. (Description of the largest Bermuda specimen).

Beebe, 1937, p. 199. (Preliminary list of Bermuda specimens).

\section{Subgenus Achirostomias Regan \& Trewavas, 1930. \\ Eustomias lipochirus Regan \& Trewavas, 1930.}

\section{SPECIMEN TAKEN BY THE BeRMUdA OCEANOGRAPHiC EXPEDITIONS.}

1 specimen (Department of Tropical Research No. 18,597, Net 889); September, 1930 ; 500 fathoms; from a cylinder of water 800 miles in diameter ( 5 to 13 miles south of Nonsuch Island, Bermuda), the center of which is at $32^{\circ} 12^{\prime} \mathrm{N}$. Lat., $64^{\circ} 36^{\prime} \mathrm{W}$. Long.; standard length $50 \mathrm{~mm}$.

\section{SPECIMEN PREVIOUSLY RECORDED.}

1 specimen; ca. 220 fathoms; Caribbean Sea; standard length $88 \mathrm{~mm}$.

\section{DESCRIPTION.}

(From the type, probably immature, and the transitional adolescent Bermuda specimen).

With the characteristics of the genus.

Proportions: Depth in length 12 to 12.8 (7.8\% to $8.5 \%$ ) ; head in length 6.8 to $8(12.5 \%$ to $14.7 \%)$; eye in head 5 to $6.2(16.1 \%$ to $20 \%)$; interorbital width in head $5.5(18.2 \%)$; snout to pelvic in length $2(50 \%)$. 


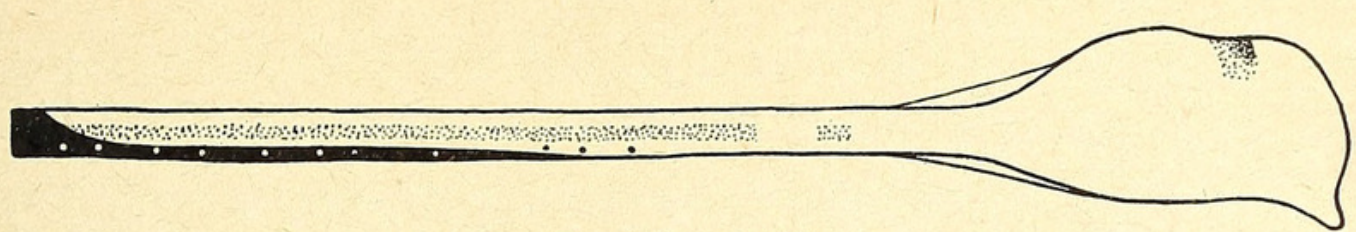

Text-figure 73 . $50 \mathrm{~mm}$.

Eustomias lipochirus. Barbel of transitional adolescent, standard length

Barbel: Slightly shorter than head, with a rather large bulb having the anterior, distal corner produced as a blunt appendage; stem white, with a series of black dots anteriorly, and, proximally, an anterior blackish streak on axis.

Light Organs: Postorbital rudimentary in the Bermuda specimen, which is too young to sex. Serial photophores with the following counts: ventral series, I-V 35, V-A 12, A-C 20; lateral series, O-V 28, V-A 13.

Teeth: All depressible, except a few, small, outer, fixed teeth; in the Bermuda specimen there are 8 teeth in the premaxillary, 10 in each half of the mandible.

Fins: Pectoral 0 (represented by a fleshy nubbin in the young Bermuda example); pelvic 7, inserted about middle of length; dorsal 23 ; anal 39 .

Remarks: The barbel bulb of the Bermuda transitional adolescent differs from that of the type in being comparatively elongate, and in having a transverse, posterior band of pigment in a shallow depression slightly more than half-way to the bulb's tip. There is an irregular double row of about 8 small photophores along the posterior side of the black, proximal portion of the stem. The general characteristics of the specimen are typical of its growth stage (see p. 79).

Eustomias lipochirus:

\section{REFERENCES.}

Regan \& Trewavas, 1930, p. 95, fig. 80A. (Type description).

Beebe, 1937, p. 199. (Preliminary list of Bermuda specimens).

\section{Subgenus Dinematochirus Regan \& Trewavas, 1930. Eustomias bigelowi Welsh, 1923.}

(See also p. 213).

\section{Specimens Taken by the Bermuda Oceanographic Expeditions.}

2 specimens; May and August, 1929 and 1930; 700, 800 fathoms; from a cylinder of water 8 miles in diameter ( 5 to 13 miles south of Nonsuch Island, Bermuda), the center of which is at $32^{\circ} 12^{\prime} \mathrm{N}$. Lat., $64^{\circ} 36^{\prime} \mathrm{W}$. Long.; standard lengths 108 and $134 \mathrm{~mm}$. a female and male, respectively.

\section{SPECIMENS PREVIOUSLY ReCORDED.}

10 specimens; ca. 0 to 833 fathoms; North Atlantic; standard lengths from 56 to $204 \mathrm{~mm}$.

\section{DESCRIPTION OF ADULT.}

Color (from the fresh Bermuda specimens): General color almost jet black; male postorbital silvery-white with green reflections; male antorbital 


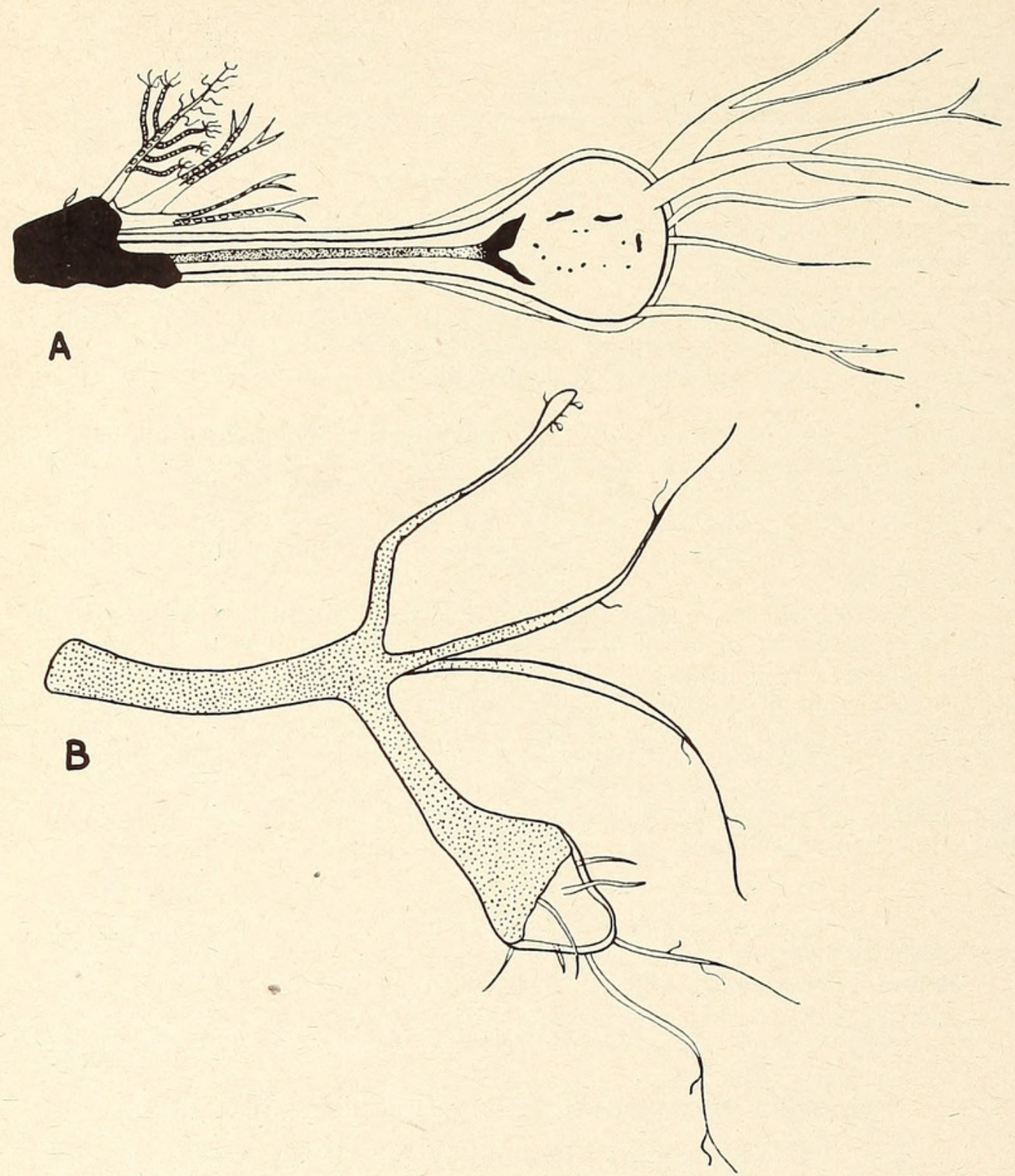

Text-figure 74 .

Eustomias bigelowi. Barbels. A, adult male, standard length $134 \mathrm{~mm}$.; B, transitional adolescent female, standard length $108 \mathrm{~mm}$.

(crescentic, below eye, small) violet blue ; male barbel bulb brilliant greenishyellow, marked externally with flecks of black pigment; two fine, scarlet blood vessels also branched over the bulb, arising from the black core of the stem; the yellow of the bulb extends up into the translucent sheathing of the stem; distal filaments cream-colored, translucent, with numerous coffeecolored granules inside and slender, scarlet cores (doubtless blood vessels) ; the posterior branches are similar to the distal filaments, except that the median branch is almost as bright yellow as the bulb; the swellings of the fine filaments of the branches are coffee-colored. Female barbel bulb, small bulb on median branch, and swellings on filaments all vivid bluish-green; branches and filaments translucent white.

Proportions: Depth in length 10 to 12 (8.5 to $10 \%$ ); head in length 
7.3 to 8.7 ( $11.5 \%$ to $13.3 \%$ ) ; eye in head 5 to 7 (14.3\% to $20 \%$ ), less than interorbital width which is contained about 4.5 in head $(22.2 \%)$.

Barbel: About as long as head, with three moderate branches, giving off varying numbers of sub-branches and filaments; bulb large, ovoid or round, giving rise to a varying number of terminal filaments with fine branches. Female characteristics: Median branch shorter than lateral branches and tipped with a small, round bulblet giving rise to a fringe of fine, swollentipped filaments; lateral branches without major sub-branches; bulb tiny, oval, proximally covered with black skin of stem. Male characteristics: Median branch longer than lateral branches, without terminal bulblet; lateral branches distinctly bifid; bulb round with a posterior patch of pigment; black skin of stem stopping at base of posterior branches.

Light Organs: Postorbital as large as or larger than eye in male, atrophied in female. Serial photophores with the following counts: ventral series, I-P 7, P-V 28 to $30, \mathrm{~V}-\mathrm{A} 13$ to $16, \mathrm{~A}-\mathrm{C} 20$ to 22 ; lateral series, O-V 26 to $29, \mathrm{~V}-\mathrm{A} 14$ to 16 .

Fins: Pectoral 2; dorsal 22 to 26 ; anal 39 to 42.

\section{DEVELOPMENT.}

As shown by the barbel of what was formerly distinguished as typical $E$. bigelowi, the barbel bulb in young females is much larger than in adults of the same sex, and the lateral branches are shorter. The Bermuda female is a late transitional adolescent.

\section{STUDY MATERIAL.}

The following list gives the catalogue number, depth in fathoms, date, length and growth stage of each specimen of Eustomias bigelowi taken by the Bermuda Oceanographic Expeditions. All were caught in the cylinder of water off the Bermuda coast described in Zoologica, Vol. XVI, No. 1, p. 5 and Vol. XX, No. 1, p. 1.

No. 12,602; Net 393; $800 \mathrm{~F}$.; August, $1929 ; 134 \mathrm{~mm}$.; Adult Male.

No. 15,145; Net 597; 700 F.; May, 1930; 108 mm.; Trans. Adolescent Female.

\section{SYNONYMY AND REFERENCES.}

Eustomias bigelowi:

Welch, 1923, p. 6 , figs. 5, 6. (2 specimens; 88 and $102 \mathrm{~mm}$.; 500 to $0 \mathrm{~m}$.; off Cape Hatteras). Examined by the present authors.

Parr, 1927, p. 77, fig. 44. (Résumé of type description).

Regan \& Trewavas, 1930 , p. 98 , fig. 85 . (2 specimens; 56 and $95 \mathrm{~mm}$.; $600,2,000 \mathrm{~m}$. wire; Florida Strait and east of Bermuda).

Beebe, 1937, p. 199. (Preliminary list of Bermuda specimens).

Eustomias bigelowi paucifilis:

Parr, 1927, p. 79, fig. 45 . (1 specimen; $125 \mathrm{~mm}$.; 7,000 ft. wire; Bahamas). A male; examined by present authors.

Eustomias bigelowi parvibulbus:

Parr, 1927, p. 79, fig. 46. (1 specimen; $204 \mathrm{~mm}$.; 10,000 ft. wire; Bahamas). Adult female; examined by present authors.

Eustomias parvibulbus:

Regan \& Trewavas, 1930, p. 98. (Résumé of description of preceding specimen). 


\section{? Eustomias triramis:}

Regan \& Trewavas, 1930, p. 99, fig. 86. (1 specimen; $73 \mathrm{~mm}$; $110 \mathrm{~m}$. wire; western Atlantic).

\section{Eustomias paucifilis:}

Regan \& Trewavas, 1930 , p. 99, fig. 87. (3 specimens, 68 to $70 \mathrm{~mm}$.; 300 to $2,000 \mathrm{~m}$. wire; near Barbuda and near Cape Verde Islands).

Beebe, 1937, p. 199. (Preliminary listing of Bermuda male).

\section{Eustomias silvescens Regan \& Trewavas, 1930.}

(See also p. 213).

\section{SPECIMEN TAKEN BY THE BERMUdA OCEANOGRAPHIC EXPEDITIONS.}

1 specimen (Department of Tropical Research No. 13,457; Net 455); September 10, 1929; 1,000 fathoms; from a cylinder of water 8 miles in diameter ( 5 to 13 miles south of Nonsuch Island, Bermuda), the center of which is at $32^{\circ} 12^{\prime} \mathrm{N}$. Lat., $64^{\circ} 36^{\prime} \mathrm{W}$. Long.; standard length $140 \mathrm{~mm}$.; a female; the type of $E$. satterleei Beebe, 1933.

\section{SPECIMEN PREVIOUSLY ReCORDED.}

1 specimen; ca. 220 fathoms; Caribbean Sea; standard length $111 \mathrm{~mm}$.

\section{DESCRIPTION OF ADULT.}

With the characterstics of the genus.

Color (from the fresh Bermuda female): General color brownish-black. Postorbital light organ opalescent white. Iris metallic sapphire blue. Barbel bulbs, bulblets and oval bodies in branches brilliant chrome yellow, except posterior part of bulb, which was streaked with apple green; branches translucent white. Serial photophores amethyst violet, those of the ventral series with broad gold frames.

Proportions: Depth in length 11.8 to 12 (8.3\% to $8.5 \%)$; head in length $8(12.5 \%)$; eye in head 4.7 to $5.4(18.5 \%$ to $21.3 \%)$; equal to interorbital width; snout to pelvic in length $1.94(51.5 \%)$.

Barbel: A little shorter than head to end of bulb, but 3 posterior branches extending far beyond bulb tip; bulb large with a short terminal filament, its base sometimes surrounded by several still shorter ones; all branches elaborately branched, beaded and filamented. Sexual differences: Male with the central branch much longer than the lateral branches, very thick proximally with many ovate bodies fastened directly to it, tapering distally, giving off beaded filament, but without a conspicuous terminal bulblet. Lateral branches similar but smaller, each with a stout secondary branch. Barbel stem pigmented only to base of branches; from there to bulb is a dark, median core; bulb expanded distally, rather truncate, with a single median filament. Female with central branch much shorter and thinner than lateral branches, simple basally but with a distinct bulblet near the end which gives rise to two subdivded filaments; one or two fine, simple filaments just below bulblet; lateral branches simpler than in male, without secondary branches, except fine, subdivided filaments. Barbel stem entirely pigmented, the pigment extending over three-quarters of the posterior face of the oval bulb in a narrow, forked tongue; four minute filaments clustering around base of the central, short terminal filament.

Light Organs: Postorbital apparently well developed in male (in illustration of the type); much smaller than eye, but apparently functional in female; serial photophores with the following counts: ventral series I-P 7, 

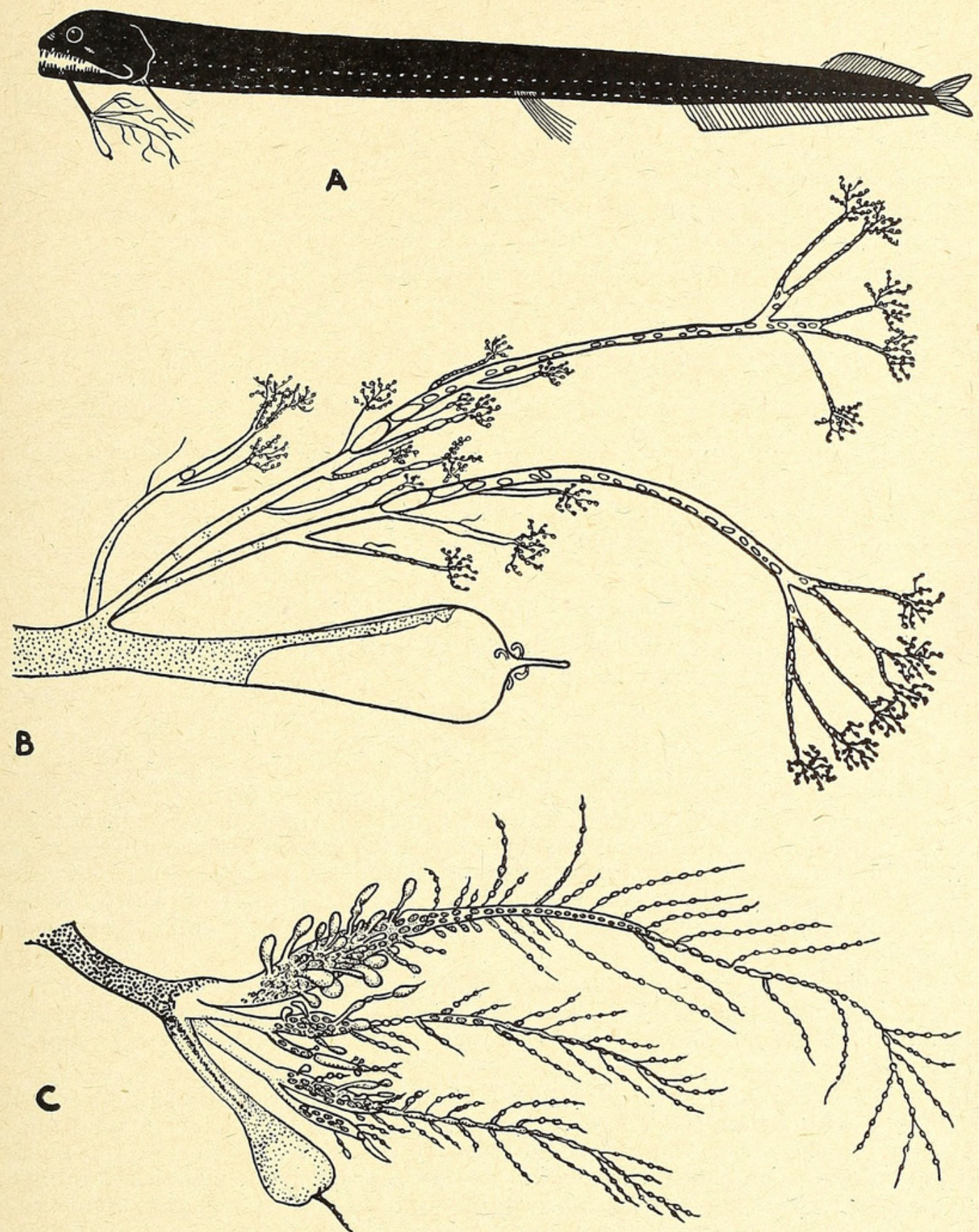

Text-figure 75.

Eustomias silvescens. A, adult female, standard length $140 \mathrm{~mm}$. (total number of fine filaments not shown); B, barbel of same. C, presumably male, standard length $111 \mathrm{~mm}$. A and B, from specimen in present collection; C, after Regan \& Trewavas.

P-V 27 to 29 , V-A 14 to 16 ; A-C 20 to 21 ; lateral series, O-V 27 to $28, \mathrm{~V}-\mathrm{A}$ 15 to 16.

Teeth: Premaxillary with about 11 teeth, maxillary about 12 denticles, minute; each half of mandible with about 18 teeth.

Fins: Pectoral 2; the bases of both rays are tightly sheathed in a common covering of skin, making them appear as a single unit proximally; dorsal 22; anal 41. 


\section{SYNONYMY AND REFERENCES.}

Eustomias silvescens:

Regan \& Trewavas, 1930 , p. 100, fig. 88; pl. IX, fig. 2. (Description of the type).

\section{Eustomias satterleei:}

Beebe, 1933.2, p. 165, fig. 3. (Description of the Bermuda specimen now referred to $E$. silvescens).

Beebe, 1937, p. 199. (Listing of above specimen).

\section{Eustomias schmidti Regan \& Trewavas, 1930.}

\section{SPECIMENS TAKen by the Bermuda OCEANOGRAPHiC ExPEditions.}

2 specimens; July to September, 1929 and $1930 ; 700$ to 800 fathoms; from a cylinder of water 8 miles in diameter ( 5 to 13 miles south of Nonsuch Island, Bermuda), the center of which is at $32^{\circ} 12^{\prime} \mathrm{N}$. Lat., $64^{\circ} 36^{\prime} \mathrm{W}$. Long.; standard lengths 55 and $118 \mathrm{~mm}$.

\section{SPECIMENS PREVIOUSLY RECORDED.}

3 specimens; $c a$. 41 to 220 fathoms; eastern and western tropical North Atlantjc; standard lengths 55 to $70 \mathrm{~mm}$.

\section{DESCRIPTION OF ADULT.}

With the characteristics of the genus.

Color (from the $118 \mathrm{~mm}$. Bermuda male): General color brownishblack; postorbital light organ silvery-white with golden rim, especially ventrally; main barbel bulb and that of median branch pale rose pink; branches and all filaments translucent, packed with tiny beads of pale ochre; serial photophores phlox purple; non-serial organs very numerous, minute, pale violet blue.

Proportions (from the Bermuda adult, the only mature example known): Depth in length $11.8(8.5 \%)$; head in length $7.4(13.5 \%)$; eye in head 4.5 $(22.2 \%)$; interorbital width about equal to eye; snout to pelvic in length $1.93(52 \%)$.

Barbel: As long as head. Bulb large, divided by a constriction into a longer, oval proximal part and a shorter, rounded, distal part; a small filament from the anterior part of the base of the distal portion of the bulb; three posterior branches, the median one largest, without branches but with a prominent elongate or round swelling and one or two distal filaments; lateral branches bifurcate, each main branch having one or more filaments beyond the bifurcation; no bead-like bodies in branches. Sexual Differences: In the Bermuda male the median branch is longer than in the illustration of the type, with only a slight swelling with a long terminal filament, instead of a distinct bulb wth two short terminal filaments; judging by the barbel form in related species, we are fairly certain that the larger type specimen, at least, will prove to be a female.

Light Organs: Postorbital well developed in Bermuda male, slightly smaller than eye. Serial organs with the following counts: ventral series, I-P 7 to 8, P-V 27 to 28, V-A 14 to $15, \mathrm{~A}-\mathrm{C} 20$ to 23 ; Lateral series, O-V 27 to $29, \mathrm{~V}-\mathrm{A} 14$ to 15 .

Fins: Pectoral 2; sheathed basally in a common skin; dorsal 22 to 26 ; anal 40 to 44 . 


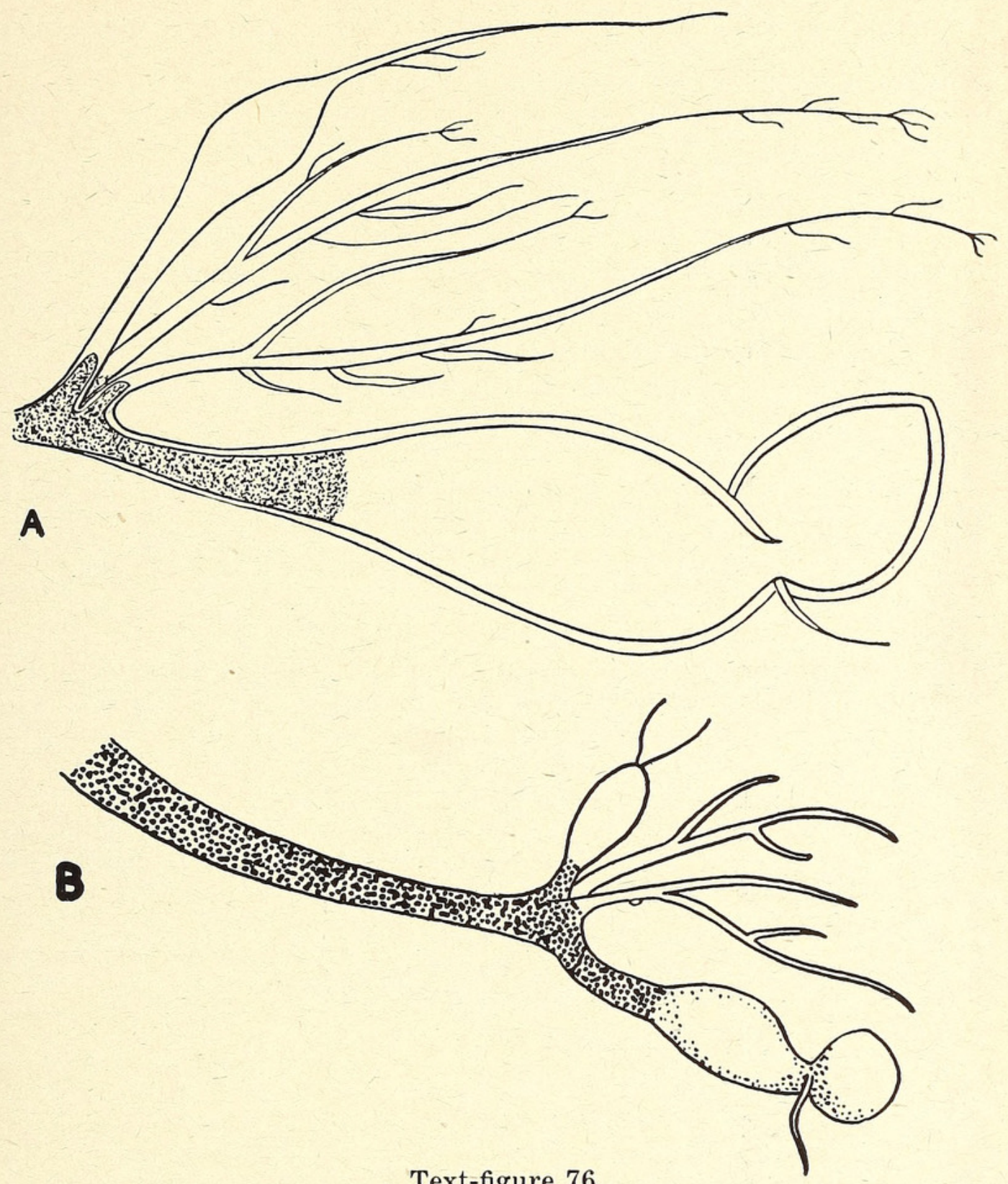

Eustomias schmidti. Barbels. A, adult male, standard length $118 \mathrm{~mm}$.; B, presumably an immature female, standard length $70 \mathrm{~mm}$. A, from specimen in present collection; B, after Regan \& Trewavas.

\section{DEVELOPMENT.}

Besides the $118 \mathrm{~mm}$. adult male, the Bermuda collection contains an adolescent $55 \mathrm{~mm}$. in length, with characteristics typical of its growth stage. The barbel is similar to that of the $70 \mathrm{~mm}$. young specimen figured by Regan \& Trewavas (1930, p. 101, fig. 89).

\section{STUDY MATERIAL.}

The following list gives the catalogue number, net, depth in fathoms, date, length and growth stage of each specimen of Eustomias schmidti taken by the Bermuda Oceanographic Expeditions. All were caught in the cylinder 
of water off the Bermuda coast described in Zoologica, Vol. XVI, No. 1, p. 5 and Vol. XX, No. 1, p. 1.

No. 11,726; Net $312 ; 700 \mathrm{~F}$; July 22, $1929 ; 118 \mathrm{~mm}$.; Adult Male.

No. 13,883; Net 513; 700 F.; Sept. 27, 1929; 55 mm.; Adolescent.

Eustomias schmidti:

\section{REFERENCES.}

Regan \& Trewavas, 1930, p. 100, figs. 89, 90. (Type description).

Beebe, 1937, p. 199. (Preliminary list of Bermuda specimens).

\section{Eustomias fissibarbis (Pappenheim, 1914).}

(See also p. 213).

SPECIMEN TAKEN By the BeRmuda OCEANOgRAPHiC EXPEditions.

1 specimen (Department of Tropical Research No. 13,791, Net 509); September 25, 1929; 800 fathoms; from a cylinder of water 8 miles in diameter (5 to 13 miles south of Nonsuch Island, Bermuda), the center of which is at $32^{\circ} 12^{\prime} \mathrm{N}$. Lat., $64^{\circ} 36^{\prime} \mathrm{W}$. Long.; standard length $130 \mathrm{~mm}$.

\section{SPECIMENS PREVIOUSLY RECORDED.}

11 or 12 specimens; ca. 14 to 330 fathoms; North and South Atlantic; standard lengths from 50 to $112 \mathrm{~mm}$.

\section{DESCRIPTION.}

With the characteristics of the genus.

Color (from the fresh Bermuda female): General color brownish-black; postorbital light organ greenish-silver; serial photophores lavender with narrow gold frames.

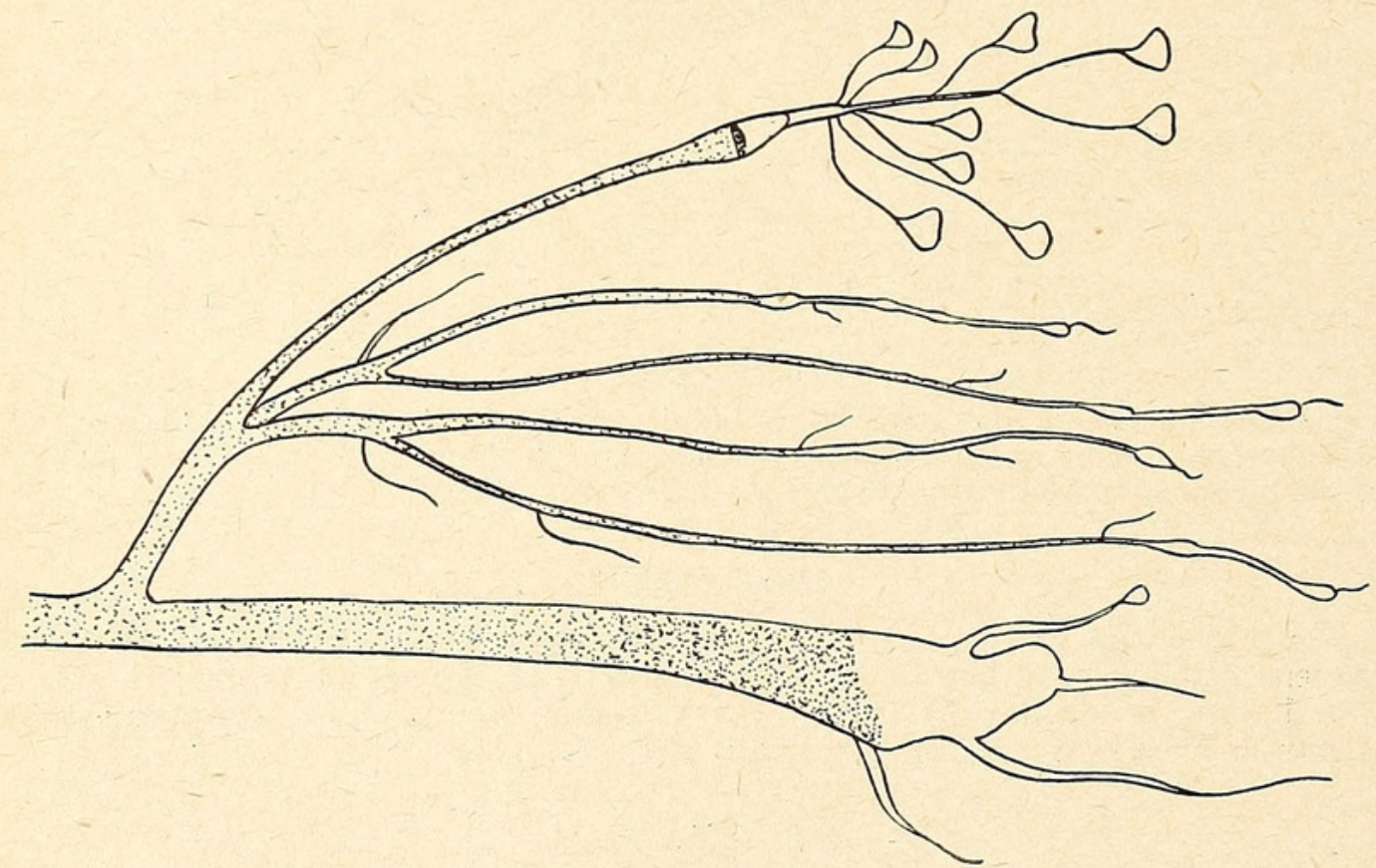

Text-figure 77.

Eustomius fissibarbis. Barbel of transitional adolescent female, standard length $130 \mathrm{~mm}$. 
BARNARD, K. H.:

1925. A monograph of the marine fishes of South Africa. Pt. I. Ann. S. African Mus., Vol. XXI.

BEEBE, W.:

1926. The Acturus adventure. An account of the New York Zoological Society's first oceanographic expedition.

G. P. Putnam's Sons. New York.

1930. A perfect depth recorder. Bull. N. Y. Zoo. Soc., Vol. XXXIII, No. 6.

1931.1 Bermuda oceanographic expeditions 1929-1930. Introduction. Zoologi$c a$, Vol. XIII, No. 1.

1931.2 Bermuda oceanographic expeditions 1929-1930. List of nets and data. Zoologica, Vol. XIII, No. 2.

1932.1 A new deep-sea fish. Bull. N. Y. Zool. Soc., Vol. XXXV, No. 5.

1932.2 Nineteen new species and four post-larval deep-sea fish. Zoologica, Vol. XIII, No. 4.

1932.3 Bermuda oceanographic expeditions 1931. Individual nets and data. Zoologica, Vol. XIII, No.3.

1933.1 Preliminary account of deep sea dives in the bathysphere with special reference to one of 2200 feet. Proc. Nat. Acad. Sci. U. S. A., Vol. XIX, No. 1.

1933.2 Deep-sea stomiatoid fishes. One new genus and eight new species. Copeia, 1933, No. 4.

1933.3 Deep-sea fishes of the Bermuda oceanographic expeditions. Introduction. Zoologica, Vol. XVI, No. 1.

1934.1 Deep-sea fishes of the Bermuda oceanographic expeditions. Family Idiacanthidae. Zoologica, Vol. XVI, No. 4.

1934.2 Classified résumé of organisms observed from the bathysphere. (in "Half Mile Down," Appendix G; Harcourt Brace \& Co., New York).

1935. Deep-sea fishes of the Bermuda oceanographic expeditions. Family Derichthyidae. Introduction. Zoologica, Vol. XX, No. 1.

1937. Preliminary list of Bermuda deep-sea fish. Based on the collections from fifteen hundred metre-net hauls, made in an eight-mile circle south of Nonsuch Island, Bermuda. Zoologica, Vol. XIII, No. 14.

BeEbe, W., \& Crane, J.:

1936. Deep-sea fishes of the Bermuda oceanographic expeditions. Family Serrivomeridae. Part I: Genus Serrivomer. Zoologica, Vol. XX, No. 3.

1937. Deep-sea fishes of the Bermuda oceanographic expeditions. Family Nemichthyidae. Zoologica, Vol. XXII, No. 27.

BoLIN, R. L. :

1939. A new stomiatoid fish from California. Copeia, 1939, No. 1.

BRODIN, N.:

1930. Some more new deep-sea fishes. Proc. New England Zool. Club., Vol. $\mathrm{XI}$.

1931. Atlantic deep-sea fishes. Bull. Mus. Comp. Zool., Vol. LXXII, No. 3.

BOUlenger, C. L. :

1913. The luminous organs of Lamprotoxus flagellibarba. Fisheries, Ireland Sci. Invest. 1912, II, (1913).

BRAUER, A.:

1902. Diagnosen von neuen tiefseefischen, welche von der Valdiva-expedition gesammelt sind. Zool. Anz., V, Vol. XXV, No. 668.

1906. Die tiefsee-fische. I. Systematischer teil. Wiss. Ergeb. Deutsch. Tiefsee-Exp. Valdivia. Vol. XV, Part 1.

1908. Die tiefsee-fische. II. Anatomischer teil. Wiss. Ergeb. Deutsch TiefseeExp. Valdivia. Vol. XV, Part 2. 
Chapman, W. McL.:

1939. Eleven new species and three new genera of oceanic fishes collected by the international fisheries commission from the northeastern Pacific. Proc. U. S. Nat. Mus., Vol. 86.

DODERLEIN, L.:

1882. Eine stomiatidae aus Japan. Wiegman Arch. f. Naturgesch., Vol. I.

EGE, V.:

1918. Stomiatidae (Stomias). Report on the Danish oceanographical expeditions, 1908-1910, to the Mediterranean and adjacent seas, Vol. II (Biology), Article 4.

FOWLER, H. W.:

1928. The fishes of Oceania. Mem. Bernice P. Bishop Mus., Vol.X.

1934. Descriptions of new fishes obtained 1907 to 1910 , chiefly in the Philip. pine Islands and adjacent seas. Proc. Acad. Nat. Sci. Philadelphia, Vol. LXXXV.

1936. The marine fishes of West Africa, based on the collection of the American Museum Congo Expedition, 1909-1915. Part. I. Bull. Amer. Mus. Nat. Hist., Vol. LXX.

1938. The fishes of the George Vanderbilt South Pacific Expedition of 1937. Acad. Nat. Sci. Philadelphia, Monograph No. 2.

Fraser-BrunNer, A.:

1931. Some interesting West African fishes, with descriptions of a new genus and two new species. Ann. Mag. Nat. Hist., Series 8, Vol. XLV.

GARMAN, S.:

1899. The fishes. Report on an exploration ... . by the U. S. Fish Commission steamer Albatross, during 1891. Mem. Mus. Comp. Zool. Harvard Coll., Cambridge, Mass., Vol. XXIV.

Giglioli, E. H.:

1884. Pelagos, saggi sulla vita e sui prodotti del mare. Tip. Roy. Inst. Sordo. Mut, Geneva, 1884.

GILBERT, C. H.:

1905. The aquatic resources of the Hawaiian Islands. II. The deep sea fishes. Bull. U. S. Fish. Comm., 1903 (1905), Vol. XXIII, Part II.

GILChrist, J. D. F.:

1908. Descriptions of fifteen new South African fishes. Mar. Inv. S. Africa, Vol. IV.

GILChrist, J. D. F., \& Bonde, C. von :

1924. Deep-sea fishes procured by the S. S. "Pickle" (Part II). Rep. Mar. Biol. Survey Union S. Africa, Cape Town, Vol. III, Spec. Rep. No. 7.

GILL, T. H. :

1883. Diagnoses of new genera and species of deep sea fish-like vertebrates. Proc. U. S. Nat. Mus., Vol. VI.

GoOdE, G. B., \& BEAN, T. H.:

1895. Oceanic ichthyology. A treatise on the deep-sea and pelagic fishes of the world. Special Bull. U. S. Nat. Mus.

GREGORY, W. K., \& CONRAD, G. M.:

1936. Pictorial phylogenies of deep-sea Isospondyli and Iniomi. Copeia, 1936, No. 1. 
GUNTHER, A.:

1878. Preliminary notices of deep-sea fishes collected during the voyage of the H. M. S. Challenger. Ann. Mag. Nat. Hist., Series V, Vol. II.

1887. Report on the deep sea fishes collected by H. M. S. Challenger during the years 1873-1876. Report. Scient. Results Challenger, Zool., London, Vol. XXII.

HARVEY, E. N.:

1931. Stimulation by adrenalin of the luminescence of deep-sea fish. Zoologi$c a$, Vol. XII, No. 6.

Holt, E. W. L., \& ByrNe, L. W.:

1910. Preliminary diagnosis of a new stomiatid fish from south-west of Ireland. Ann. Mag. Nat. Hist., Series VIII, Vol. VI.

1913. Sixth report on the fishes of the Irish Atlantic slope. The families Stomiatidae, Sternoptychidae, and Salmonidae. Fisheries Ireland Sci. Invest. 1912, I. (1913).

Jespersen, P., \& TANing, A. V.:

1926. Mediterranean Sternoptychidae. Rept. Danish Oceanogr. Exped. 19081910 to the Med. \& Adj. Seas. No. 9 (Vol. II, Biology, A. 12).

LOWE, R. T.:

1843. Notices of fishes newly observed or discovered in Madeira during the years 1840-1841 and 1842. Proc. Zool. Soc. London, Part XI.

MATSUBARA, K.:

1938. Studies on the deep-sea fishes of Japan. VI. On some stomiatoid fishes from Kumano Nada. Jour. Imp. Fish. Inst. Tokyo, Vol. XXXIII, No. 1.

MYERS, G. S.:

1935. A new genus of opisthognatid fishes. Smithsonian Misc. Coll., Vol. XCI, No. 23.

NORMAN, J. R.:

1930. Oceanic fishes and flatfishes collected in 1925-1927. Discovery Reports, Discovery Committee, Colonial Office, London, Vol. II.

PAPPENHeIM, P.:

1914. Die fische der deutschen sudpolar-expedition, 1901-1903. II. Die Tiefseē-fische. Deutsche Sudpolar-Exp., 1901-1903, Vol. XV, Zool. Vol. VII.

PARR, A. E.:

1927. Scientific results of the third oceanographic expedition of the Pawnee, 1927. The stomiatoid fishes of the sub-order Gymnophotodermi (Astronesthidae, Melanostomiatidae, Idiacanthidae) with a complete review of the species. Bull. Bing. Ocean. Coll., Vol. III, Art. 2.

1930. A note on the classification of the stomiatoid fishes. Copeia, 1930, No. 4.

1931. Scientific results of the second expedition of the Pawnee, 1926. Deepsea fishes from off the western coast of North and Central America. With keys to the genera Stomias, Diplophos, Melamphaes and Bregmaceros, and a revision of the macropterus group of the genus Lampanyctus. Bull. Bing. Ocean. Coll., Vol. II, Art. 4.

1933. Two new records of deep-sea fishes from New England, with description of a new genus and species. Copeia, 1933, No. 4.

1934. Report on experimental use of a triangular trawl for bathypelagic collecting. With an account of the fishes obtained and a revision of the family Cetomimidae. Bull. Bing. Ocean. Coll., Vol. IV, Art. 6.

REGAN, C. T.:

1916. Larval and postlarval fishes. British Antarctic (Terra Nova) Exped. Zool. 1, No. 4.

1923. The classification of the stomiatoid fishes. Ann. Mag. Nat. Hist., Series IX, Vol. XI. 
Regan, C. T., \& Trewavas, E.:

1929. The fishes of the families Astronesthidae and Chauliodontidae. Danish Dana Exped. in the North Atlantic and Gulf of Panama, 1920-22, Report No. 5.

1930. The fishes of the families Stomiatidae and Malacosteidae. Danish Dana Expeditions in the North Atlantic and Gulf of Panama, 1920-22, Report No. 6.

Roule, L.:

1934. Les poissons et le monde vivant des eaux. Vol. VII. L'abime des grands fonds marins.

Roule, L., \& ANGel, F.:

1930. Larves et alevins de poissons provenant descroisieres du Prince Albert Ier de Monaco. Res. Camp. Sci. Monaco. Vol. LXXIX.

1931. Observations et rectifications concernant divers poissons recueillis par S. A. S. le Prince Albert Ier de Monaco au cours des campagnes 1911 à 1914. Bull. Inst. Oceanogr. Monaco, No. 581.

1933. Poissons provenant des campagnes du Prince Albert Ier de Monaco. Res. Camp. Sci. Monaco, Vol. LXXXVI.

Roxas, H. A.:

1934. A review of Philippine isospondylous fishes. Philippine Jour. Sci. Vol. LV, No. 3.

SANZ0, L.:

1912.1 Larva di Stomias boa Risso. Mem. del R. Com. Talass. Ital. Venez., No. 10.

1912.2 Uova di Sternoptychidae. Boll. Bimestr. del R. Com. Talass. Ital. Venez.

1913.1 Larva di Ichthyococcus ovatus (Cocco). Mem. R. Com. Talass. Ital. Venez. No. 27.

1913.2 Stadi post-embrionali di Vinciguerria attentuata (Cocco) e V. poveriae (Cocco) Jordan and Evermann. Mem. R. Com. Talass. Ital. Venez. No. 35.

1914.1 Stadi larvali di Chauliodus sloanii Bl. Mem. R. Com. Talass. Ital. Venez. No. 39.

1914.2 Contributo alla conoscenza degli stadi larvali negli Scopeleni Muller (Bathophilus nigerrimus Gigl., Scopelus caninanus C. \& V., Sc. humboldti Risso). Roma Men. Acc. Lincei, Ser. V, Vol. X.

1915. Stadi larvali di Bathophilus nigerrimus Gigl. Mem. R. Com. Talass. Ital. Venez., No. 48.

1918.1 Nuovo contributo alla conoscenza della svilluppo larvale di Bathophilus nigerrimus Gigl. Roma Red. Acc. Lincei, Vol. XXVII, Sem.2.

1918.2 Nuovo contributo alla conoscenza della svilupno larvale di Stomias boa Risso. Roma Red. Acc. Lincei. Vol. XXVII, Sem. 2.

1928. Uova, svilluppo embrionale, stadi larvali, post-larvali e giovanili di Sternoptychidae e Stomiatidae. Sternoptychidae. 1. Argyropelecus hemigymnus Cocco. Monogr. R. Com. Talassogr. Ital., Vol. II.

1930. Uova, sviluppo embrionale, stadi larvali post-larvali e giovanili di Sternoptychidae e Stomiatidae. Sternoptychidae. 2. Ichthyococcus ovatus (Cocco). Monogr. R. Com. Talassogr. Ital., Vol. II.

1931. Salmonoidea e Stomiatoidea. (In "Fauna e Flora del Golfo di Napoli. Monografia: Uova, larva e stadi giovanili di Teleostei." Ia. Puntata. Pubblicata dalla Stazione Zoologica di Napoli). Monografia 38.

1932. Uova e larve di Gonostoma denudatum Raf. Boll. Zool. Napoli, Vol. III.

1935. Uova, sviluppo embrionale, stadi larvali post-larvali e giovanili di Sternoptychidae e Stomiatidae. Sternoptychidae. 3. Maurolicus pennanti (Walb.). Monogr. R. Com. Talassogr. Ital., Vol. II. 
Tizard, T. H., Moseley, H. N., Buchanan, J. Y., \& Murray, J.

1885. Narrative of the cruise of H. M. S. Challenger with a general account of the scientific results of the expedition. Rep't. Sci. Res. Chall., Vol. I, First Part.

VAILlant, L.:

1888. Expeditions scientifiques du Travailleur et du Talisman, pendant les années $1880,1881,1882,1883$. Poissons. Paris.

WEILL, R.:

1938. Statistiques et hypothèses sur les organes lumineux des poissons bathypelagiques. Revue Scient., July 15, 1938.

WeLsh, W. W.:

1923. Seven new species of fish of the order Malacopterygii. Proc. U. S. Nat. Mus., Vol. LXII, Art. 3.

ZUGMAYER, E.:

1911.1 Diagnoses des poissons nouveaux provenant des campagnes du yacht Princesse Alice (1901-1910). Bull. Inst. Oceanogr. Monaco, No. 193.

1911.2 Poissons provenanat des campagnes du yacht Princesse Alice (19011910). Res. Camp. Sci. Monaco, Vol. XXXV.

1913. Diagnoses de stomiatides nouveaux provenant des campagnes du yacht Hirondelle II (1911 et 1912). Bull. Inst. Oceanogr. Monaco, No. 253. 


\section{$2 \mathrm{BHL}$ Biodiversity Heritage Library}

Beebe, William and Crane, Jocelyn. 1939. "Deep-sea fishes of the Bermuda Oceanographic Expeditions. Family Melanostomiatidae." Zoologica : scientific contributions of the New York Zoological Society 24(6), 65-238.

https://doi.org/10.5962/p.203628.

View This Item Online: https://www.biodiversitylibrary.org/item/207506

DOI: https://doi.org/10.5962/p.203628

Permalink: https://www.biodiversitylibrary.org/partpdf/203628

\section{Holding Institution}

Smithsonian Libraries

\section{Sponsored by}

Biodiversity Heritage Library

\section{Copyright \& Reuse}

Copyright Status: In Copyright. Digitized with the permission of the rights holder

Rights Holder: Wildlife Conservation Society

License: http://creativecommons.org/licenses/by-nc/3.0/

Rights: https://www.biodiversitylibrary.org/permissions/

This document was created from content at the Biodiversity Heritage Library, the world's largest open access digital library for biodiversity literature and archives. Visit BHL at https://www.biodiversitylibrary.org. 